\title{
Analyzing Growth-Track and Uncertainties in Asia's Irrigated Areas
}

A fact finding study to track the growth \& scale of discrepancies in Asia's irrigated areas and their potential implications.

Ali Ajaz

MSc Thesis WSE-HELWD 16.19

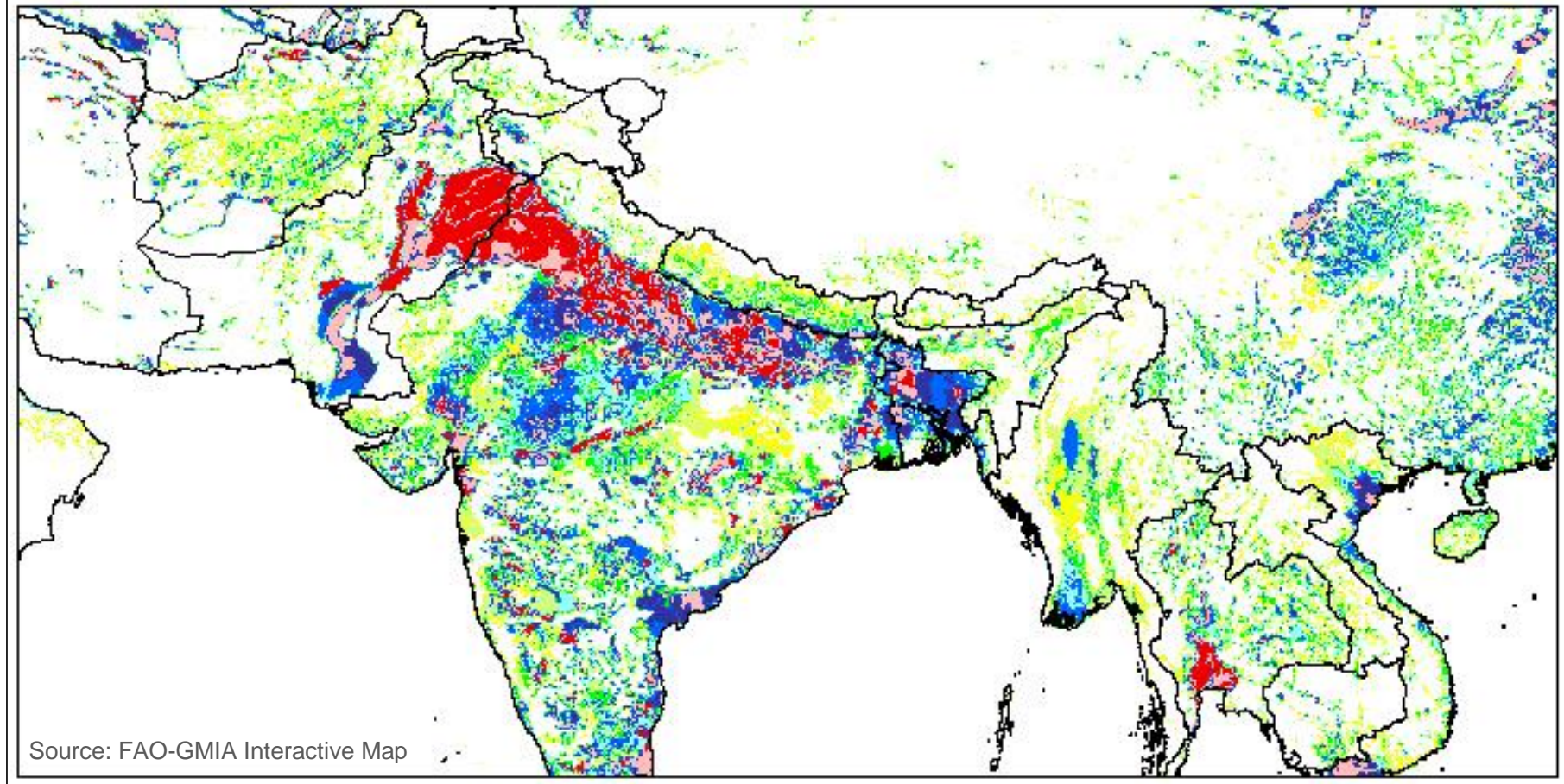

Percentage of land irrigated

$\begin{array}{lll}1-2 & 2-5 & 5-10\end{array}$

$10-20$

$20-35$

$35-50$

$50-75$

$75-100$ 


\title{
Analyzing Growth-Track and Uncertainties in Asia's Irrigated Areas
}

\author{
Master of Science Thesis \\ by \\ Ali Ajaz \\ Supervisors \\ Prof. Dr. Charlotte de Fraiture (UNESCO-IHE) \\ Mentors \\ Dr. Poolad Karimi (UNESCO-IHE) \\ Dr. Xueliang Cai (IWMI-SA) \\ Examination committee \\ Prof. Dr. Charlotte de Fraiture \\ Dr. Poolad Karimi \\ Dr. Aditya Sood
}

This research is done for the partial fulfilment of requirements for the Master of Science degree at the UNESCO-IHE Institute for Water Education, Delft, the Netherlands

Delft

March 2016 
Although the author and UNESCO-IHE Institute for Water Education have made every effort to ensure that the information in this thesis was correct at press time, the author and UNESCOIHE do not assume and hereby disclaim any liability to any party for any loss, damage, or disruption caused by errors or omissions, whether such errors or omissions result from negligence, accident, or any other cause.

(C) Ali Ajaz 2016.

This work is licensed under a Creative Commons Attribution-NonCommercial 4.0 International License. 


\section{Summary}

Asia holds $70 \%$ of global irrigated areas which accounts for $62 \%$ of world food demand. Reliable information regarding irrigated areas are of crucial importance for effective future planning. National datasets for irrigated areas, collected by different agencies, e.g. statistical agency, agriculture department, irrigation authorities often vary from each other, while global datasets such as FAO's show a huge divergence with remote sensing estimates of irrigated areas. Confusions about the accuracy and reliability of data could jeopardize the effectiveness of future policies aiming at securing food production for rapidly growing population of Asia. Without having consistent and dependable data of such a basic input, food and water security of Asian nations would be at stake. In addition, global commitments such as SDGs, climate change, increasing domestic and industrial water demand and ecological concerns would also put more pressure on irrigated agriculture.

In this study, a detailed analysis has been conducted for the growth track of irrigated areas in Asia, with the purpose to understand the development of different types of irrigation, investments, trends and resilience of irrigated agriculture against major climate events over the time. Secondly, comprehensive comparison has been made within national statistics, FAO's data and high resolution irrigated area maps (up to 250m) from IWMI (International Water Management Institute) together with other available raster datasets. Variations in data have been estimated using different statistical tools while distribution and dispersion analysis has also been made to look into the extent of irrigated areas in different climatic regions and to find country wise clusters/patterns of large, medium and small scale irrigation schemes. Furthermore, country's reporting methods have been investigated thoroughly for the limitations and strengths of existing data collection mechanisms to find the possible loop holes, which might induce uncertainty in data.

Results of the study showed a $15 \%$ average decline per decade in irrigated areas growth in Asia for last 50 years, while focus on rehabilitation of old infrastructure and implementation of climate smart irrigation has been relatively increased. Uncertainty analysis indicated significant difference in irrigated areas information collected from different sources. Remote sensing estimates were found $96 \%$ higher than country estimates on an average, while dispersion analysis showed $300 \mathrm{M}$ ha of non-reported irrigated areas in large scale irrigated schemes for Asia. Qualitative analysis of irrigated areas' reporting mechanisms showed that mostly traditional statistical methods are used by data collection agencies, e.g. sample surveys based on farmer interviews and global datasets also receive their information from same agencies. Reliability of these methods have been scaled by developing a scoring mechanism by using a quantitative analysis approach. On the other hand, implications of uncertainty came up with some critical questions, i.e. what is the actual annual land productivity? what about per capita irrigated areas? What is the actually utilized irrigation potential? Consequently this study has been concluded by putting forward some genuine facts and recommendations to improve the existing reporting systems of irrigated areas information and to look for imminent role of remote sensing to compare the national statistics with ground facts.

Keywords: irrigated areas, statistical methods, remote sensing, uncertainty in data, reporting methods, land productivity, irrigation potential, spatial dispersion, small scale irrigation. 


\section{Table of Contents}

Summary

(19)

List of Figures viii

List of Tables $\quad x$

Abbreviations $\quad$ xi

List of Symbols $\quad$ xiii

Introduction $\quad 1$

1.1. Background 1

1.2. Problem Statement 3

1.3. Rationale of Study 3

1.4. Research Questions 5

1.5. Research Objectives 5

Literature Review $\quad 6$

2.1. Challenges for Food Security Goals 6

2.2. History and Development of Asian Irrigation 6

2.3. Irrigation in Current Global Context 7

2.4. Future Strategies 8

2.5. Uncertainty Level in Irrigated Areas 8

2.6. Possible Reasons of Uncertainty 10

2.7. Implications of uncertainty on Policy 11

Data Collection and Methodology 12

3.1. Developing a database 12

3.2. Understanding Methods of data collection 15

3.2.1. National Statistical Archives $\quad 15$

3.2.2. Raster Datasets 16

3.3. Quantifying Uncertainty and Defining an Appraisal System 17

$\begin{array}{ll}\text { 3.3.1. Qualitative Analysis } & 17\end{array}$

$\begin{array}{ll}\text { 3.3.2. Quantitative Analysis } & 18\end{array}$

3.4. Finding Spatial Uncertainty in Agro Ecological Zones 21

3.4.1. Length of Growing Period: 21

3.4.2. Sorting Data from FAO-GMIA Map: 22

3.5. Country wise spatial uncertainty and dispersion analysis 25

3.6. Linking Uncertainty with Food Production and Water Resources 26

Growth Track of Asia's Irrigated Areas $\quad 27$

4.1. Irrigated Areas Development in Asia 27

4.1.1. India 27

4.1.2. China 30 
4.1.3. Pakistan 32

4.1.4. Bangladesh 35

4.1.5. Iran 38

4.1.6. Thailand 40

4.1.7. Vietnam 43

4.1.8. Indonesia 45

4.1.9. Nepal 47

4.1.10. Japan 49

4.2. Growth-Track for Asia 51

Uncertainties in Irrigated Areas Datasets $\quad 53$

5.1. Irrigated Areas of Asia 53

5.2. Discrepancy in Data Sets 56

5.3. Scaling Discrepancy in Agro-Ecological Zones 59

5.3.1. Distribution of Irrigated Areas in Climatic Zones $\quad 59$

5.3.2. Zonal Discrepancy Analysis 63

5.4. Country wise spatial dispersion analysis of irrigated areas (using 250m
resolution IWMI map)

$\begin{array}{ll}\text { Active Methods for Irrigated Areas Reporting } & \mathbf{7 0}\end{array}$

6.1. Overview of National Reporting Mechanisms and Existing Methods 70

6.1.1. Reporting Mechanism in China $\quad 70$

6.1.2. Reporting Mechanism in India $\quad 72$

6.1.3. Reporting Mechanism in Pakistan 74

6.1.4. Reporting Mechanism in Iran 77

6.1.5. Reporting Mechanism in Thailand 78

$\begin{array}{ll}\text { 6.1.6. Reporting Mechanism in Bangladesh } & 79\end{array}$

6.1.7. Reporting Mechanism in Indonesia $\quad 81$

6.1.8. Reporting Mechanism in Vietnam $\quad 82$

6.1.9. Reporting Mechanism in Nepal $\quad 84$

6.1.10. Reporting Mechanism in Japan $\quad 87$

6.2. Mechanism of FAO, AQUASTAT and GMIA Statistics 88

$\begin{array}{ll}\text { 6.2.1. FAOSTAT } & 88\end{array}$

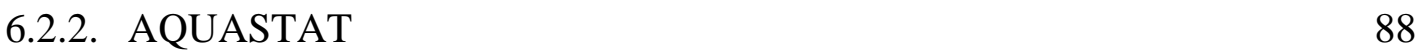

6.2.3. Global Map of Irrigated Areas (GMIA) 89

6.3. Scoring System for the Reporting Methods 91

Implication of Uncertainty on Food Production and Water Resources $\quad 96$

7.1. Uncertainty and Link with Food Production 96

7.2. Uncertainty and Link with Water Resources 99

$\begin{array}{ll}\text { Conclusions and Recommendation } & 101\end{array}$

8.1. Conclusions 101

8.1.1. Future of Asia's Irrigated Agriculture 101

8.1.2. Uncertainties in data, Spatial Dispersion and Reporting Methods 101

8.2. Recommendations 102

8.3. Prospects for Future Research 103 


\section{List of Figures}

Figure 1. Trends in Investments in Irrigation and Drainage Sector in Asia .............................................. 2

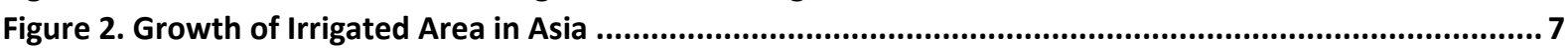

Figure 3. Comparison between Irrigated Areas estimates .................................................................. 9

Figure 4. Comparison between Agricultural Census and Land Use maps ....................................................9.

Figure 5. Tabular dataset from Iran (in Persian language) ....................................................................... 14

Figure 6. Raster Dataset (Pixels are shown carrying different values) .................................................. 14

Figure 7. Farmer Field Interview is being conducted during Agricultural Survey in India ..............................15

Figure 8. LULC China (Irrigated Cropland-3) .......................................................................................16

Figure 9. IWMI-Global Irrigated Areas Map (Pakistan. India, Nepal, and Bangladesh) .................................. 17

Figure 10. Group of datasets (Irrigated Area) Bangladesh ..................................................................... 19

Figure 11. GMIA-FAO Raster Dataset (Bangladesh) attribute table ..................................................... 22

Figure 12. Combine Map GMIA (Percentage of Cell Area Actually Irrigated) .............................................23

Figure 13. Extraction of raster dataset using AEZ polygons (Schematic Illustration) ...................................... 24

Figure 14. Over estimation of irrigated area due to double counting of pixels ............................................25

Figure 15. Categories of Dispersion Analysis (clusters of $250 \mathrm{~m}$ x $250 \mathrm{~m}$ pixels in $10 \mathrm{~km}$ Grid) ........................25

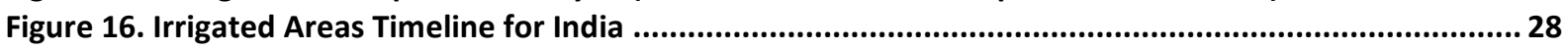

Figure 17. Investments in Irrigation and Drainage Sector in India .............................................................. 28

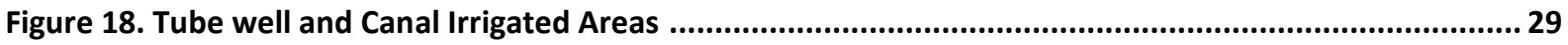

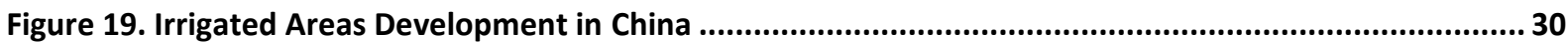

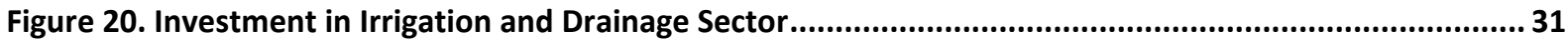

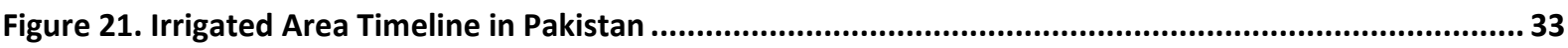

Figure 22. Tube well Irrigated Area and Conjunctive use Area (Tube well + Canal) ......................................34

Figure 23. World Bank Investment in Irrigation and Drainage Sector in Pakistan .........................................34

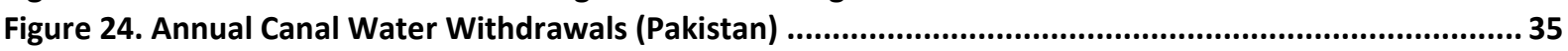

Figure 25. Irrigated Areas Development Timeline in Bangladesh...............................................................35

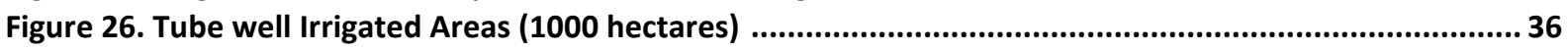

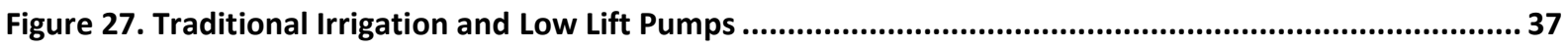

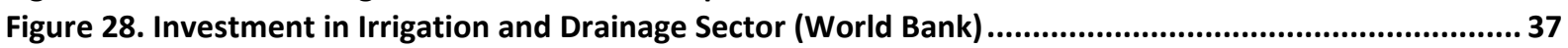

Figure 29. Canal Irrigated Areas ('000 hectares) ...........................................................................................37

Figure 30. Irrigated Harvested Area in Iran (36 years' Timeline) Source: Ministry of Agriculture .................... 38

Figure 31. Agricultural ground water extraction in Iran a and Alavi, 2010) ................................................39

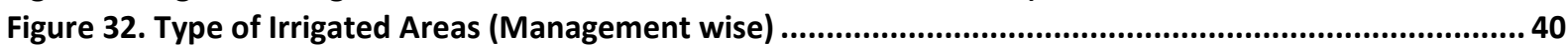

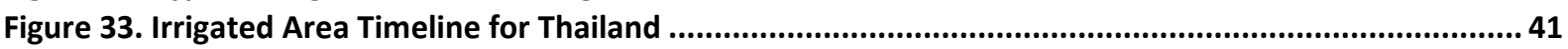

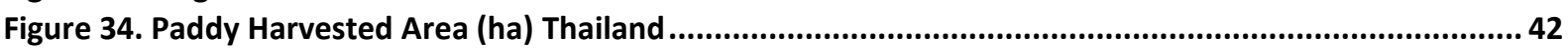

Figure 35. Projected timeline of irrigated areas in Thailand ................................................................42

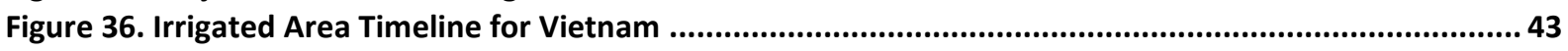

Figure 37. World Bank's Investment in Irrigation and Drainage Sector ......................................................44

Figure 38. Development of Area Equipped for Irrigation in Indonesia ......................................................46

Figure 39. World Bank Investment in Indonesia's Irrigation and Drainage Sector.......................................... 46

Figure 40. Irrigated Area's Timeline for Nepal ....................................................................................48

Figure 41. World Bank Investment in Nepal (Irrigation and Drainage Sector) ...........................................49

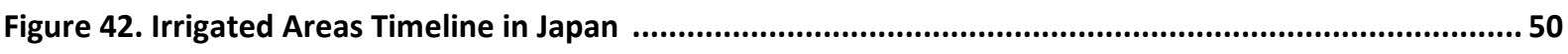

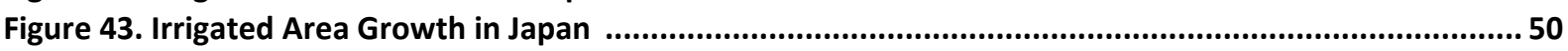

Figure 44. Cumulative development of irrigated areas in Asia ..............................................................51

Figure 45. Irrigated Areas Growth per Decade (1960-2010) .....................................................................51

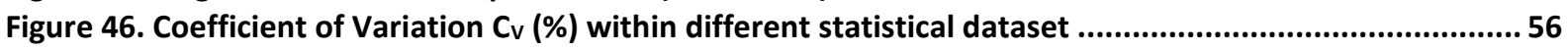

Figure 47. Coefficient of variation $C_{v}(\%)$ including RS based map products .................................................5. 56

Figure 48. Descriptive statistics: Mean, Standard Deviation and Range RS based data ..................................58 
Figure 49. Climatic Zones in Asia (classification based on LGP) .................................................................59

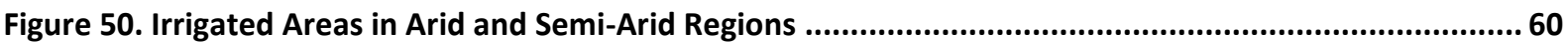

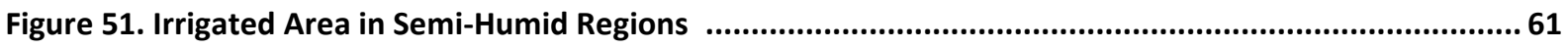

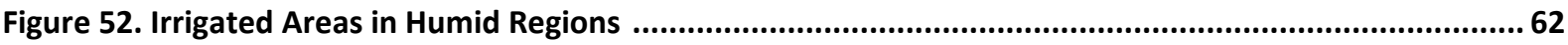

Figure 53. Percentage distribution of Irrigated Areas in different climatic regions .....................................62

Figure 54. Comparison of Zonal Discrepancy Analysis ........................................................................63

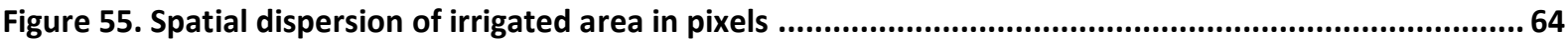

Figure 56. Spatial Dispersion of Irrigated Areas (India and China) ............................................................66

Figure 57. Spatial Dispersion of Irrigated Areas (Pakistan and Iran) .......................................................6.67

Figure 58.Spatial Dispersion of Irrigated Areas (Bangladesh, Nepal) .........................................................68

Figure 59. Spatial Dispersion of Irrigated Areas (Thailand, Vietnam) ........................................................68

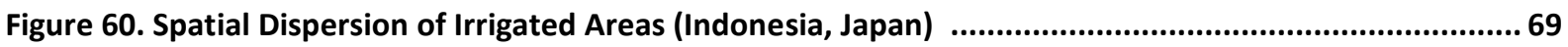

Figure 61. Results of Minor Irrigation Survey 2014-15 .............................................................................8 80

Figure 62. Proportion of Irrigated and Drained Land - Vietnam ................................................................ 83

Figure 63. Irrigated Areas information based on payment terms ..........................................................86

Figure 64. AQUASTAT Data Collection, Analysis and Dissemination Process .............................................89

Figure 65. Methodology for Global Irrigated Area Maps ..............................................................................90

Figure 66. Flow Chart Diagram (General mechanism of irrigated areas reporting systems) ..........................92

Figure 67. Modified Reliability Score Chart ........................................................................................95

Figure 68. Annual Land Productivity (ALP) Comparison for Irrigated Grain Production (tonne per hectare), .. 97

Figure 69. Per Capita availability of Irrigated Areas in Asian Countries.......................................................98

Figure 70. Total Irrigation Potential and so far Utilized .................................................................. 100 


\section{List of Tables}

Table 1.Area Equipped for Irrigation (AEI) Source: AquaStat-FAO ......................................................... 12

Table 2. Tabular assortment and criteria for qualitative analysis .......................................................... 18

Table 3. Statistical analysis for finding the coefficient of variation (Bangladesh) Source: Analysis using various

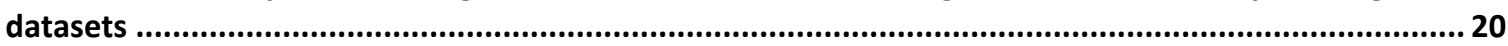

Table 4. Rationale of the Appraisal System (Quantitative Analysis) .........................................................20

Table 5. Percentage of total irrigated area assigned to regions of different map quality (Source: FAO-GMIA) 24

Table 6. Development of Area under Irrigation and Drainage Network in Iran ...........................................39

Table 7. Different water sources and their fraction in total water usage

(Source: Ministry of Energy, Overview of Water Resources in Iran) .................................................. 40

Table 8. Cultivated land and percentage area equipped for formal irrigation (Source: AquaStat 2016)......... 53

Table 9. Datasets collected from National Data Archives (Unit: 1000 ha) .................................................54

Table 10. Datasets collected from FAO Subsidiaries and Raster Maps (Unit: 1000 ha) .................................54

Table 11. Statistical test results-I (Source: National data archives and FAO datasets) Unit: 1000 ha ............. 57

Table 12. Statistical test results-II (Source: National data archives, FAO datasets and RS based maps) Unit: 1000 ha

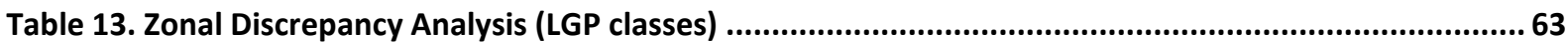

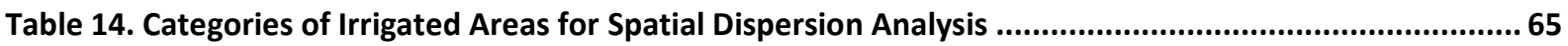

Table 15. Source wise Irrigated Area Pakistan (Source: Agriculture Census 2010) ......................................... 76

Table 16. Reliability and Impact Range/Ranking Table for Sub-Parameters of Irrigated Areas Reporting Mechanism

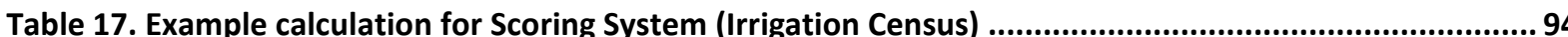

Table 18. Score Table (Standardized Reliability in Irrigated Areas Reporting Mechanisms) ...........................94

Table 19. Share of Irrigated Agriculture in Grain Production of Asian countries Source: AquaStat, Agricultural Censuses, Annual Crop Reports, Estimates etc

Table 20.Grain Production from Irrigated Agriculture, Source: Calculations based on FAOSTAT Cereals Production Quantity Data

Table 21. Agricultural Water use in Asian Countries (Source: AquaStat) ................................................. 99 


\section{Abbreviations}

AAI

ADB

AEI

AFSIS

APCAS

ASEAN

BADC

BWDB

DES

DoI

DTW

EIA

ESA

FAO

FMIS

GAEZ

GIAM

GLAD

GMIA

GMRCA

GSO

IBC

IBIS

ICID

IIMI

IPC

IPU

IWMI

JRC
Area Actually Irrigated

Asian Development Bank

Area Equipped for Irrigation

ASEAN Food Security Information System

Asia and Pacific Commission on Agricultural Statistics

Association of Southeast Asian Nations

Bangladesh Agricultural Development Corporation

Bangladesh Water Development Board

Directorate of Economic Studies

Department of Irrigation

Deep Tube Wells

Effective Irrigated Area

European Space Agency

Food and Agriculture Organization

Farmer Managed Irrigation System

Global Agro-Ecological Zones

Global Irrigated Area Maps

General Department of Land Administration

Global Maps of Irrigated Areas

Global Maps of Rainfed Cropland Areas

General Statistics Office

Irrigation Booking Clerk

Indus Basin Irrigation System

International Commission on Irrigation and Drainage

International Irrigation Management Institute

Irrigation Potential Created

Irrigation Potential Utilized

International Water Management Institute

Joint Research Centre 
Low Lift Pump

Ministry of Agriculture and Rural Development

Millennium Development Goals

MILT

Ministry of Land, Infrastructure, Transport and Tourism

NBS

National Bureau of Statistics

OAE

Office of Agricultural Economics

PBS

Pakistan Bureau of Statistics

PEC

Post Enumeration Check

PIM

Participatory Irrigation Management

RID

Royal Irrigation Department

RS

Remote Sensing

SOPs

Standard Operating Procedures

STW

Shallow Tube Wells

SDGs

Sustainable Development Goals

TRS

Timely Reporting System

USDA

United States Department of Agriculture

USGS

United States Geological Survey

WB

World Bank

WUA

Water User Association

MoAC

Ministry of Agriculture and Cooperation

CBS

Central Bureau of Statistics

NLSS

National Living Standards Survey

MAFF

Ministry of Agriculture, Forestry and Fisheries

ALP

Actual Land Productivity 


\section{List of Symbols}

$\begin{array}{ll}\mathrm{C}_{v} & \text { Coefficient of Variation } \\ \text { ha } & \text { Hectares } \\ \mathrm{M} \text { ha } & \text { Million Hectares } \\ \text { '000 } & \text { Value is to be multiplied with } 1000 \\ \mathrm{USD} & \text { United States Dollar } \\ \mathrm{BCM} & \text { Billion cubic meter } \\ \mathrm{m}^{3} & \text { cubic meter } \\ \mathrm{m}^{2} & \text { square meter } \\ \mathrm{T} / \mathrm{ha} & \text { tonnes per hectares } \\ \sigma & \text { Standard deviation } \\ \mu & \text { Mean } \\ \mathrm{N} & \text { Size of Sample }\end{array}$

Raster Resolution: 0.083333 decimal degrees $\approx 5$ arc minutes $\approx 10,000 \mathrm{~m}$ 


\section{CHAPTER 1}

\section{Introduction}

\subsection{Background}

Asia being home to more than 4.42 billion people, has long standing integrated link with agriculture and irrigation from Bronze Age. Throughout history irrigation has always played a key role ensuring the food requirement of the civilizations. Already holding 62\%of world population, Asia has been predicted to reach 5.2 billion number of people by the year 2050 . This might give a $70 \%$ rise to food demands in terms of caloric needs and balance between rural and urban population of the continent (FAO \& ADB, 2014). By having limited land and water resources, it would be a challenge for the countries in the region to cope increasing demands. $70 \%$ of the world's irrigated areas are located in Asia and despite their generally low performance and efficiency; these irrigated areas are striving hard to ensure the food security of billions of people.

Though the marvellous outcomes of green revolution during 70's and 80's ruled out the threats of famines in Asia (Mukherji and Facon, 2009). Food production was boosted and yields were increased incredibly, but now looking at future these firm steps taken in past seems insufficient as Asia is still prone to face hunger due to several factors. Such as stagnating food productivity, climate change, population rise, limited water resources, change in diet, fluctuation in food prices and land degradation among others. Agriculture water demand of South, East and Central Asia will reach at $6387 \mathrm{~km}^{3}$ by year 2050 which is almost twice of the current water use (Molden et al 2007).

In Asia, regional food security is closely linked to irrigated agriculture. The whole continent is facing a paradigm shift where rural hydraulic societies or moving towards economies based on industrial development and services (Barker \& Molle, 2004). Though, somehow it indicates a positive trend in the overall condition of deprived population but there are still more than 500 million malnourished people in Asia, suffering from physical or economic paucity of food.

On the other hand, Investments in irrigation sector is also a point of discussions since last decade, there are several confusions associated with food security which strengthen the argument against further investment in irrigated agriculture. There are also some discussions to redirect the fresh water intake towards urban requirements from those irrigation system which are not performing efficiently. Moreover, Rosegrant (1995) described that globally there was $1.7 \%$ annual reduction in irrigated areas.

It is believed that green revolution has almost lost its effectiveness as gain on investments is not that high and subsidies are required to keep the whole system working. This is also a reason which gave rise to the concept of participatory irrigation management (PIM) where states wants 
farmers to think and act on more rational basis in order to peruse a self-dependency up to a certain extent. As discussed earlier, there is a need to enhance the productivity both in water usage and crop yield. So that, these effort may bring a positive change in the scenario as farming community would perform better when they deal less with bureaucratic constraints.

Further, we will be dealing with more climatic uncertainties in near future which could deteriorate the infrastructure strengthening the food security objective. Looking at the economic side, Asian Development Bank (2014) predicts almost a 70\% rise in food prices and on the same hand there $70 \%$ of total population will be living in cities as well by 2050 , which would carry its own intricate challenges, as dietary patterns would be changed.

On the contrary, available resources and their management does not provide comforting facts. As surface water resources in Asia have already been exploited for irrigated agriculture, project costs for irrigation have been double or triple folded, irrigation agencies are more focused towards rehabilitation of old schemes, high concerns for the eco-system damages of large irrigation schemes etc. Perhaps donors have also shifted their preference index more towards new scopes. (FAO, 2003) Following graph shows the variation in investments in irrigation sector over time, starting from 1993.

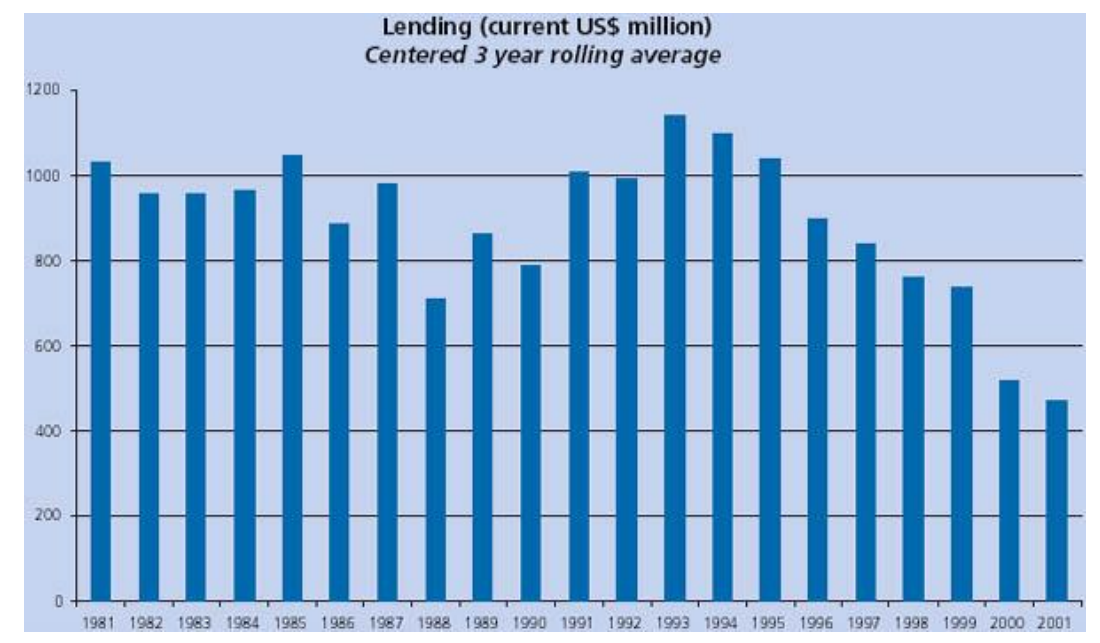

Figure 1. Trends in Investments in Irrigation and Drainage Sector in Asia (Source: World Bank)

By having all these in hand challenges, reliable information of irrigated areas would be inevitable in near future. Irrigated agriculture is struggling with other water users, while having more pressure for increasing yield and water productivity. Policy makers can efficiently deal with these challenges when reporting mechanism is based on effective data collection methods.

Moreover, looking at Sustainable Development Goals set by United Nations in 2015, including worldwide eradication of hunger, twofold increase in agricultural yield, ensuring the sustainable food production and ecosystem persistence. Job for Asian countries is more tough now as precise and holistic knowledge of irrigated areas would be inevitable to support global objectives along with achieving regional goals. 


\subsection{Problem Statement}

Irrigated Agriculture has always played a key role in the economy of many countries in Asia. Irrigation provides a better opportunity to attain higher and reliable crop yields as opposed to rain fed agriculture which is not consistent under varying climate of Asia. Nearly $40 \%$ of total world's food is produced by irrigation which covers $17 \%$ of total area under cultivation (Merret, 2002). Reliable information on the extent and spatial distribution of these irrigated areas has vital importance to policy makers.

Asia holds the $70 \%$ of global irrigated areas and Asian countries have been spending billions of dollars into irrigation sector, considering it a pillar of national food security, poverty alleviation, and economic development (ADB, 2012). Consequently, irrigation experienced rapid development, which in turn, contributed to satisfying the growing demand in food and rural income. So, it becomes significantly important to analyse the growth track overtime in Asia's irrigated areas, which could provide a valuable information to policy makers for devising strategies in accordance with the future needs.

Asian countries have been collecting this information using several methods which are based on statistical enumeration, surveys and estimation techniques. For a long time, it was believed that the information generated from countries regarding irrigated area is reliable. But with the evolution of aerial surveys and satellite imagery, new methods have been developed to measure the extent and type of irrigation in irrigated lands. These techniques have enabled researchers to develop new datasets for the extent of irrigated agriculture at a global scale. This information when compared with the national data archives, showed large variations between the results as most of the time remote sensing methods came up with large numbers. This created doubts in spatial coverage of national reporting mechanisms and data collection methodologies used by countries to furnish datasets for irrigation.

This problem can be linked with the previous discussion for the need of a reliable data in order to make consistent policies and future strategies to achieve food and water security goals. Information collection methods which work behind the once called reliable datasets, are needed to be reviewed in a systemic way to find weaknesses and strengths of those systems. It will enable us to come out from the chaos of variations in datasets and improvements can be suggested to revitalize old systems of data collection.

\subsection{Rationale of Study}

While irrigation development is central to policies and to investment in many Asian countries, there is however a lack of understanding at national level. An important question regarding the pace of irrigation development over overtime is, to what level it is meeting the goals and national targets and what is the remaining potential considering land and water resources development? These questions are pivotal to the new sustainable development goals (SDGs), as there is a definite need to put irrigation in the context of food demand, rural development, water resources development, ecosystems conservation.

Furthermore, without having a reliable database regarding the extent of irrigated agriculture, which is the largest consumer of fresh water withdrawals in Asia. It is quite difficult for national 
governments to track the realisation of annual grain production targets. Several other significant implications of this drawback could appear on the achievement of goals linked with food security as well. It is very obvious that states are not fully capable to track the progress on food production and especially on the planning side there is big gap of accurate data availability. Mostly yield prediction is based on the extent of croplands and in Asia where irrigated agriculture has significant share in staple food production e.g. rice and wheat, a poor information availability could lead to impractical planning and non-effective investments.

As discussed earlier, public sector is also under stress due to reluctance of donors to invest in irrigation development projects. This means in near future there will a huge pressure on state treasury to allocate funds to irrigation sector, either it could be for new development or rehabilitation. Furthermore, justified investment definitely needs a precise cost-benefit analysis with a reliable data input, which rise the need of having reliable database inevitable. Moreover, any irrigation project needs an updated database of existing or proposed extent of command area to calculate the return on investments.

The reason for the misapprehension is that there is a general lack of accurate, up to date and comprehensive information set of timely reporting for changes in irrigated areas and their production. Existing countrys' reporting systems, on which global datasets such as FAOAQUASTAT Irrigated Areas rely, are often just conventional statistics and estimates coming through layers of national administrative systems. These results are often subject to errors and biases due to various reasons. New methods of data collection such as remote sensing are being used to help tracking land use changes, but so far they have not been fully endorsed by relevant authorities.

Future development in Asia's agriculture will determine the fate of the continent as food requirement will be doubled in next 30 years. Water resources will be scarcer in future and there is a dire need to determine fine approximate future water demands for effective planning (Seckler et al. 2000). Overall scenario of irrigation in Asia is also moving towards a change as more small irrigation schemes would pop up from large scale irrigation systems, transforming according to market needs and public sector irrigation policies (Facon \& Mukherji, 2010) Though, several attempts have been made to collect and record the data of irrigated areas on global scale, but still there are lot of discrepancies in the measured data and data provided by the states. This uncertainty is developing a large gap in the way of integrated planning approach for the whole continent and obviously policy makers will not be aware with the actual ground situation and any long-term future planning could bring calamity as it will not be based on real facts.

The proposed research will be based on available timelines of irrigated areas to study their growth tracks. All available datasets available at country level will be studied for variation and the procedures involved in reporting of irrigated areas will be reviewed for all the possible causes of deviations and uncertainties. Implications of variation in datasets would also be discussed. For strengthening the arguments made during introduction and rationale of study, some existing studies and reports have been reviewed briefly to develop an initial understanding regarding the reasons and ramifications of the stated problem, which will be discussed in next chapter. 


\subsection{Research Questions}

1. What is the extent of variation in irrigated areas in Asia over time?

2. What is the degree of uncertainties and variations in different datasets of irrigated areas and their reporting methods?

3. What is the link of variation in irrigated areas information with food production and agricultural water use?

\subsection{Research Objectives}

1. To analyse the growth track of irrigated areas, their typology and investments involved and to find out the factors inducing variations over time.

2. To analyse the variation in different datasets of irrigated areas available in Asian countries and to conduct a spatial variation analysis for agro-ecological zones in Asia.

3. To conduct a qualitative analysis for irrigated areas reporting methods and to transform it into a generalized scoring system for Asian countries.

4. To develop and analyse a link between the discrepancy in datasets with national food production and water use in agriculture.

5. To develop a set of recommendations for possible improvements in reporting mechanism of irrigated areas to facilitate better decision making for future developments. 


\section{CHAPTER 2}

\section{Literature Review}

\subsection{Challenges for Food Security Goals}

Planet earth is home to 7 billion people and 56\% of this population lives in Asia and the Pacific and by the mid of twenty first century, one third of total rise in global population will be accommodated by this region as well. There is an extensive pressure on natural resources as the economic boom, development in industrial sector, expansion in urban areas and modified food requirements are using most of the scarce supplies. Per capita land available for agriculture will also be reduced by $10 \%$ and on other hand there will be an additional water requirement of 2.4 billion $\mathrm{m}^{3}$ in order to fulfil the basic food requirements of the region (Asian Development Bank, 2013). Asian countries are not producing enough food to cope with addition of 1.5 billion in the population by the year 2050 . Food and fodder demand could get two folded and there will be a need of improved management of already present irrigated lands as resources are not copious (Mukherji et al., 2009) Climate change will also play an eccentric role in world food production in near future. There will be severe pressure on agriculture due to inconsistency in rainfall, droughts and soil erosion. Yields will be adversely affected due to warm weather in future as the rise in temperature will cross the verge for many crops (Asian Development Bank, 2011).

\subsection{History and Development of Asian Irrigation}

Early history of irrigation in Asia can be linked to Indus basin civilization and following timeline gives a glimpse from past as irrigation has been applied by various people in different times.

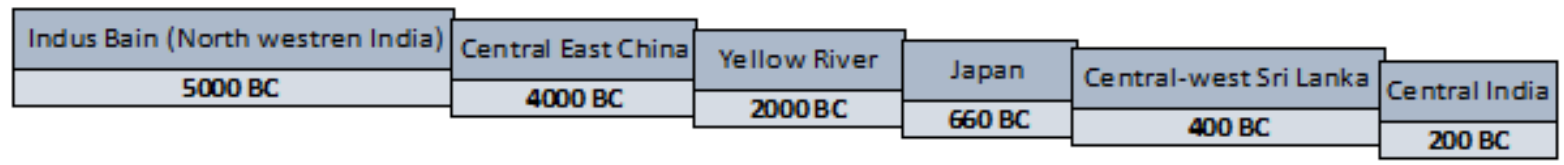

Source: (Li et al, 2009).

History of large scale irrigation in Asia dates back to 1370 AD when Yuan dynasty in China initiated large developments for crop production. While in India, Mughal empire ensured the availability of water throughout the year for irrigation in 1619 ( $\mathrm{Li}$ et al, 2009). Later in history, the irrigation development has been categorized as Colonial Era (1850-1940), Cold War Era (1950-1990) and New Era of Globalization (1990 till now) by Molle \& Barker (2004) in South Asia and South East Asia. These phases has been described as tools for famine control, food security and income generators respectively. Rosegrant and Svendsen (1993) described that there was a boost in irrigated agriculture in Asia during late 60s and 70s (referring towards green revolution), mainly because of the introduction of genetic development in two staple crops of the region, rice and wheat. Moreover, enhanced fertilizer 
use brought reasonable increase in rice and wheat yields (2.3\% and $4.1 \%$ respectively), which was relatively high than last decade. Moreover, a decline in agricultural production was noticed in early 80 s due to several factors like price fluctuations and restructuring of investment policies from donors.

Postel (1999) explains that by year 2020 per capita global irrigated area could decrease by 17 to $38 \%$ in comparison with the hike in late 70 's. An annual average global growth of $2 \%$ was noticed between the period of 1970 and 1982 and it followed by a decrease of $1.3 \%$ per year till 1994. She is of the view that irrigated agriculture is about to reach its maximum limits as most of the feasible area has already been developed. Moreover, per hectare cost for the development has been increased by 2 times and it also varies spatially.

Furthermore, irrigated agriculture was boosted up in India, Pakistan and China by extensive use of ground water resources in last five to six decades. In India alone there was almost $200 \%$ increase in tubewell irrigated areas within a period of 24 years. In China, $46 \%$ rise was noted in number of tube-wells from 1961 to 1980 as a source of water for $18 \%$ cultivated land, while in Pakistan total number of tube wells grew by $160 \%$ in 3 decades from 1963 . These figures shows the large dependency of Asian agriculture on ground water resources which is obviously a perishable resource if not used within sustainable limits (Postel, 1999).

Looking at possible future developments in irrigated agriculture, the overall dynamics has been changed for irrigation over time in Asia. Being started as an effective tool for famine protection and revenue generation, it has moved towards guarantying food security in the region and new era of civilization is forcing irrigated agriculture to focus on global markets, improving livelihoods and protecting the environment. (Barker and Molle, 2004)

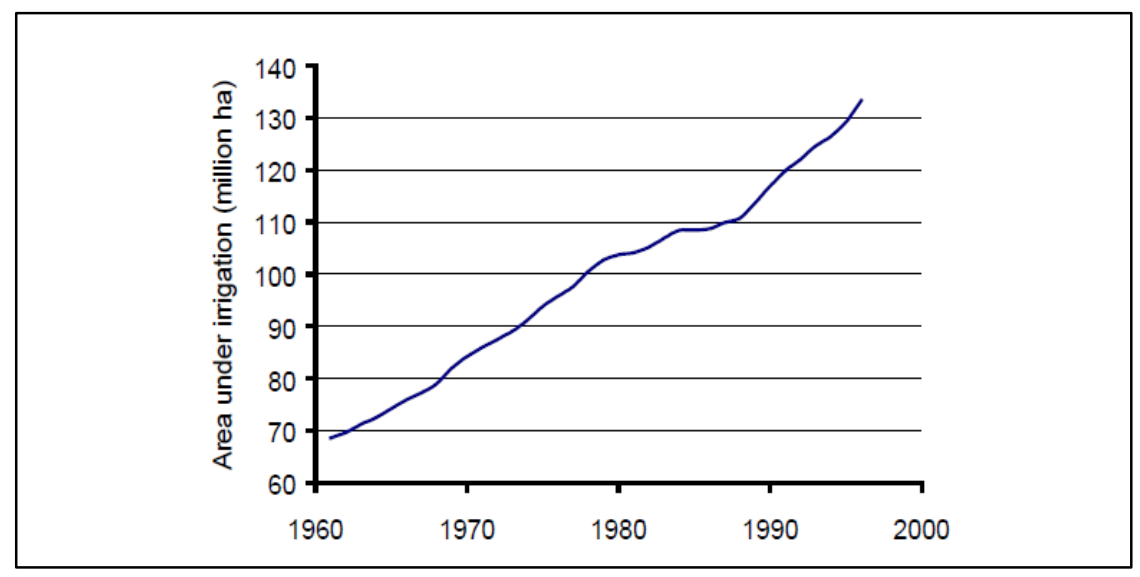

Figure 2. Growth of Irrigated Area in Asia (Source: AQUASTAT)

In Figure 2, a significant expansion in irrigated areas can be noted between mid-60s and 70s which indicates the impact of green revolution in Asia.

\subsection{Irrigation in Current Global Context}

Millennium Development Goals, set by United Nations in 2000 for a period of 15 years, mentioned the most vital global objectives to be achieved by 2015 as poverty reduction, eradicating hunger, environmental sustainability etc (UN Millennium Project, 2006). No doubt, 
in a global context these goals were highly integrated with irrigated agriculture in developing countries especially Asia. In the continuation of MDGs, sustainable development goals (SDGs) have been introduced now as guidelines for future global objectives which includes SDG6 as to improve the water productivity extensively for all stakeholders and to deal with water scarcity by maintaining the use of freshwater resources within a sustainable range in order to mitigate the effects of scarcity on communities. Moreover, SDG2 states about double folding the global agricultural productivity by 2030 . Furthermore emphasize has been given to the implementation of integrated water resources management approach in every sector which is linked with water as well (Global Goals, 2015)

On other hand, (Rosegrant and Svendsen, 1993) explained that there was an overall decline of investments in irrigation development in Asia by the end of twentieth century which resulted a reduction in growth of irrigated areas, however it was caused by high input costs and global recession of commodity prices which ultimately lead to underinvestment. Moreover, twenty first century has brought new challenges for agriculture for example climate change, struggle for water resources, low efficiency and aging infrastructure etc.

\subsection{Future Strategies}

Four comprehensive strategies has been suggested by Fraiture et al (2007) to develop guidelines for future water developments and policy decisions. These strategies describe about future investments in rainfed and irrigated agriculture. They highlighted the prospects of improved water productivity instead of escalating the irrigated areas, as globally $35 \%$ expansion in irrigated areas could add only 260 million metric tons in world granary but on other hand focusing more on the gaps of water use efficiency can add up 540 million metric tons of grain which would be sufficient enough to meet the $75 \%$ global food requirement by 2050 . There is an obvious need of precise information regarding extent and location of irrigated areas, water sources, land-use and water use efficiency trends. Policy makers could use these tools effectively in order to draft achievable and realistic agriculture strategies and policies which would be helpful to attain food security goals and to predict the needs of investment in agriculture (Thenkbail et al, 2009). Estimation for crop water use and yield forecasting would be more reliable if irrigated lands are recorded precisely for their location and area. (Thenkabail et al, 2008).

\subsection{Uncertainty Level in Irrigated Areas}

National datasets have been compared with estimates of remote sensing to look at the actual extent of irrigated areas. (Thenkabail et al, 2009) found the irrigated areas in India, estimated using remotes sensing methods, were almost $44 \%$ higher than ministry of water Resources records. 


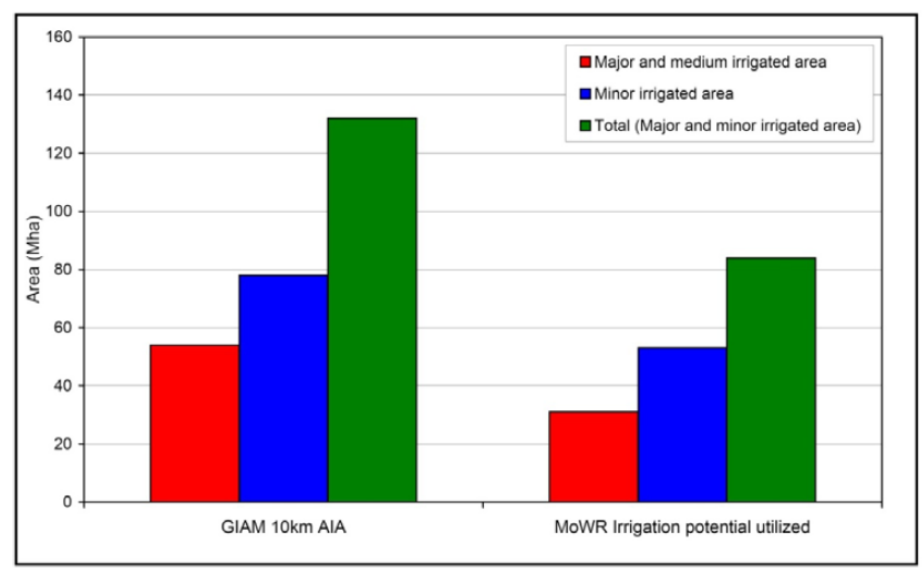

Figure 3. Comparison between Irrigated Areas estimates (Source: Themkabail et al, 2009)

50 to $100 \%$ agricultural areas were found to be in surplus in China as compared between the official record and measured by satellite imagery; relatively flat areas showed high correlation with the computed data and vice versa. They compared the land cover maps of China with agricultural census data of 1990 at county level and the coefficient of determination $\left(r^{2}\right)$ was found to be 0.23 , which showed a high level of variation between data collected on ground and estimated by remote sensing. (Frolking et al, 1999)

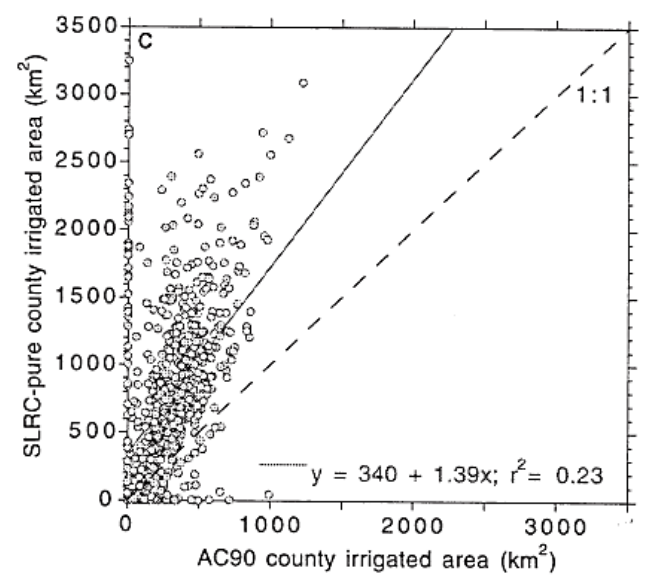

Figure 4. Comparison between Agricultural Census and Land Use maps (Source: Frolking et al, 1999)

Though Food and Agriculture Organization (FAO) working under United Nations maintains database of agricultural lands but flaws have been reported by some researchers as the information is based on purported facts and figures are usually collected from member countries (Droogers, P. 2002).

FAO data sets have their own practical impediments along with plausible political interference, reported by (Bastiaanssen, 1998). There is also a worldwide muddle for the definition of irrigated land which creates certain snags e.g., actual or retired irrigated area and extrapolating the crop rotation as double area in records (Frolking et al., 1999). Several attempts have been made to measure the irrigated areas using remote sensing techniques e.g., Global Irrigated Area Mapping (GIAM), Global Map of irrigated Area (GMIA), Global Map of rainfed cropland areas (GMRCA) and Global map of land use/land cover areas have been prepared on $10 \mathrm{~km}$ 
nominal scale. (Hugh Turral et al, 2005). These maps have brought up some gaps between realities and recorded datas for irrigated areas.

Irrigated areas around the globe, calculated by IWMI using mostly remote sensing techniques were estimated $40 \%$ higher in comparison with FAO database. In addition, $65 \%$ contradictions were present in national datasets of India and China which are world's first two largest irrigated area holders (Wisser et al, 2008). Even there were dissimilarities found in different remote sensing based products for irrigated areas, mostly because of variation in definitions of irrigation (Thenkabail et al, 2004).

The extent of paddy fields was analysed by X. Xiao et al (2006) in South Asia, which are sown on irrigated and rainfed lands. MODIS imagery was used and results were validated by setting a correlation with national agricultural statistics. The coefficient of determination revealed a large disparity as $\mathrm{R}^{2}$ value was $0.47,0.48,0.44,0.42$ and 0.7 for India (district level), Nepal, Bangladesh, Cambodia and Vietnam respectively. In addition, countries like Afghanistan where statistical datasets are considered to be highly unreliable; Pervez et al. (2014) computed average span of agriculture lands under irrigation using MODIS 250m NDVI for 2000-2013 including dry year and wet year. Outcome of their study showed that there was a difference of 0.6 to 1 million hectares in comparison with studies based on statistical approach and FAO data which shows higher figures.

\subsection{Possible Reasons of Uncertainty}

There could be several reasons for the inconsistency between the RS based irrigated areas information and data which is maintained by countries using different statistical techniques. For example, Indian statistics were found lacking for any checks regarding the validity of irrigated areas data. Sometimes the data is kept ambiguous by the state purposely in order to manipulate with facts and figures of their national water share and data analysis also lacks the required statistical approach which ultimately results huge discrepancies between data even within different departments (Thenkabail et al, 2009). This study also found that the area being irrigated by 19 to 26 million tube-wells has also not been included in national data archive which could be a potential cause of truncated national figures of irrigated areas in India. Resolution of satellite imagery, contradictions in definition of irrigation and computation errors are other possible reasons of divergence.

Double standards for the reporting of rain-fed and irrigated areas were indicated by Vaidyanathan and Sivasubramaniyan (2004). Rural land revenue system in India is based on the holding of irrigated land, which is deliberately reported low by the farming community to snip their land taxes. In their study, they also pointed out the adversity caused by the limitations of on field data collection system for land use on agricultural water productivity studies. Besides, National Statistical Commission (2001) highlighted the precincts of agricultural statistics which showed that village accountancy system (patwar system) is responsible for the inconsistency of crop and irrigated area data. It has been mentioned that accountants are reluctant to tally the data with supervisors and on other hand almost $22 \%$ sample villages are not accounted or missed for their crop statements. 


\subsection{Implications of uncertainty on Policy}

Any data incongruities might ultimately result in weak policies as Droogers et al (2009) highlighted the importance of precise information regarding agricultural water for viable irrigation planning and management as water scarcity is a growing threat for food security and reliable knowledge of irrigated agriculture would prove as most effective tool to tackle with upcoming farming predicaments including climate change. Furthermore, Bastiaanssen et al (2000) also emphasized on the importance of knowing the consistent details of water use in agriculture sector. The information regarding the spatial and quantitative use of water is significant in order to find the better opportunities for water conservation and modify policies accordingly.

A dire need to increase the agricultural productivity has been suggested by Asian Development Bank (2013) as in Asia and Pacific there is no more room for future expansion and the positive impacts of green revolution are fading rapidly which shows that by following current agricultural pace will make it difficult to cope the growing food demands of the region. On the other hand, if there is uncertainty exists in data it will be more difficult to look for a feasible long term solution. 


\section{CHAPTER 3}

\section{Data Collection and Methodology}

In this chapter data collection phase and methodology has been discussed. A comprehensive database development could prove a significant milestone for a detailed analysis. The step by step analysis approach is adopted for this research and it has been elaborately described. It is anticipated that it will also help readers to understand the calculations and methods which have been applied for statistical analysis and raster processing.

First 10 countries from Asia are selected on the basis of the extent of their irrigated areas and secondary data has been collected to conduct this research. Following are those countries and their area which is equipped with irrigation including surface and ground water irrigation facilities.

\begin{tabular}{|c|c|c|}
\hline No. & Country & AEI ( 1000 ha) \\
\hline 1 & India & 66,334 \\
\hline 2 & China & 62,938 \\
\hline 3 & Pakistan & 19,990 \\
\hline 4 & Iran & 8,700 \\
\hline 5 & Indonesia & 6,722 \\
\hline 6 & Thailand & 6,415 \\
\hline 7 & Bangladesh & 5,050 \\
\hline 8 & Viet Nam & 4,585 \\
\hline 9 & Japan & 2,500 \\
\hline 10 & Nepal & 1,255 \\
\hline
\end{tabular}

Table 1.Area Equipped for Irrigation (AEI) Source: AquaStat-FAO

Generally there are two kind of datasets available on AQUASTAT; Area Equipped for Irrigation (AEI) and Area Actually Irrigated (AAI) but as some countries have not shared the information about area actually irrigated with AQUASTAT, so AEI has been used for the comparison.

\subsection{Developing a database}

The very initial step for the conducted research was to develop a fine and detailed data base for the irrigated areas of the encompassed countries. For this purpose there were several ways which were considered to get the required data. As the area was relatively large and it was expanded in South and South East Asia, there was quite a dissimilarity in the mode of dissemination for data. Furthermore, each country does not share the information in a uni standard way. 
Discussing the approaches, which were followed during the database development phase; following are the data collection sources which were explored to find all the available data of the countries regarding irrigated areas.

\title{
a. National Published/Shared Data
}

$\begin{array}{ll}\text { i- } & \text { Statistical Year Books } \\ \text { ii- } & \text { National Survey Reports } \\ \text { iii- } & \text { Agricultural Census Reports } \\ \text { iv- } & \text { Irrigation Census Surveys } \\ \text { v- } & \text { National Land Use Surveys } \\ \text { vi- } & \text { Irrigation Department Records } \\ \text { vii- } & \text { Agriculture Department Record } \\ \text { viii- } & \text { Agricultural Survey Reports } \\ \text { ix- } & \text { National Living Standard Rural Surveys } \\ \text { X- } & \text { Regional Cooperation Organizations' Database }\end{array}$

\section{b. International Datasets}

\author{
i- $\quad$ World Bank Datasets \\ ii- $\quad$ FAO Datasets \\ iii- $\quad$ AQUSTAT Datasets \\ iv- $\quad$ Global Maps of Irrigated Areas (GMIA-FAO) \\ v- $\quad$ Global Irrigated Areas Map (IWMI) \\ vi- $\quad$ Land Use Land Cover Maps 1992 (USGS) \\ vii- $\quad$ GLC-2000 (JRC-EU) \\ viii- GlobCover 2009 Maps (ESA)
}

These datasets have been divided into two categories National and International datasets depending upon the spatial and temporal resolution of the data and the collection method as well up to a certain extent. This database collection phase was completed mostly using internet by using a data mining approach as the extent of information was too large. Whereas, information regarding irrigated areas was parted precisely by avoiding all the possible confusions in relation with definition, types and language.

Mainly, two major subcategories were sorted as tabular/statistical data and raster data. Tabular datasets were present in different kind of disseminated reports, records and statistical books but their resolution was not same for different countries. As information for irrigated areas was broken up differently, e.g. country wise, region wise, state/province wise or district wise. So, initially the database has been developed country wise and further comparative analysis have been performed with finer resolution.

In figure 5, part of an agricultural survey report has been shared from Iran. This report has been published in Persian language and reference years are according to Persian calendar. 


\begin{tabular}{|c|c|c|c|c|c|c|c|}
\hline ( : هكتار ) ) & & & كشور & هولات زراعت لغايت & اعى (هV كل محد & سطح برد & جدول شماره l-r \\
\hline بر بل & تيرات سط بار & درصد تغ & رتبه طى & & سطح برداشت & & سال زراعى \\
\hline جمع & טيم & آبى & & جمع & ديم & آبى & \\
\hline & - & - & ra & qFVI... & - & - & $\Delta G-\Delta V$ \\
\hline$r, F l$ & - & - & rF & १९११... & - & - & $\Delta V-\Delta \Lambda$ \\
\hline$-T, V T$ & - & - & ra & qrTג.... & - & - & $\Delta \wedge-\Delta q$ \\
\hline 19 & & & Te & $1111 r . .$. & $\varphi \wedge \Delta \wedge \ldots$ & FTDF... & Q9-9. \\
\hline$-\Delta, g F$ & $-1 \Delta, \Delta$ & $1 ., T \Delta$ & $r$. & $1 . F \wedge \Delta 1 .$. & 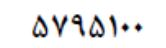 & fqq.... & $9 \cdot-91$ \\
\hline$r, F$ & 1,9 & $r, f$ & $r 9$ & 1.VTVIrI & $\Delta \Lambda \Lambda \vee V I F$ & FAFGFIV & $91-95$ \\
\hline $1, \pi \Delta$ & $-1,19$ & $\Delta, \bullet V$ & rA & $1 . \wedge \vee \backslash \Delta \Lambda$. & DVVArGI & $\Delta .9 \Delta T 19$ & $G r-9 T$ \\
\hline$r$ & r,vq & T,YF & $r \Delta$ & III9VAT. & DqrvarG & DTG.TAF & $G r-G F$ \\
\hline 1,91 & t,V T & $\cdot, 99$ & TF & llfllvrv & 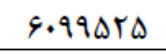 & DTITTAT & $G F-9 D$ \\
\hline $9, \Delta 9$ & $r, r v$ & 9,10 & IV & ITIEFTIS & GTGGTHA & $\Delta \vee ৭ \wedge \cdot \vee \wedge$ & $90-99$ \\
\hline$-\cdot, \Delta l$ & $1 \cdot, 1 \mathrm{~V}$ & $-I T, K F$ & r. & $1 \pi 1.1909$ & V.ITVFG & D.ANTIT & $9 G-9 V$ \\
\hline
\end{tabular}

Figure 5. Tabular dataset from Iran (in Persian language) Source: Ministry of Agriculture, Iran

On the other hand, raster datasets are type of spatial database where information in stored into grids or matrix of cells which is further processed using appropriate geographic information system software to extract required information. Mostly, they were available in the form of land use land cover (LULC) maps, where information regarding the extent of irrigated areas were extracted by zonal analysis according to country boundaries shapefiles then sorted in tabular forms. In addition, the spatial and temporal resolution of the raster data sets were not same for different datasets, which indirectly helped to see the development of irrigated areas over time.

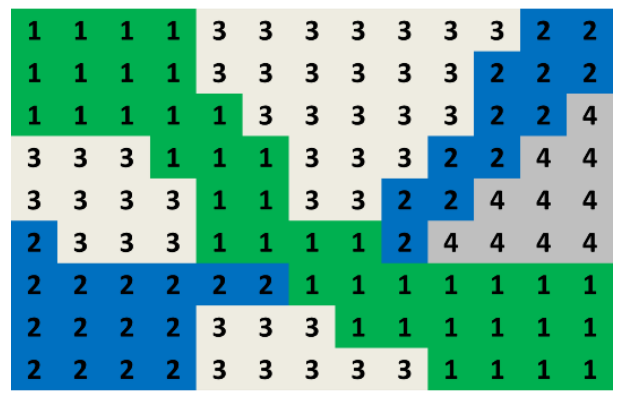

Figure 6. Raster Dataset (Pixels are shown carrying different values) Source: Internet

Dedicated irrigated areas maps in the form of raster datasets were also referred, e.g. IWMIGIAM, FAO-GMIA, which are considered to be more helpful in the research. 


\subsection{Understanding Methods of data collection}

As explained earlier, the detailed datasets of irrigated areas were sorted in different categories depending on their source and type of dissemination. So, in the second phase of analysis it was important to understand those methods. A general approach was followed to develop a detailed understanding of reporting mechanism which is being followed to collect the information of irrigated areas at regional or national level. While raster datasets were studied briefly for their metadata.

\subsubsection{National Statistical Archives}

A vital reason to understand methods working behind national statistics was, to evaluate the reliability of these datasets which carries the uncertainty in comparison with other statistics. Following are those methods which are used in Asian countries at national level to gather the data of irrigated areas.

- Survey of Cultivated/Irrigated Land

- Interviewing Farmers

- Administrative Record Keeping by Irrigation or Agricultural Department

- Log Books of Farms

- Records of Water User Associations

- Records of Land/Revenue Department

A detailed analysis was conducted by studying the methodologies of each technique of data collection. Going further into finer details; sampling ratios, interviewing methods, methods to define the coverage of survey areas, methods of extrapolation, definitions of terminologies, frequencies, framework of census, size of enumeration areas, questionnaires and coefficients of variation were studied thoroughly.

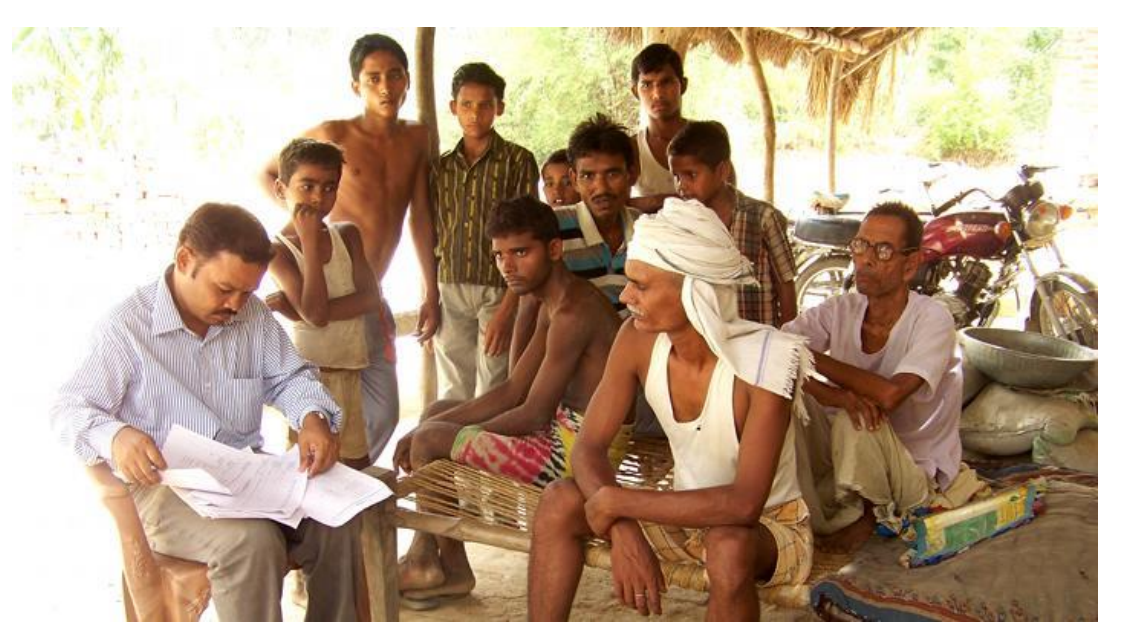

Figure 7. Farmer Field Interview is being conducted during Agricultural Survey in India (Source: Internet)

During this phase, it was realized that methods of collecting data carries a wide pocket of variation in relation with different means of getting the information. It was learned that FAO has published some certain guidelines for conventional methodologies to collect information for agricultural statistical indicators, which includes information of irrigated land along with 
other general statistics. Moreover, some countries have developed their distinct methodologies to conduct irrigation surveys/census. But still the factor of variation exist in every country which was tried to be understood in the context of irrigated areas information.

To know more in details for some countries, e.g. China, Vietnam etc, where there was less clarity for the techniques or methods, extensive literature review was done. As methodologies about collecting the information of irrigated areas for some certain agencies were not published or shared on web. Past research work on the similar topic was tried to be reviewed thoroughly but it is worth mentioning that very less work has been done on this very field of research.

Furthermore, a general understanding was required to be ascertained to move further for detailed analysis. In this regard, questionnaires were developed to be sent to irrigation officials of countries under study. These questionnaires were designed specifically to get required information about the reporting mechanism and standard operating procedures of irrigation department to collect data about area actually irrigated. Emphasizes has also been given on informal and farmer managed irrigation schemes as these type of irrigation systems might be considered to be cause of uncertainty in the national database where most of the time they does not come under the reporting coverage of official agencies. Though in Asian countries they are a big stake holder in irrigation sector now. Information was gathered from China, Indonesia, Nepal, Pakistan, and Bangladesh using the questionnaire. Questionnaire copy received from Nepal has been shown in Appendix A.

\subsubsection{Raster Datasets}

Metadata was collected for raster datasets to understand the temporal and spatial resolution of these maps. Raster datasets are based on satellite imagery and the land is usually classified into different land use types, depending upon the difference in reflectance from land, e.g. type of vegetation etc. Some algorithms have also been developed to classify for irrigated crops/lands and the intensity of irrigation. It is important to mention that, raster datasets also have a vast variation in the methodologies which could cause disparity in the results even for the same temporal/spatial resolution and with the same source.

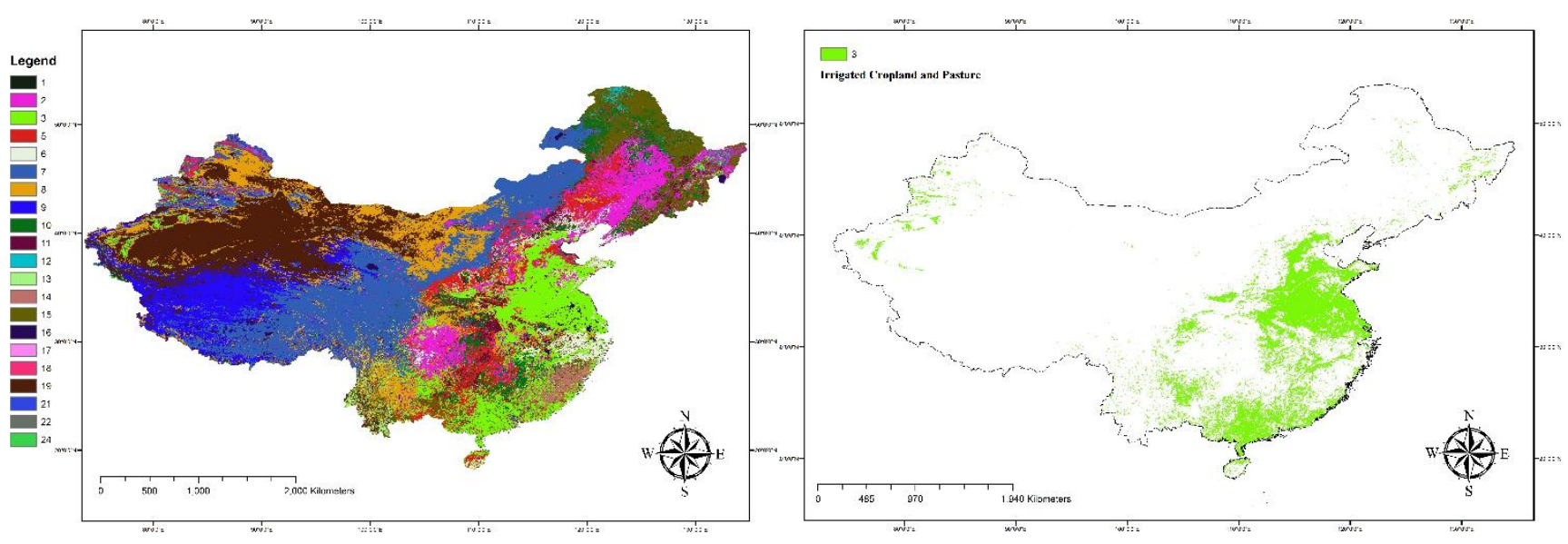

Figure 8. LULC China (Irrigated Cropland-3) Source: USGS Global Land Cover Characterization 1992 


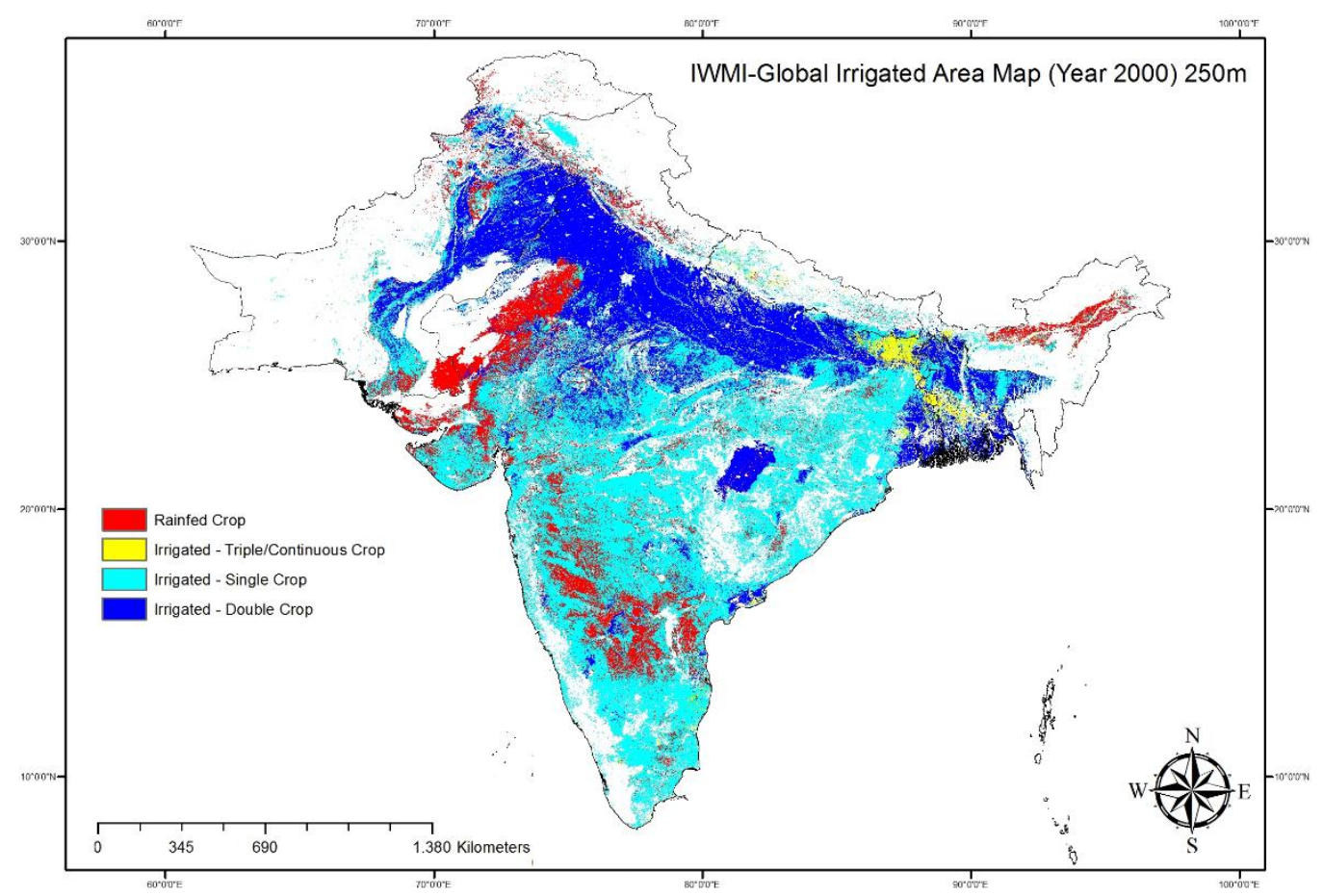

Figure 9. IWMI-Global Irrigated Areas Map (Pakistan. India, Nepal, and Bangladesh) Source: Processed from IWMI's raster file

\subsection{Quantifying Uncertainty and Defining an Appraisal System}

\subsubsection{Qualitative Analysis}

Developing the understanding for applied methods was a pre-requisite for a qualitative analysis in the first step of conducted study. As described earlier, there was a huge variation in different methods $^{1}$ and reporting mechanisms which are being used in Asian countries to collect information of irrigated area and the aim of the study was to evaluate different methods in a comparative mode. So quantifying the uncertainty was a vital phase which was based on the qualitative analysis of all the studied methodologies which were understood by reports, literature and personal communication.

By putting all the information together in tabular form, strengths and weakness of the systems were evaluated apparently and they were noted for each method. This qualitative analysis was based on the reliability of that data source which was further linked with the enumeration methods, mode and way of verification, post-survey checks, data processing, coverage and frequency. Reasonable consideration was also given to the official questionnaires which were used during the statistical enumeration as they were a source of information for analysing the priority of the data collection agency for irrigated areas, which was further classified as primary or secondary.

\footnotetext{
${ }^{1}$ Tabular/Statistical Datasets (Country Sources, e.g. Census, Surveys etc)
} 


\begin{tabular}{|l|l|l|l|l|l|l|}
\hline Country & Dataset & Timeline & $\begin{array}{l}\text { Periodicity of } \\
\text { Downloaded Dataset }\end{array}$ & $\begin{array}{l}\text { Frequency of } \\
\text { Data Collection }\end{array}$ & Methodology & $\begin{array}{l}\text { Agency } \\
\text { Responsible }\end{array}$ \\
\hline
\end{tabular}

\begin{tabular}{|l|l|l|l|l|l|}
\hline $\begin{array}{l}\text { Coverage } \\
\text { /Reported } \\
\text { Area }\end{array}$ & $\begin{array}{l}\text { Sample Size (If } \\
\text { Sampling Survey) }\end{array}$ & $\begin{array}{l}\text { Resolution of Disseminated Report } \\
\text { Country/Province/District }\end{array}$ & Remarks & + Advantage & - Risks \\
\hline
\end{tabular}

Table 2. Tabular assortment and criteria for qualitative analysis

While analysing the advantages and risks of different reporting systems the confidence level of the data was also investigated. Confidence level can be defined as the assurance of the data source as it was not necessary that in every data collection method the enumerator physically visit the farms or irrigated area. So it was tried to find the actual procedures which were adopted during the enumeration process. In some cases, it was found that the irrigated areas datasets are actually relying on the administrative records of the relevant departments. So, the authenticity and the methods or the SOPs of the concerned departments were needed to study as well, to be able to look at clearer picture. This phase certainly zoomed into many interesting aspects of the irrigated areas data collection methods which are implemented in different Asian countries and also it enabled the researcher to think for the certainty of the available data sets which are originated at country level.

\subsubsection{Quantitative Analysis}

Completing the detailed quality analysis by analysing the methodologies and procedures involved in collecting irrigated areas information, the next phase was to look for a possibility of quantifying the uncertainty. For this purpose a two-dimensional approach was used where all the available datasets of the countries were analysed statistically in order to find the variation in terms of standard deviation. On the other hand, a ranking system was developed to scale those methods in general, which were investigated qualitatively.

During the quantitative analysis of available datasets it was realised that there is a huge variation in the irrigated areas extent for different countries and there is a need to find a normalized or equivalent tool which could compare the variation among different datasets, having different means of collection. Later on the results could also be used to compare the level of uncertainty among countries.

In this regard, coefficient of variation was calculated to find the inclusive variation among datasets. Coefficient of variation can be generally defined as standardized measure of dispersion in a group of datasets. Following is the equation no.1.

Where:

$$
c_{v}=\frac{\sigma}{\mu}
$$

$\mathrm{c}_{v}=$ Coefficient of variation

$\sigma=$ Standard deviation

$\mu=$ mean 
Standard deviation is the quantitative dispersal of a certain unique value within a group of datasets from the cumulative mean and it was calculated using following equation no. 2 :

Where:

$$
S=\sqrt{\frac{\sum_{i=1}^{n}\left(x_{i}-\bar{x}\right)^{2}}{n-1}}
$$

$\mathrm{x}_{\mathrm{i}}=$ data values

$\overline{\mathbf{x}}=$ mean value

$\mathrm{N}=$ size of sample (square root of sample variance)

Following is an example of a set if datas which were processed for statistical analysis:

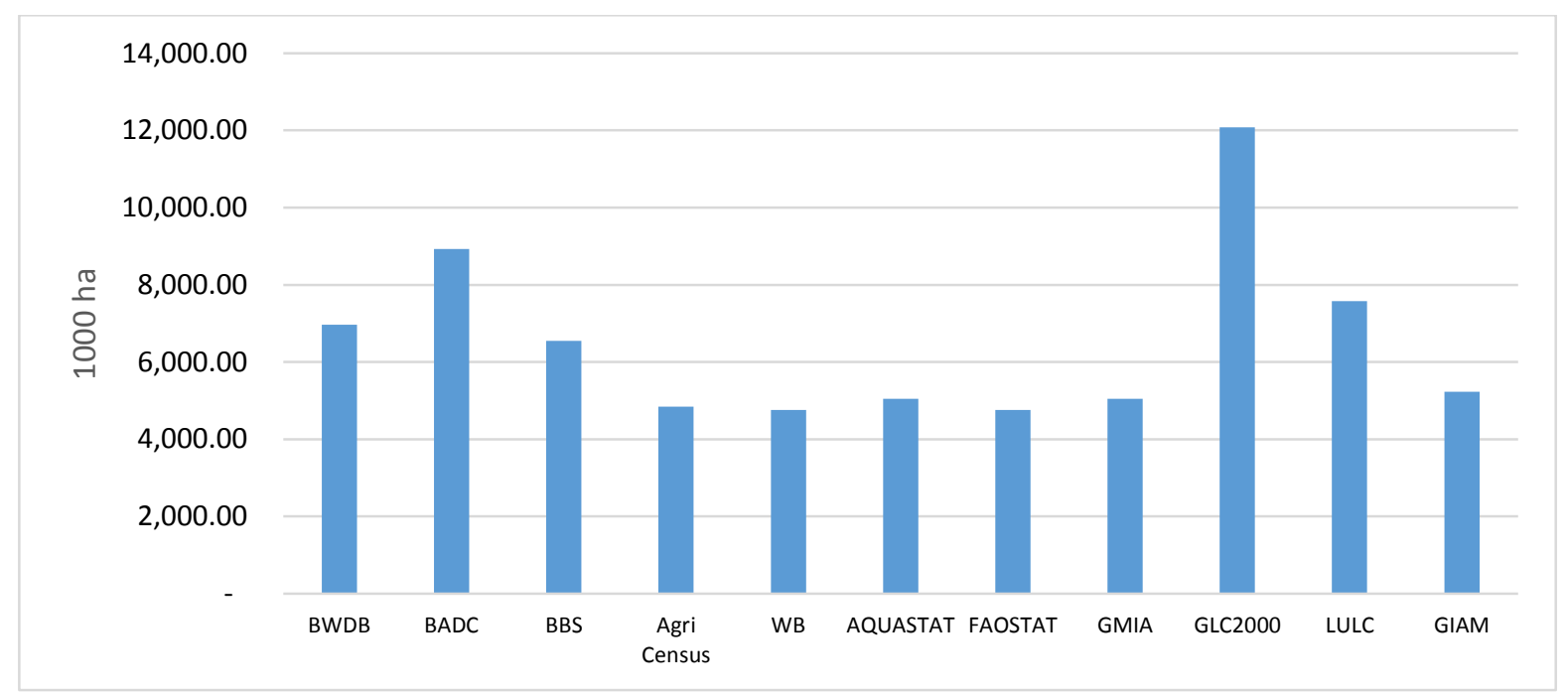

Figure 10. Group of datasets (Irrigated Area) Bangladesh (Various Sources)

A large variation can be seen here in datasets which are representing almost the same year ${ }^{2}$ for the irrigated area of Bangladesh. As the variation was relatively large between datasets obtained from Raster maps (generated by remote sensing) and statistical table obtained from national data archives, so two statistical analysis were performed for each country.

Following table 3 showing the statistical analysis done for all the available datasets of a country. This analysis was performed using excel statistical tool (descriptive statistics) and $\mathrm{C} v$ has been calculated using equation 1 .

\footnotetext{
${ }^{2}$ Some data were not available for the same year, so comparison was made with the nearest year data which was available, e.g. 2005, 2009, 2010
} 


\begin{tabular}{|l|c|c|}
\hline Statistical Tools & With RS & Without RS \\
\hline Mean & 6082.5 & 5251.5 \\
\hline Median & 5180.5 & 5049.7 \\
\hline Standard Deviation & 2172.3 & 624.9 \\
\hline Minimum & 4760.0 & 4760.0 \\
\hline Maximum & 12079.6 & 6550.0 \\
\hline Sum & 66907.8 & 42011.9 \\
\hline Count & 11.0 & 8.0 \\
\hline$C_{V} \%$ & 35.7 & 11.9 \\
\hline Average $C_{V} \%$ & \multicolumn{2}{|c|}{$\mathbf{2 3 . 8}$} \\
\hline
\end{tabular}

Table 3. Statistical analysis for finding the coefficient of variation (Bangladesh) Source: Analysis using various datasets

As described earlier, a two dimensional approach was used for conducting a quantitative analysis which was completed to develop an appraisal system eventually. A scoring system was proposed to determine the reliability of the data available by having a rational base. During qualitative analysis it was investigated that how a data collection system varies from other and what are the possible pro and cons of that system which could bring reliability and uncertainty in the datasets of irrigated areas. During the quantitative analysis, this investigation was brought up one step forward and relevant parameters, sub-parameters and their reliability was defined.

The main idea behind ranking these parameters was to create a bigger frame where all countries' methods could be compared to look for a better representation of correct data and to develop a set of recommendations in general. Following is the rationale of ranking which was allotted to different parameters.

\begin{tabular}{|c|l|l|}
\hline \multirow{4}{*}{$\begin{array}{c}\text { Main Parameter } \\
\text { Enumeration Strategy } \\
\text { and Type of Coverage }\end{array}$} & \multicolumn{1}{|c|}{ Sub-Parameter } & \multicolumn{1}{c|}{ Reliability } \\
\cline { 2 - 3 } & Complete Enumeration & Very Good \\
\cline { 2 - 3 } & Se-Checks (Re-Interview) & Fair \\
\cline { 2 - 3 } & Physical Verification (Total Area) & Good \\
\cline { 2 - 3 } & Physical Verification (Sample Area) & Fair \\
\hline \multirow{4}{*}{ Implicit Data Source } & Interviews & Poor \\
\cline { 2 - 3 } & Administrative Records & Fine \\
\cline { 2 - 3 } & Farm Records / WUA Reporting & Very Good \\
\cline { 2 - 3 } & Subjective Estimate & Very Poor \\
\hline \multirow{2}{*}{$\begin{array}{c}\text { Explicit Data Source } \\
\text { Priority to Irrigation }\end{array}$} & Farm Survey with Sampling & Very Good \\
\cline { 2 - 3 } Data & Maps and Aerial Survey & Very Good \\
\cline { 2 - 3 } & Secondary & Good \\
\cline { 2 - 3 } & Primary & Fxcellent \\
\hline \multirow{2}{*}{\begin{tabular}{c} 
Dissemination Type \\
\cline { 2 - 3 }
\end{tabular}} & Means of Irrigation & Very Good \\
\cline { 2 - 3 } & $\begin{array}{l}\text { Type of Management } \\
\text { (Farmers/State/Semi) }\end{array}$ \\
\hline
\end{tabular}

Table 4. Rationale of the Appraisal System (Quantitative Analysis) 
Reliability of the parameters has been rated as excellent, good, fair, fine, poor and very poor, depending upon the qualitative analysis and the consistency of the method used to collect information for irrigated area would be reflected in the ranks as well. For example reliability of the irrigated data sets developed from complete enumeration in 'agricultural' and 'irrigation' census would be very good but when priority of the data is investigated; it will be good for first method and excellent for second one.

A range of scores has been allotted to each sun-parameter depending on the reliability, which has been shown in table 16 in detail. This quantitative scoring approach, eventually provided a base to scale the reliability in link to coefficient of variation, which has been discussed thoroughly in section 6.3.

\subsection{Finding Spatial Uncertainty in Agro Ecological Zones}

While quantifying the difference of datasets originated from various sources, it was necessary to look at the bigger picture in the context of irrigated areas reporting. Which is a significant agricultural statistical indicator in order to plan for future strategies and policies of natural resources management especially water. In addition to this, it is also necessary to know about the spatial extent of ambiguity in datasets.

Though by looking in multilayer statistics carrying irrigated areas information at district level, one can get a hint of uncertainty by comparing different datasets of the same locality. But exploring another dimensions of spatial uncertainty in the context of agro-ecological zones, is also quite helpful to look Asian irrigated agriculture with the perspective of climate and ecology, e.g. aridity. As rainfall and temperature plays a vital role in agriculture and it also affects the extent of irrigated farming.

FAO's GAEZ (Global Agro-Ecological Zones) database has been referred to find the shape files showing different ecological zones in Asia. These zones are based on modelling and defined as length of growing period (LGP) instead of just rainfall intensity. In simple words, days which are suitable for crop growth in the presence of sufficient natural soil moisture and temperature.

\subsubsection{Length of Growing Period:}

Length of growing period is defined in days and it is a period when naturally supplied moisture (rainfall) is higher than half of the potential evapotranspiration ${ }^{3}$. The calculation of LGP includes a period up to the evapotranspiration of $100 \mathrm{~mm}$ water available/stored in soil profile of 1 meter depth, excluding the time when the average means temperature is below $5^{\circ} \mathrm{C}(\mathrm{FAO})$. This definition can be considered as a more holistic approach for zoning as it is not only based on rainfall but also includes other climatic factors as well.

Following are the thresholds for the climatic zones based on LGP

\footnotetext{
${ }^{3}$ Potential Evapotranspiration is the maximum possible amount of water which will evaporate from soil and transpire from plant in one day, if already available/stored in sufficient quantity in soil. Rate of PET depends upon solar radiation, temperature, wind speed and humidity etc.
} 


\begin{tabular}{|c|c|}
\hline Ecological Zone & LGP duration \\
\hline Arid & $<75$ days \\
\hline Semi-arid & $75-180$ days \\
\hline Sub humid & $180-270$ days \\
\hline Humid & $>270$ days \\
\hline \multicolumn{2}{|c}{ Source: FAO \& IIASA-GAEZ }
\end{tabular}

The main idea for this phase of investigation was to compare the data available through remote sensing products about irrigated areas, e.g. GLC-2000, LULC, with the statistical data available on the ground by framing them into the boundaries of agro-ecological zones (country wise, intercontinental). In order to get a more clear sense of the uncertainty which is present on the ground especially on the basis of different agricultural climate boundaries. For this purpose the very first step was to find a raster product which carries the information of the statistical datasets

\subsubsection{Sorting Data from FAO-GMIA Map:}

In this regard, FAO-GMIA (Global Map of Irrigated Areas) was used as a source of statistical datasets as the data source of GMIA is based on questionnaires and information provided by countries about the command areas of irrigation networks (polygon data) etc. Which was then processed as raster map in which pixels (spatial resolution $10 \mathrm{Km}$ ) are carrying the data regarding area equipped for irrigation (AEI) and area actually irrigated (AAI) separately within the same spatial extent. The temporal resolution of GMIA dataset is one year and maps shows the records of year 2005. Following is the schematic illustration of the raster dataset FAOGMIA

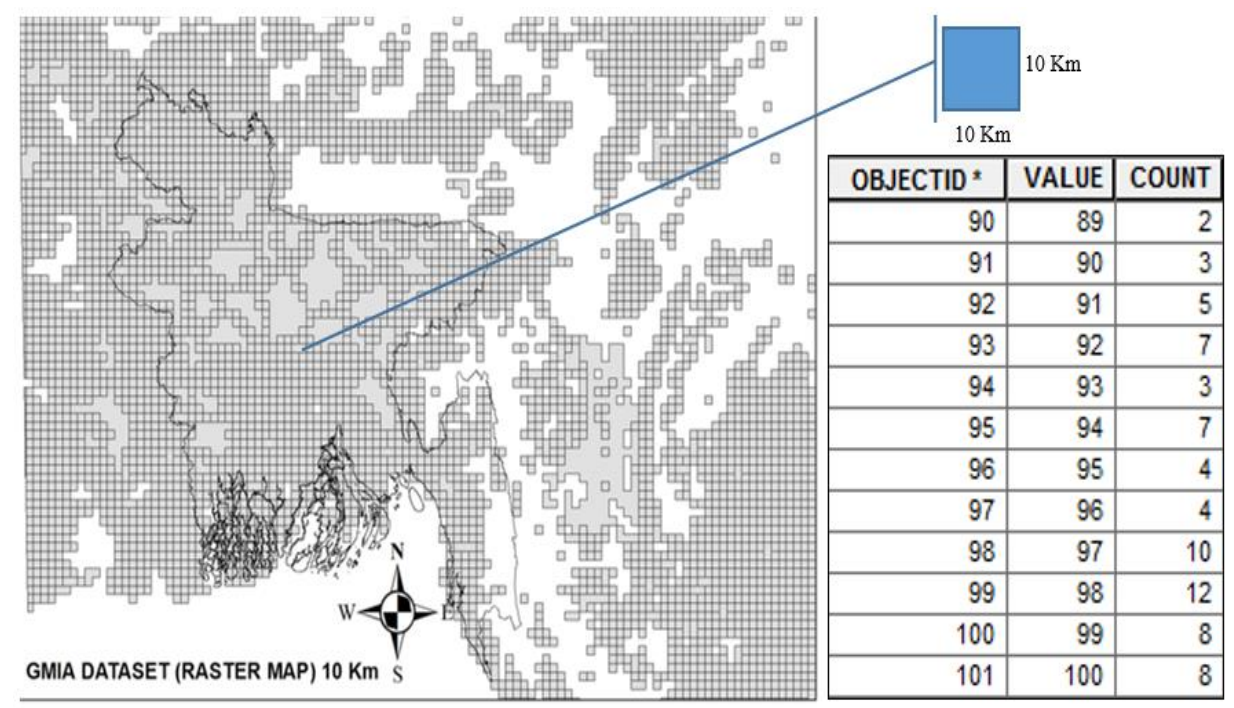

Figure 11. GMIA-FAO Raster Dataset (Bangladesh) attribute table showing values stored in in one pixel (Source: GMIA-FAO)

The attribute table in figurell carries the percentage value of the pixel which is equipped for irrigation and count represents the number of pixels. Raster maps; AEI (percentage area equipped for irrigation in one pixel area) and AAI map (percentage area actually irrigated of area equipped for irrigation) were downloaded from FAO-GMIA web portal. A raster map 
having pixel values for area actually irrigated in hectare was required for the desired comparison so a combine map was created which was further processed by adding extra fields in the attribute table of combined product. Following python script (combinatorial And tool) was used in ArcGIS to combine two raster maps:

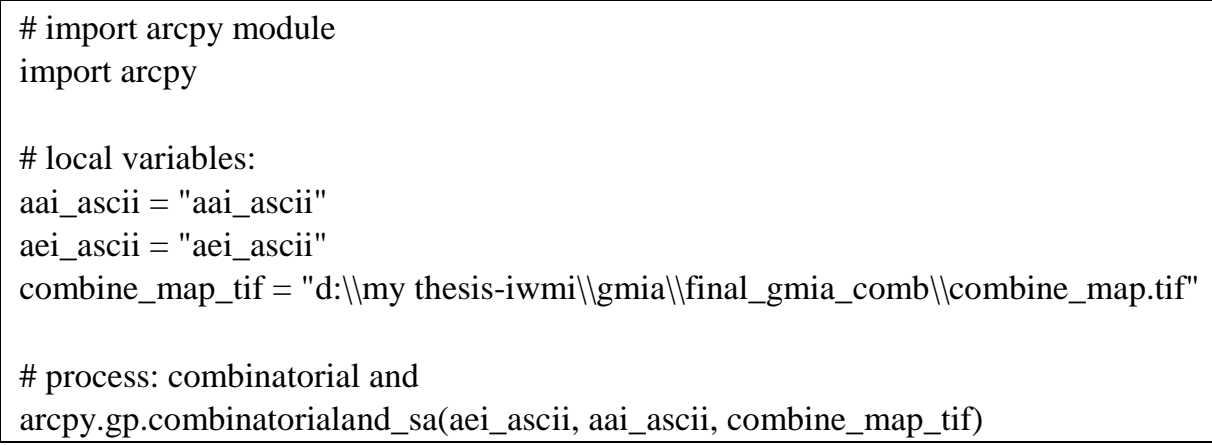

Following is the combined raster map, where cell values carries the information of area actually irrigated in hectares.

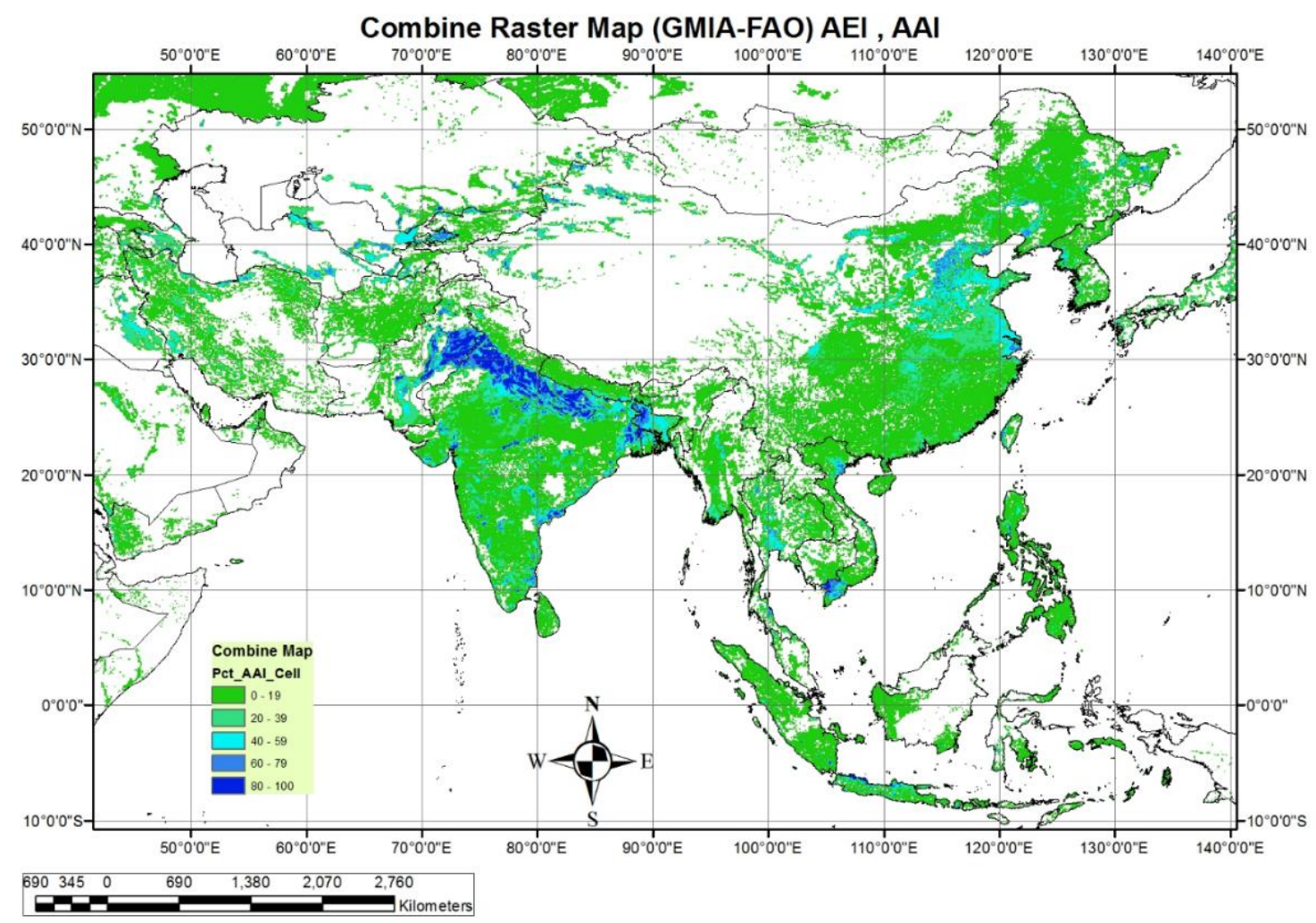

Figure 12. Combine Map GMIA (Percentage of Cell Area Actually Irrigated) Source: GMIA AAI and AEI raster map 
Table 5 shows the accuracy matrix of GMIA-FAO maps provided in documentation:

\begin{tabular}{|c|c|c|c|}
\hline Mark & $\begin{array}{c}\text { Area equipped for } \\
\text { irrigation \% }\end{array}$ & $\begin{array}{c}\text { Area actually } \\
\text { irrigated \% }\end{array}$ & $\begin{array}{c}\text { Source of water for irrigation } \\
\%\end{array}$ \\
\hline Excellent & 2.2 & 2.4 & 4.0 \\
\hline Very good & 17.1 & 2.2 & 3.5 \\
\hline Good & 73.5 & 38.5 & 31.4 \\
\hline Fair & 4.8 & 1.2 & 9.7 \\
\hline Poor & 2.2 & 4.1 & 7.0 \\
\hline Very poor & 0.1 & 51.6 & 44.5 \\
\hline
\end{tabular}

Table 5. Percentage of total irrigated area assigned to regions of different map quality (Source: FAO-GMIA)

After completion of raster map processing, next step was to extract the values of irrigated area from GMIA and from other land use or irrigated areas maps which are based on remote sensing techniques. For this step agro-ecological zone shapefiles were used as mask in order to extract the relative values from raster files.

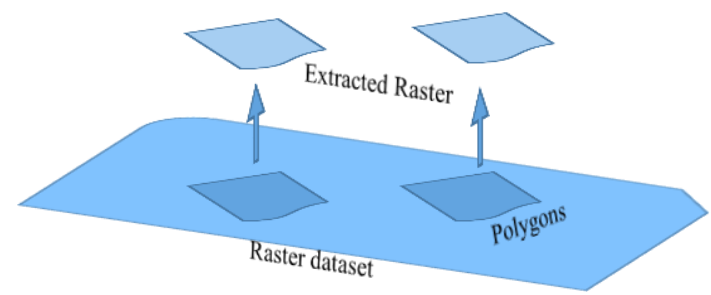

Figure 13. Extraction of raster dataset using AEZ polygons (Schematic Illustration)

These values were processed afterwards in tables for the values of irrigated area and then compared with other data sets (remote sensing products).

It is worth mentioning here that during the process of data extraction from GMIA map, values obtained for area actually irrigated were higher than those values which are provided at GMIA country wise web portal. The most possible reason causing this problem could be the over estimation of pixels due to inclusion of neighbourhood cells along the boundary of shape files. This happenes mainly due to coarser spatial resolution of raster dataset. Following image showing the phenomena causing the error by a polygon representing semi-arid agro-ecological zone in India. 


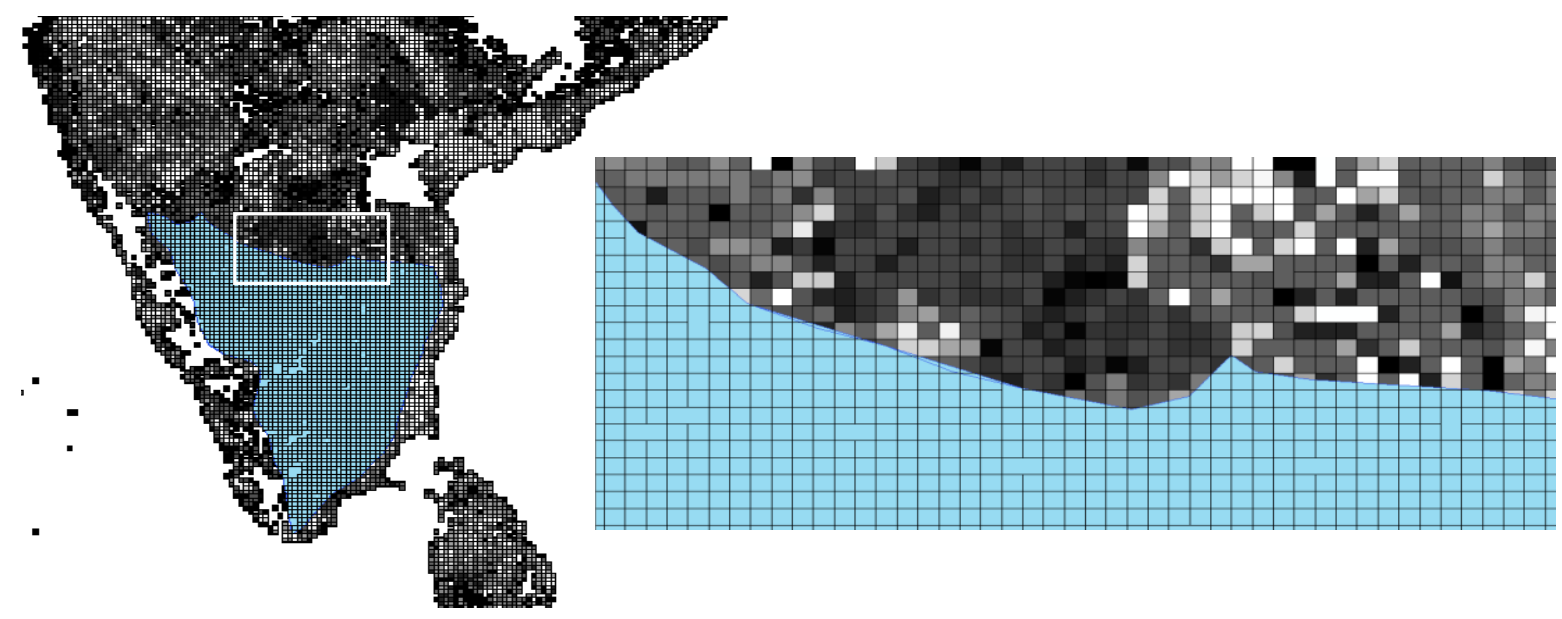

Figure 14. Over estimation of irrigated area due to double counting of pixels (Source: Analysis of GMIA map)

This problem of over estimation was resolve by normalizing the actual cell area in relation with target values of area actually irrigated available in database.

\subsection{Country wise spatial uncertainty and dispersion analysis}

IWMI's global irrigated area maps (for year 2000) has been used for the dispersion analysis. The purpose behind this analysis was to look for the total extent of small, medium and large scale irrigation schemes in the country.

Resolution of IWMI maps is $250 \mathrm{~m}$ and in order to look at the bigger picture, the map was aggregated in $10 \mathrm{~km}$ grid. Following steps were followed to get the results in dispersion analysis.

1- Reclassification of IWMI map:

2- Aggregating in $10 \mathrm{~km}$ grid

3- Calculating the total and percentage of irrigated area in grid

4- Sorting out the percentages for 3 categories a- $0-30 \%$, b- $30.1-60 \%$, c- $60.1-100 \%$

5- Summing the irrigated area of these categories

6- Comparing the sums of these categories

\section{$10 \mathrm{~km} \times 10 \mathrm{~km}$ Grid}

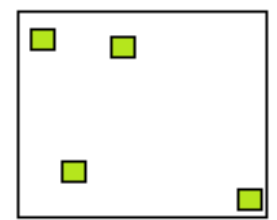

(a)

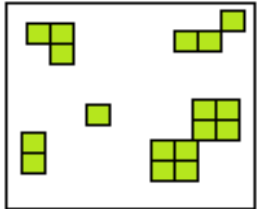

(b)

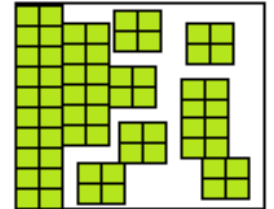

(c)

Figure 15. Categories of Dispersion Analysis (clusters of 250m x 250m pixels in 10km Grid) 


\subsection{Linking Uncertainty with Food Production and Water Resources}

To link uncertainty in irrigated areas information with food production following datasets were collected.

1- Annual Food Production (Cereals Total) from FAO-STAT

2- Population Data (FAO-STAT)

3- Irrigation Potential (Aqua Stat)

4- Irrigated Areas information (National Statistics)

5- Percentage of Grain Production coming from Irrigated Agriculture

6- Country wise Irrigated Area data from IWMI map (year 2000 - 250m resolution)

Two different annual land productivity calculations have been made in order to compare national statistics with IWMI statistics. Using equation 3.

National Annual Land Productivity $=\frac{(\text { Total Grain Production) } x \text { Percentage share of Irrigated Grain }}{\text { Irrigated Area }}$

While per capita irrigated area has been calculated using equation 4 .

Per capita Irrigated Area $=\frac{\text { Total Irrigated Area }}{\text { Total Population of country }}$

Irrigation potential values have been used to calculate the percentage of so far utilized potential in link with current records of irrigated areas, both National statistics and IWMI data. Following equation has been used for this purpose.

Percentage of Irrigation Potential Utilized $=\frac{\text { Total Irrigatied Area }}{\text { Total Irrigation Potential }} \times 100$ 


\section{CHAPTER 4}

\section{Growth Track of Asia's Irrigated Areas}

In this chapter development pace of irrigation in Asian countries will be analysed by studying available timelines of irrigated areas. These timeline are helpful to develop an understanding about the growth and utilization of irrigated areas overtime in Asia. Investments, type of irrigation systems and nature of development projects have been discussed side by side. Moreover, resilience of irrigated agriculture against uncertain climatic events have also been studied. These timeline can be further used as a reference to compare with numbers collected from other sources in different time duration. This growth track analysis is also helpful to project the future scenario of the region in the context of food production and water resources management, as $90 \%$ of the consumptive water use in Asia is associated with agriculture.

\subsection{Irrigated Areas Development in Asia}

A massive growth was noted in Asia's irrigated agriculture during the period of green revolution (1960-1970) along with use of other agricultural inputs, e.g. seeds, fertilizers, mechanization etc. This enabled Asian countries to enhance their yields and to feed the rapidly increasing populations and a comprehensive food security goal for this region was almost achieved (FAO, 2015). In last decade, the development in irrigated agriculture faced a slow pace in Asia and apparently the population rise and food production in the region will be struggling to match up as still $66 \%$ of world's undernourished population lives in Asia and Pacific. So, by analysing the growth track of irrigated areas, valuable information regarding the utilization of irrigated land each year can be obtained. Sensitivity of irrigated agriculture for droughts and flooding events can also be tracked from timelines.

Growth in irrigated areas of the countries under study have been discussed in the light of area actually irrigated (AAI), but in the unavailability of data, area equipped for irrigated has been analysed. This analysis is also important to compare varying figures which are not collected at same year, so having an extended time series is helpful to compare several data points, collected by other sources, in one graph.

\subsubsection{India}

Situated in South Asia; India has the largest inventory of irrigated areas in region with an annual estimated agricultural water use of $688 \mathrm{BCM}$, which is $90 \%$ of total water use. India receives $1083 \mathrm{~mm}$ of average annual rainfall and having a big part of the country in Semi-Arid and Arid region, India produces 54\% of its grain from irrigated agriculture (AQUASTAT, 2011). Country's reliance on surface water resources for irrigation is $24 \%$, while the contribution of ground water is $44 \%$ (DES, 2012)

In figure 16, two detailed timelines have been shown which articulate the development of irrigated areas in the country. Steady increase in irrigated land has been noted in India in last 
50 years which accounts a rise of almost $97 \%$ on an average of two timelines. Ministry of Water resources provide the data titled as irrigation potential created and utilized (IPC, IPU) while Agricultural ministry provide data of irrigated areas which is equivalent of IPU. In figure 18, Agricultural ministry's timeline has been discussed by source of irrigation.

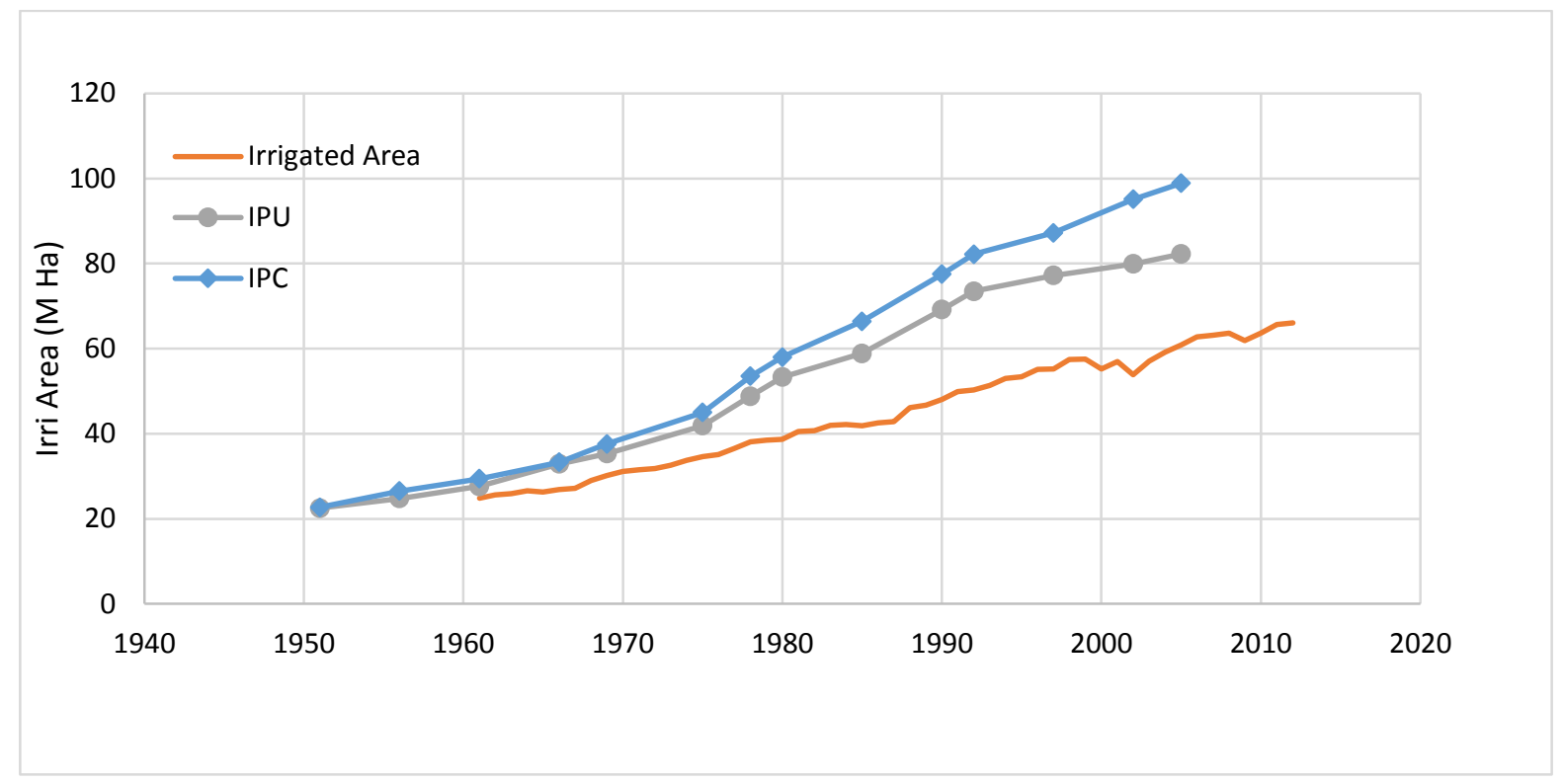

Figure 16. Irrigated Areas Timeline for India (Source: Ministry of Agriculture, Ministry of Water Resources)

Irrigation sector has been intensively invested overtime in India, targeting the development of irrigated land. Figure 17 shows the World Bank's timeline of investments in India to develop and rehabilitate the irrigation infrastructure.

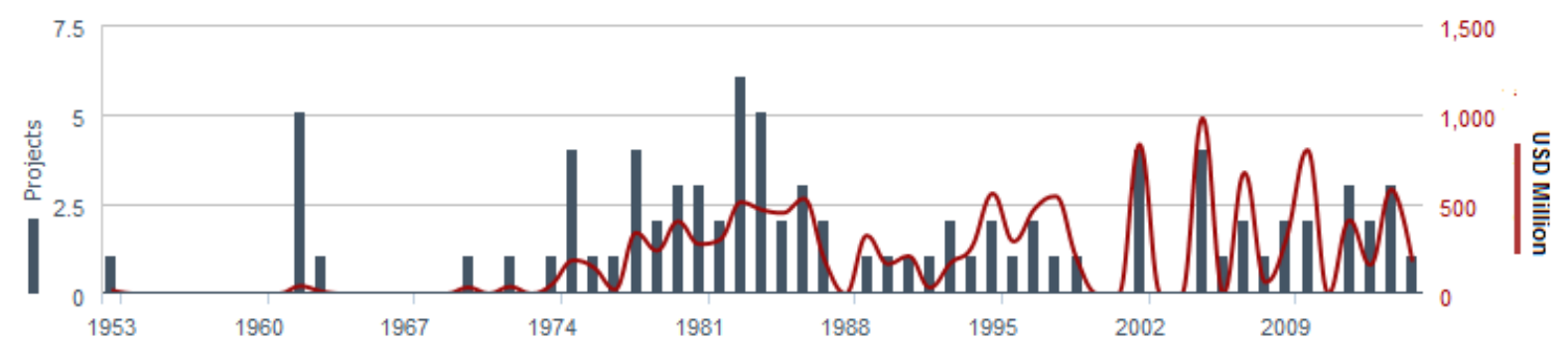

Figure 17. Investments in Irrigation and Drainage Sector in India (Source: World Bank)

As per World Bank's projects and operations record India has invested/allocated 75.5 million, 1.46 billion, 3.2 billion, 2.7 billion, 3.65 billion and 1.33 billion USD in year 1953-1962, 1963 1980, 1981-1990, 1991-2000, 2000-2010 and 2010-2015 respectively. The impact of this investment is quite visible in the graph as there is a steep upward trend in (IPC) irrigation potential created and it includes both surface and ground water irrigation projects. As per ministry of water resources the development in irrigation sector is measured with 5 years planning tenure and from 1950 till 2005, 10 development plans have been implemented, which in totality increased the irrigation potential by $76.2 \mathrm{M}$ ha in 54 years. Whereas, looking at the second timeline provided by agricultural department (DES), a continuous rise of $22 \%, 20 \%$, 
$16 \%, 10 \%$ and $11 \%$ can be seen in irrigated areas in every decade respectively starting from 1961.

Data provided by DES (Agricultural Ministry) also gives details about areas irrigated by tube wells and canals, which has been plotted in figure 18. It can be clearly seen that tube well irrigated areas are increasing rapidly, mostly because of the non-reliable surface irrigation network where water supplied in canals is diverted from rivers. Annually 1869 BCM FAO water is total renewable water which India receives in its rivers and about $64 \%$ of it comes from rainfall and rest comes from snowfall and ground water streams. Due to erratic patterns of rainfall which varies in time and space, irrigated agriculture relies more on ground water resources, which can also be seen in the graph below. There is a visible drop in from 2001 to 2003 in canal irrigated areas which reflects the drought situation ${ }^{4}$ occurred in same years and there was might not enough surface water to feed irrigation canals, and consequently there was an upward hike in the land irrigated by tube wells in the next year, as more farmers were shifted towards ground water resources which are reliable but perishable over time. The consequences of other dry years can also be seen in the time line for drought events, e.g. 1972, 1974, 1979, 1982, 1987 and 2009.

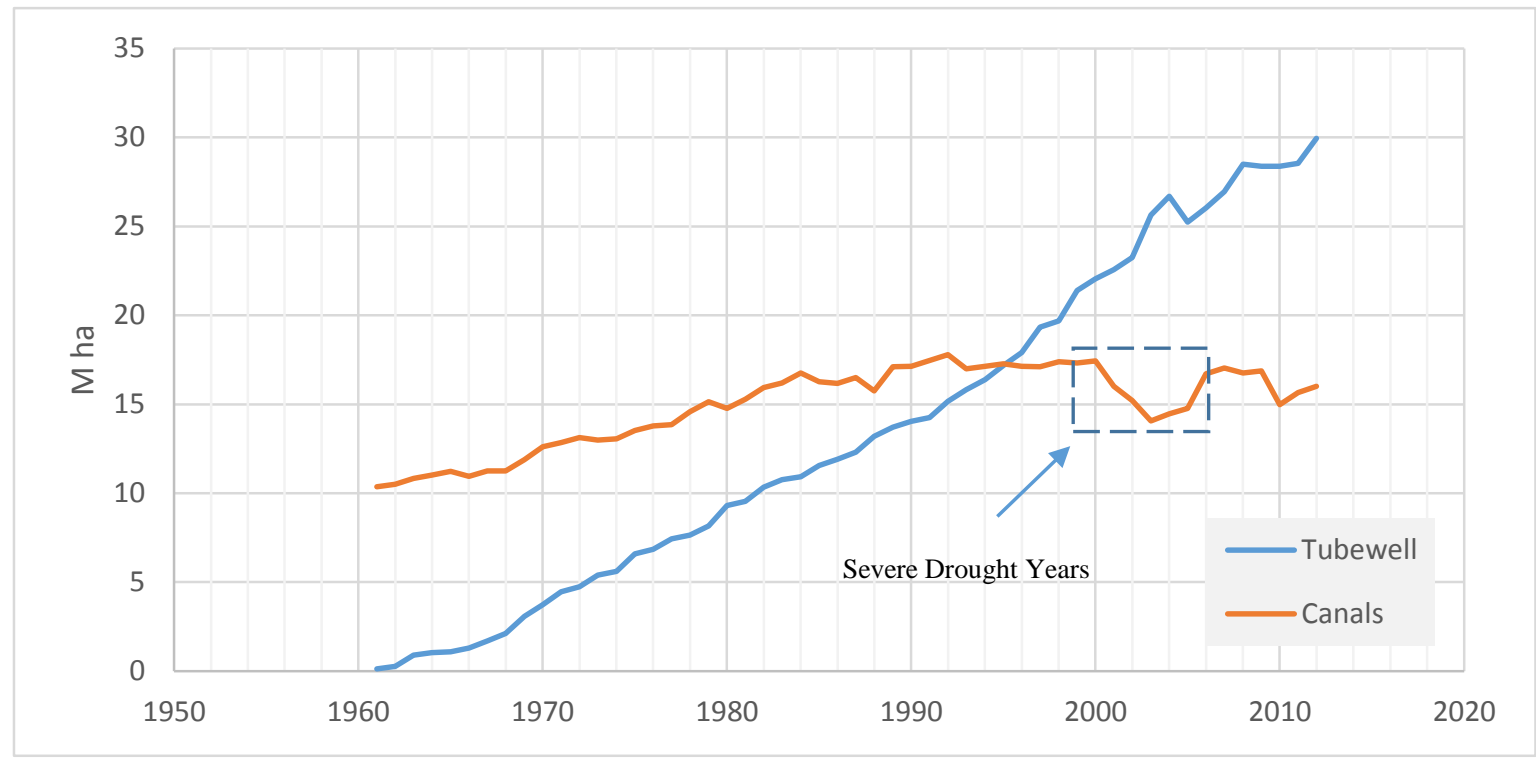

Figure 18. Tube well and Canal Irrigated Areas (Source: DES, Ministry of Agriculture)

It has been reported that by keeping drought threat in view; in next coming 5 years India has planned to spend 8 billion dollars to expand its irrigated areas to decrease the dependency of rain-fed agriculture on annual rainfall, which will enhance the overall agricultural yields of the country ((Reuters India, 2015). In addition, while reviewing the current projects, it can be noted that more emphasizes is being given to climate resilient agriculture, watershed management, water sector improvement, minor irrigation, dam rehabilitation, land reclamation and community tank management projects (World Bank, 2015). These new projects could positively reinforce irrigated agriculture in India, as adoption of climate resilient techniques

\footnotetext{
${ }^{4}$ Severe drought conditions were experienced in India during 2002, which was indicated by gradually decreasing rainfall in preceding years. (Indian Meteorological Department)
} 
would strengthen irrigation sector to cope with new future challenges. While minor and tank irrigation has a significant role in development of low income farming communities which rely on small scale irrigation to produce food and to support their dependents. In addition, rehabilitation projects would enhance the dependency of already existing irrigated areas.

\subsubsection{China}

China stands almost parallel to India spatially, for Asia's irrigated areas figures in Asia. Annual agricultural water use for China has been estimated as $358 \mathrm{BCM}$, which is $65 \%$ of total water withdrawal. With an average annual rainfall of $645 \mathrm{~mm}$, country falls largely in arid and semiarid zones in north-west while south western part has humid and semi-humid climate. Figure 19 shows time line for irrigated areas in China. It carries a cumulative timeline on left axis and size wise distributed timelines are on right axis.

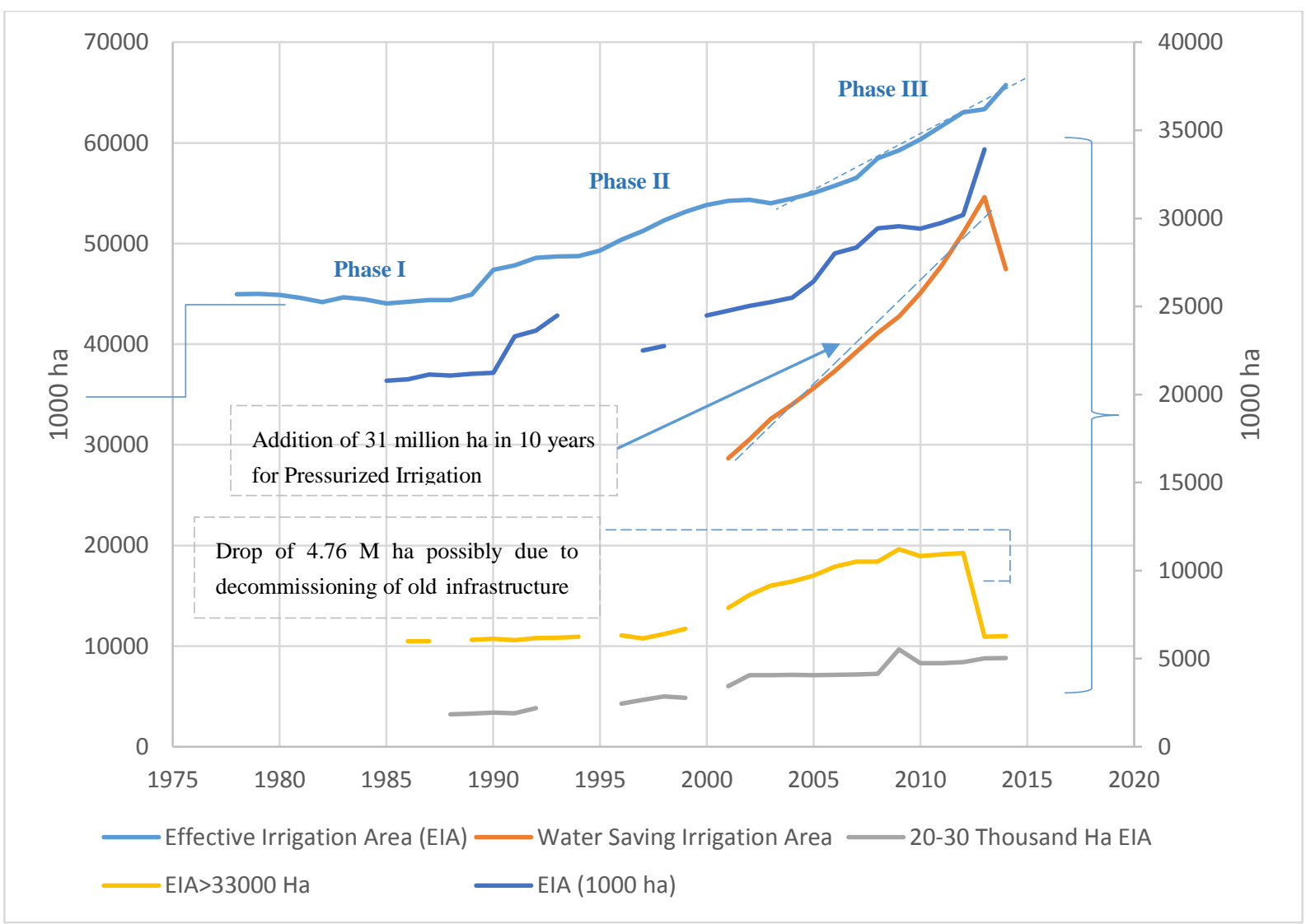

Figure 19. Irrigated Areas Development in China (Source: NBS China)

Irrigated areas in China are generally divided in three administrative tiers on the basis of their extent. As shown in figure 19, the effective irrigated area has been sub-divided into following 3 types:

1. $\quad$ Large Irrigated Areas ( Area $>33$ thousand ha)

2. Medium Irrigated Areas ( between 20 to 30 thousand ha)

3. Water Saving Irrigation Areas 
One more category ${ }^{5}$ has been added in the figure which represents the farmer managed irrigation systems and their extent in within 1000 hectares.

By looking at the cumulative growth of irrigated areas, the timeline can be divided in 3 development periods, which is visible in the graph. The $1^{\text {st }}$ period is from 1978 till 1989 where a gradual rise can be seen in the irrigated areas, there in parallel 4 major investment projects can be seen as well from the investment history ${ }^{6}$ of World Bank database, which shows an overall investment of 152 million USD in figure 20.

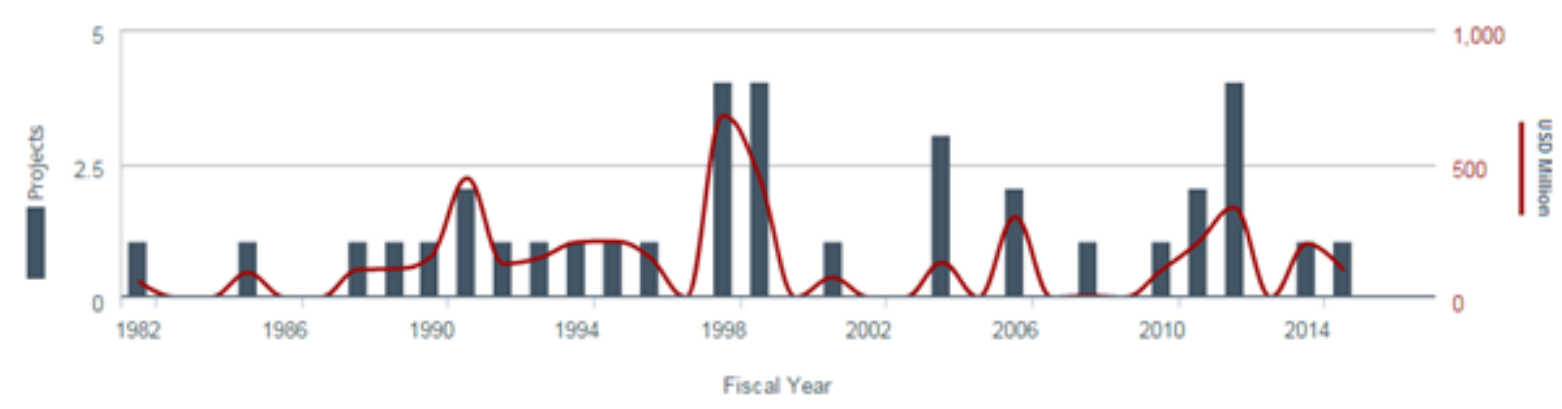

Figure 20. Investment in Irrigation and Drainage Sector (Source: World Bank)

In the next development period, we can see a rise of 3 million hectares in fiscal year 1989-90 which could be a possible add-up due to the commissioning of the projects from previous years. Between the 1990 and 2002 a rise of 7 million hectares is a large addition in irrigated areas, which is considered to be the possible outcome of 5 projects of amount 631 million USD and one project of almost 445 million USD as investments from World Bank.

In development phase III, the timeline is steepest as there is a rapid expansion in irrigated areas in china, which could be an effect of rise in farmer managed irrigation system, as this sector is also focused now which duly contribute in national grain production. On other hand we see a big drop in large irrigation system (type $1>33,000$ ha) which could be a result of possible decommissioning of old infrastructure, whereas, the development pace of medium sized irrigated area is almost same with a visible rise of 1.3 Million hectares following with a drop of 0.7 $\mathrm{M}$ hectares in the next year which could also due to decommissioning of system.

On other hand, a 62\% rise can be noted in a decade from year 2000 to year 2013 as $31 \mathrm{M}$ hectares in water saving irrigated areas where pressurized irrigation techniques are used to grow crops, which has a good water application efficiency of 70 to $80 \%$, which is a part of china's policy to focus more on water saving techniques to water shortages in country (Yuping 2001). But it is followed by an unexpected drop of 4 Million hectares, which is needed to be investigated.

\footnotetext{
${ }^{5}$ China operates the irrigation according to production units or the communes where several villages might operate and it is then defined as irrigation district which is controlled by county's irrigation authorities which works under Ministry of Water Resources.

${ }^{6}$ Investment history depends upon availability of data. In this research World Bank database has been referred, as other information about investment, e.g. ADB, IFAD, and Internal Funds in irrigations sector was not accessible.
} 
Offsetting the argument on the investment side, we can see a major investment of 1128 M USD during the year 1998 and 1999 which is duly reflected in the timeline of irrigated areas. Between the year 2000 and 2005 an investment of almost 203 M USD has been made in irrigation sector, following by once again huge investments of 1142 M USD between 2006 till 2014 and another investment of almost $100 \mathrm{M}$ USD is in pipeline, which would definitely give another boost to development of irrigated areas and the rehabilitation of old infrastructure as in Year 2030, China will reach it development potential of irrigated areas which are 70 Million Hectares FAO and more funds will be consumed in the operation and maintenance of existing irrigated areas.

As EIA might translate the area equipped for irrigation, so it is difficult to develop a relationship between the drought years and the response or the resilience of irrigated infrastructure in china against it. But the reported drought in 2010 which affected 51 million people in China, could be linked with the drop of 147,000 hectares in farmer managed irrigation systems in year 2010 and FMIS consists $56 \%$ of China's irrigation schemes (FAO).

Current developments in China show that besides developing new infrastructure for irrigation; investments are being made on water conservation irrigation techniques and climate smart agriculture. More future investment in irrigation sector might be seen in water saving irrigation schemes as climate change and water scarcity would limit any extensive infrastructural development in the region.

\subsubsection{Pakistan}

Pakistan depends upon Indus Basin Irrigation System (IBIS) for its agriculture, which has the most important role in economy. IBIS is a large surface irrigation system which is based on gravity and water is delivered to farms by primary, secondary and tertiary canals. This water is utilized mostly by using by flood irrigation methods and also by tube wells, which extract water from aquifers which get recharged by the seepage from canals mostly.

During our research, we were able to find the very detailed time line for Pakistan's irrigated areas and the information has been collected by provincial agriculture departments which are combined to look at bigger picture for the whole country. The farming systems is managed privately by farmers and there are very few large production units. Pakistan inherited its irrigation infrastructure from colonial period and this makes it more vulnerable against aging factor. Likewise India, Pakistan's surface irrigation network also depends on annual rainfall which generates run-off from catchment and then the water is diverted in canal system. During last 68 year Pakistan has fairly developed its irrigated areas, following is the timeline of irrigated land. 


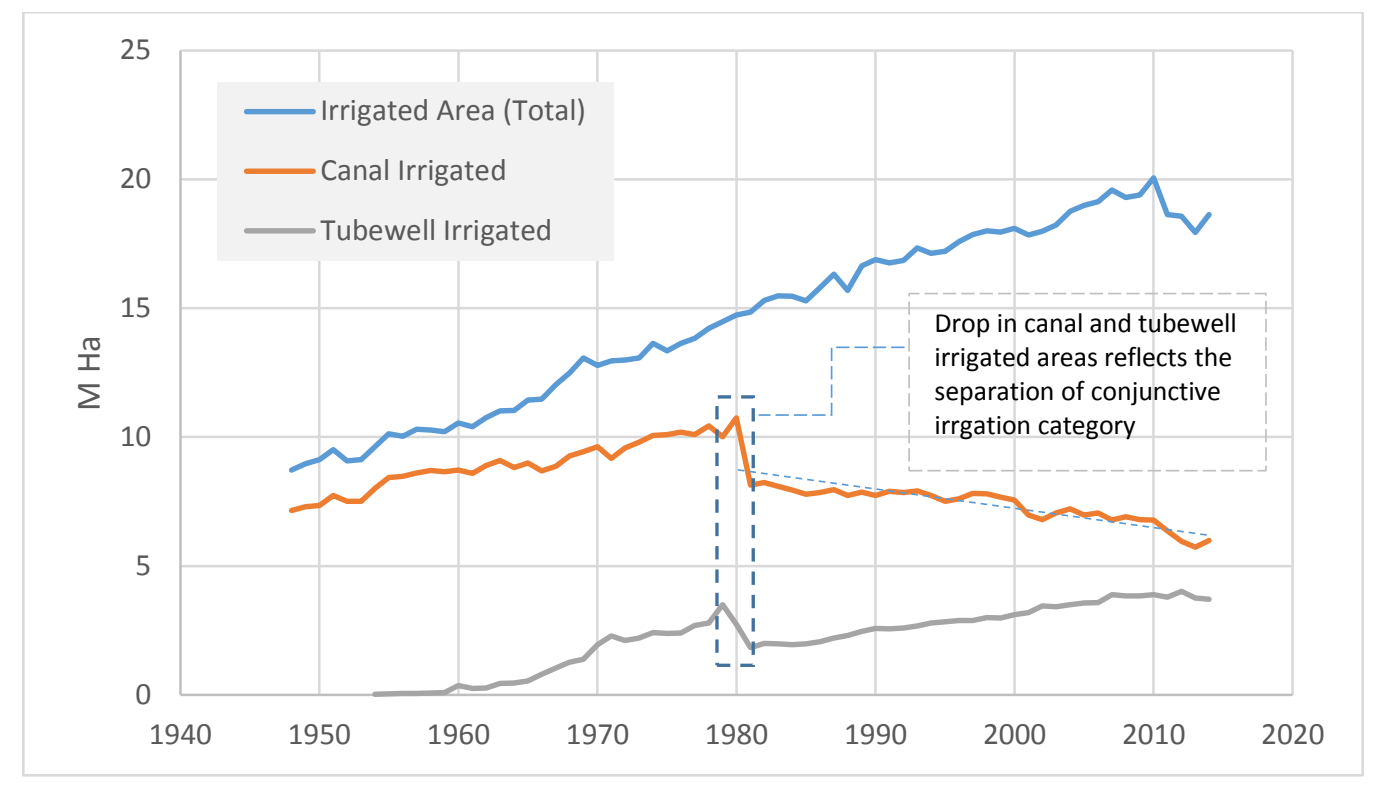

Figure 21. Irrigated Area Timeline in Pakistan (Source: Agriculture Department)

The timeline in figure 21 represents the area actually irrigated per year, which could help us to analyse both the development and any influence of management or climate on the irrigated areas. If we look at the timeline with an interval of ten years, we can see there is almost $20 \%$ increase in irrigated areas consecutively with first two decades which gives a figure of 13 million hectares as several mega irrigation projects were completed during this time period. Furthermore, we see a rise of $27 \%$ in irrigated area in next 20 years with 17 million hectares in 1990.

It is worth mentioning here that from 1960 to 1980 there is a rapid growth of tube well irrigated areas. This shows the green revolution impact (1960-1970) and its strengthening policies to boost up the irrigated areas in country. Waterlogged areas were also reclaimed by adding intensive number of tube wells (Chaudhry 1990). From 1990 till 2010 we see an overall growth of $17 \%$ in irrigated areas (20 million hectares) which has brought the country almost near to its ultimate irrigation potential which is 23 million hectares.

As explained earlier, country's irrigation system is dependent on rainfall and snowmelt in catchment which makes it highly vulnerable against any events of climate change. We can see an overall decrease in canal irrigated areas from 1980, while on the other hand there is a steep rise in conjunctive irrigation in figure 22 which represents the dependency of farming community on additional source of irrigation water to counterbalance the deficit of canal water. While a drop of almost 1 million ha in 2010 might reflect any data adjustments according to agricultural census conducted in 2010. As there is no parallel drop in timeline of tube well or canal irrigated areas. 


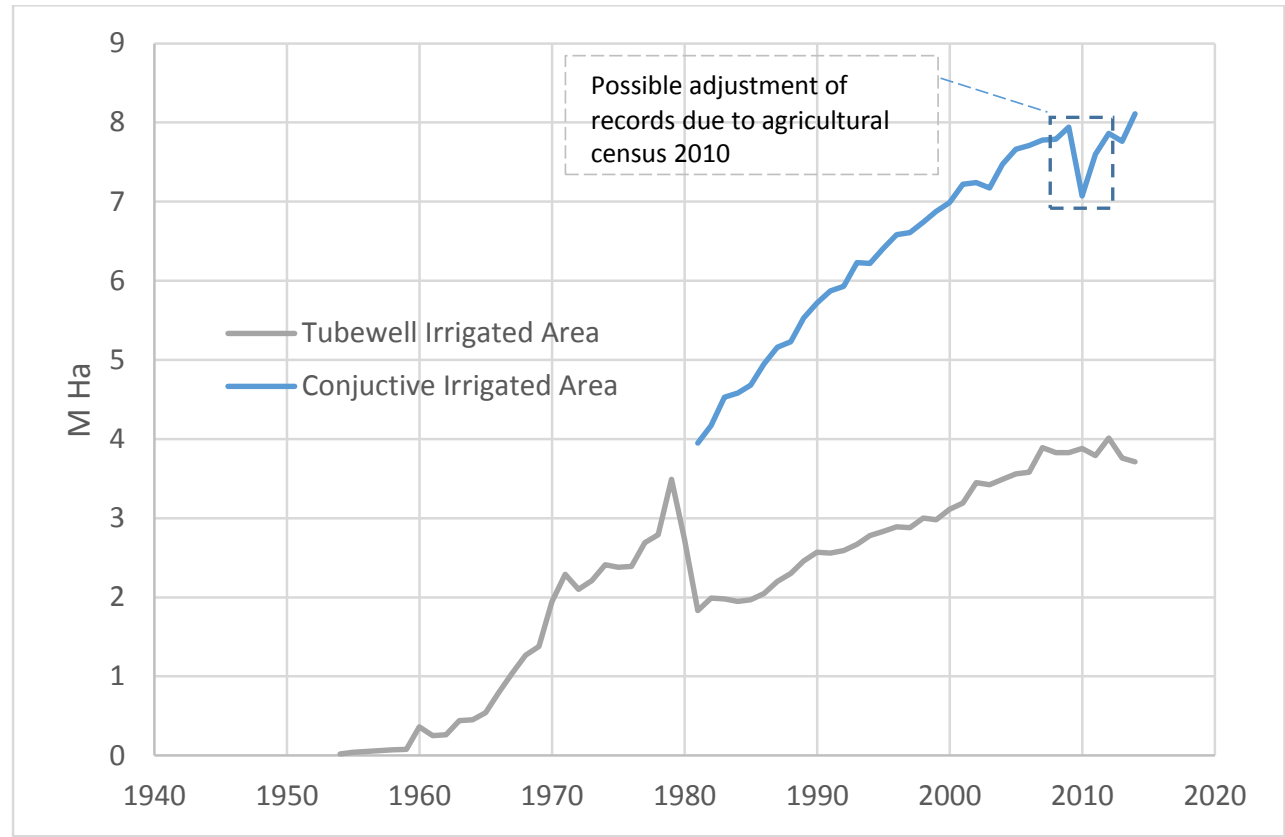

Figure 22. Tube well Irrigated Area and Conjunctive use Area (Tube well + Canal) (Source: Agriculture Department)

Following Figure 23 shows the investment in the sector of irrigation and drainage in Pakistan, made by World Bank including construction of two major reservoirs in Pakistan, which were completed in 1976 and 1967 with a storage capacity of almost 22 BCM to develop resilience against the discharge fluctuation in Indus river system. But in a general scenario, the irrigation infrastructure of Pakistan is facing severe maintenance issues due to their almost over life span, so most of the investment is being diverted towards rehabilitation and on the other hand, huge investments are also being made to improve the irrigation system and field application efficiency by lining the canals and introducing water saving irrigation techniques in the country e.g. pressurized (trickle, sprinkler) irrigation.

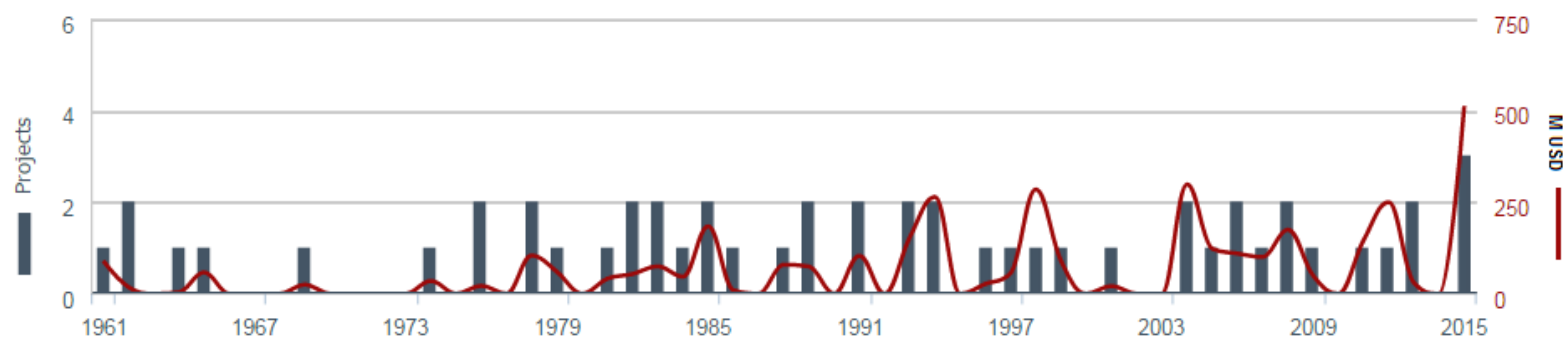

Figure 23. World Bank Investment in Irrigation and Drainage Sector in Pakistan 
In figure 24 variation in canal diversions for Indus basin irrigation system has been shown. A severe drought ${ }^{7}$ year in 2001 reflects its worst effect on surface water availability, as it had decreased $20 \%$ from last 10 years mean. This situation do reflects its slight impact on irrigated areas in above figures as there was decrease of 1million hectares of canal irrigated land. But it is not necessary that dependency on ground water resources could offset this natural calamity every time, as this resource could deplete rapidly due to overuse.

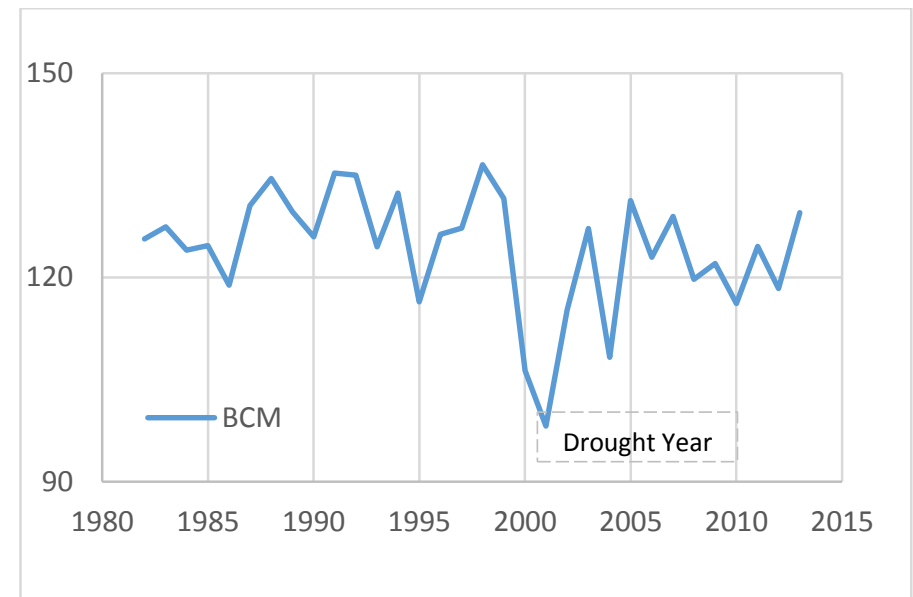

Figure 24. Annual Canal Water Withdrawals (PBS)

By exploring this growth-track for Pakistan, it is very obvious that without making any sustainable plans for the irrigated agriculture, it will be difficult for country to tackle with its food demands in near future (food production in context of population rise will be analysed further). Future climate trends in climate change could severely affect the vulnerable agriculture in Pakistan and a comprehensive policy for managing its ground resources will be required. As they are strengthening the huge load of irrigation in country by contributing almost $70 \%$ in overall irrigated lands.

\subsubsection{Bangladesh}

Irrigation plays a key role in Bangladesh's economy as it contributes in $54 \%$ of rice production in country which is a staple food nationwide. Irrigation sector in the country is mainly dominated by the groundwater irrigation as it has 64\% share in total irrigated agriculture 2009-10 and canal command area only covers $3 \%$ of the irrigated land. Rest is covered by low lift pumps and traditional irrigation $(24 \%)$.

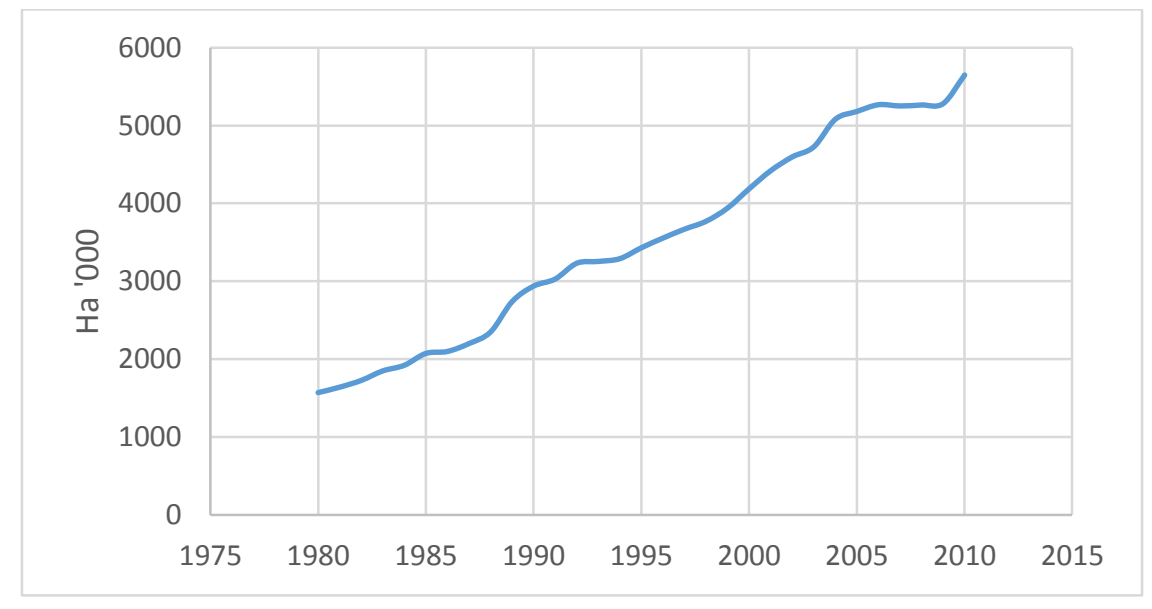

Figure 25. Irrigated Areas Development Timeline in Bangladesh Source: BADC

\footnotetext{
7 Pakistan faced a severe drought between years 1999-2001. (Pakistan Meteorological Department)
} 
In figure 25 timeline of irrigated areas development has been shown. From year 1980 to 1988 an overall increase of $40 \%$ can be seen, with an average development of 97,000 hectares per year. In the following years from 1989 to 2000 there is total addition of 1.83 million hectare irrigated land with an average increase of 153,000 hectares per year. In next 10 years a slow increase of $29.7 \%$ has been noted with an interesting rise of 367,000 hectares within two fiscal years 2008-09 to 2009-10.

To develop a complete understanding of the growth in irrigated areas in country, a detailed analysis was performed by looking in timeline of different type of tube wells, as Bangladesh has emphasized more in the development of minor irrigation. So it would possibly give a finer picture.

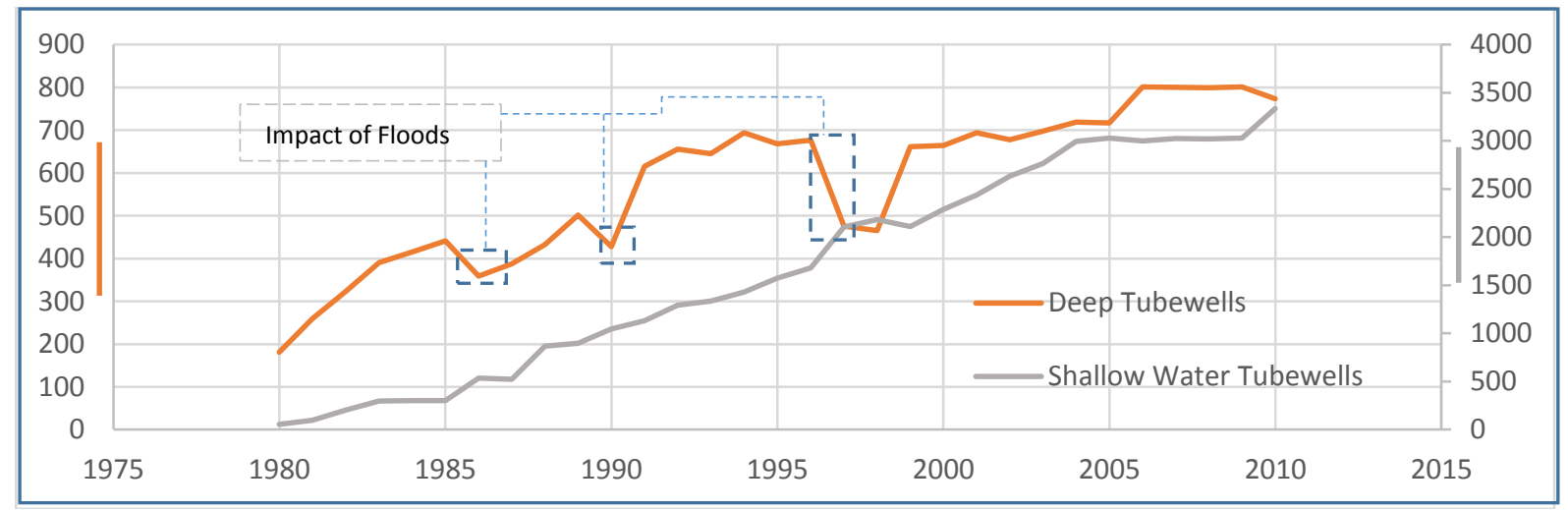

Figure 26. Tube well Irrigated Areas (1000 ha) Source: BADC

Tube well irrigated areas can be divided into two categories; deep and shallow. Comparing two timelines, we can see that there is a gradual increase in areas irrigated by shallow water tube wells (STW) and on the contrary there is a continuous disruption in areas depending on deep water tube wells (DTW). This abrupt rise and fall in the area is most possibly due to the introduction of subsidies by government for the installation of DTW which brought a boost in irrigated areas. But on the other hand, due to its high installation and operation cost and privatization $^{8}$ of tube wells, farmers were more inclined towards STW as their maintenance cost is also relatively low (Rahman, 2009). A moderate decline can be seen in DTW timeline in 1987, 1990 and 1997 which reflects the impacts of floods. On the other hand, there is a rise in the irrigated areas during 1997-98, which reflects the high water table levels where shallow water tube wells were more cost effective. While comparing the overall increase in DTW and STW from 1980, it is $124 \%$ and $193 \%$ sequentially. (World Bank, 1991)

\footnotetext{
${ }^{8}$ Bangladesh Agricultural Development Board initiated huge investments in DTW for a rapid boost of large public sector irrigation projects which started from 1960, but these programs were later privatized and subsidies were called off.
} 


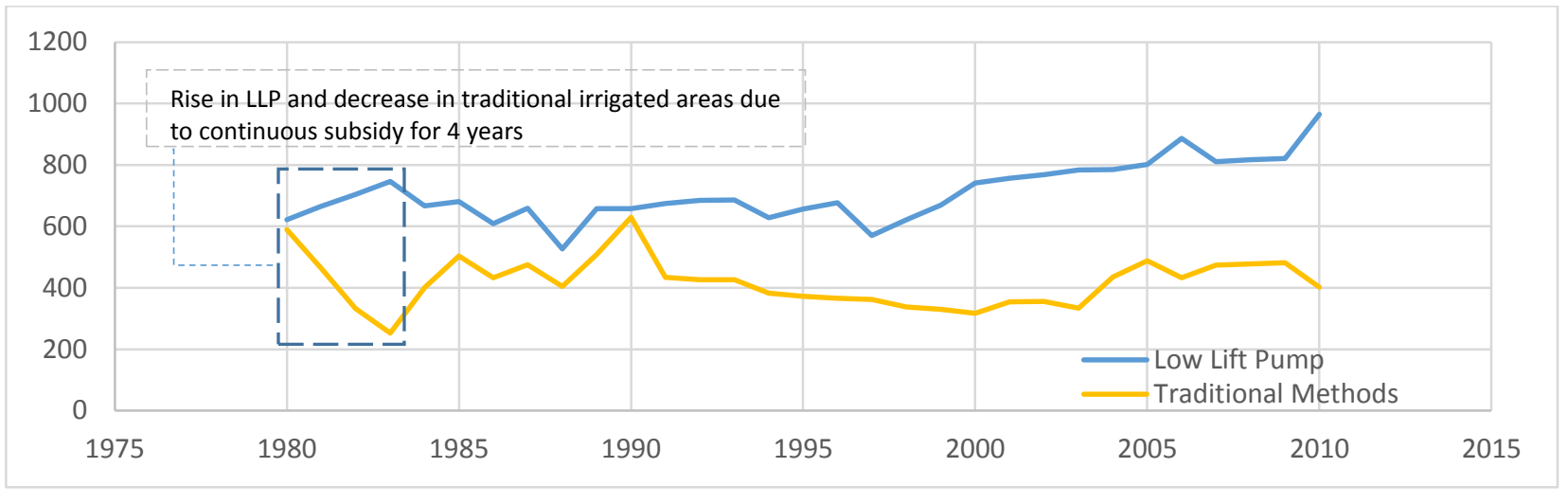

Figure 27. Traditional Irrigation and Low Lift Pumps (1000 ha) Source: BADC

LLPs are used to lift water from water ditches or from other available surface water resources, while the traditional irrigation includes using swing basket to bring the water in farm. As per World Bank's project records; low lift pumps project was initiated in 1980 for a period of four years. In this context, we can observe a rise in LLPs and a decrease in traditional irrigation as it saved man power, but in the following years there are rise and falls in the irrigated areas under LLPs most possibly due to the maintenance factor of the mechanical pumps. But generally looking at the overall rise there is a decrease of almost 180,000 hectares in traditional irrigation with a rise of 340,000 hectares of LLP irrigated areas within a timeframe of 30 years.

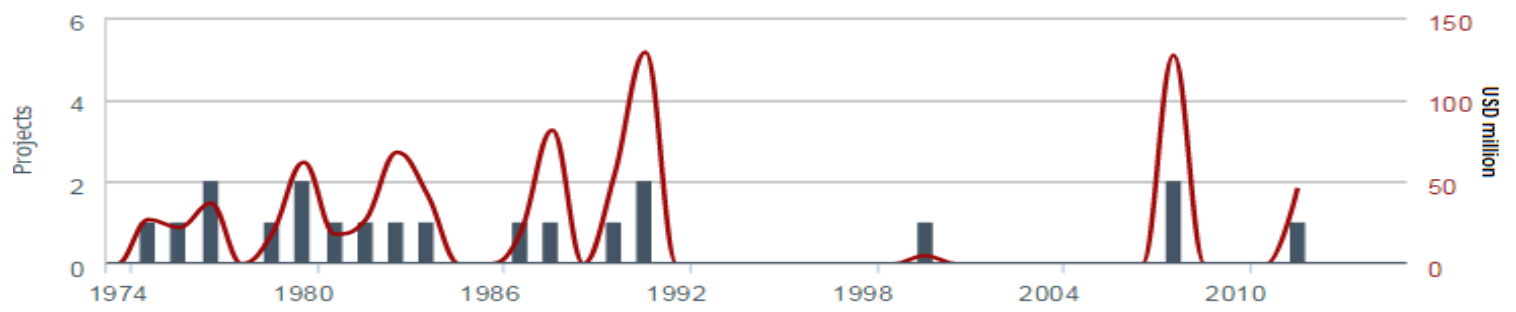

Figure 28. Investment in Irrigation and Drainage Sector (World Bank)

A significant fluctuation can be seen in canal irrigated areas in Bangladesh (figure 29), which is mostly due to lack of sufficient water at the headworks as country receive its surface water from Transboundary Rivers. Being at downstream the annual availability of sufficient water for irrigation network is not reliable subject to upstream water use, drought conditions or compliance of treaties.

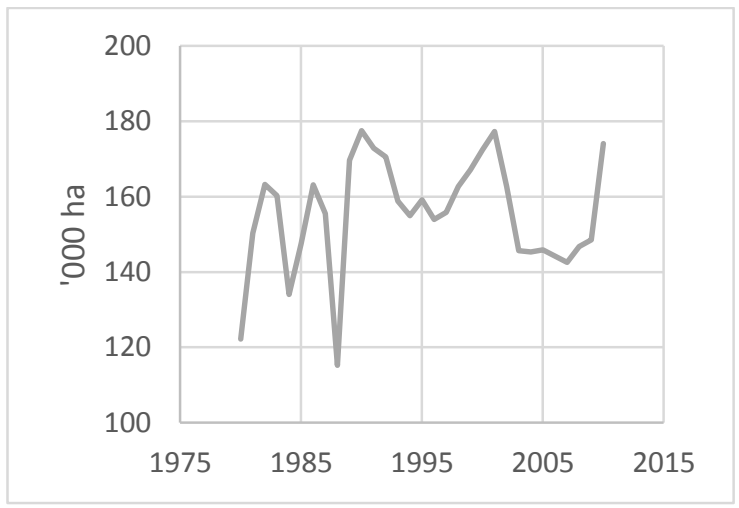

Figure 29. Canal Irrigated Areas ('000 hectares) Source: $B A D C$ 


\subsubsection{Iran}

Iran is situated in arid and semi-arid regions of Asia and total average annual rainfall is not more than $300 \mathrm{~mm} .61 \%$ of Iran's total grain production comes from irrigated agriculture which is fed by groundwater and canal irrigation. Contribution of ground water in Iran's irrigated areas is $62 \%$ and surface water resources share $38 \%$ of the total 8.13 million hectares (AquaStat 2008)

The growth-track analysis for irrigated areas of Iran is based on the data available on irrigated crop areas in 36 years and it is further analysed by looking into groundwater and surface water input.

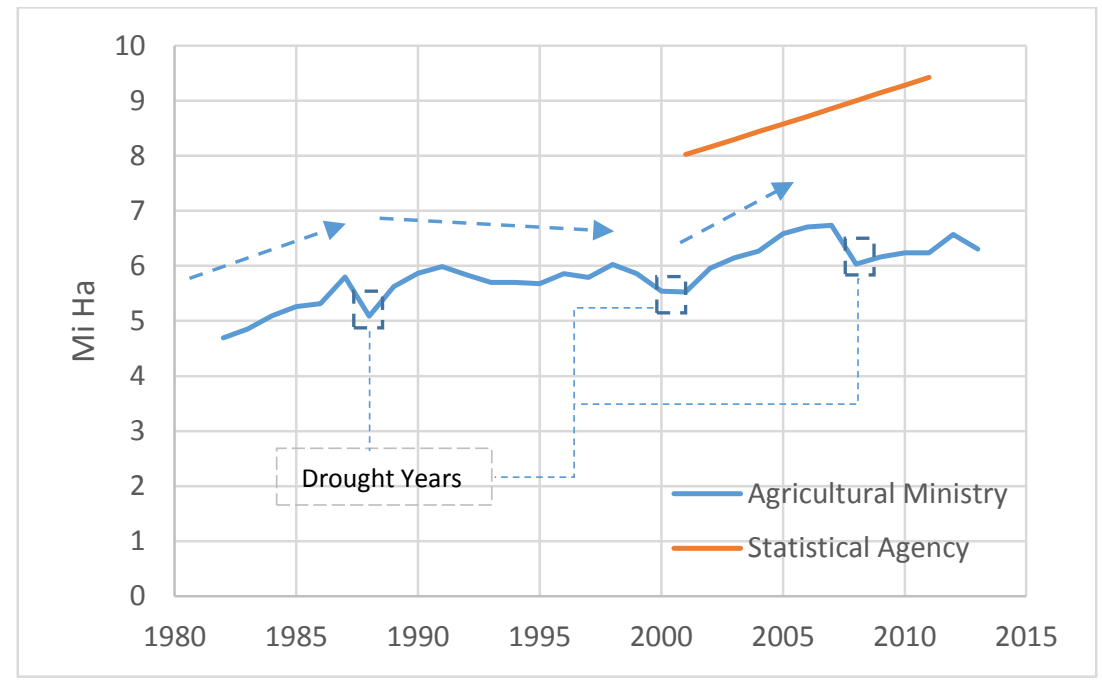

Figure 30. Irrigated Harvested Area in Iran (36 years' Timeline) Source: Ministry of Agriculture

This growth-track has been formulated by adding the timeline data from Ministry of Agriculture, $\operatorname{Iran}^{9}$ and data of irrigated area available at statistical department website.

Discussing the overall development in the irrigated areas of Iran, an increase of $21.1 \%$ can be seen in first 6 years (1982-1987) of the time line with a drop of $0.7 \mathrm{M}$ ha in 1988, reflecting drought year (Haghighi, 2008). In next 10 years there is an addition of almost 1 million ha by 1998, which is then followed by a continuous decrease of 166,137.6 ha annually till 2001 mainly because of severe spell of extended drought (Haghighi, 2008).

In next 6 years, there is an addition of 1.22 million ha with a growth percentage of $20 \%$ in comparison with year 2001. But in 2008, the timeline drops by $0.7 \mathrm{M}$ ha within one year caused again by a severe weather conditions of high temperature and low rainfall. This drought caused $20 \%$ decrease in national wheat production (USDA, 2008). By the year 2012, there is only a growth of $8.6 \%$ which shows the slow revival of irrigated agriculture from drought's effects.

On the contrary, while looking at the parallel timeline of statistical department (AMAR, 2015) the year wise growth of irrigated areas from 2001 till 2011 there is an incremental value of 137,000 to 140,000 hectares every year which makes the timeline perfectly linear and it might not seem realistic in comparison with previous timelines.

9 Harvested Area and Yield Survey, 36 cropping years (1961-1992) 
While looking into source wise distribution of irrigated agriculture growth, Iran has developed its surface water resources by constructing dam which are mainly used for irrigation, under four development plans. Following table 6 shows the details of the plans.

\begin{tabular}{|c|c|}
\hline Development Phase & $\begin{array}{c}\text { Area Developed for } \\
\text { Irrigation (ha) }\end{array}$ \\
\hline Up to 1979 & 676,224 \\
\hline from 1980 to 1989 & 252,778 \\
\hline first plan: from 1990 to 1995 & 241,596 \\
\hline second plan: from 1996 to 2000 & 245,446 \\
\hline third plan: from 2001 to 2005 & 386,809 \\
\hline forth plan: from 2006 to 2009 & 150,493 \\
\hline Total & $\mathbf{1 , 9 5 3 , 3 4 6}$ \\
\hline
\end{tabular}

Table 6. Development of Area under Irrigation and Drainage Network in Iran

(Source: 30 Year Function Report of Water Sector, Ministry of Energy, Iran)

As explained earlier, Iran extensively depends on groundwater resources to support its irrigated agriculture, but there was no detailed data or timeline was available to analyse its growth overtime. But as surface water development pace has been mentioned in Table 6, so by subtracting the area developed in every development plan we can see a parallel growth of ground water irrigation as it increased from 9000 wells in 1970 to more or less 450,000 in 2001 with an annual discharge of 44 BCM (FAO).

Following figure 31 shows the groundwater extractions in Iran, from 1972 to 2001, which includes tube wells, qanats (subterranean canals) and springs. The total ground water use has been increased by 3.5 times $(29.5 \%)$ within a period of 29 years, reflecting the almost same growth in irrigated areas which increased by $33 \%$ in this period.

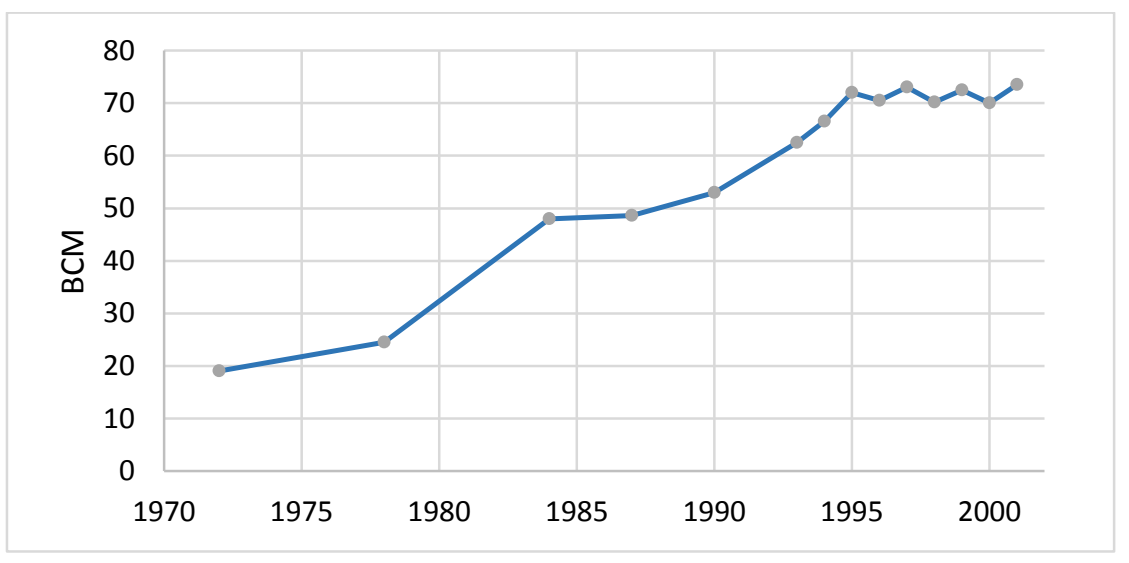

Figure 31. Agricultural ground water extraction in Iran (Source: Messdaghinia and Alavi, 2010) 
It is worth mentioning here that Iran has 1.1 million hectares of irrigated area under pressurized irrigation which could deliver water with a relatively high application efficiency i.e. $70 \%$ and 3.5 million hectares are irrigated using traditional methods, e.g. qanats. Different sources of irrigation has been mentioned in following table along with their contribution in total water use.

\begin{tabular}{|l|l|l|}
\hline Water Source & BCM & Fraction \\
\hline Surface Water & 40.2 & $45.30 \%$ \\
\hline Qanats & 4.6 & $5.20 \%$ \\
\hline Wells & 44 & $49.50 \%$ \\
\hline Total & $\mathbf{8 8 . 8}$ & $\mathbf{1 0 0 \%}$ \\
\hline
\end{tabular}

Table 7. Different water sources and their fraction in total water usage

(Source: Ministry of Energy, Overview of Water Resources in Iran)

Considering the timeline of statistical department and country's irrigation potential to look for the future developments in irrigated areas of Iran, there is still a potential of almost 5 million hectares of extra land to be brought under irrigation network. But by looking at country's drought facing agriculture, focus of development might be diverted to enhance water conservation practices in near future within existing infrastructure. This would help Iran to strengthen already present irrigation which would improve overall water producticivty, which is the need of time.

\subsubsection{Thailand}

Thailand is situated in South-East Asia and it is has world's fifth largest area under rice crop. $40 \%$ of country's grain production comes from irrigated lands and it has $6.4 \mathrm{M}$ ha $2007 \mathrm{AQUASTAT}$ of irrigated land with an irrigated cropping intensity of $146 \%$. As per FAO, total water withdrawal in 1990 was 33 BCM and $91 \%$ was used for agricultural purpose. Thailand depends highly on surface water irrigation as country receives a high amount of rainfall; 1,622 mm average and most of the irrigation is supplementary as it is done during wet season. The contribution of groundwater irrigation is $9.1 \%$.

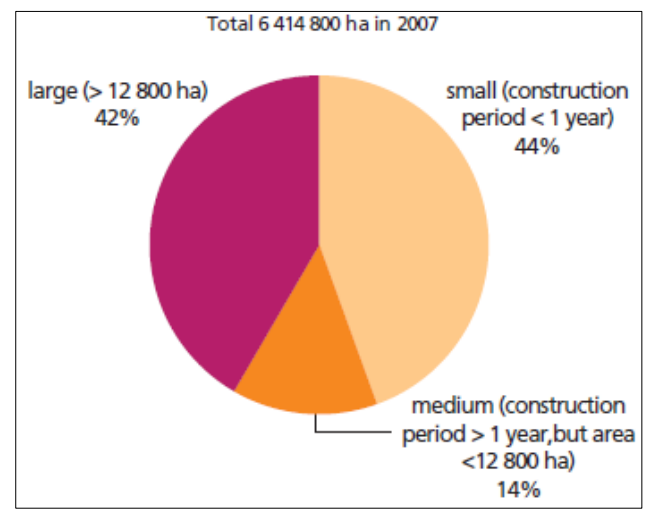

Figure 32. Type of Irrigated Areas (Management wise) Source: AquaStat (Water Reports-Irrigation in Asia in Figures)

Irrigated areas in Thailand can be divided in large, medium and small schemes, where the development and management of large and medium schemes (3.38 million hectares) is done by country's irrigation department. Besides, there are also pump schemes $(318,630 \mathrm{ha})$, irrigation 
department's development projects $(79,039 \mathrm{ha})$ and self-defence village projects which are comprise of 16,377 ha. Following is the graph showing the size of irrigated areas on the basis of the management.

To analyse the growth-track in irrigated areas, the only available timeline was retrieved from ASEAN's database (AFSIS 2015). This dataset is believed to be sourced from office of agricultural economics, the department of Thai agricultural ministry responsible for collecting the agricultural data from the country.

Figure 33 is showing the timeline, starting from 1983 and it will be discussed further.

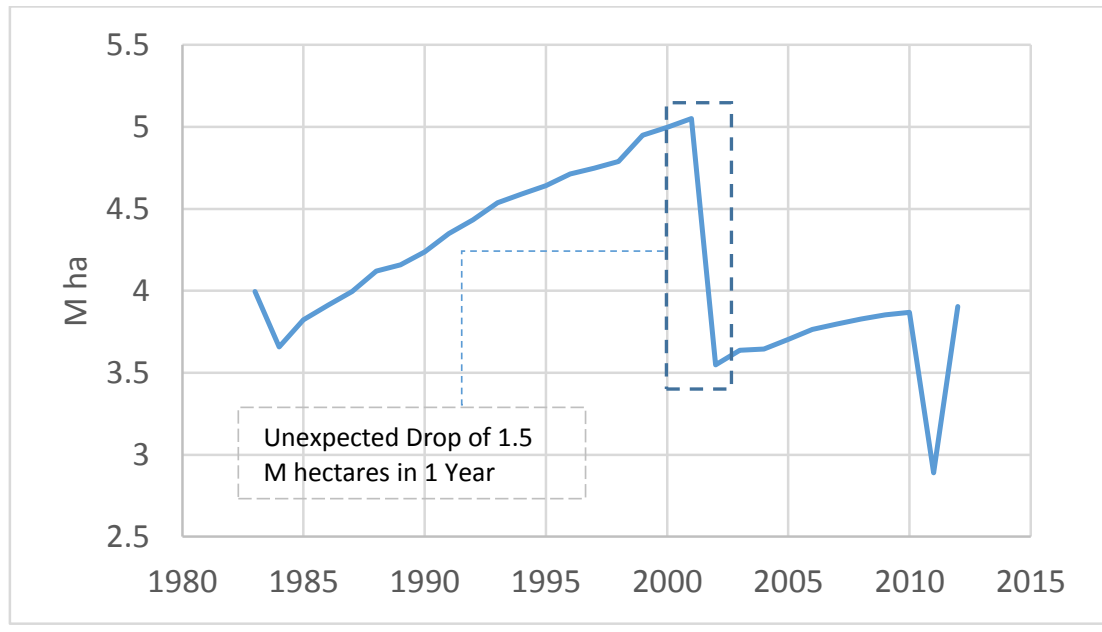

Figure 33. Irrigated Area Timeline for Thailand (Source: AFSIS 2015)

While analysing the growth of irrigated areas in Thailand, a growth of $1.5 \%$ can be seen till year 1990 as 241,950 hectares increased in the period of 8 years, though there is a small drop in 1984 which might reflect any drought phenomena. Moving on further, in next decade there is a growth of $4 \%$ in irrigated areas with an addition of 760,120 hectares in the inventory of irrigated agriculture.

A very interesting change could be noticed in timeline as there is a drop of 1.5 million hectares of irrigated land with one year between 2001 and 2002. This loss of irrigated areas could have been studied to link it with any possible cause of climatic damage or due to the loss of aging infrastructure as irrigation in Thailand is dependent on surface water/dams. As described earlier major and medium schemes are controlled by government. But after this drop there was no visible recovery noted in next 10 years. As the value of irrigated areas suddenly dropped from 5 million hectares to 3.5 million, there should be a significant impact on the harvested area as well which was then analysed from the same data source of ASEAN to find any decline in yield. 
In figure 34, timeline of paddy harvested area has been shown which is the $40 \%$ of the actual values, to simulate the irrigated areas which are mostly rice in Thailand. Here a small drop of $7 \%$ can be seen between year 2001 and 2002 instaed of 34\% in irrigated areas graph. In addition the differnce between overall rice production between two years was $5 \%$ which by no means reflect such a large drop.

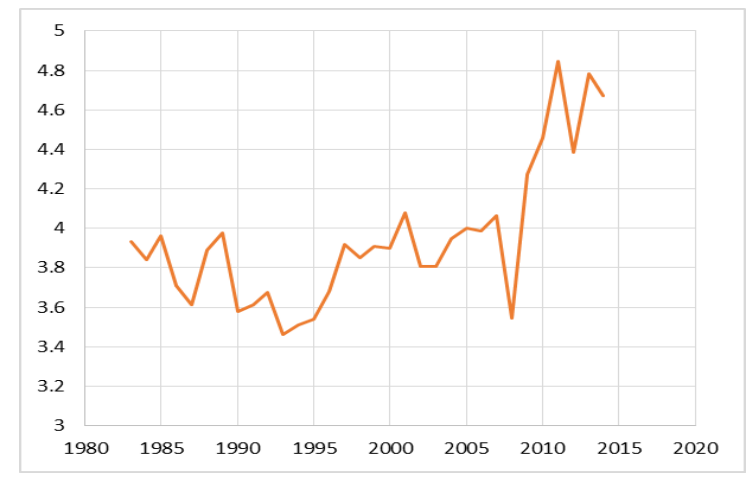

Figure 34. Paddy Harvested Area (ha) (Source: AFSIS)

To understand this possible discrepancy in the timeline other information sources were investigated to look for the potential area in thailand for irrigation, it has been found that at maximum 5 million hecatre land can be brought under irrigation (ICID, 2012). As the timeline was dropped down when the value crossed 5 million, so it is quite possible that the organization compiling the information of irrigated area might have changed their definition as virtually it could not cross the upper ceieling within the given time frame.

It is also possible that two different datastes were combined to make one timeline which led towards confusion. So, this could initiate the next argument for more realisitic value of irrigated areas, as such a big gap in timeline does not fit with the harvested and production data and this issue of variation in general has been discussed in next chapter.

This timeline was projected forward and backwards to comapre it with other available datasets of irrigated areas from Thailand.

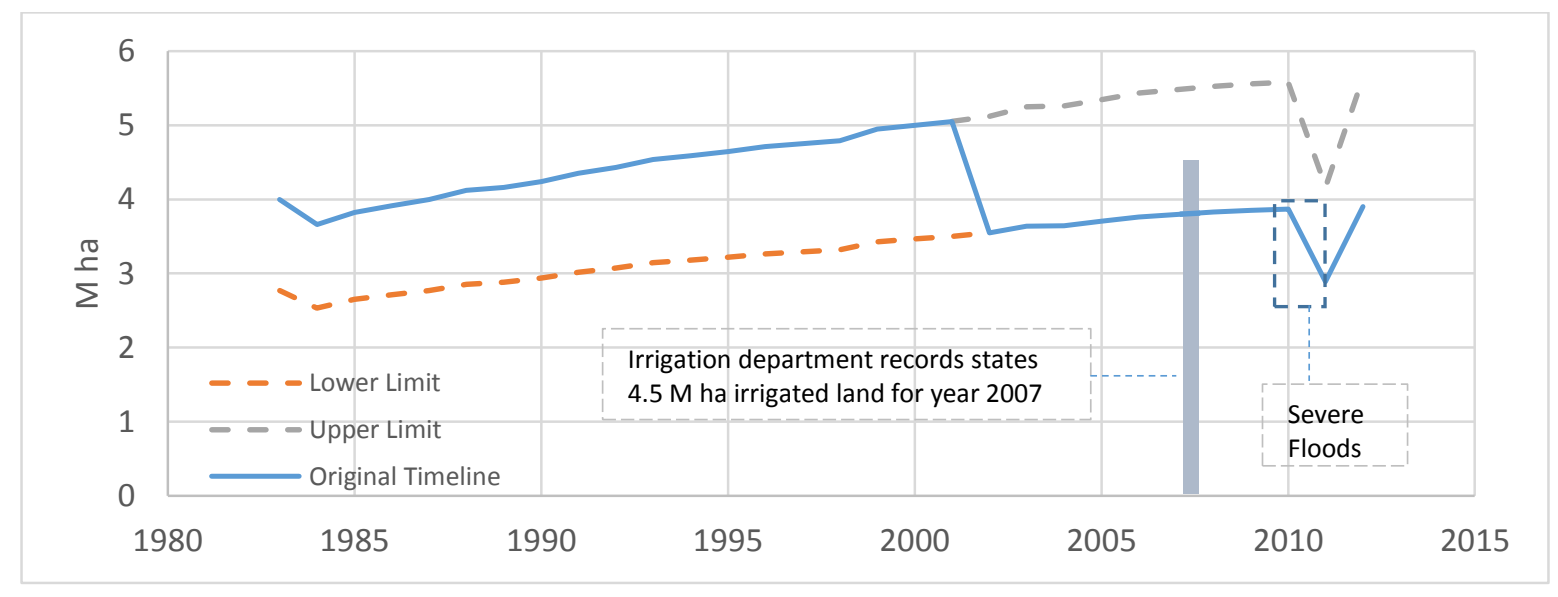

Figure 35. Projected timeline of irrigated areas in Thailand (Source: Extrapolations made with AFSIS timeline)

The value for irrigated areas as per the record of irrigation department was 4.5 million hectares in 2007 (shown with gray bar in graph) which does not match with these projected values but an average between original timeline and upper limit. 
On the other hand, the annual development pace for Thailand's irrigated land has been described in FAO's publication as 120,000 ha. If the trend line is extrapolated from 2001 by adding the described number, it would give us a figure of 6.35 million ha of irrigated land in year 2011, which exceeds the limit of projected timeline. Another visible drop of 1 million ha has been noted in year 2011 which might reflects the severe floods in Thailand in the same year, (Oldenborgh et al 2012).

It can be realized that, irrigated agriculture in Thailand would face some severe climatic challenges in near future. As in year 2016, country is facing worst irrigation water shortages due to drought which could restrict the further expansion of irrigated areas in country (USDA, 2016). In this context, high dependence of irrigation on surface water resources would also discourage farmers to rely on large public irrigation schemes and irrigated agriculture might shift more towards ground water resources in coming years.

\subsubsection{Vietnam}

Vietnam is situated in South East Asia and it lies in sub-tropical climate zone. Cultivated area of the country is 9.63 million ha with rice as a largest crop. Vietnam is second largest rice exporter worldwide with annual rice production of 40 million tonnes in 2010 . This country is covered with hills, mountains, low lands and forests. The average annual rainfall in the Vietnam is $1820 \mathrm{~mm}$ and surface water resource are used mostly for irrigation (99\%) by using canals and pumps and contribution of groundwater is $1 \%$. Total water withdrawal for agriculture including irrigation and livestock is 78 BCM. (AquaStat, 2011)

For the growth-track analysis of irrigated areas, several datasets were referred to find a detailed timeline of irrigated land in Vietnam but only a small fraction of values was available on internet as none of the government agency i.e. agricultural ministry, statistics office maintains the datasets for irrigated areas annual data. Only values available for irrigated area were from 1999 to 2000, which were obtained from agricultural ministry planning document (MARD, 2005).

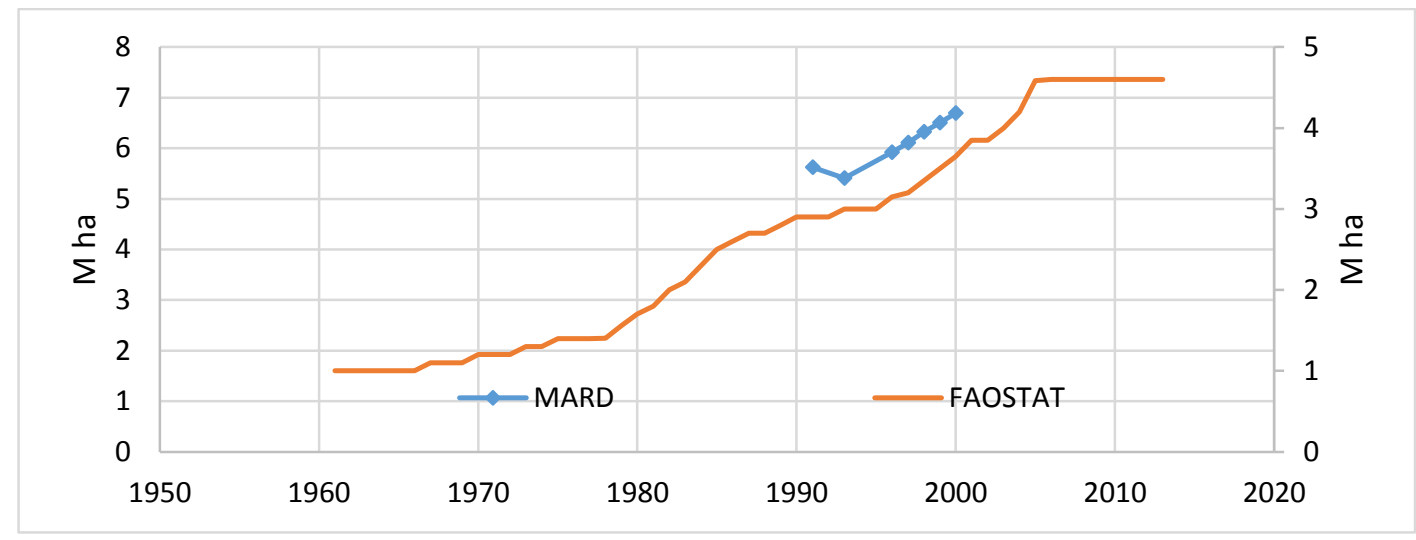

Figure 36. Irrigated Area Timeline for Vietnam (Source: MARD, FAOSTAT)

As this dataset was not sufficient to conduct a detailed analysis so FAOSTAT's dataset of AEI (Area Equipped for Irrigation) has been discussed here which might not show a true picture of irrigated areas' development in the country as this data itself carries $58 \%$ information from 
FAO's estimates, 34\% manual estimates (i.e. irrigated area synthesized from crop production data), FAO's country questionnaires and some data values from non-governmental international organizations. The reliability of these datasets will be discussed in next chapter.

Irrigation sector in Vietnam was scattered in small scale farmer managed irrigation systems before 1975 as the country was unified afterwards. So, while analysing the growth of area equipped for irrigation in Vietnam, a relatively slow growth of $18 \%$ in first decade can be noted which consisted mostly of small and medium irrigation schemes, it is followed by $34.5 \%$ rise by 1980 and we can also see an investment of 60 million USD in 1978 in irrigation project(s) which contributed positively in the development of irrigated area with a growth of 52\% (World Bank, 2003), as there was an addition of 1.2 million hectares of land in irrigation network. Moreover, a sequential development of $22 \%$ in irrigated areas can be noted by the end of year 2000, while the World Bank investment in year 1995, 1999 was 200 million USD and half of the amount was for irrigation rehabilitation project which includes the rehabilitation and development works for an overall area of 130,000 hectares. (World Bank, 2003)

Between year 2000 and 2013 there was an increase of almost 1 million hectare land in irrigated areas which reflects $23 \%$ growth. While on investment side we can see an overall investment consisting of 803 million USD which includes irrigated agriculture improvement, water resources assistance, water management, natural disaster risk management and climate change resilience projects. Afterwards in 2015 there is a huge investments of 415 million USD dam rehabilitation project consecutively, which has been designed to acclimatise the huge infrastructure of 6,648 small and medium irrigation dams (with a command area of 3 million hectares) as per modern day requirements of safety and design in order to ensure the safe water supplies in future, as these dams were created between the period of 1960-1980 with several constraints of technology and design.

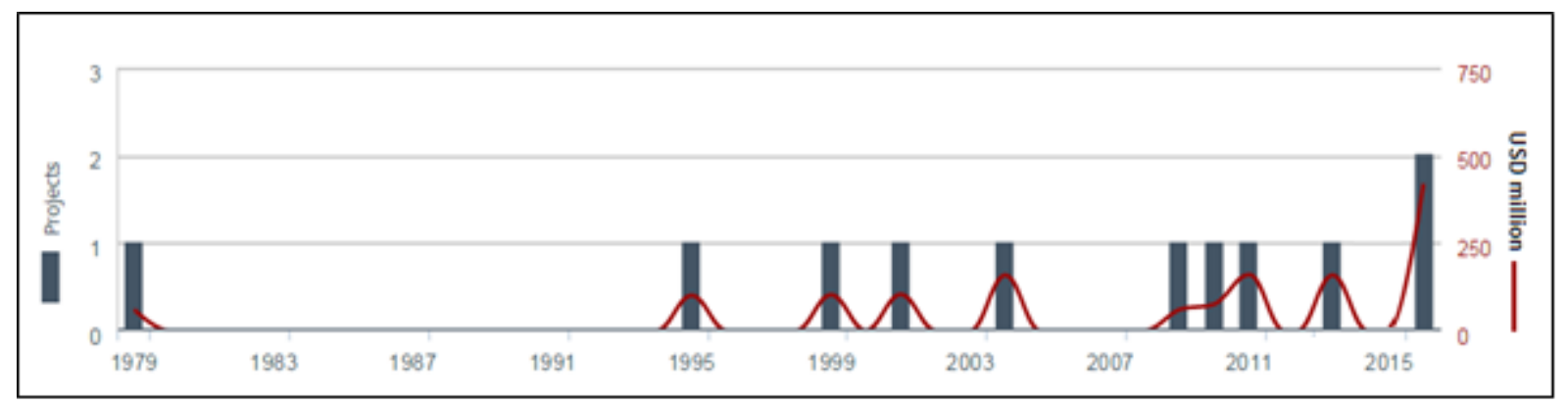

Figure 37. World Bank's Investment in Irrigation and Drainage Sector

In addition, by looking at World Bank and Asian Development Bank database and we don't see any near future projects for further development of irrigated lands, as by looking at the timeline provided by MARD, in year 2000 the irrigated area in country was 6.69 ha which shows the irrigation intensity of $184 \%$, almost equal to irrigated cropping intensity mentioned by AQUASTAT for year $2005190.4 \%$ and irrigation potential for Vietnam is calculated as $9.4 \mathrm{M}$ ha.

Moreover, looking at current climate scenario, we see Vietnam struggling with severe droughts, e.g. in 2010; 100,000 ha of rice was damaged by drought in Vietnam as there was no enough water in reservoirs to irrigate the crops (MARD, 2010). In the result, Vietnam is moving towards climate smart agriculture and instead of developing new land for irrigation, country is 
finding its way for sustainable agriculture which is visible is recent World Bank and ADB funded projects, e.g. Vietnam Climate Change Development Policy, Vietnam Irrigated Agriculture Improvement Project, Promoting Climate Resilient Rural Infrastructure in the Northern Mountain Provinces, Water Resources Development (improvement) in the Mid- and Northeast Red River Delta etc (ADB, 2011, 2012).

\subsubsection{Indonesia}

Indonesia is situated in South East Asia and it is a cluster of more than 17000 islands. It falls in wet tropical region with an average rainfall of $2700 \mathrm{~mm}$. Its major irrigated crop is Rice followed by maize and Indonesia is world third largest rice producer with annual production of 70.8 million tonnes (including irrigated and upland rice). Total cultivated area of country was 46 million hectare in 2014 which is $24 \%$ of total country area. Total area equipped for irrigation in Indonesia is 6.72 million hectares (AQUSTAT, 2005). Total water withdrawal for agriculture including irrigation and live stock was 92.7 BCM in year 2000 out of which $99 \%$ is used from surface water resources and there is $1 \%$ contribution of ground water.

Indonesian irrigation sector consists of three types of irrigated areas which are different on the basis of management i.e. Technical, Semi-Technical and Simple Irrigation. Technical irrigation schemes are managed and controlled by ministry of public works and they are equipped with large and permanent irrigation infrastructure from head to tail. Semi-technical schemes are categorized as irrigated areas with permanent irrigation canals but with a minor infrastructure at secondary and tertiary levels. Which have been built by the public works ministry but it is managed by farmer's water user associations. Simple or People's Irrigation schemes have very limited level of infrastructure mostly of temporary nature constructed by farmers. Moreover, there is also rural wetland water management systems and tidal irrigation is also used to feed crops in swamplands (AQUASTAT, ICID 2011)

For the analysis of growth-track in irrigated areas (AAI) of Indonesia, a detailed timelines was not available with ministry of public works, agriculture ministry and national statistics agency Though the data of actual irrigated area is collected by public works ministry and agriculture department but it was not found in the publications available on internet and it will be discussed in detail in next chapter. There were 2 time series available of area equipped for irrigation i.e. FAO-STAT and Directorate General of Water Resources (DGWR), Ministry of Public works. As the first dataset is mostly based on estimates so the official time series from DGWR was selected for analysis. 


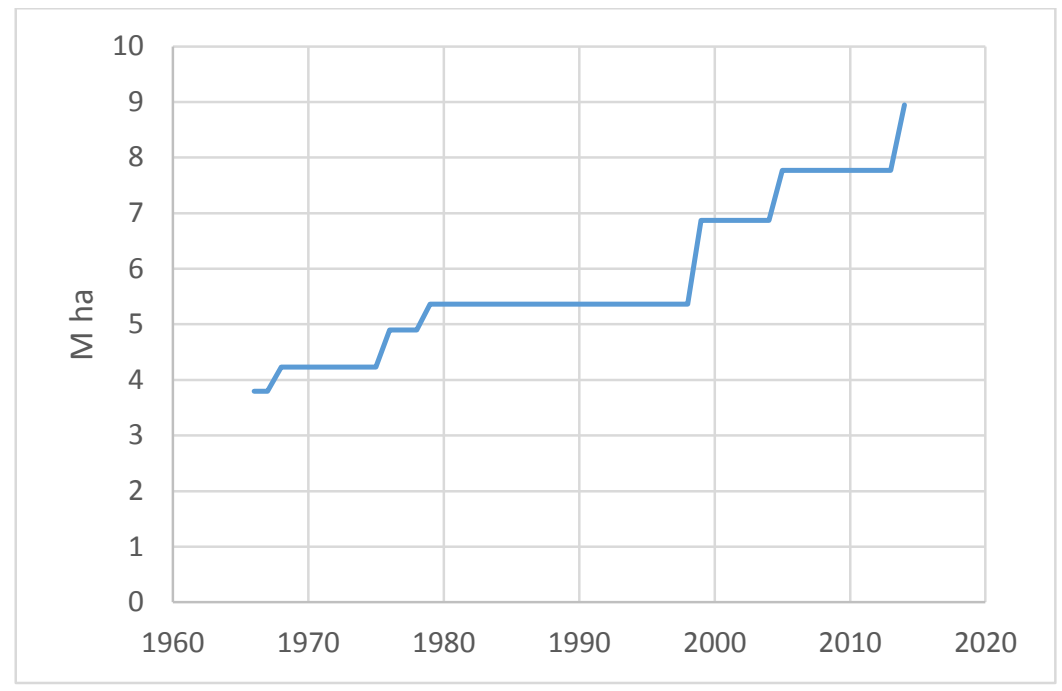

Figure 38. Development of Area Equipped for Irrigation in Indonesia (Source: DGWR)

Besides the small scale farmer managed irrigation in Indonesia, the development of large scale irrigation system starts from colonial time in 1880. When Dutch developed the irrigation systems of covering almost 70,000 hectares in the country, focusing on famine protection. After the establishment of a sovereign Indonesian government in 1948, the first development plan was launched in 1969 which was mainly focused on the restoration of old irrigation infrastructure and developing new irrigated areas. In figure 38, starting from year 1966 we can see an addition of 433,000 hectares in irrigated land by year 1970. On the same hand, looking at the investment side in figure 39 we can see 6 medium size projects by year 1976 with total investment of almost 300 million USD ,irrigation/rehabilitation project 1 to 5 (World Bank, 2015). Which jointly added up 1.13 million hectares by year 1980 showing a growth of $23.5 \%$. Irrigated area's inventory increased by 1.5 million hectares in next 20 years with a growth of almost $25 \%$ and we again see a rise of 0.89 million hectares within next 5 year (by 2005) which sums up the area equipped for irrigation as 7.76 million hectares. On the investment side we see a massive investment of about 2.57 billion USD in irrigation and drainage sector, e.g. Continuation of irrigation projects (6 to 17), provincial irrigation projects, swamp reclamation projects, ground water development project, dam safety project, village infrastructure projects, water resources and irrigation implementation projects etc.

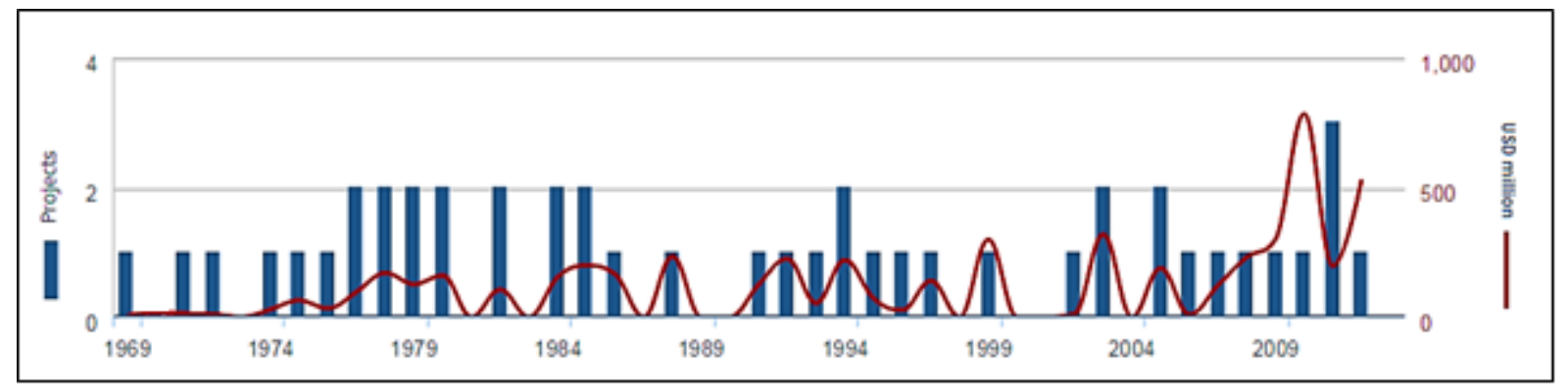

Figure 39. World Bank Investment in Indonesia's Irrigation and Drainage Sector (Source: World Bank)

By year 2014 the timeline shows total area equipped for irrigation as 8.9 million hectares with a growth of $14 \%$ in last 10 year. By reviewing the investment graph, we can track a cumulative investment of 2.68 billion USD in this sector with one huge project of 785 million USD; Third National Program for Community Empowerment in Rural Areas (World Bank 2015). 
It is worth mentioning here, that most of the investments in last 10 years are not fully dedicated for the development of irrigated areas, as they are coupled with community and rural infrastructure development and poverty alleviation tasks as well e.g., the earlier mentioned project has $22 \%$ financing in irrigation and drainage sector and rest is allotted to water supply, rural to urban connecting roads and primary education as a combine package whereas, the project appraisal report categorize irrigation as highest income multiplier ${ }^{10}$ which validate its prominence in the project.

\subsubsection{Nepal}

Nepal is a landlocked country situated in South Asia and $80 \%$ of its area is covered with Himalayan Mountains and slopes including world's largest peak Mount Everest and 20\% are almost plain lands adjacent to India with an average annual rainfall $1,530 \mathrm{~mm}$. Nepal's total cultivated area is 2.5 million hectares (2009) among which 1.2 million hectares is irrigated with an average irrigated cropping intensity of $120 \%$ (DoI, 2007). The annual agricultural water withdrawals are 9.6 BCM including irrigation and livestock. Nepal's irrigation sector depends $76 \%$ on surface water resources $(960,237 \mathrm{ha})$ and $22 \%$ share comes from ground water resources $(278,158 \mathrm{ha}$ ) while $1 \%$ area is irrigated by conjunctive use of water. (AquaStat, 2011)

Irrigation in Nepal can generally be divided into two types, i.e. Public Irrigation Schemes and Farmer Managed Irrigation systems. Public irrigation schemes are designed and managed by irrigation department along with water user associations (WUA) these schemes include 314,521 ha of surface irrigation and 278,158 ha equipped with shallow and deep tube wells. While farmer managed irrigation systems (FMIS) consist of 645,716 ha equipped with surface irrigation schemes including agency assisted (new, rehabilitation projects) and non-assisted schemes (2007, Irrigation Department Nepal). Surface irrigation schemes in Nepal are categorized by the size of scheme, i.e. in plain lands (Terrai region) irrigation scheme would be ranked as major, large, medium and small if the area equipped for irrigation is greater than 5000 ha, between 5000 to 2000 ha, between 200 to 2000 ha and less than 200 ha accordingly. Whereas for mountainous regions the scheme will be called major, large, medium and small if the area equipped for irrigation is greater than 1000 ha, between 500 ha to 1000 ha, between 50 to 500 ha and smaller than 50 ha sequentially.

Detailed statistical dataset of area actually irrigated for a long period of time was not available online, as irrigation department just compile the data for at least a period of 5 years which is not published as timeline (Personal Communication, 2015) which will be discussed in next chapter. So, by collecting the data from other available sources, e.g. agricultural census, irrigation department reports a timeline was created which then compared with dataset of AQUASTAT for area equipped for irrigation.

\footnotetext{
${ }^{10}$ World Bank defines Income multiplier as "the circulation of money in a village caused by the utilization of funds for the development of infrastructure projects"
} 


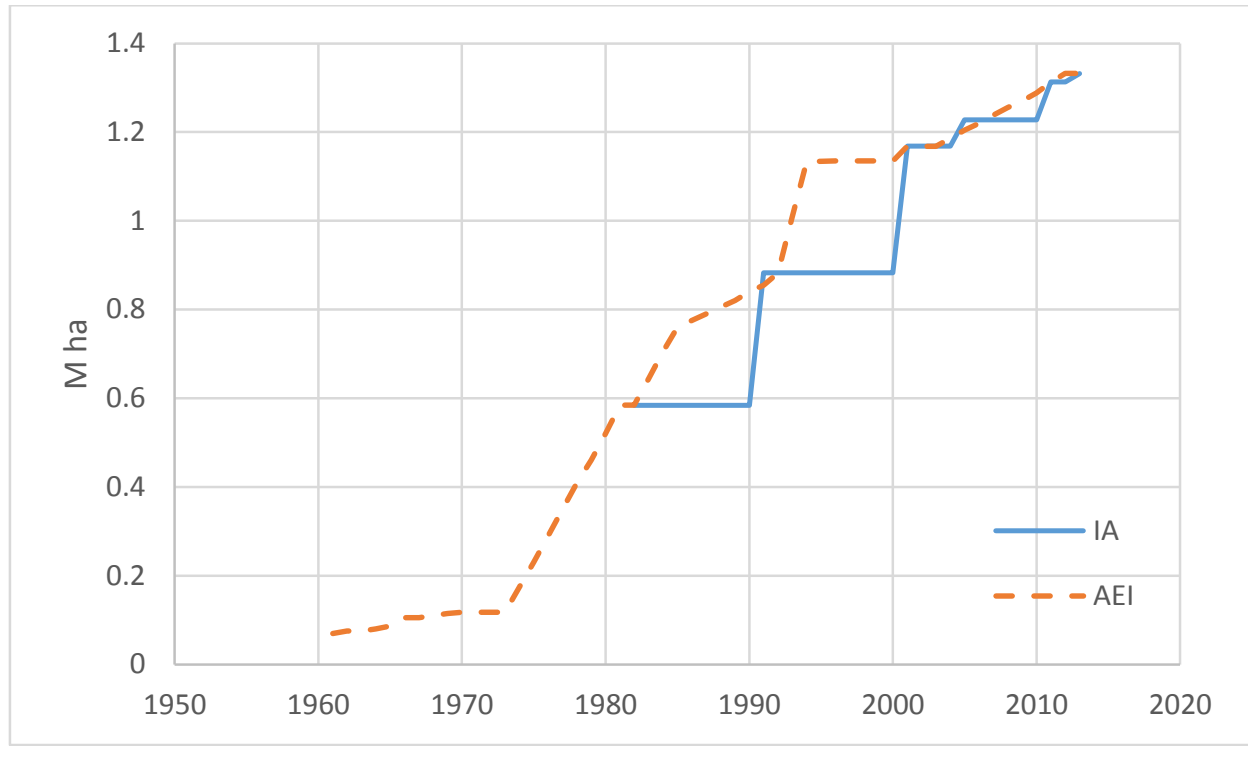

Figure 40. Irrigated Area's Timeline for Nepal (Source: AEI-FAOSTAT, Irrigation Department)

It is important to explain the development plans of Nepal for irrigated areas expansion which are mostly based on 5 years program. By the end of year 1990 Seventh Plan (1985-1990) was completed with a cumulative development of 420,104 ha which shows $40 \%$ achievements against a development target of 1 million ha, starting from first plan in 1956. While looking at the irrigated areas' timeline in figure 40, timeline for AEI starts from 1961 with 70,000 ha of land for irrigation and within the first decade we see a rise of $50 \%$, following with a huge increment of 403,000 hectares within next 10 years which reflects $126 \%$ growth with the investment of almost 90 million USD. Which was almost 5\% (1970-75) and 10\% (1975-80) of total national development expenditures (Benjamin et al, 1994). In next 10 year we see a growth of $47 \%$ with an investment of 240 million USD and by year 2000 there is an increase of 295,000 ha against proposed irrigable area expansion of 358,000 ha by adding up the progress of eighth and ninth plan. Later on for the tenth and eleventh plan there are 250 million USD were allotted for irrigation development with 1.29 million ha of total area equipped for irrigation by the end of year 2010 and 440 million USD for thirteenth and fourteenth plan in long terms planning.

Likewise, the irrigation projects in Asia, Nepal also depends upon international financing agencies, e.g. World Bank, ADB, IFAD etc. Reviewing briefly some of the active projects in irrigation and drainage sector, we can see that irrigation investment from world bank has been coupled with poverty reduction as largest investment in 2007 (Poverty Alleviation Fund II Project Cost: 100 million USD) is a package of improving community infrastructure by supporting micro irrigation, e.g. construction of ponds, improving canals, provision of drip and sprinkler irrigation equipment (World Bank, 2007). Similarly, a community irrigation project costing 26.4 US\$ million is being implemented (ADB, 2011). 


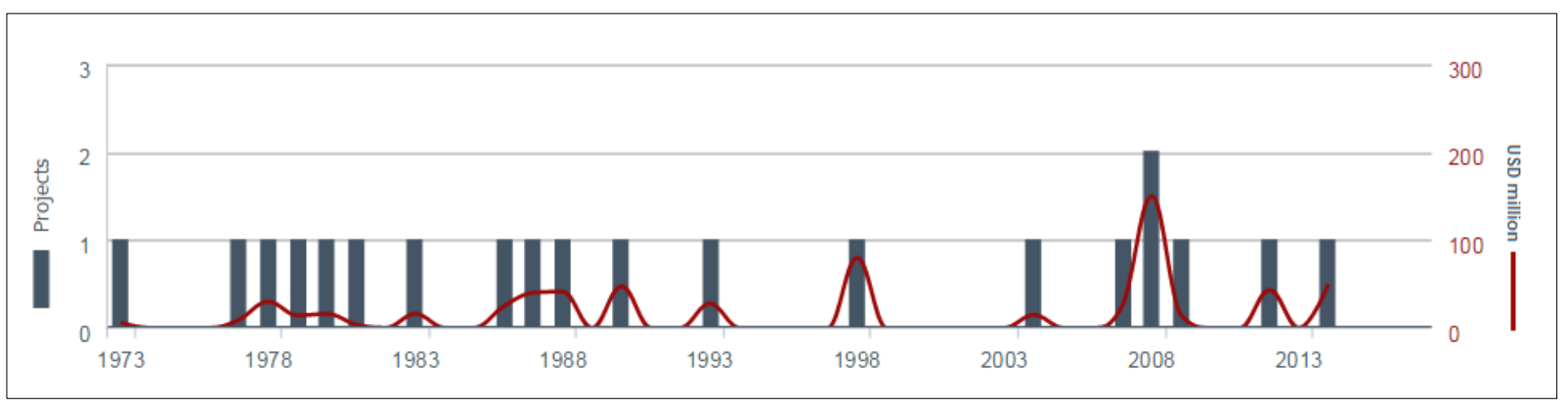

Figure 41. World Bank Investment in Nepal (Irrigation and Drainage Sector) Source: World Bank

Nepal's irrigation department has also started implementing a project costing 50 million USD in 2007 to improve integrated water resource management in farmer managed irrigation systems of about 26,808 ha along with irrigation management transfer in 29,000 ha (World Bank, 2007). Which was further continued with a supplement of 14.3 million USD. Focus on rehabilitation and modernization of old irrigation infrastructure has been increased along with the strengthening of water user association by improving their skills for operations and management of irrigation network (World Bank, 2011).

On other hand, being considered as a special case country, where farmer managed irrigation systems are more than public irrigation schemes, Nepal is more prone to any climate change events as FMIS mostly depends upon local streams within the watershed, so we also see investment in improving the climate resilience of mountain communities (ADB, 2012). This predicts relatively less growth of new irrigated areas in near future, instead the emphasis is high of management and tackling the new challenges.

\subsubsection{Japan}

Japan is a cluster of 5 main and 3,300 small islands. It is situated in East Asia with temperate climate in most of the regions. 70 to $80 \%$ of country is covered with mountains with an average annual rainfall of $1,668 \mathrm{~mm}$. Cultivated land in country was 4.5 million hectare in 2013 with $56 \%$ irrigated area. Total annual water withdrawal for agriculture was 58.6 BCM in 1992 which is $64 \%$ of the total water extraction. Main source of irrigation in Japan is surface water while $6.6 \%$ water is pumped from ground in order to meet the requirement in dry season. Main irrigated crop in Japan is paddy which consists $95.5 \%$ of total irrigated areas (AquaStat, 2015).

Information regarding irrigated areas and their growth was not directly available with statistics or agriculture department. So the growth analysis has been conducted using data from FAOSTAT (AEI) and ASEAN-Food security information system. 


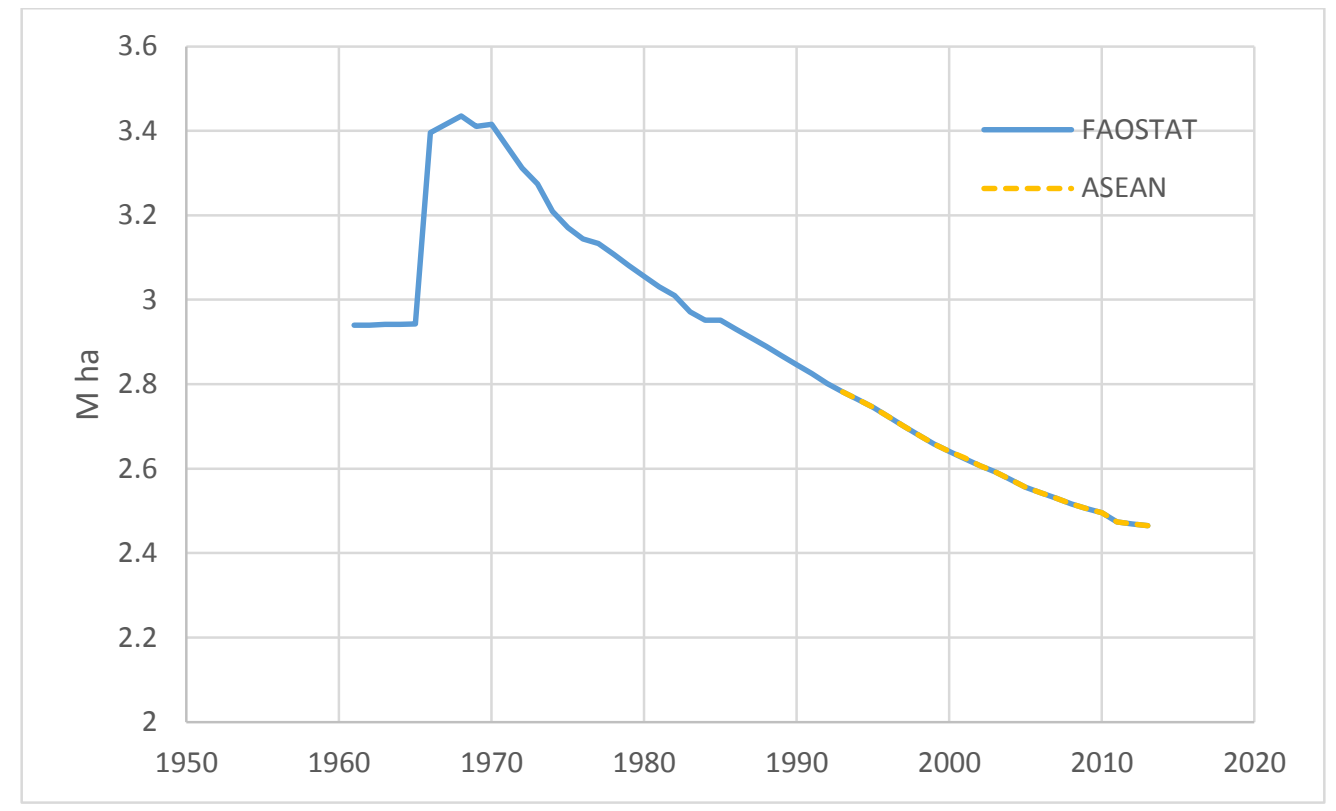

Figure 42. Irrigated Areas Timeline in Japan (Source: FAOSTAT, ASEAN)

In figure 42, ASEAN's data overlaps the FAOSTAT data from 1993 till 2013 which points out the same source for both datasets. After the addition of almost $0.5 \mathrm{M}$ ha from 1965 till 1969, a gradual decrease can be seen in the irrigated areas. This shows a drop of more than 20,000 hectares of irrigated land every year on an average from 1970. While looking at the other side, remote sensing data shows an increase of 2.1 $\mathrm{M}$ ha in 10 years from year 2000-2010 and the total extent of irrigated area is $85 \%$ and $110 \%$ greater than FAO statistics respectively.

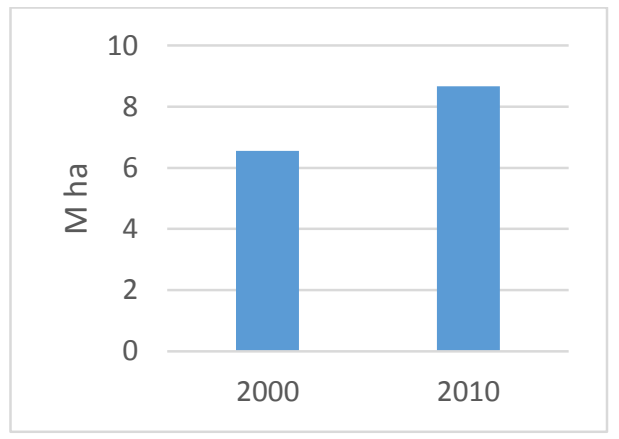

Figure 43. Irrigated Area Growth in Japan (Source: IWMI)

The overall decline in FAO dataset might be reflecting the drop in irrigated area due to competition between industry/domestic use and agriculture, as industrial use of water has significantly increased overtime (MILT, 2008). On the other hand, an increase in irrigated areas could provide a hint towards commercial large scale farming which may not be included in routine agriculture statistics or the growth of small scale but largely dispersed irrigated agriculture which might be ignored in data collection process (discussed in Zonal Dispersion Analysis, Chapter 6). 


\subsection{Growth-Track for Asia}

A cumulative graph has been shown in figure 44 to discuss the general development growth of irrigated areas in Asia. Starting from 1961, an overall growth of almost 80 percent can be seen in 50 years till 2010 , with an average growth of $15 \%$ every 10 years.

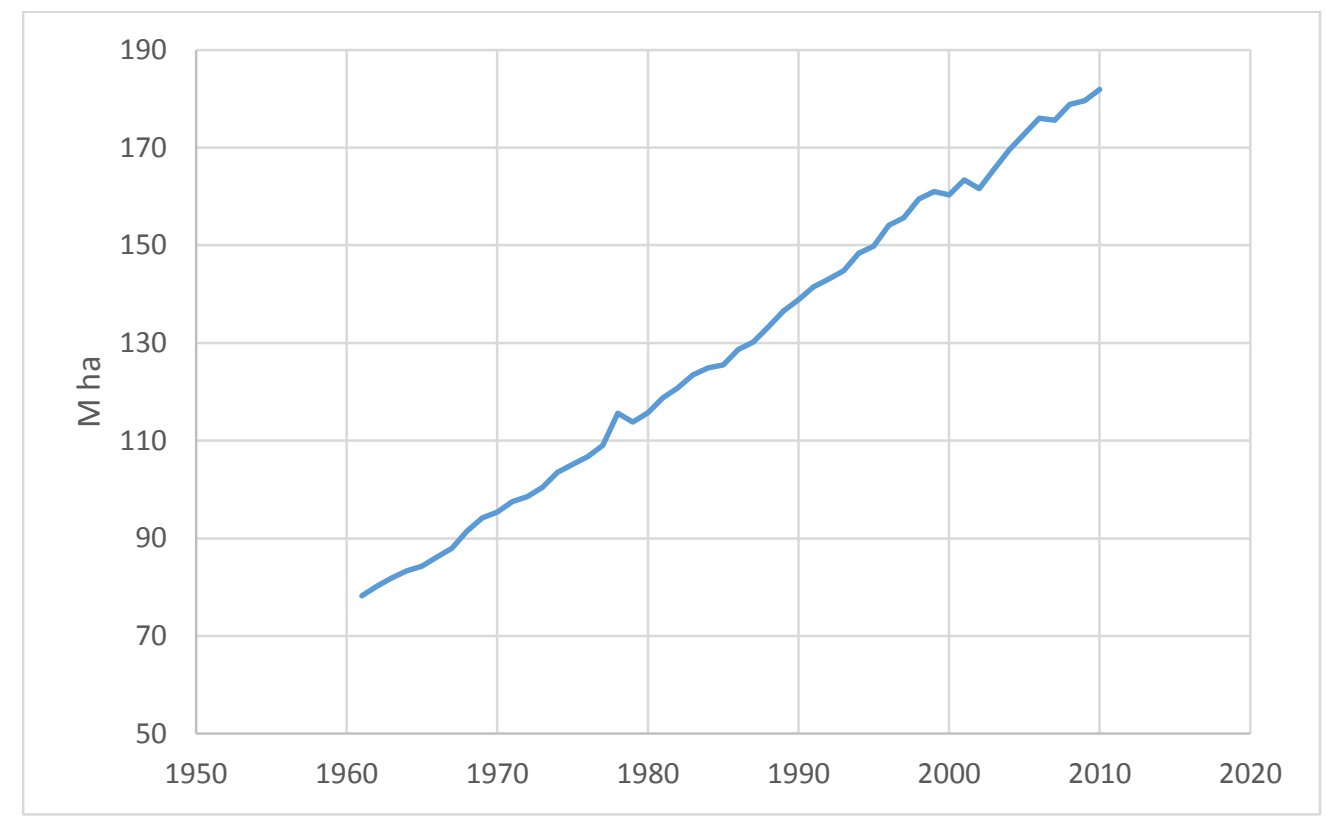

Figure 44. Cumulative development of irrigated areas in Asia (Source: National and FAO Statistics)

Analysing the growth trend by putting cumulative timeline in the frame of successive 10 year period, a continuous decline can be noted which has been shown in figure 45.

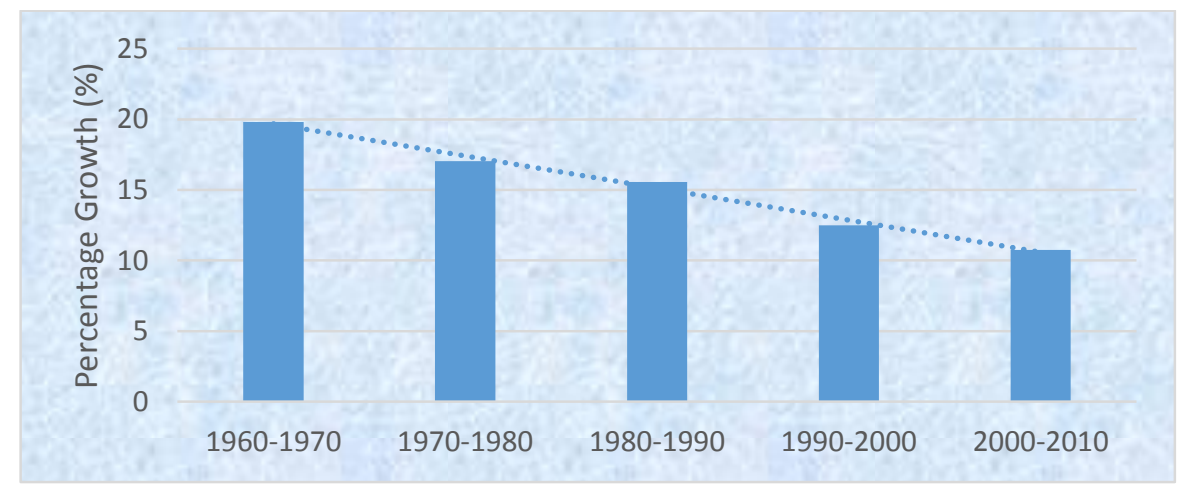

Figure 45. Irrigated Areas Growth per Decade (1960-2010) Source: Analysis based on cumulative timeline data

This descending inclination has also been noted in country wise analysis in previous section. As most of Asian countries are almost reaching their irrigation potential and in current scenario, the irrigation development is just not considered as developing more land to grow more food. Instead, it is more associated with community development and poverty alleviation.

On other hand, most of the irrigation infrastructure developed in past is aging, which needs rehabilitation and it was duly realized from recent irrigation investments in most of the big 
countries, e.g. India, Pakistan, China and Indonesia. As they are spending more funds on rehabilitation and to improve the efficiency instead of developing new land.

Climate change and increased droughts would also effect the irrigated areas in Asia and for some countries there might be a shortage water to feed the existing irrigated agriculture in future, and for some countries excess or unexpected rains would create problems. These situations would compel Asian nations to focus more on climate smart and water conservation irrigation techniques with significantly high water application efficiency to attain improved yields. 


\section{CHAPTER 5}

\section{Uncertainties in Irrigated Areas Datasets}

Uncertainties in Asia's irrigated areas will be comprehensively discussed in this chapter. Results of various statistical analyses, described in methodology part, are included with a detailed discussion on the findings. Exploring the extent of the uncertainties; readers would be able to visualize the level of uncertainty within different data sources of irrigated areas. A connection can be made with growth track analysis to realize the importance of irrigated areas in Asia and the significance of reliable information. Further this chapter describes the discrepancy of data in the context of agro-ecological zones to look at a bigger picture of Asia's irrigated agriculture. Moreover, spatial dispersion analysis has also been included to investigate and compare the uncertainty between large, medium and small scale irrigation schemes.

\subsection{Irrigated Areas of Asia}

As described in methodology part; a detailed database was established by finding all accessible information from web sources.Table 8 shows the cultivated area of countries under study and the percentage of cultivated land which is equipped for irrigation.

\begin{tabular}{|c|c|c|c|c|c|}
\hline Country & $\begin{array}{c}\text { Total area } \\
\text { '000 ha }\end{array}$ & Year & $\begin{array}{c}\text { Cultivated area } \\
\text { '000 ha }\end{array}$ & Year & $\begin{array}{c}\text { \% of the cultivated area equipped } \\
\text { for formal irrigation }\end{array}$ \\
\hline China & 960,000 & 2013 & 122,524 & 2006 & 51.35 \\
\hline India & 328,726 & 2012 & 169,346 & 2008 & 39.17 \\
\hline Pakistan & 79,610 & 2012 & 31,063 & 2008 & 64.35 \\
\hline Iran & 174,515 & 2012 & 16,783 & 2009 & 51.84 \\
\hline Indonesia & 191,093 & 2013 & 46,000 & 2005 & 16.0 \\
\hline Thailand & 51,312 & 2012 & 21,060 & 2007 & 33.76 \\
\hline Viet Nam & 33,097 & 2012 & 10,211 & 2005 & 48.67 \\
\hline Bangladesh & 14,846 & 2012 & 8,520 & 2008 & 59.27 \\
\hline Japan & 37,796 & 2012 & 4,549 & 2010 & 54.96 \\
\hline Nepal & 14,718 & 2013 & 2,326 & 2002 & 47.58 \\
\hline
\end{tabular}

Table 8. Cultivated land and percentage area equipped for formal irrigation (Source: AquaStat 2016)

Table 9 and 10 will show the different datasets which were collected during data collection phase and later their uncertainty will be discussed exclusively by including the statistical analysis made to find the level of variation. 


\begin{tabular}{|c|c|c|c|c|c|c|c|}
\hline Sr. No & Country & $\begin{array}{l}\text { Statistical Agency } \\
\text { (Main Role in data collection) }\end{array}$ & $\begin{array}{l}\text { Agriculture /Irrigation } \\
\text { Department/Land-use data }\end{array}$ & Agricultural Census & $\begin{array}{l}\text { Irrigation } \\
\text { Census }\end{array}$ & World Bank & $\begin{array}{c}\text { Land Survey/Other } \\
\text { Surveys }\end{array}$ \\
\hline 1 & India & & 55,2052000 & 50,2892001 & 79,9002002 & 59,2062005 & \\
\hline 2 & China & & 55,0292005 & 54,6312007 & & 53,8922006 & 56,3282005 \\
\hline 3 & Pakistan & & 19,1302005 & 13,8012010 & & 18,9802005 & \\
\hline 4 & Iran & & 8,5732005 & 70,152003 & & 8,7152006 & \\
\hline 5 & Thailand & 5,3551998 & 4,5022007 3,7972007 (OAE) & & & & \\
\hline 6 & Bangladesh & 6,5502009 & $6,969_{2008}$ & 4,8482008 & 5,8132005 & 4,7602005 & \\
\hline 7 & Indonesia & 6,1162010 & 7,7752005 & & & & 4,8282008 \\
\hline 8 & Vietnam & & 6,8942000 & 4,5022001 & & & $5,570_{2000}$ \\
\hline 9 & Japan & 2,782 (OECD) 1993 & 2,5562005 & & & 1,6842006 & \\
\hline 10 & Nepal & & $1,408.82012$ 1,227.4 2005 (Dol) & 1,3132011 & & 1,1682005 & 2,0652010 (NLSS) \\
\hline
\end{tabular}

Table 9. Datasets collected from National Data Archives (Unit: 1000 ha)

\begin{tabular}{|c|c|c|c|c|c|c|c|c|c|c|}
\hline \multirow{2}{*}{ Sr. No } & \multirow{2}{*}{ Country } & \multirow{2}{*}{ AQUASTAT } & \multirow{2}{*}{ FAOSTAT } & \multirow{2}{*}{$\frac{\text { GMIA }_{2005}}{\mathbf{1 0} \mathbf{~ k m}}$} & \multirow{2}{*}{$\frac{\text { LULC }_{1992}}{1 \mathbf{~ k m}}$} & \multirow{2}{*}{$\frac{\text { GLC2000 }_{2000}}{1 \mathrm{~km}}$} & \multirow{2}{*}{$\begin{array}{c}\text { Globe Cover } 2009 \\
311 \mathrm{~m}\end{array}$} & \multicolumn{3}{|c|}{ GIAM-IWMI } \\
\hline & & & & & & & & 10 km 2000 & $250 m_{2000}$ & $250 m_{2010}$ \\
\hline 1 & India & $58,130 \quad 2001$ & 58,1302001 & 57,890 & & 166,149 & & 101,234 & 217,086 & 222,639 \\
\hline 2 & China & 54,219 2006 & 62,2762005 & 52,758 & 110,290 & & 61,504 & 111,988 & 257,612 & 231,646 \\
\hline 3 & Pakistan & & 18,9802005 & 13,378 & 20,689 & 29,184 & 20,540 & 14,036 & 28,641 & 29,521 \\
\hline 4 & Iran & 6,423 2006 & 8,1562008 & 6,407 & 1,902 & & 279.0 & 2,623 & 22,291 & 9,225 \\
\hline 5 & Thailand & 5,0602007 & 5,1102005 & 6,414 & 26,599 & & 5,102 & 6,610 & 19,402 & 17,525 \\
\hline 6 & Bangladesh & 5,0502008 & 4,7602005 & 5,049 & 7,581 & 12,079 & & 5,235 & 11,369 & 13,541 \\
\hline 7 & Indonesia & 6,722 2005 & 6,722 2005 & 6,722 & 11,852 & & & 3,172 & 13,180 & 14,057 \\
\hline 8 & Vietnam & 4,5852005 & 4,585 2005 & 4,585 & 10,864 & & 3,305 & 4,384 & 11,612 & 10,021 \\
\hline 9 & Japan & 2,6002006 & 17022005 & 2,651 & $33,19$. & & & 2,525 & 6,566 & 8,667 \\
\hline 10 & Nepal & 1,1682002 & 1,031 2006 & 1,168 & & 2,916 & & 1,251 & 4,402 & 3,248 \\
\hline
\end{tabular}

Table 10. Datasets collected from FAO Subsidiaries and Raster Maps (Unit: 1000 ha) 
Tables 9 and 10 carry the country level values for irrigated areas while some of these datasets also carries regional information, for example state/province/district wise. It can be noted that within a same country several agencies are involved in collecting information which mostly don't have same numbers. Most likely due to using different methods of data collection, which will be discussed in detail later.

FAO datasets (FAOSTAT and AQUASTAT) has been mentioned in Table 10, but a relevant similarity has been noted between national data archives and FAO figures. This shows the dependency of FAO on countries to collect agricultural statistics.

Furthermore, Table 10 also carries the information which is retrieved using remote sensing techniques. A variation can also be noted within raster map information as well, as several raster datasets including LULC, GLC2000, GlobeCover and IWMI-GIAM has been used. It is important to mention here that GMIA maps which are produced by FAO are available in the form of raster data but mostly they are based on statistical datasets collected by countries. So in further analysis their values are analysed with national data archives and FAO datasets. Earlier stated raster datasets are mostly based on land use maps, where they have several classes including irrigated area or irrigated croplands. Difference in numbers within these maps could occur due to using different approaches to classify the land features and using different image resolution as well. For example, in case of Thailand values for irrigated areas vary between 5.1 $\mathrm{M}$ ha to $26.6 \mathrm{M}$ ha. While for Iran this value varies between 279,000 ha to $22.2 \mathrm{M}$ ha. On other hand, AQUSTAT database shows the figure of $5 \mathrm{M}$ ha and $6.4 \mathrm{M}$ ha for Thailand and Iran respectively.

As described earlier, raster maps carries the information of irrigated agriculture along with other land use type. Which might have a possible chance of mixing different land types together as mostly these land classification analysis are based on some general algorithms. While IWMI maps provide dedicated version of irrigated areas information carrying the values for intensity of irrigation, i.e. single crop, double crop and continuous. However, variation in IWMI figures can also be noted in different resolutions for same year 2000 and on other hand the classification process and percentage coverage of ground truthing activities are also needed to be investigated in context of uncertainty.

Though Table 9 and 10 show the uncertainty on one side, but by putting this information in a big frame, it can be clearly seen that these countries are highly depending on irrigation for agricultural production. But actual information regarding the extent of their irrigated land is lacking drastically. This makes it inevitable to critically review and analyse the multi-source information available in huge statistical inventory to validate its ingenuity. 


\subsection{Discrepancy in Data Sets}

Information for a same statistical indicator, being collected by different sources, could possibly have some variation. Which arises due to change in time, environment, level of seriousness, priority, training, methods of data collection and personal abilities to collect the data etc. In the preceding section, different datasets have been presented which varies from each other in the extent of irrigated land. To look at the level of discrepancy, several statistical tests were applied as discussed is the methodology part, which further led the research to develop a scoring mechanism as well. Results of those test have been shown here:

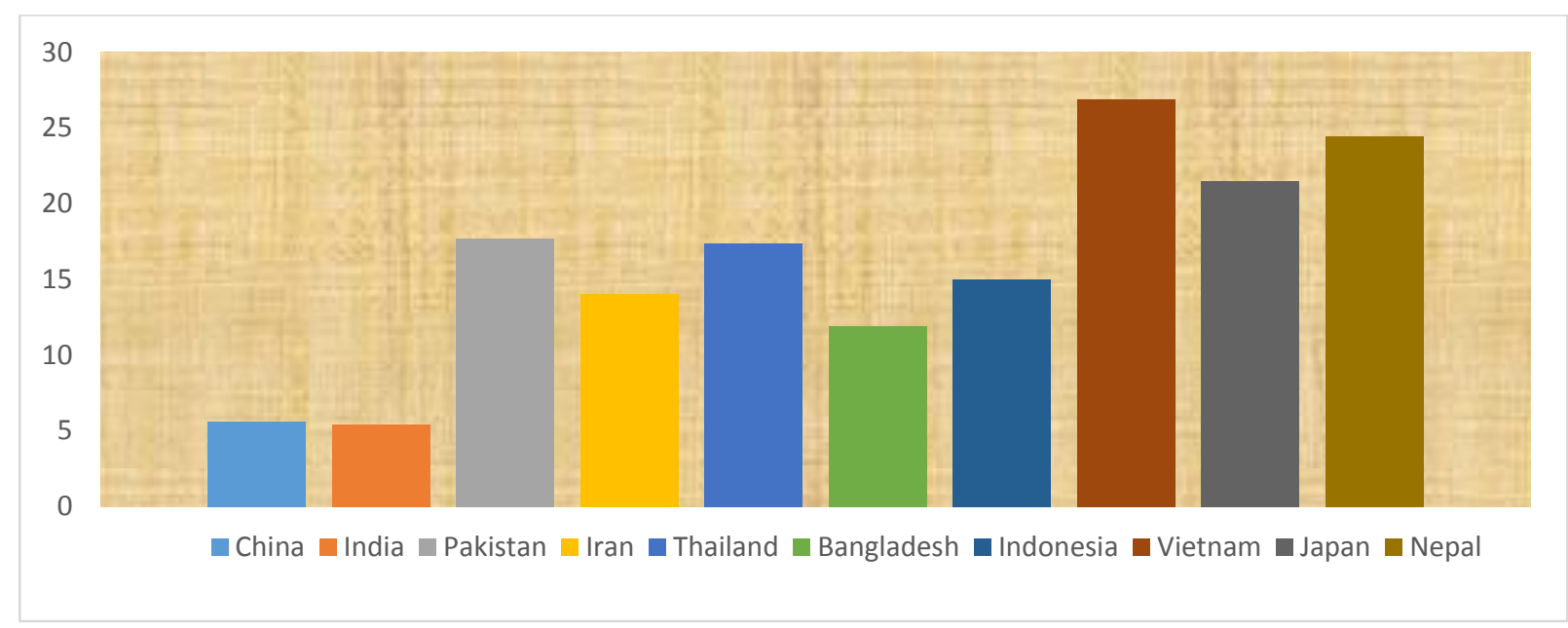

Figure 46. Coefficient of Variation $C_{V}(\%)$ within different statistical dataset

(Source: Analysis based on National Data Archives and FAO datasets)

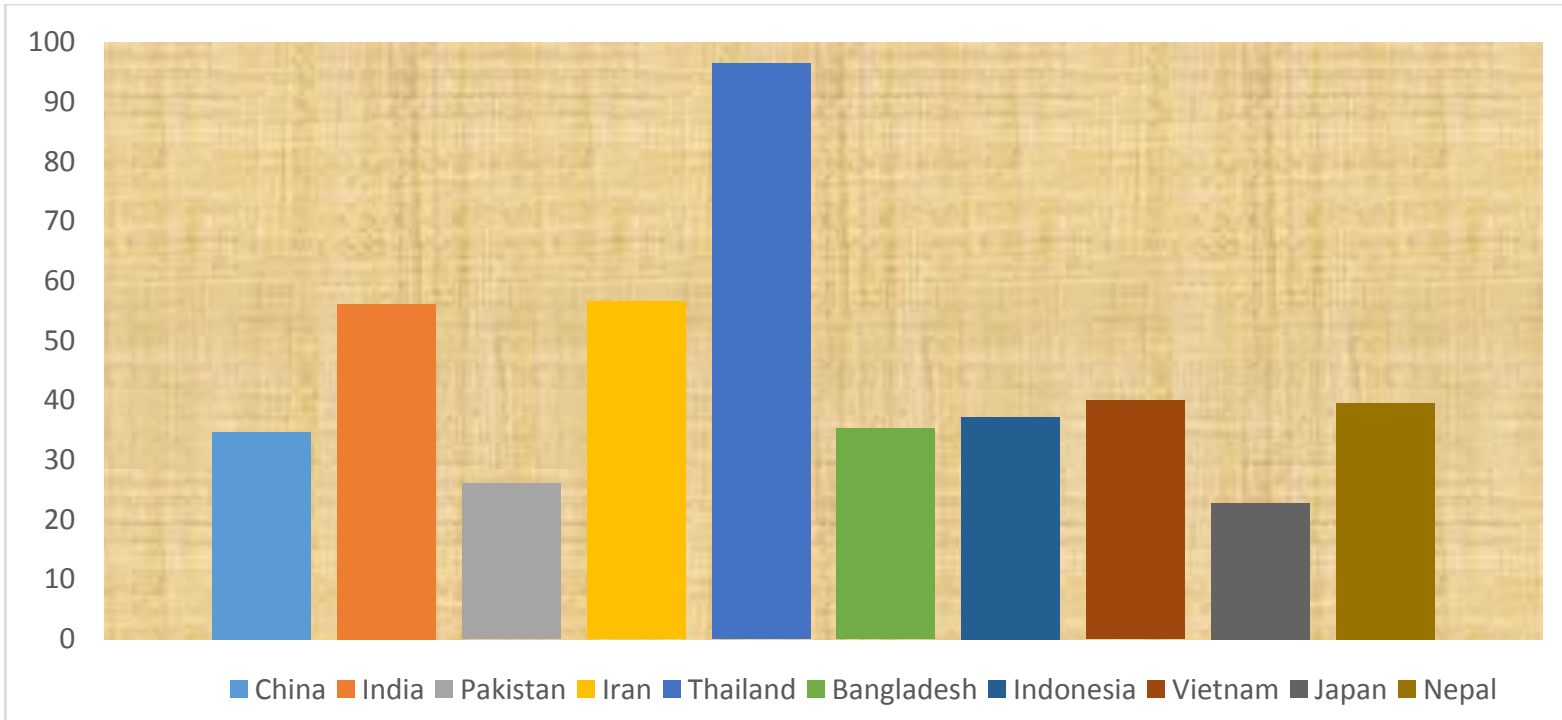

Figure 47. Coefficient of variation $C_{V}(\%)$ including $R S$ based map products

(Source: Analysis based on Raster datasets and Statistical datasets) 
As shown in Figure 46 the coefficient of variation $\left(\mathrm{C}_{V}\right)$ has been calculated by comparing data available in national data archives and datasets available in FAO datasets including FAOSTAT, AQUASTAT and Global Maps of Irrigated Areas (GMIA) as the methods associate in obtaining the information for these datasets are more similar.

Mostly, the data has been collected by administrative records, surveys, interviews and questionnaires etc, which will be discussed in details in next chapter. A big variation can be seen in $\mathrm{C}_{V}$ for different countries which ranges between $5 \%-27 \%$, China and India have the smallest $\mathrm{C}_{V}$, in comparison with countries like Bangladesh, Vietnam, Nepal and Japan which have high value of variation within their national and FAO datasets which ranges near about $25 \%$ in average. On other hand, Pakistan, Iran, Thailand and Indonesia have the value of $\mathrm{C}_{V}$ between 14 to $19 \%$, which can be considered as having a relatively intermediate variation.

\begin{tabular}{|c|c|c|c|c|c|c|c|c|c|c|}
\hline $\begin{array}{l}\text { Statistical } \\
\text { Test }\end{array}$ & China & India & Pakistan & Iran & Thailand & Bangladesh & Indonesia & Vietnam & Japan & Nepal \\
\hline Mean & 55591 & 56678 & 16854 & 7548 & 5040 & 5252 & 6481 & 5580231 & 2264 & 1319 \\
\hline $\begin{array}{l}\text { Standard } \\
\text { Error }\end{array}$ & 1188 & 1160 & 1334 & 433 & 357 & 221 & 396 & 566 & 184 & 114 \\
\hline Median & 54631 & 57895 & 18980 & 7586 & 5085 & 5050 & 6722 & 4585 & 2556 & 1198 \\
\hline $\begin{array}{l}\text { Standard } \\
\text { Deviation }\end{array}$ & 3143 & 3070 & 2984 & 1061 & 875 & 625 & 971 & 1499 & 486 & 322 \\
\hline Range & 9517 & 8917 & 5752 & 2308 & 2617 & 1790 & 2947 & 3837 & 1098 & 1035 \\
\hline Minimum & 52759 & 50289 & 13379 & 6407 & 3798 & 4760 & 4829 & 4503 & 1684 & 1031 \\
\hline Maximum & 62276 & 59206 & 19130 & 8715 & 6415 & 6550 & 7775 & 8340 & 2782 & 2066 \\
\hline
\end{tabular}

Table 11. Statistical test results-I (Source: National data archives and FAO datasets) Unit: 1000 ha

\begin{tabular}{|l|c|c|c|c|c|c|c|c|c|c|}
\hline $\begin{array}{l}\text { Statistical } \\
\text { Test }\end{array}$ & China & India & Pakistan & Iran & Thailand & Bangladesh & Indonesia & Vietnam & Japan & Nepal \\
\hline Mean & 67292 & 78809 & 18747 & 5566 & 7617 & 6083 & 6739 & 5761558 & 2411 & 1472 \\
\hline $\begin{array}{l}\text { Standard } \\
\text { Error }\end{array}$ & 7377 & 14757 & 1632 & 1049 & 2390 & 655 & 886 & 727837 & 183 & 184 \\
\hline Median & 55679 & 58130 & 18980 & 6423 & 5110 & 5181 & 6722 & 4585000 & 2556 & 1240 \\
\hline $\begin{array}{l}\text { Standard } \\
\text { Deviation }\end{array}$ & 23328 & 44271 & 4895 & 3147 & 7171 & 2172 & 2507 & 2301622 & 549 & 582 \\
\hline Range & 59230 & 115860 & 15806 & 8435 & 22802 & 7320 & 8680 & 7559266 & 1636 & 1885 \\
\hline Minimum & 52759 & 50289 & 13379 & 280 & 3798 & 4760 & 3173 & 3305334 & 1684 & 1031 \\
\hline Maximum & 111989 & 166149 & 29184 & 8715 & 26600 & 12080 & 11853 & 10864600 & 3320 & 2916 \\
\hline
\end{tabular}

Table 12. Statistical test results-II (Source: National data archives, FAO datasets and RS based maps) Unit: 1000 ha

Various reasons were found during this research for the variation within national and $\mathrm{FAO}^{11}$ datasets. Mostly the lack of coordination between departments induce this variation as they use different kind of methods to collect the information. Somehow this discrepancy also comes due to the difference of definition and sometime due to the area which is irrigated by different means

\footnotetext{
${ }^{11}$ FAO datasets (FAOSTAT, AQUASTAT and GMIA) are linked with national statistical systems, as they do not have any independent system to collect data of irrigated areas country wise. GMIA maps are in raster form, but as it is mostly based on information provided by countries, so it is added in this analysis.
} 
of irrigation which could be recorded by different departments in a diverse way. In some cases, it was noted that actual irrigated area was not recorded and just command area of scheme (area equipped for irrigation) is documented which cause variation. In some, cases it was also found that some datasets do not represent the actual extent of ground water irrigation which in most of Asian countries is contributing 50\% to irrigated agriculture.

Moving to next Figure.47 where a bar graph shows the coefficient of variation within all the available datasets including the remote sensing based map which are prepared using satellite imagery obtained from different sources and different timeline. A relatively high variation can be seen in all countries in comparison with preceding analysis. Very unusual and high variation has been seen for Thailand which has the value of $\mathrm{C}_{V}$ as $96.35 \%$, the cause of this high value is the extent of irrigated area obtained from LULC map (26.6 M ha) which is $120 \%$ higher than the value of FAO-GMIA.

Relatively high values for $\mathrm{C}_{V}$ could be noted for India and Iran with values of 56.1 and $56.5 \%$ accordingly. In the case of Iran, a very small extent of calculate irrigated (0.279 $\mathrm{M}$ ha) was obtained from Globe Cover, which is 9.4 times smaller than GIAM-10km and 6.8 times smaller than LULC. Whereas, Pakistan, Bangladesh, Indonesia, Vietnam and Japan has a $\mathrm{C}_{V}$ between a range of 26 to 40. This could also provide us a hint to look for the more reliable mechanism for the reporting of irrigated areas. As spatial information does not come from bureaucratic channels or from any statistical agency. So, there might be high chances of the reliability of this information.

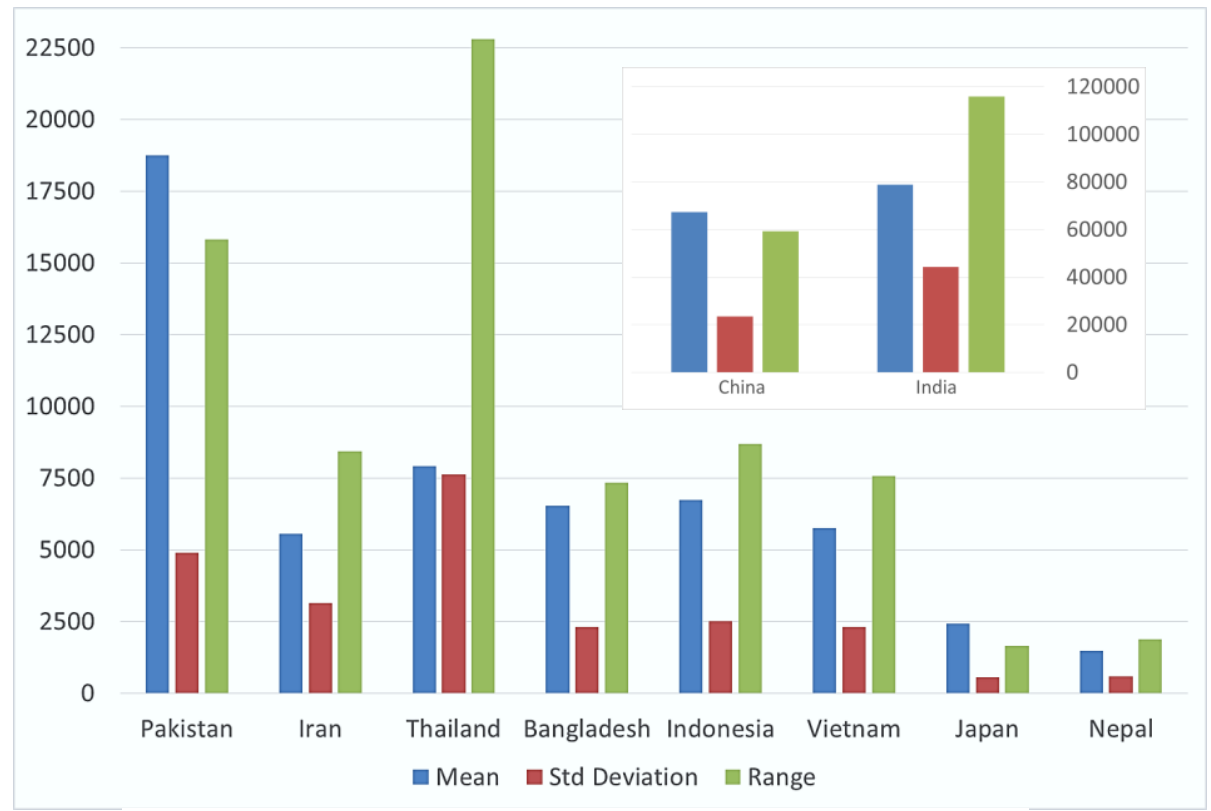

Figure 48. Descriptive statistics: Mean, Standard Deviation and Range of all datasets including RS based data (Unit: $1000 \mathrm{Ha}$ )

Descriptive statistics including mean, standard deviation and range of all datasets analysed can be seen in the figure 48. Range is the difference between largest and smallest values in the datasets of a country, which is highest for Thailand. In case of China, Pakistan and Japan, the range is smaller than mean which represents less variation in data, whereas India, Iran, 
Indonesia, Vietnam are showing high value of range than mean which correspond to a high level of variation, while the difference is relatively small for Bangladesh and Nepal.

\subsection{Scaling Discrepancy in Agro-Ecological Zones}

After developing a detailed understating of uncertainties in available datasets, it was also important to know the spatial distribution of irrigated areas in different agro-ecological zones. Earlier studies have analysed the variation within the national boundaries, mostly state or county wise. But within a large administrative unit, there might be different agro-ecological conditions, inducing patterns of irrigation, which are required to be studied as well in context of discrepancy. As we talk about future challenges to deal with food and water security issues; it is better to study Asia within one frame work for discrepancies in data of irrigated areas.

\subsubsection{Distribution of Irrigated Areas in Climatic Zones}

As described in methodology, climatic zoning has been done on the basis of length of growing period data available at GAEZ web portal. Figure 49 shows the arid, semi-arid, semi-humid and humid areas of countries under analysis in Asia. We can see that most of the area of Iran and Pakistan is arid and northern parts of these countries have semi-arid and semi-humid climate. Almost $40 \%$ area of China is also arid in north-west and it moves towards semi-arid and humid climate in eastern and south-eastern parts with a strip of semi-humid climate in south-east. Nepal is covered with $40 \%$ semi-arid region in south, and Himalayan Mountains in north have arid climate while in southern-eastern part has semi-humid climate. In Thailand, Northern and central part of the country has semi-humid climate while southern part of the country has humid climate. Vietnam has humid climate in most of its regions and some parts have semi-humid climate in north-central coast and south-eastern region. Furthermore, 90\% regions of Indonesia have humid climate with a small region of semi-humid climate in south-eastern part of the country while Japan mostly has semi-humid conditions in country with some parts with semiarid and humid climate in north-east and south-west consecutively.

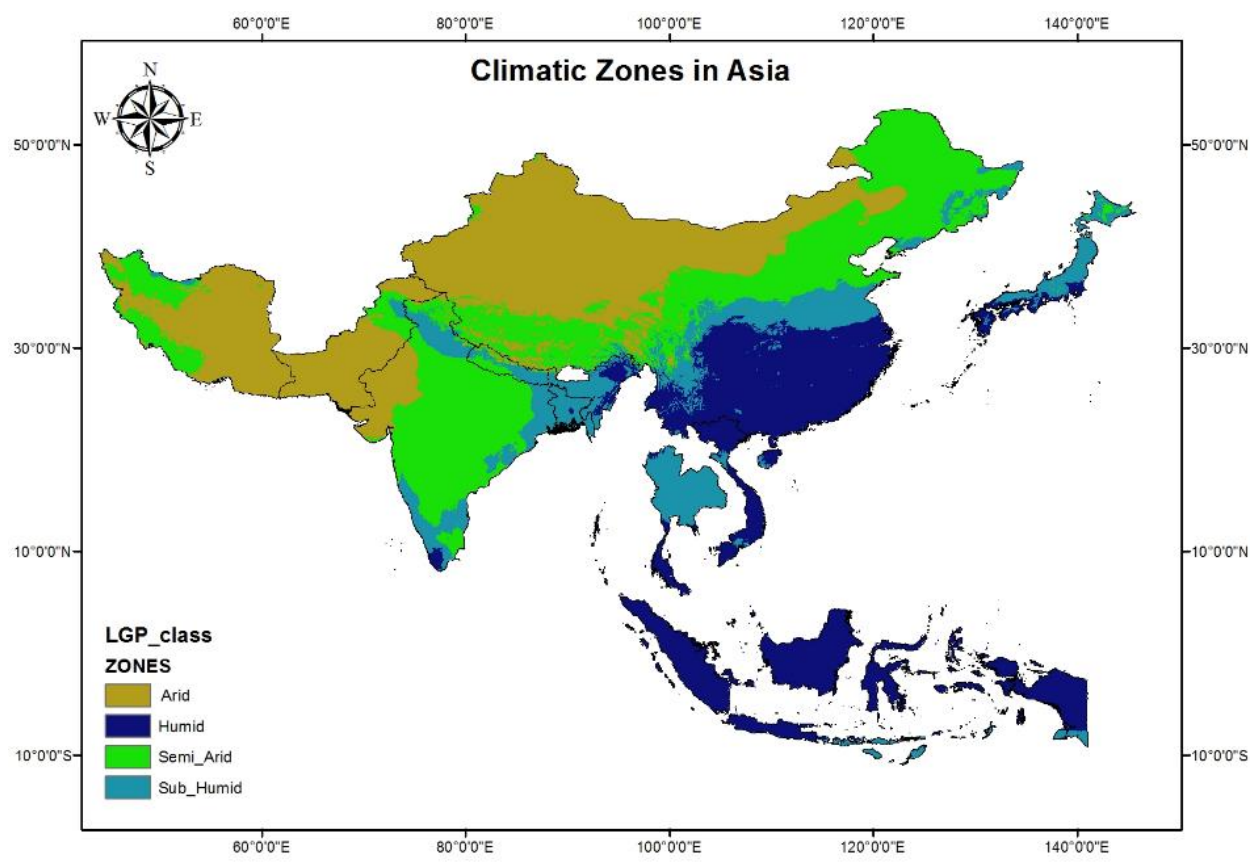

Figure 49. Climatic Zones in Asia (classification based on LGP) Source: FAO-GAEZ 
Following figures (50, 51 and 52) are showing the distribution of irrigated areas (GMIA-AEI) in Arid, Semi-Arid, Semi-Humid and Humid regions in countries under study.
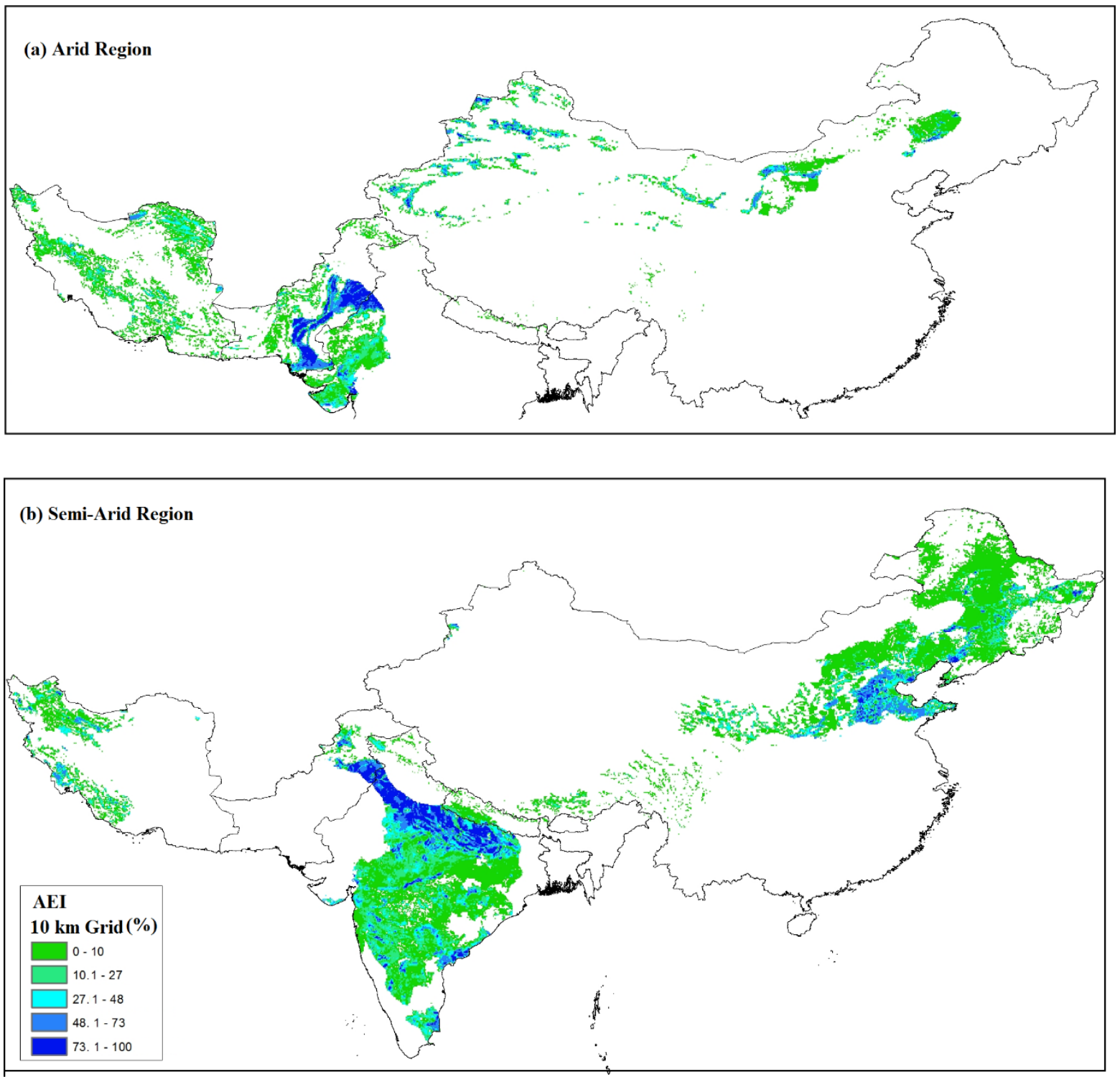

Figure 50. Irrigated Areas in Arid and Semi-Arid Regions (Source: Analysis Based on FAO-GAEZ, FAO-GMIA)

In arid regions, we can see most of the irrigated areas are situated in Pakistan, Iran and China. Almost $80 \%$ part of Indus basin irrigation system of Pakistan lies in arid region while China's north-western and north-eastern regions also falls under this region. Whereas a large part of central and eastern Iran's irrigated areas also comes under arid climate with low and relatively unpredictable rainfall. While irrigated areas of semi-arid regions consist large parts of central and northern India along with China's fertile north-eastern plains, central parts of intensively cultivated yellow-huai-hai river zones, upper central parts of Pakistan and north-western and southern Iran. 


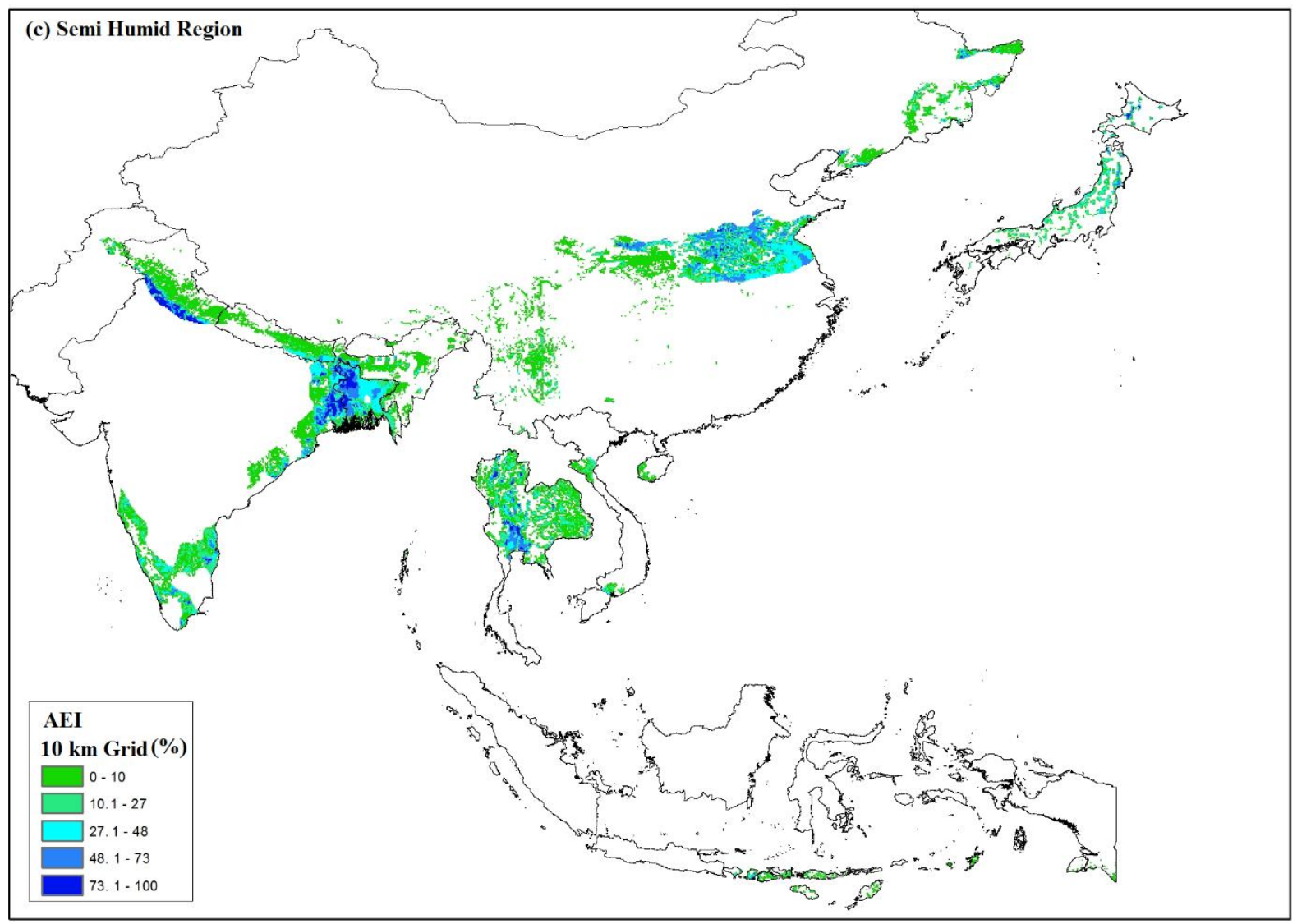

Figure 51. Irrigated Area in Semi-Humid Regions (Source: Analysis Based on FAO-GAEZ, FAO-GMIA)

In semi-humid regions, northern and southern coastal regions of India, northern parts of Pakistan, central parts of Nepal, almost all parts of Bangladesh, central parts of china, northern, north-eats and central parts of Thailand, north central parts of Vietnam, central parts of Japan and south-western parts of Indonesia are equipped with irrigation.

On other hand, in humid regions; a large part of southern and south eastern china consist of irrigated land along with big portion of irrigated areas from northern and southern Vietnam, small parts of southern Thailand, a small chunk from southern part of India and a large share from Indonesia's Java, Sumatra and Kalimantan province.

In figure 53, the distribution of irrigated areas in different climatic regions has been show in pie graph, which shows the largest percentage of irrigated area in semi-arid regions (41\%), followed by semi-humid (21\%), arid (19\%) and humid (19\%). 


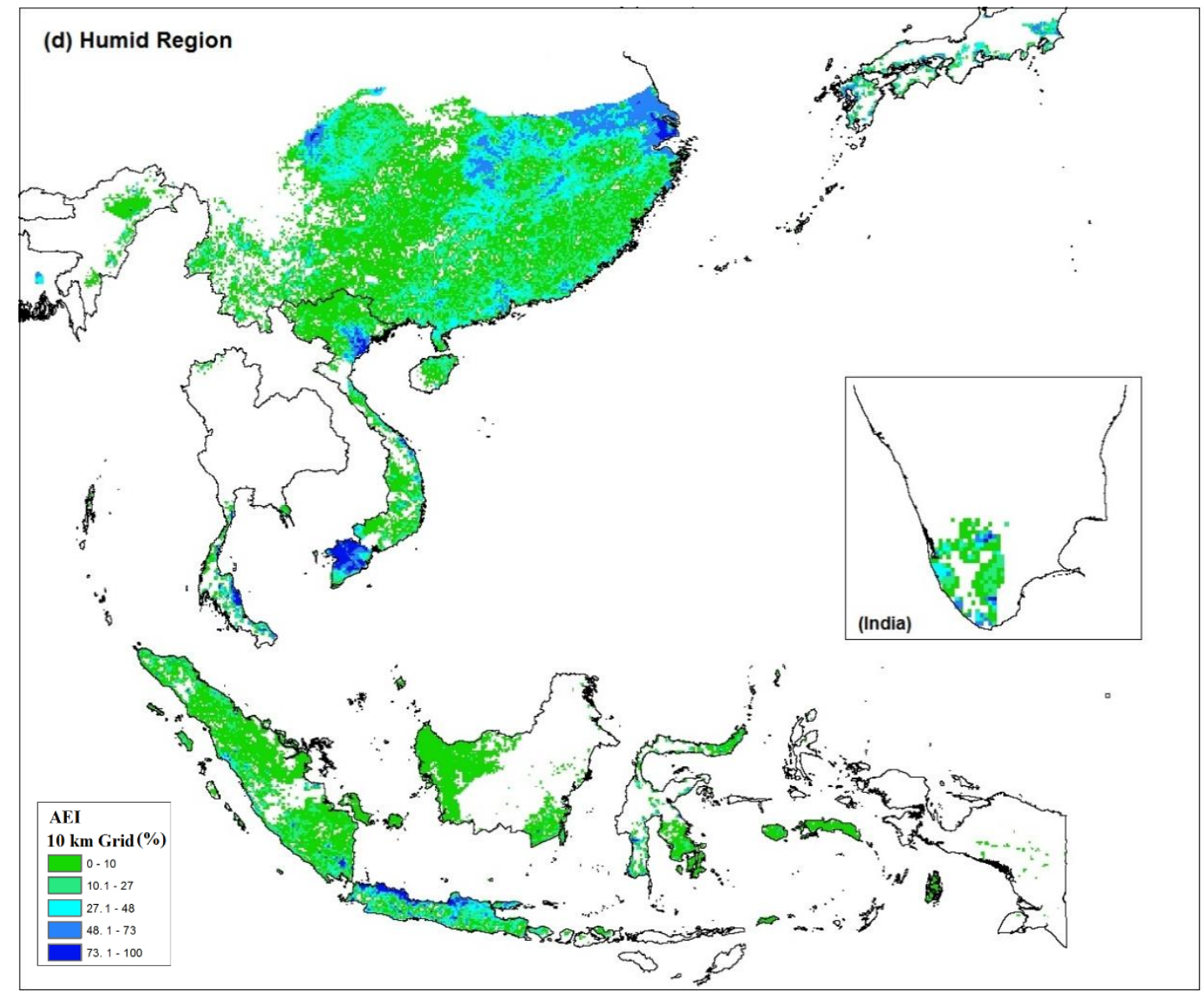

Figure 52. Irrigated Areas in Humid Regions (Source: Analysis based on FAO-GAEZ, FAO-GMIA

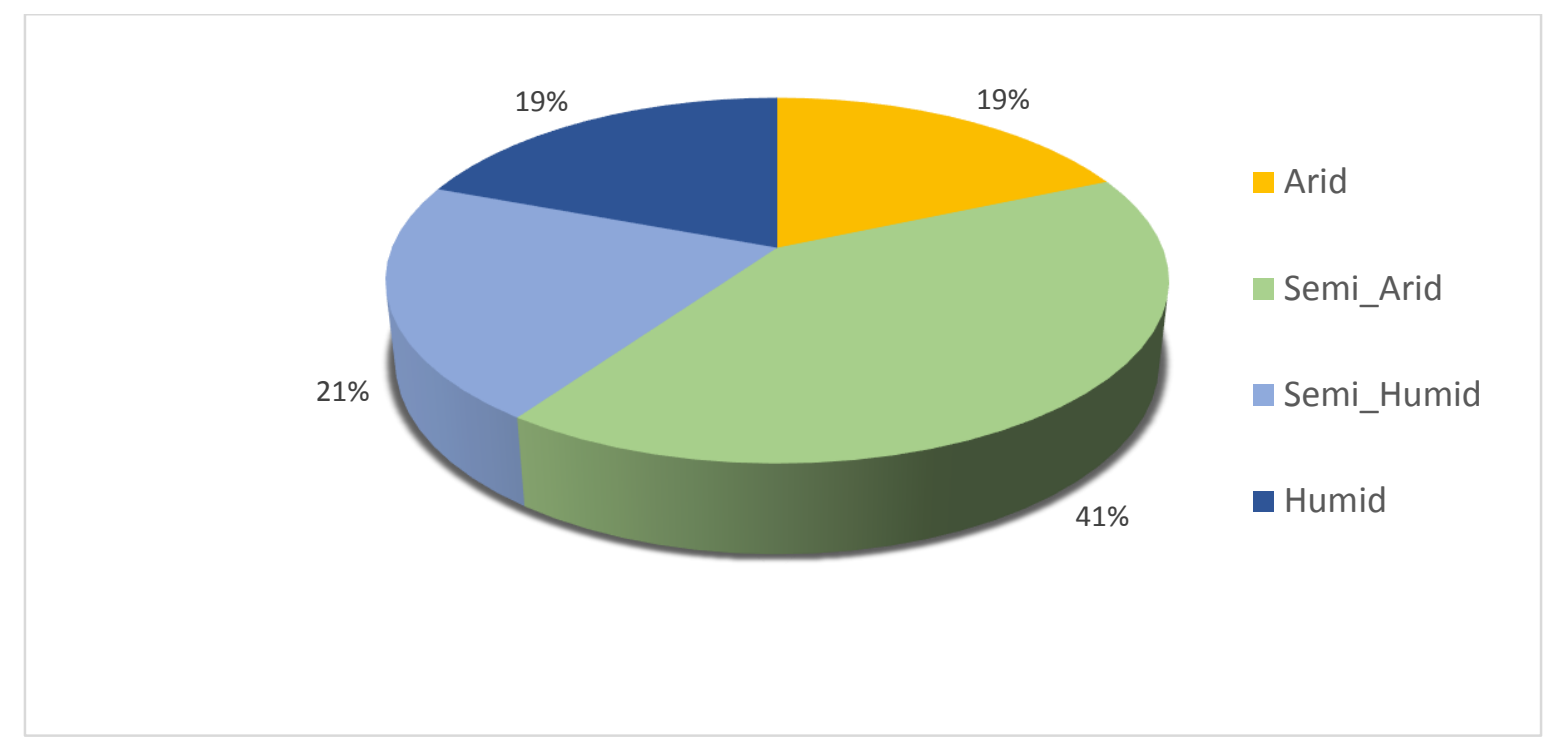

Figure 53. Percentage distribution of Irrigated Areas in different climatic regions (Source: Analysis Based on FAO-GAEZ, FAO-GMIA) 


\subsubsection{Zonal Discrepancy Analysis}

Distribution of irrigated areas in four agro-ecological zones of Asia has been linked with spatial variation and the comparative discrepancy between datasets. Same zonal analysis was performed using RS-based raster datasets of irrigated areas in order to compare it with results of GMIA-FAO.

Table 13 shows the results of comparison between AEI, AAI and AI (RS database).

\begin{tabular}{|l|c|r|r|c|}
\hline LGP Classes & $\begin{array}{l}\text { Are Equipped for } \\
\text { Irrigation (M ha) }\end{array}$ & $\begin{array}{l}\text { Area Actually } \\
\text { Irrigated (M ha) }\end{array}$ & $\begin{array}{l}\text { Area Irrigated } \\
\text { (RS source) M ha }\end{array}$ & $\begin{array}{l}\text { Difference (\%) } \\
\text { AEI vs AI }\end{array}$ \\
\hline Arid & 32.53 & 26.40 & 42.51 & 46.7 \\
\hline Semi-Arid & 72.73 & 66.13 & 139.49 & 71.4 \\
\hline Semi Humid & 36.92 & 32.28 & 89.04 & 93.6 \\
\hline Humid & 33.97 & 30.37 & 83.19 & 93.0 \\
\hline All Regions & 176.16 & 155.18 & 354.23 & 78.1 \\
\hline
\end{tabular}

Table 13. Zonal Discrepancy Analysis (LGP classes)

Table 13 has also been described by bar graph in figure 54 .

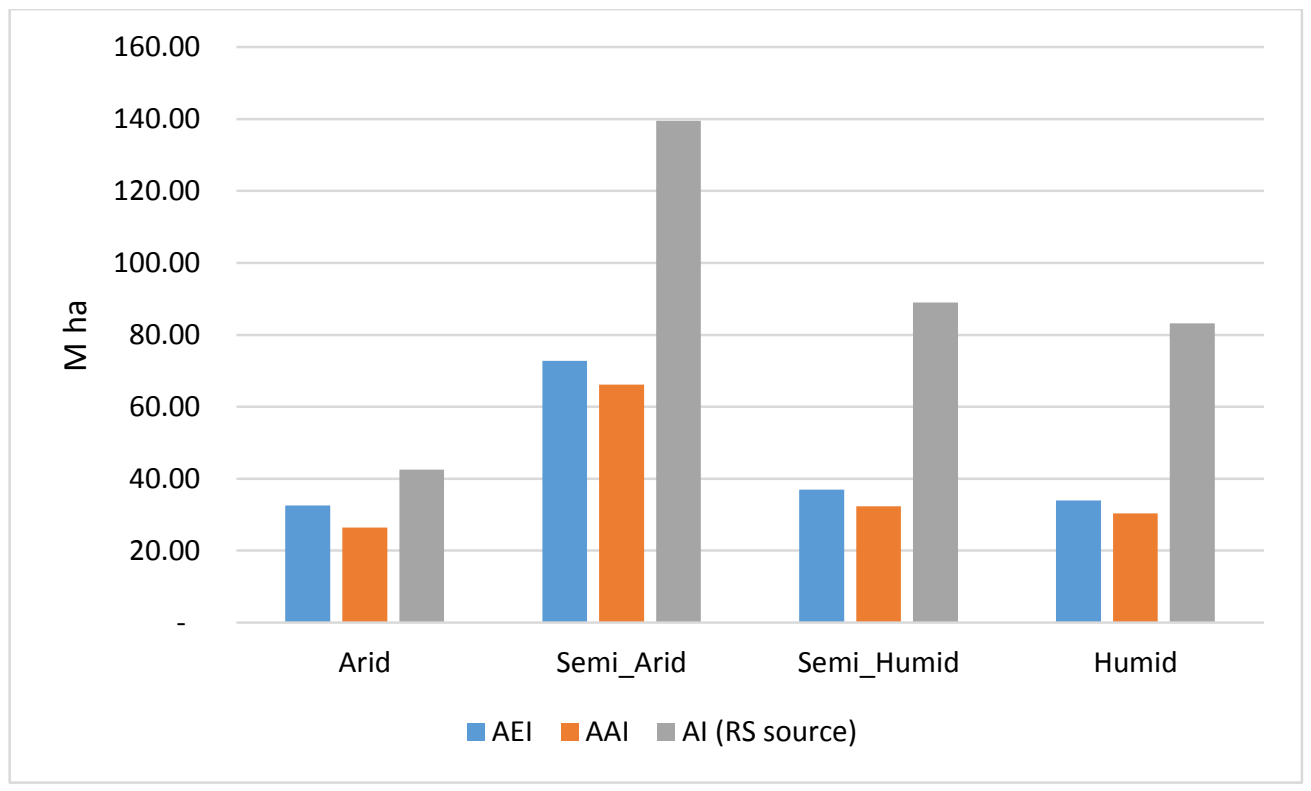

Figure 54. Comparison of Zonal Discrepancy Analysis (Source: Analysis based on FAO-GMIA and RS based Maps)

By comparing the extent of irrigated areas by two different sources of datasets, it has been found that the highest variation exists in humid and semi-humid region with a percentage difference between GMIA and RS-based dataset values of 93\%. While smallest difference was found in arid region with almost $47 \%$ higher values of irrigated areas and in semi-arid region, irrigated areas (having highest proportion in Asia), were found $71 \%$ less than remote sensing estimates.

To find any potential patterns (extent wise) in spatial distribution of irrigated areas in different agro-ecological regions, dispersion analysis was performed using GMIA-FAO datasets. The result of the dispersion analysis (using default grid of $10 \mathrm{~km} \mathrm{x} \mathrm{10km)} \mathrm{shown} \mathrm{in} \mathrm{figure} 55$. 


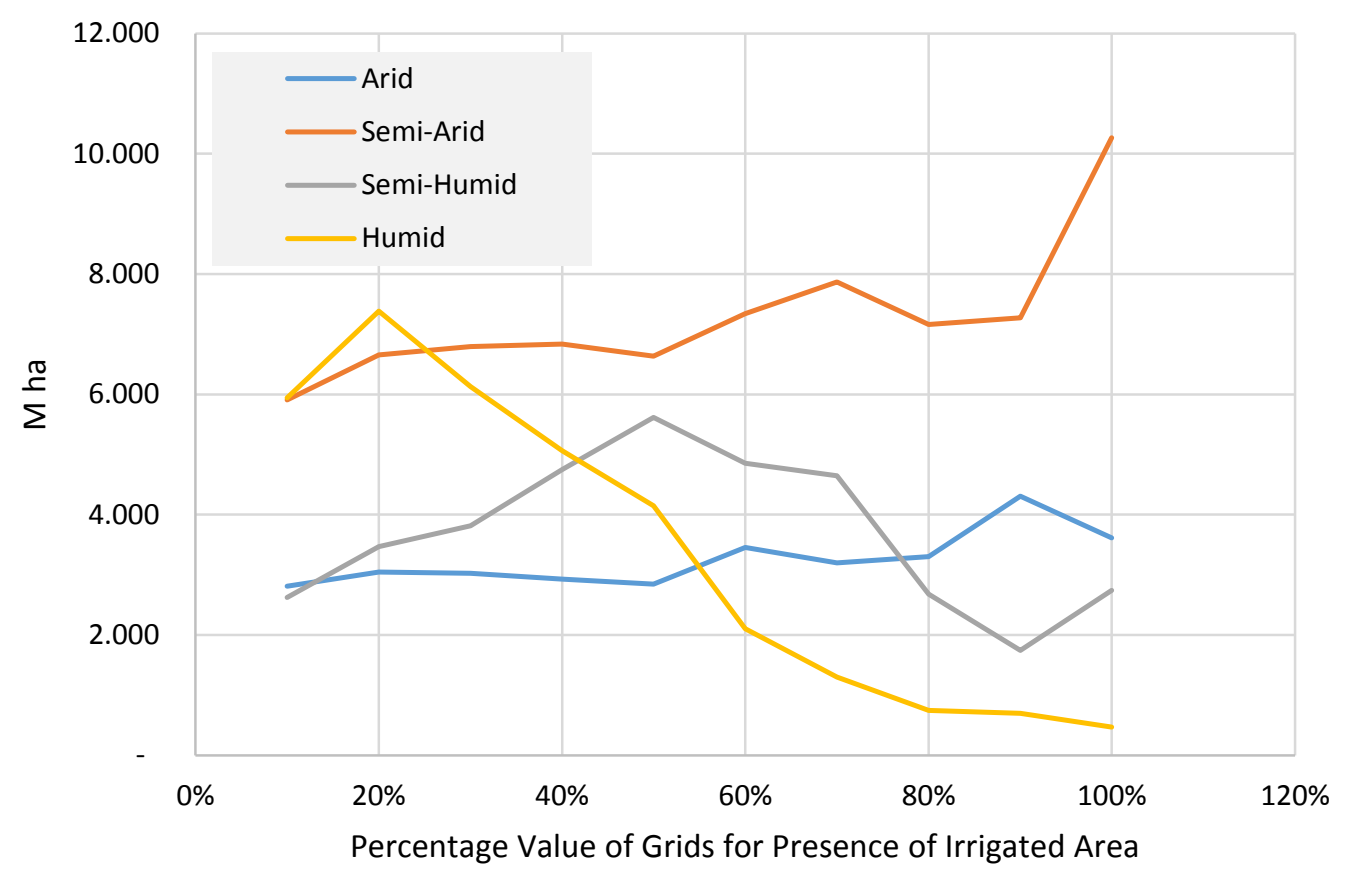

Figure 55. Spatial dispersion of irrigated area in pixels (Source: Analysis based on FAO-GMIA, FAO-GAEZ Maps)

In figure 55, a clear difference in the spatial distribution of irrigated areas can be seen for different categories of agro-ecological zones, i.e. humid regions have the highest proportion of scattered irrigated areas as grids representing 10 to $20 \%$ irrigated areas provide sum of 7.4 million ha followed by 5, 2, 0.75 and 0.47 million hectares of irrigated areas in $40 \%, 60 \%$, $80 \%$ and $100 \%$ grid type. This type of distribution might points towards the small scale, informal or supplementary irrigation in the region probably using ground water, small reservoirs or tanks.

Looking for the dispersion in semi-arid regions, we can see an inverse trend here in comparison with humid regions. As the graph move upwards in increasing order for percentage area irrigated in a grid. Large scale irrigation systems have been estimated as 10.3 million hectare and on the other hand the small scale or more scattered irrigation has a total sum of 6 million hectare, which might represents informal or farmer managed irrigation. Whereas, grids with 40 to $60 \%$ pixel coverage have cumulative area of almost 21 million hectare which consist of $30 \%$ of total land equipped for irrigation in semi-arid regions.

Discussing the distribution patterns in semi-humid regions, a hike can be seen in the graph for $50 \%$ pixel area tier, which might translate the high extent of medium scale irrigation scheme in this agro-ecological zone. The total area covered by irrigated agriculture between 40 to $60 \%$ tier is 15.22 million hectares which is more than $40 \%$ of the total irrigated area in the region. While the irrigated land located in pixels with 80 to $100 \%$ fill is 7.15 million hectares followed by 9.90 million hectares of irrigated land which is spatially dispersed between 10 to $30 \%$ coverage in grids. 
In Arid regions, a relative consistency can be observed in the geographic distribution of irrigated areas, as there is no significant hike in the graph which extends from 2.63 million hectares in 10\% tier towards 3.641 million hectares in areas with $100 \%$ of irrigated land in the pixels with an average of 3.25 million hectares of land equipped for irrigation in all tiers.

As zonal discrepancy analysis shows a high level of contradiction between state furnished and remote sensing based datasets in semi-humid and humid regions, we can look for some relevant hints in the dispersion analysis as well. Where almost $60 \%$ of irrigated area in dispersed between 10 to $30 \%$ tier in humid areas while medium scale irrigation schemes have a major share in semi-humid regions. So, an argument can be set for the possible relation of extent of dispersal with discrepancy in irrigated areas, within different climatic boundaries. This might induce or cause the variation due to non-recorded or non-informed highly dispersed small scale irrigation in the region.

\subsection{Country wise spatial dispersion analysis of irrigated areas (using $250 \mathrm{~m}$ resolution IWMI map)}

As explained in methodology, a country wise spatial dispersion analysis has been conducted while comparing FAO-GMIA and IWMI-GIAM raster dataset. The main purpose for this analysis is to have a look at the distribution of large, medium and small scale irrigation, at country level, as an argument has been established regarding the lack of reporting in widely spread small scale irrigation. Though every country has its own definition for large and small scale irrigation schemes extent, but in this analysis 10,000 ha of land has been used as reference box/grid to find clusters of irrigated areas on raster maps.

IWMI map (250 m resolution) was aggregated at a gird size of $10 \mathrm{~km} \times 10 \mathrm{~km}$ in order to compare it with FOA-GMIA (AEI) map of irrigated areas. Following three categories were established:

\begin{tabular}{|l|c|}
\hline \multicolumn{1}{|c|}{ Sum of Areas (Category wise) } & Type of Schemes \\
\hline Grids Containing 10 to 30\% irrigated areas & Small Scale Irrigation \\
\hline Grids Containing 40 to $60 \%$ irrigated areas & Medium Scale Irrigated Areas \\
\hline Grids Containing 70 to $100 \%$ irrigated areas & $\begin{array}{c}\text { Largely Managed Irrigated Areas } \\
\text { (Large Public Schemes or Farmer Managed) }\end{array}$ \\
\hline
\end{tabular}

Table 14. Categories of Irrigated Areas for Spatial Dispersion Analysis

Actual distribution of irrigated areas sum is $0.01-30 \%, 30.1-60 \%$ and 60.1 to $100 \%$, but it has been in general numbers have been used for the sake of easier understanding. This analysis has been discussed country wise according to following graphs. 

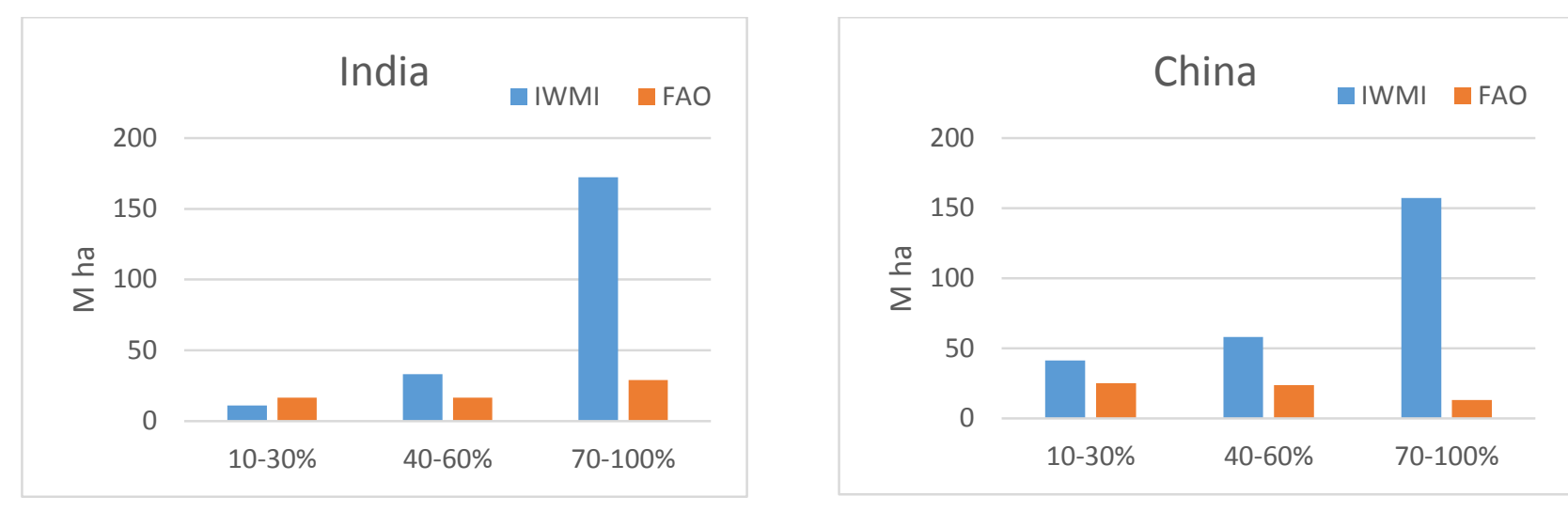

Figure 56. Spatial Dispersion of Irrigated Areas (India and China) Source: Analysis based on IWMI, FAO data

If IWMI maps are assumed to be more reliable in comparison with FAO-GMIA maps, which are based on statistics collected via national reporting systems and have been used as reference, a significant difference can be noted for 3 categories of irrigated areas.

In case of India small irrigation schemes (10 M ha) which are scattered on an area of $99.8 \mathrm{M}$ ha were $46 \%$ smaller than the area calculated from GMIA (16.4 M ha) for the same category. While medium scale irrigated areas which are consisted of 40 to $60 \%$ of total grid area were calculated as $33.15 \mathrm{M}$ ha and it is $67 \%$ higher than GMIA estimates. The largest difference which was observed in comparative graph (figure 56) was in large irrigation schemes which were found to be extended on an area of $201.52 \mathrm{M}$ ha with an estimated value of $172.2 \mathrm{M}$ ha, which is $142 \%$ higher than GMIA's reported values, based on national data archives.

On other hand, we have almost same situation in China, where large irrigation schemes were estimated to be $157.16 \mathrm{M}$ ha using IWMI maps which are $169 \%$ more than the information available in GMIA's data sets. While medium scale and small scale irrigation schemes are $84 \%$ and 48\% larger than total irrigated area estimates retrieved from GMIA's map respectively. It is worth mentioning here that small scale irrigation which has been estimated as almost 41.25 $\mathrm{M}$ ha from IWMI maps has been dispersed on an area of 491.96 M ha while IWMI's pixel size consist of an area almost equal to 6.25 ha.

Analysing this variation in the context of large irrigation schemes, there might be two possible reasons which could cause this uncertainty in these datasets. Either it is the under reporting of large public irrigation schemes or these are the irrigated areas which are being managed largely by farmers and does not come under any reporting system. Moreover, another possibility could be those irrigated areas which are in the vicinity of public irrigation schemes but they are not registered with those water user association which formally report the cultivated area under irrigation. 

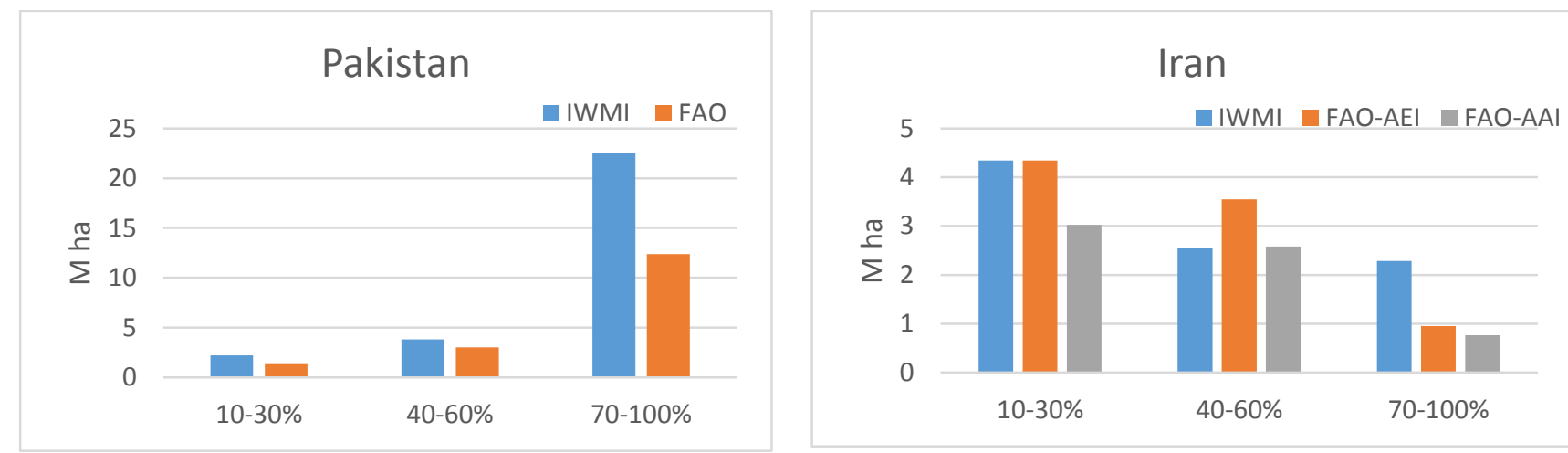

Figure 57. Spatial Dispersion of Irrigated Areas (Pakistan and Iran) Source: Analysis based on IWMI, FAO data

In case of Pakistan, small variations can be seen in the comparison of medium irrigation schemes $(22.8 \%)$ while for small scale irrigation and large irrigation schemes the difference between IWMI and FAO maps has been calculated as 50\% and 58.2\% respectively. Though small scale irrigation just consists of $2.23 \mathrm{M}$ ha spread on $38 \mathrm{M}$ ha (IWMI map figures) while the large scale irrigation has been estimated as $22.52 \mathrm{M}$ ha out of which $10.15 \mathrm{M}$ ha has not been recorded by national statistical systems which could be either tube-well irrigated land or land under irrigation using ponds or tanks.

This comparative analysis has revealed a very interesting aspect of irrigated areas reporting from Iran, as it can be seen in the graph above (figure 57) that difference of IWMI and FAO maps is almost negligible while the grey bar shows the area actually irrigated (AAI). It is important to mention here that as data collected for irrigation might differ in time/year, so comparing AEI provides the analysis more flexibility to look in a bigger context. Small scale irrigation schemes in Iran have been summed as $4.34 \mathrm{M}$ ha which are dispersed on an area of 102.1 M ha (irrigation scheme represents less than 5\% of 102.1 M ha).

Continuing with medium scale irrigation schemes in Iran, the difference between FAO map and IWMI map is just $1.4 \%$ when compared with AAI. While for the large scale irrigation schemes which have been summed as $2.28 \mathrm{M}$ ha from IWMI map, the difference is $82 \%$ and $99 \%$ as compared with FAO map for AEI and AAI respectively.

The huge difference in large irrigated schemes is quite astonishing for the complete area reporting, though they are half in size if compared with small scale irrigation schemes. This could raise doubts on under reporting of large water users associations or huge farmer managed irrigation systems which are not covered in enumeration process. But it would be also interesting to look further for the data collection methods in Iran especially for small scale schemes which is the only case in this comparison where the least variation has been noted. 

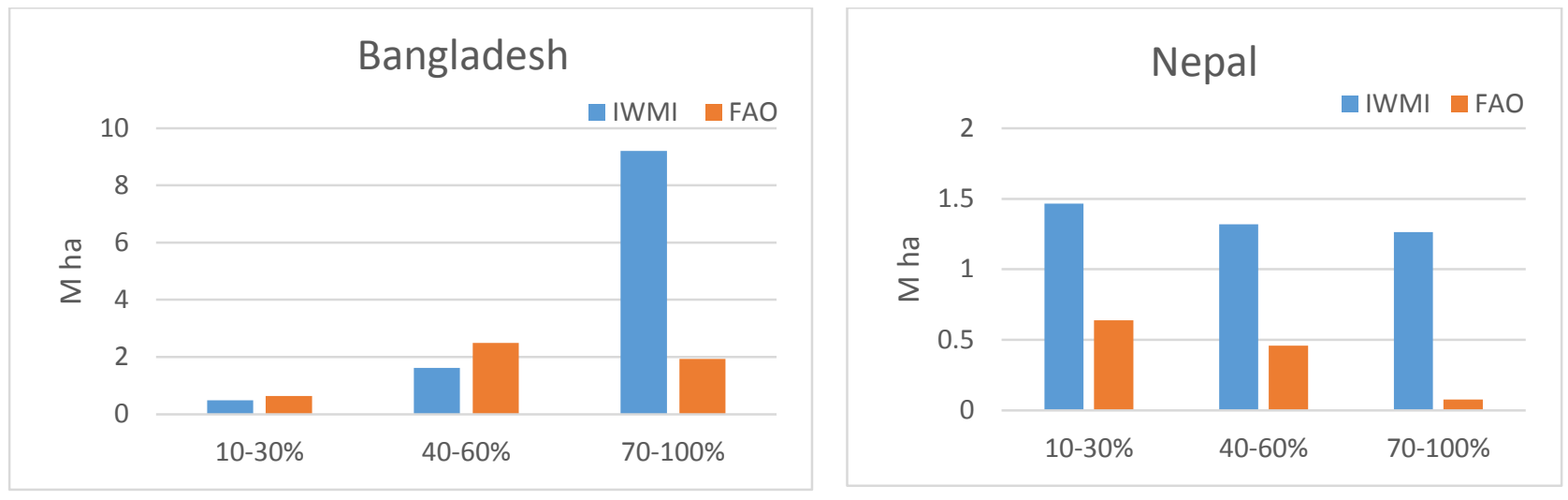

Figure 58.Spatial Dispersion of Irrigated Areas (Bangladesh, Nepal) Source: Analysis based on IWMI, FAO data

Spatial dispersion analysis for Bangladesh has shown over reporting for small and medium scale irrigation schemes, where the percentage difference between FOA and IWMI map is 26\% and $42 \%$ respectively. Though average farm size in Bangladesh is relatively small ( 0.5 ha IFAD, 2011) but due to clusters of small farms it can be misinterpreted in spatial dispersion analysis, which is needed to be investigated further, while the difference due to under reporting of large/cluster irrigated agriculture with the reported ones has been calculated as $130 \%$

Nepal gives quite different results in this analysis, as country has been divided in plain lands, hills and mountains where farm size and type of irrigation is also different (explained in trends). Almost $90 \%$ of the country's irrigated agriculture consists of farmer managed irrigation systems which are mostly based in hills and mountains. Small scale irrigation schemes have been summed as $1.46 \mathrm{M}$ ha which is spread on $13.08 \mathrm{M}$ ha land, while the difference between IWMI and $\mathrm{FAO}$ records is $78.87 \%$. Medium scale irrigation schemes are $94.84 \%$ large in sum of areas (1.31 M ha) in comparison with $0.46 \mathrm{M}$ ha (FAO numbers). While large scale irrigation schemes or may be the big clusters of small size farms has been estimated in sum as $1.26 \mathrm{M}$ ha which is $177.64 \%$ higher than FAO-GMIA map. These discrepancies could be mostly due to noninclusion of farmer managed irrigation schemes in irrigation statistics which don't seek any assistance for rehabilitation or modernization from irrigation department.
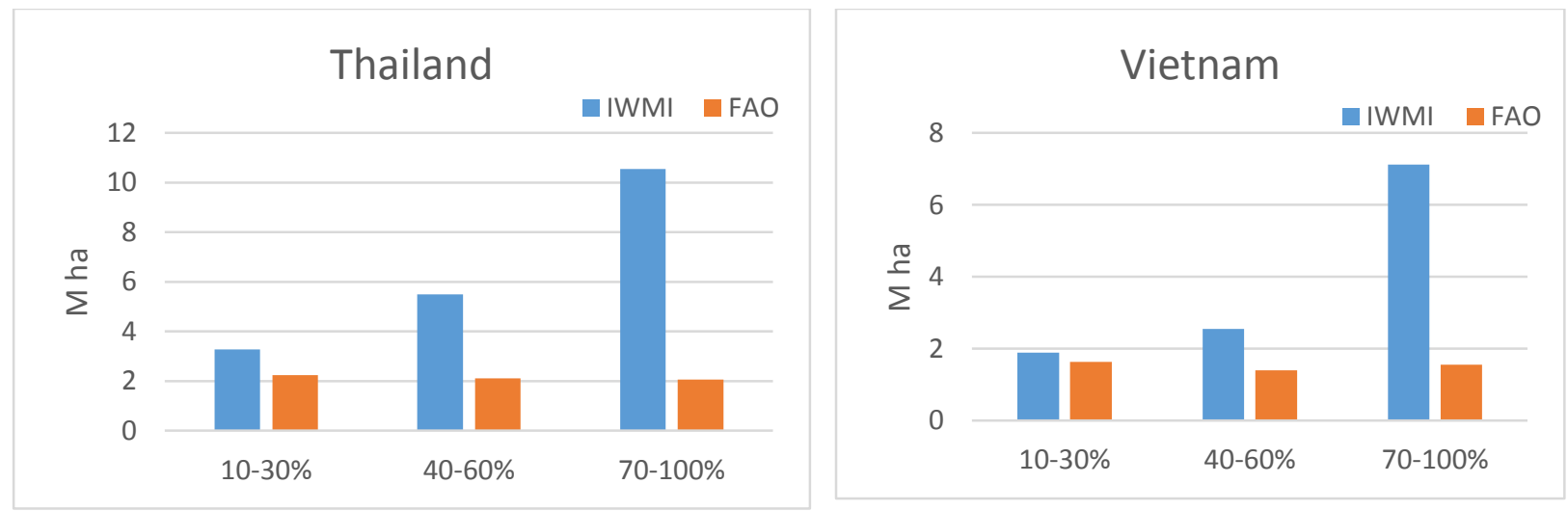

Figure 59. Spatial Dispersion of Irrigated Areas (Thailand, Vietnam) Source: Analysis based on IWMI, FAO data

In case of Thailand and Vietnam, dispersed small scale irrigation has been estimated with a sum of $3.27 \mathrm{M}$ ha and $1.89 \mathrm{M}$ ha, which is spread in total area of $35.7 \mathrm{M}$ ha and $25.7 \mathrm{M}$ ha 
respectively. The percentage difference of IWMI maps based on remote sensing with FAO records is $37.14 \%$ and $15 \%$ respectively which is relatively low.

On the other hand, difference for medium and large scale irrigation schemes for Thailand and Vietnam is $89.14 \%, 134.63 \%$ and $58.17 \%, 128.3 \%$. This shows the same trend of high variation in large cluster of irrigated areas which could be linked with largely irrigated farms being managed by farmers using private sources of irrigation which are not recorded by irrigation or agricultural officials. Or it might be large areas being irrigated outside the command area of large public irrigations schemes which are not brought under log book records of water user or farmer's associations.
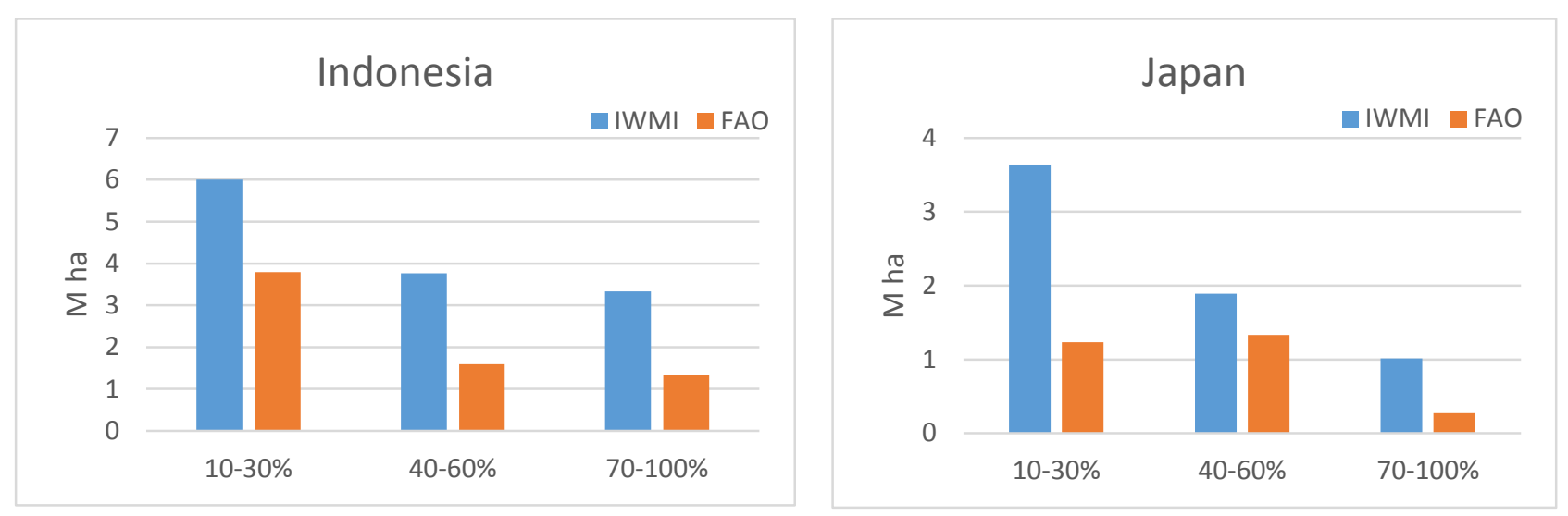

Figure 60. Spatial Dispersion of Irrigated Areas (Indonesia, Japan) Source: Analysis based on IWMI, FAO data

Indonesia lies in humid regions where small scale farming has a bigger share in irrigation sector and it is more spatially dispersed. IMWI maps calculate $6 \mathrm{M}$ ha of small scale irrigation schemes which are dispersed on a total area of $152 \mathrm{M}$ ha (almost $4 \%$ of total land). The percentage difference with FAO map has been calculated as $45.1 \%$ while medium scale and large scale irrigation schemes or large clusters of small irrigated areas have been estimated $81 \%$ and $85.8 \%$ higher than national data archives based FAO maps.

In case of Japan, There is a huge uncertainty in small scale widely dispersed irrigated areas estimated as $3.64 \mathrm{M}$ ha which are calculated from a net area of $56.3 \mathrm{M}$ ha (6.8\%). On other hand, $1 \mathrm{M}$ ha of area has been estimated as large irrigation schemes or big clusters of small farms which are $115 \%$ more than FAO records $(0.27 \mathrm{M}$ ha). While medium irrigation schemes are $34.8 \%$ larger than the sum of FAO estimations.

This huge variation in datasets is quite interesting, as Japan has shown a constant decline in recorded irrigated areas of almost $1 \mathrm{M}$ ha in past 40 years. Discussing in the context of small scale dispersed irrigation, it could be linked with the existence of farmer managed irrigation which might be missed during enumeration process. While the possible reason behind the variation in large and medium scale irrigation schemes might be the commercialization of farming sector as the regional statistical authorities might be collecting data from conventional farmers. 


\section{CHAPTER 6}

\section{Active Methods for Irrigated Areas Reporting}

In this chapter all the active methods in Asian countries for the reporting of irrigated areas will be studied, which are working behind those datasets which have been discussed and analysed previously in chapter 4 and 5 regarding the discrepancies in different sets of information. These methods has been studied for their methodology, reliability and also the possible errors which could occur while compiling the data.

As the analysis is more subjective so methodologies have been discussed qualitatively. A quantitative approach has also been introduced afterwards in the form of scoring system for the relevant reporting system in different countries. This analysis will provide a holistic understanding about the strength and weaknesses of different reporting mechanism and it will also help to establish a baseline for future research to analyse the reliability of these reporting methods existing on the grounds.

\subsection{Overview of National Reporting Mechanisms and Existing Methods}

The reporting mechanism and existing methods of data collection have been discussed and critically analysed here for irrigated areas in Asia.

\subsubsection{Reporting Mechanism in China}

China's irrigated area datasets were collected for the comparison from following sources;

1. Department of Irrigation, Ministry of Water Resources

2. National Bureau of Statistics

3. Agricultural Census

4. National Land Survey

Ministry of Water Resources shares the data of irrigated land as "Effective Irrigated Area" (EIA), which is considered to be the irrigated area regularly cultivated of annual crops or the area equipped for irrigation. This information is generally gathered from the production units (which is the common unit to record the agricultural water consumption in China) or from the village irrigation administration groups which are responsible for irrigation water management. Several agencies are involved in this data reporting including project management bodies and county water control authority who coordinate at township level with water management stations. This data is collected on yearly basis, but sometimes the frequency may also change depending on the irrigation season, intensity of irrigation or the request of data from the regional offices. In some cases irrigation officials also visit the farms to actually measure the extent of 
land which is equipped for irrigation but it is mostly done by observation and estimates (Nickum, 1995) (Personal Communication, 2015). On other hand, as the irrigation fee is linked with irrigated area or volume of water used (differ region wise); production units might under report the irrigated area in order to find some reduction in fees or in inverse case the irrigation officials could over report the irrigated area to show their progress and in absence of any recheck or validation system it could induce discrepancy in data. While the parallel dataset available with SSB (state statistical bureau) which is collected and maintained by SSB and agriculture ministry, was found $2 \%$ less than the national figure of irrigated in 2000 (has not been considered for growth -track analysis) and it is collected by a self-reporting mechanism of the basic production units. (Nickum, 2003)

Another source available for irrigated areas data is agricultural census which is generally conducted after every 10 years to compile all the information of agricultural statistical indicators. It is a large and national scale activity and it is mostly performed under the guidelines of FAO by statistical agency and agricultural department. Agricultural census methodology for year 2007 was reviewed to understand its reporting mechanism. In this census complete enumeration process was adopted and each rural household was included in the data collection process. Mode of data collection was face to face interview and minimum recordable land ${ }^{12}$ standard, which was recorded during census was $0.1 \mathrm{mu}\left(66 \mathrm{~m}^{2}\right)$. Post Enumeration Survey coverage was 5\% (agricultural land household wise) as conducted for more than 20,000 households. The underreporting percentage for the registered households was $0.2 \%$ with an error percentage of 0.14 for the initial data collection phase (APCAS-FAO, 2008). On other hand, as the data for irrigated area was collected along with other agricultural statistical indicators with a same practice, so the priority assigned to irrigated areas information, is assumed to be secondary.

National Land Survey in China, has furnished land-use maps which includes irrigated areas in China. These maps were published in 1996 and they are generated by airborne remote sensing data, based on aerial photography and large scale topographic maps. These land use maps were also calibrated by field investigations to calculate the major land types and it mainly focused on agricultural land and it also provided the basis to change the policy of agricultural land contracting and taxes. Moreover, this land-use map also provide a different category for the slope of land which is higher than 25 degrees (NBS, 2001). This dataset could be considered more reliable but the methodology for the field investigation has not been described clearly. For the statistical analysis these numbers of irrigated areas (51.7 million ha) have been increased by $8.8 \%$ to normalize the data with the annual increase in irrigated areas as timeline provided by MoWR.

On other hand, FAO states about land-use atlas in GMIA's country information portal, which was published in 1990 also based on topographic maps $(1: 1,000,000)$ and large-scale aerial photographs. The figure of irrigated areas has been stated as 68 million ha which is $27 \%$ higher than previously stated value, but some doubts have been pointed out in the data because of difference in definition of irrigated areas. This figure was not included in the analysis as the source defined (land use map of China 1990) was not accessible on internet.

\footnotetext{
${ }^{12}$ Minimum landholding which is considered to be valid to include as a household in census.
} 


\subsubsection{Reporting Mechanism in India}

Irrigated area datasets were collected for the comparison from following sources;

1. Directorate of Economics And Statistics (DES), Ministry Of Agriculture

2. Irrigation Census (Ministry of Water Resources)

3. Agricultural Census

A detailed time line for the data of irrigated areas is available with Directorate of Economics and Statistics (DES) which comes under ministry of agriculture. This dataset is detailed as it has different categories of irrigated areas i.e. crop wise, source wise, state wise, district wise; which makes it more useful for multipurpose analyses.

To discuss the methodology of this dataset, it can be divided into three types including complete enumeration, sample surveys and estimates (MOSPI: DES, 2012) ${ }^{13}$. Complete enumeration is conducted in those states who have an integrated link of land use statistics system with land records and revenue department (includes $86 \%$ of reporting area, 17 major states excluding hilly districts). These states are referred as Land Record States. A village accountant (patwari) is responsible to collect agricultural information including land use, crop statistics and irrigation data from every village and then pass it on to district revenue system. This data is either collected by visiting the farms or by information which is provided by the farming community. In these states, a timely reporting system (TRS) has been introduced which is designed for prompt reporting of land use records due to lack of timely reporting. Under TRS, village accountant is responsible to submit the crop statements within a defined timeline by conducting random sampling from $20 \%$ of village area.

Sample surveys are conducted in those states where a proper land record system or village revenue agency does not exist. This system is called (EARAS) Establishment of an Agency for Reporting of Agricultural Statistics. These states represents 9\% of the reporting area covered by DES. Staff is specially appointed to conduct sample survey in $20 \%$ of villages or investigation zones and then estimates are made based on statistical techniques. The sampling is done in this order that within 5 years term whole states would get covered for enumeration.

Remaining 5\% of reporting area (mostly mountainous areas) does not have any proper reporting system. Agricultural statistics are compiled by using traditional crop estimates methods and village guards collect the data by their subjective assessment. While $9 \%$ of the total country areas is not covered by any reporting system mostly hilly areas in north eastern regions.

Looking at the strengths and weaknesses of the system, though those states covered by village revenue and land record system, are expected to have more accurate information of irrigated area but several loop holes have been identified in this system e.g. uncomplete record submission, late response and sometimes no response at all. In some cases, entries in village record register does not tally with the registers maintained by their supervisors. Moreover, discussing about the post enumeration supervision of the data; it is conducted by an independent agency comprising of supervisor who look for the discrepancies in village accountant's reports

\footnotetext{
${ }^{13}$ Ministry of Statistics and Program Implementation, Agricultural Statistics. , Department of Economic and Statistics, Ministry of Agriculture and Farmer Welfare.
} 
by doing sub-sampling in TRS sample villages and states under EARAS are also covered by supervisors to perform checks on the validity of data.

On the other hand, the role of irrigation department is also not clear if there is any liaison between revenue and irrigation officials to validate the irrigated areas data. As Irrigation department also hires an irrigation booking clerk (IBC) who is responsible for booking irrigation demand from the farmers and then compile the record of irrigated land for the water fee/land revenue which is linked with irrigation (Irrigation and Public Health Department, 2015)

Another source of information for irrigated areas is Minor Irrigation Census, which is conducted once in 5 years under the central government scheme "Rationalization of Minor Irrigation Statistics". Previously it has been conducted in 1986-87, 1993-94, 2000-01 and recently in 2006-07 (Minor Irrigation Census, 2014). The purpose of this census is to collect the information of minor irrigation schemes including tube wells, tanks, lift schemes, ponds etc along with the data of large and medium scale irrigation schemes as well which is translated generically as irrigation potential created and utilized in order to measure the physical progress of the public schemes and proportion of farmer managed schemes in irrigation sector. Enumerators, block and district levels officers are trained for the task at district and state level. Complete enumeration method is adopted for the data collection while there are two schedules are used for gathering information (Appendix B). Village schedule is assigned to village accountant who is responsible to provide information from the land record registers about the area which is irrigated via public irrigation schemes while the MI schedule is also assigned mostly to village accountant which is completed by door to door interview of minor irrigation schemes owner and physical verification of the irrigated land is also conducted.

Verification and checks for the collected data is also done in different administrative layers i.e. at village block level where at least 5 villages in one block are visited to verify at least $10 \%$ data forms. This information is further re-verified at district level office where at least $1 \%$ of total data forms are selected on random basis and information is physically verified. Though any error ratio or coefficient of variation has not been mentioned in the $4^{\text {th }}$ minor irrigation census report. But depending on the same village revenue system and village accountants for the large and medium irrigation schemes information and the door to door enumeration could cause reasonable discrepancy in the data, which has already been discussed previously.

Agricultural census is also a source of information regarding irrigated areas along with other important agricultural statistical indicators, e.g. crop types, acreage, and land holding, social and ethnic groups etc. Which is conducted after every 10 years country wise by agriculture department. This census is also based on multi-enumeration type depending upon availability of the state land record systems. It is usually planned in 3 phases, in first phase data is collected from the village revenue department record books and the states with no land record system are surveys on the basis of $20 \%$ sample size. In this phase primary agricultural statistics are collected, e.g. data based on size class, social groups, gender, holding type etc. In second phase, data from $20 \%$ sample villages is retrieved for irrigation, tenancy details, cropping type and pattern, distribution of land holding etc. In $3^{\text {rd }}$ phase, input survey is conducted to get input data of fertilizers, irrigation and seeds etc. 
Though a big difference cannot be seen in the data collection methods, as agricultural census is also linked with village revenue and land record system and the source is almost same as the data base of DES, which already has its limitations and the data might be collected by same authorities. Instead of managing an exclusive agricultural enumeration process to be conducted by statistical or any other independent agency same level of discrepancy might be expected in this dataset as well. Moreover, no post enumeration checks, error or variation expectancy ratio in data base has been shared in report.

\subsubsection{Reporting Mechanism in Pakistan}

Following data sources for irrigated areas were available from Pakistan;

\section{Crop Reporting Services (Provincial Agriculture Departments)}

2. Agricultural Census

A detailed timeline of irrigated areas from 1947 was available within the records of statistical department which are furnished by crop reporting service (provincial agriculture department). This data consists of several categories i.e. canal, tube well, canal and tube well (conjunctive), miscellaneous (pond, tanks) etc.

In three provinces (Punjab and Sindh) having the largest extent of irrigated areas, information for irrigated areas is collected at preliminary level by crop reporting service directorate of agriculture department based on sample surveys (Pakistan Bureau of Statistics, 2015). Final information is collected from village registers, maintained by village accountant/clerks, which are finally maintained at district revenue office.

For the province of KPK (Khyber Pakhtunkhwa) the preliminary statistics are based on sample surveys and some parts of the districts are covered with subjective estimates, however final data is retrieved from revenue department records. While in province of Balochistan (area was largest province), information regarding irrigated area is collected by extension staff of agriculture department which is mostly based on their local information of the area.

Having a critical look on the methods to collect the data, it is noticed that irrigated areas reporting in the case of Pakistan is also depending on revenue department and village accountant records which have their own limitations. Irrigation and revenue departments work in collaboration to collect the water fees which are based on irrigated areas (IWMI, 2001). Records of land irrigated are compiled by irrigation department field officials i.e. irrigation booking clerks who physically visit the cultivated land following a complete enumeration strategy for 1200 to 2000 hectares of cropping areas to prepare a record of irrigated crops in their territory, on the basis of area (till crop maturity) and the records are then passed on to revenue department after a final check from canal office, for the collection of water fee. (IIMI, 1998)

On other hand, the sample surveys conducted by the crop reporting services cover maximum $5 \%$ of total areas under irrigated and non-irrigated crops which might not provide a reliable information for irrigated areas (Crop Reporting Services, 2012). The acceptable coefficient of variation for the agricultural statistics in Pakistan is considered $+/-2.5 \%$ according to crop reporting services directorate. But this variation could be more higher in province like 
Balochistan due to its vast area, where information is based on guesstimates and the irrigation might dispersed in small schemes due to lack of water availability and high aridity of the region. Higher variation could also be expected from the northern and western mountainous area e.g. Gilgit Baltistan, Federally administrated tribal areas, where irrigated plot size is quite small from other regions in Pakistan and reporting system is expected to be less streamlined as well.

The other data source for irrigated areas information in Pakistan is agricultural census in which important agricultural statistics are collected by using sample enumeration techniques. This exercise is conducted once in 10 years and the information is disseminated by farm size, percentage of cultivated area in land equipped for irrigation, mode of irrigation, crop season, perennial and non-perennial canal. The census of 2010 was conducted under the supervision of provincial revenue departments and village accountants were assigned the task of primary enumerators, while in federally administrated tribal areas it was supervised by political agents.

The enumeration process was conducted in 3 stages in order to manage the maximum representation while sorting out the enumeration blocks and over all sampling percentage from whole country was $32 \%$. Complete enumeration technique was adopted in the samples by using door-to-door interviews strategy. Though in the methodology document any post enumeration verification process has not been mentioned but coefficient of error and sampling error were calculated using statistical technique, which are not published on the statistical department website. (Agricultural Census, 2010)

Moreover, the census was performed to get all significant statistics of agricultural sector and no special importance has been given to irrigated areas information. On other hand, using statistical methods to extrapolate the data collected via sampling might be suitable for other information, e.e. production. But it might not be reliable for the irrigated areas information, though the information of irrigation for household has been further translate into different categories. A sample table from the results of census has been shown on next page. (Table 15) 


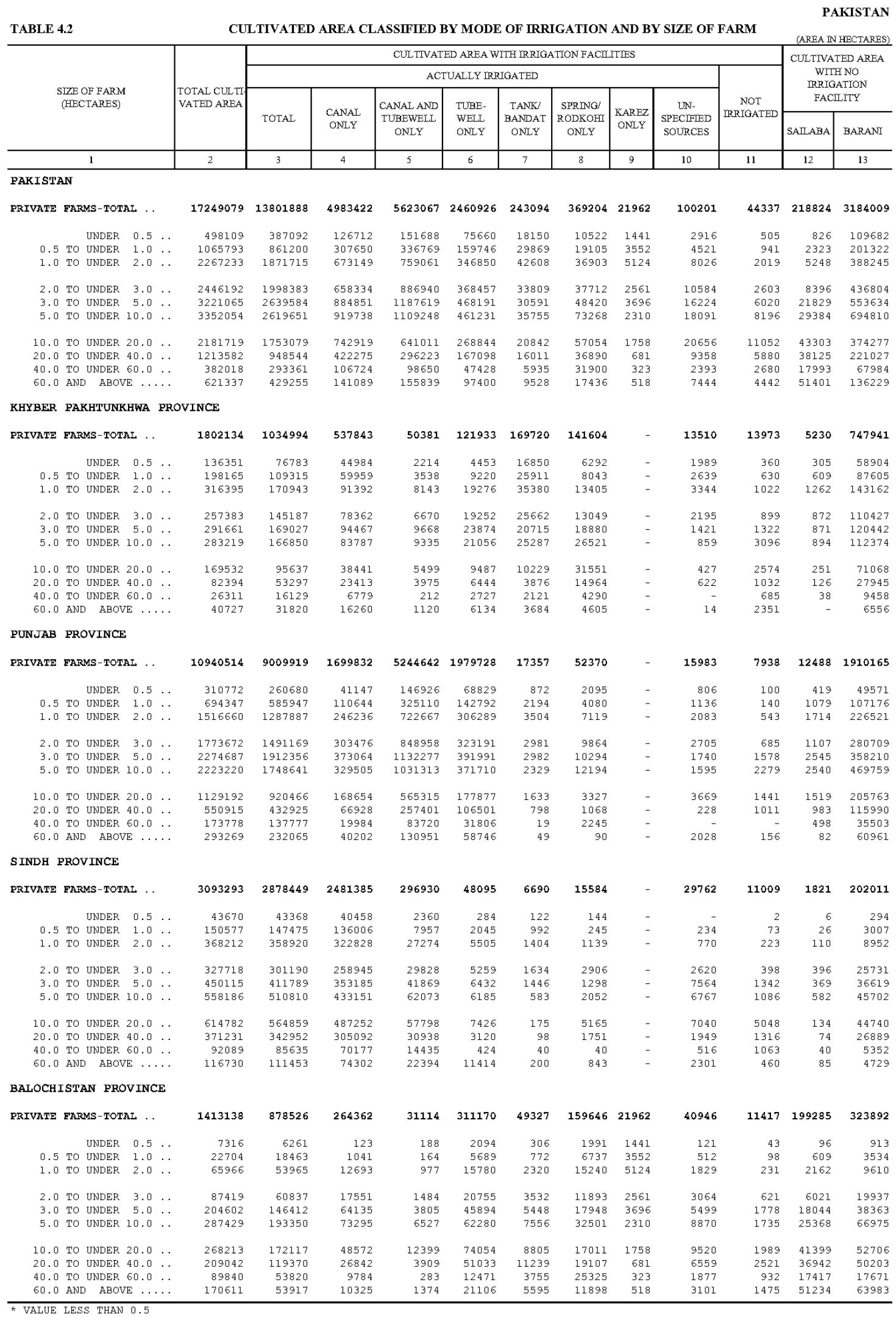

Table 15. Source wise Irrigated Area Pakistan (Source: Agriculture Census 2010) 


\subsubsection{Reporting Mechanism in Iran}

Following data sources for irrigated areas were available from Iran:

1. Ministry of Agriculture

2. Agriculture Census

Irrigation sector is managed by Ministry of Energy in Iran, but the dataset available on ministry's web portal was about area of main and subsidiary irrigation and drainage network which could be considered as area equipped for irrigation (Ministry of Energy, 2015). On other hand, ministry of agriculture publish the irrigated areas information in its statistical handbook which was found good in details mentioning all provinces.

Detailed methodology for the reporting mechanism was not accessible as most of the published information is in Persian language. But the information gathered by agriculture ministry is mostly based on annual surveys and estimates. Crop area data is segregated in two categories i.e. irrigated and non-irrigated. Each year sampling surveys are done to collect agricultural statistics after crop harvesting in fall. Generally, 4 data collection projects are executed per year for different crops (Ministry of Agriculture, 2015). Reporting system is also involved in data compilation which includes local statistics information and estimates based on experience.

Information collected via questionnaires revealed that farmers usually report the irrigated areas to government officials for the purpose of fertilizer subsidies and crop insurance (Personal Communication, 2015)

The second source for irrigated areas information in Iran is agriculture census which is performed by national statistical agency (statistical centre of Iran). Information about 2003 agriculture census was accessible at FAO's portal which has a figure of $7 \mathrm{M}$ ha of irrigated land under temporary crops (wheat, maize, barley, rice, cotton etc). But the information for irrigation in permanent crops (orchards) has not been provided.

Brief methodology for the census has been shared in explanatory notes, which is based on complete enumeration. In the contrary to agriculture census conducted in India and Pakistan, it was performed by statistical agency and 9,564 enumerators and 5,354 supervisors were hired to do the job (Statistics Centre of Iran, 2003). Reference period for land use statistics was day of data collection and minimum land holding to be included in the census was $400 \mathrm{~m}^{2}$ of land under temporary crops. Head of household was interviewed to collect the detailed information by filling up the holding form.

Any physical verification of the data collected during census has not been mentioned and also no information has been provided for any post-enumeration check or coefficient of variation. The census figure of irrigated areas is $1.5 \mathrm{M}$ ha less than the figure collected from agriculture ministry database, which might be less due to non-inclusion of orchards. As they have an irrigated area of about 1.7 million hectares according to (Shiati, K. 1999), while census figure for orchards is $1.46 \mathrm{M}$ ha.

While looking at the methods of survey and estimates used by agriculture ministry, they might work for bulk calculations of crop areas and production but some level of discrepancy from real 
figures could also be expected, especially for irrigated areas. Moreover, information regarding informal irrigation is also not available which if not added, might increase the figure of area actually irrigated to some extent.

\subsubsection{Reporting Mechanism in Thailand}

Following data sources for irrigated areas were available from Thailand:

\section{ASEAN Food security portal /Office of Agricultural Economics (Ministry of Agriculture and Cooperatives) \\ 2. Royal Irrigation Department (Ministry of Agriculture and Cooperatives) \\ 3. National Statistical Office}

Irrigation sector in Thailand works under the management of Ministry of Agriculture and Cooperatives. Office of agricultural economics (OAE) is responsible to collect agricultural data including irrigated area statistics. Though a clear methodology has not been explained for the data collection and reporting mechanism but mostly it is based on annual surveys ${ }^{14}$ (APCAS, 2008). Data regarding irrigated areas was not found on the web portal of OAE, but it was available on the website of ASEAN food security portal which works in coordination with OAE.

Agricultural statistics reporting system of OAE are not considered reliable for the accuracy and consistency of the information, as data is collected via surveys and interviewing the framers (JICA, 2015). Furthermore, the dissemination process is also slow and the gap between data collection and publishing is more than one year. Mostly irrigation data is collected during crop production surveys which puts the importance of the data at secondary level.

The other data source for irrigated areas is royal irrigation department (RID) which disseminate the data for irrigated and potential area for irrigation river basin and region wise. A clear methodology in English for the data collection was not available on the website of RID (mostly information available is in Thai language). But it is assumed that the information about irrigated areas might come from farming community, e.g. water user association. On other hand, the under reporting factor in irrigated areas reporting from farmers in order to avoid irrigation water fee should also not be ignored as Thailand has taken initiatives to implement water charges on irrigation sector which was considered free of taxes previously (Molle, 2001). Moreover, the role of department of ground water resources working under ministry of natural resources and environment is also not clear in data collection for irrigated agriculture as $17 \%$ irrigation water comes from ground water pumping.

For collecting the information of irrigated areas along with other agricultural data, National Statistical Office (GSO) also has the responsibility to compile the agricultural data by conducting agricultural census and agricultural surveys. Surprisingly, no information was available regarding irrigated areas in recent agricultural census publications for 2013. The only available statistics from GSO for land under irrigation was in tables of 1998 intercensal survey of agriculture. Which is conducted after 5 years from agricultural census in order to collect information at 5 years interval instead of only after every 10 years by agricultural census.

\footnotetext{
${ }^{14}$ Asia and Pacific Commission on Agricultural Statistics (APCAS), Thailand country Report.
} 
Recent intercensal survey was conducted in 2008 but no information regarding irrigated land has been disseminated in tables.

Intercensal survey is conducted by sample enumeration and land holder are interviewed to collect the information of land use, irrigation, crops, ownership, fertilizers, pesticides and agricultural machinery etc. The survey conducted in 2008 covered 45,000 holdings out of 7.65 million holdings which shows $1 \%$ representation from whole country.

The information is disseminated crop wise including rice, field crops, vegetables, orchards and rubber trees. Though $1 \%$ sample ratio is quite small for the data of irrigated land, besides no information is available regarding the physical verification of land covered under the survey. This makes the data less reliable and the level of importance for irrigation data can also not be considered as primary.

\subsubsection{Reporting Mechanism in Bangladesh}

Following data sources for irrigated areas were available from Bangladesh:

1. Bangladesh Bureau of Statistics (Agriculture Wing)

2. Bangladesh Water Development Board

3. Bangladesh Bureau of Statistics (Agriculture Census)

4. Bangladesh Agriculture Development Cooperation (Minor Irrigation Survey/Census)

Agriculture wing of national statistical agency is responsible to collect the data of irrigated areas along with other agricultural inputs. Statistical agency maintain their office at regional and subdistrict level where agriculture wing officials collect the data from field and send it to regional authorities which is then passed on to central office after scrutinizing. Information regarding irrigated areas is published in statistical year book annually and it is disseminated in different category i.e. region wise, district wise, different means of irrigation and crop wise.

To collect this data, two different methodologies are used by agriculture wing, subjective methods and objective methods (Bangladesh Bureau of Statistics, 2015). In subjective method one mouza (smallest administrative unit) of every union council (sub-district or town) is selected and then after categorizing the household in large, medium and small, 5 to 10 farmers are interviewed which are selected on random basis. This method has $8 \%$ sample representation.

In Objective method, 9348 sample group of plots are selected from country and one group of plots (cluster) could also be one mouza. These sample plots are visited by field staff four times in a year and information (data forms) are passed on to regional offices. These estimates of crop/irrigated area are then extrapolated using ratio method for the whole district. This method could have a sample representation of $16 \%$.

Another source of information for irrigated areas is Bangladesh water development board (BWDB), who are responsible to manage surface irrigation system in country i.e. canal irrigation. It comprises $10 \%$ of national irrigated areas as irrigation sector in Bangladesh depends $90 \%$ on ground water. Though a clear methodology was not available on the web portal of water development board but during in person interviews with BWDB official, it was told that they are mainly responsible for the construction and maintenance of canals, gates and pump stations, 
while information of irrigated area is generally linked with water fees which is area based. For this purpose BWDB depends upon water user association who reports the extent of land which is irrigated by the water provided by water board.

Agriculture census is also a source of information for irrigated areas which is conducted by statistical agency once in 10 year. Latest census results were available from 2008 and previously it has been conducted in 1984 and 1996 (Agricultural Census, 2008). Complete and sample enumeration strategy was used in order to collect basic and detailed agricultural data and minimum land holding to include in census was $200 \mathrm{~m}^{2}$. Census data for irrigated areas was disseminated in several categories, i.e. tenancy and farm size, different sources by farm size classification of holdings, different sources classified by ownership type of holdings. 140,969 young enumerators were hired and trained for the job and staff of statistics agency supervised the process. 15,183,183 farm households were interviewed by enumerators and postenumeration check was also done to ensure the quality and reliability of data. (Questionnaire for data collection and Tally sheet for PEC have been shown in Appendix C.

Though complete and sample enumeration was conducted but method used for field verification and for post-enumeration check (PEC) has not been clearly defined. Coefficient of variation and possible error ratio has not been described in report, might be published in separate PEC report which was not accessible.

Another source for irrigated areas dataset is minor irrigation survey which is conducted by Minor irrigation wing of Bangladesh Agriculture Development Cooperation (BADC). Irrigated agriculture highly depends on ground water sources in Bangladesh, so BADC conducts annual survey to gather information regarding use of tube wells (deep, shallow, low lift) and the area which is irrigated by them. A detailed methodology for the survey was not accessible as the report is not freely available on internet, but it has been assumed that these surveys might be based on sample enumeration as the data has been collected country wise just not for irrigated area but data of farmers benefited, numbers of pumps, power sources, type of pumping unit, other sources of irrigation i.e. gravity flow (canals), traditional (swing bucket) and artesian well is also collected. Moreover, the largest time series available for trend analysis was also available with results of minor irrigation survey and key priority of the data collection has been exclusively for irrigated which might make this information more reliable. Following Figure 61 shows the disseminated results of minor irrigation survey (BADC, 2015).

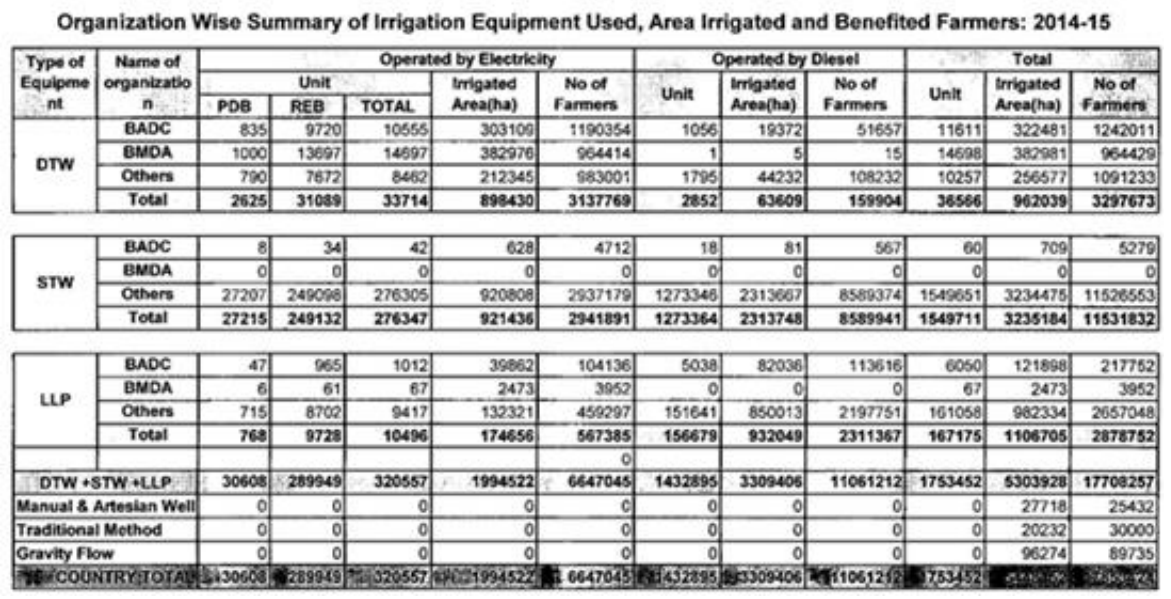

Figure 61. Results of Minor Irrigation Survey 2014-15 (Source: Bangladesh Agricultural Development Corporation) 


\subsubsection{Reporting Mechanism in Indonesia}

Following data sources for irrigated areas were available from Indonesia:

1. Ministry of Agriculture

2. National Statistical Agency

3. Ministry of Public Works

Ministry of agriculture publish the data for crop area planted and harvested annually, which includes sub category for irrigated rice. It has been learned that almost all of the formal irrigation in Indonesia has been planned for paddy rice and no exclusive information based on other crop types was available for irrigated areas in the data base.

Looking at the methodology of this database, it is generally based on administrative reports which are compiled by local government under an agreement between national statistical agency, ministry of agriculture and local government authorities (Ministry of Agriculture, 2015). Information for planted and harvested area is gathered on continuous basis on the start and end of cropping season. Moreover, legislative requirements bounds national statistics agency to help ministry of agriculture for data collection in order to achieve desired level of quality and reliability in collected information. It is worth mentioning here that unlike other countries, no information about irrigated areas was included in the published report of agriculture census, conducted in 2013.

The information gathering process is decentralized in this case and data for the extent of irrigated area in not a priority. As it is just coupled with rice crop, while the administrative reports might be based on interviewing farmers or village council reports. On other hand, no information is available for crops other than paddy which are irrigated e.g. maize and vegetables, which makes this dataset incomplete.

National statistical agency publish annual data for land area by utilization statistics which are mostly based on agricultural land use. This data is based on survey which is done in coordination with ministry of agriculture. Complete enumeration technique has been used and information is collected from wetlands ${ }^{15}$ by categorizing between irrigated and non-irrigated areas. The information for irrigated areas (for paddy) include all types of scheme i.e. technical, semi-technical, non-technical and conventional, depending on the type of facilities and management, while data has been disseminated at provincial, regency and municipal level. Data collection form SP-Lahan has been shown in Appendix D. (Lahan can be translated as Area)

Ministry of public works is responsible for operation and maintenance of public irrigation schemes in Indonesia and data for irrigated areas is also furnished by the ministry officials. A clear methodology for the data collection was not available on ministry's website so an irrigation official was interviewed using a questionnaire to get the required information.

According to the answers given in questionnaire, the data collection system for irrigated areas is de-centralized and it is gathered at district level by irrigation officials with 2 months frequency, this information is collected from water user association (WUA) which is mostly 15 Wetland is agricultural land that is separated by small dykes to resist water, where the main crop is usually
wetland paddy. 
based on their personal judgment or observations of farmers. (Personal Communication, 2015). There is no irrigation water fee for farmers in Indonesia which makes it difficult to link the discrepancy with the dilemma of under reporting by farmers. But it could also make them less efficient in submitting the actual information, as physical verification of the areas is not very common as reported by the official. (Reporting Form for Irrigated Areas Blangko 12 - $\mathrm{O}$ has been shown in Appendix E.

\subsubsection{Reporting Mechanism in Vietnam}

Following data sources for irrigated areas were available from Vietnam:

1. Ministry of Agriculture and Rural Development

2. General Statistics Office (Agriculture Census)

3. General Department of Land Administration (Land Survey)

Ministry of Agriculture and Rural Department (MARD) collects its information for important agricultural statistics via Department of Agriculture and Rural Development (DARD) who has its presence in all districts ${ }^{16}$. Mostly part time workers do the job of enumerators or statisticians. At commune level, employees of extension department, veterinary and fisheries officials collect the data as additional responsibility and they also get involved in time to time surveys (APCAS, 2012). While at village level, village heads are involved in data collection process.

Data for irrigated areas comes from survey (percentage of area planted with annual crops irrigated and drained) which is conducted annually (General Statistics Office, 2015). A clear methodology for this survey is not available online but it can be linked with other agricultural surveys conducted by MARD, e.g. agricultural crop area survey, which is based on sample enumeration with a sample representation of almost 20 to $50 \%$ depending upon crop season (ADB, 2014)

Looking critically at the methodology; the process of field verification or re-checks is not clear. Moreover, a country like Vietnam with a complex political administrative system of communes and villages, one can expect a high level of discrepancy in the data of irrigated areas. As mostly, it is collected by part-time staff or villages leaders. These enumerators might produce false data if not trained properly besides it is not their first job to do data collection.

It is worth mentioning here that MARD could only collect and analyse data for internal use as statistical legislation in the country only authorized statistical agency (General Statistics OfficeGSO) to publish data regarding agriculture statistics. Data from administrative reports is passed on to GSO on monthly basis, but the process of coordination between MARD and GSO for agricultural surveys is not clear (ADB, 2012).

Another data source for irrigated areas is agricultural census which is carried out after every ten years by Agriculture, Forestry and Fishery department of statistical agency (GSO). Latest agriculture census was arranged in 2011 but information about irrigated areas was not published in the report available at GSO's web portal. But atlas of agricultural census 2001 has the

${ }^{16}$ There are near about 600 district and towns in Vietnam. 
information for proportion of agricultural land (irrigated and drained) along with the percentage irrigated map of whole country.

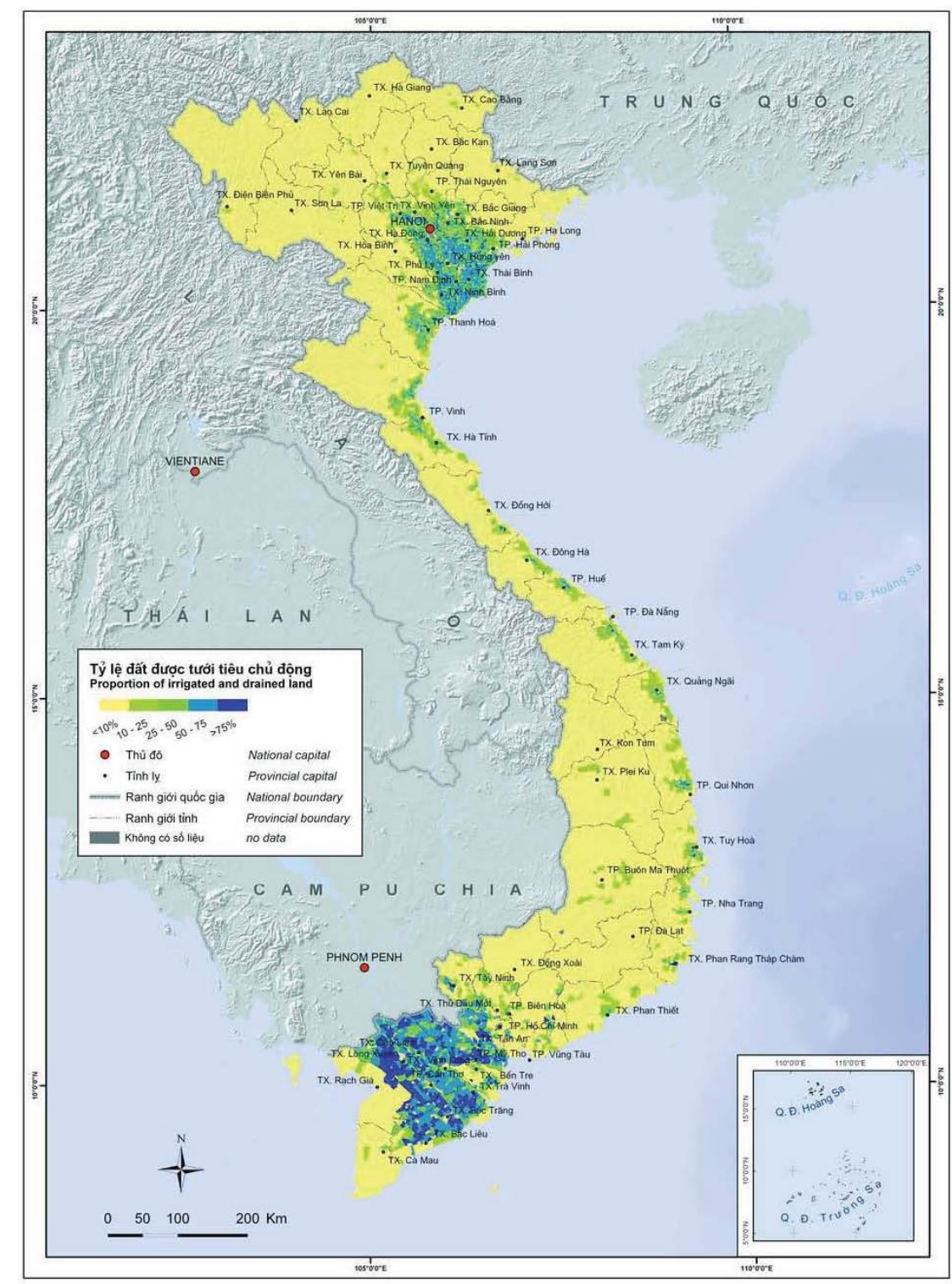

Figure 62. Proportion of Irrigated and Drained Land - Vietnam (Source: Agricultural Atlas of Viet Nam 2001)

Data collection strategy for agricultural census of 2001 was not available online so a connection can be made with agriculture census of $2011^{17}$ which was based on complete and sample enumeration to collect basic information regarding household in first step and sample surveying for collection farm information. The technique used to gather information was face to face interviews and 75,000 households were interviewed out of 15,343,852 households, which gives a sample size of $0.5 \%$. It was also followed by a post-enumeration survey which covered $0.3 \%$ households to verify the information gathered during main data collection step.

${ }^{17}$ Report on Rural, Agricultural \& Fishery Census in Vietnam, GSO Vietnam, 2001 
It can be certainly said that $0.5 \%$ representation of the country's agriculture cannot give a reliable data especially for irrigated areas. On other hand, Vietnam is mostly covered by mountains and to record the small scale irrigation by using such standards of sample representation could be really difficult. Though in atlas of 2001 census the map has been published for the proportion of irrigated areas, but unlike other countries a category wise detailed information, e.g. means of irrigation, crop wise data, land size etc, has not been collected/published. Which obviously make the practice of census less effective as irrigated areas information has not been placed within primary priority though it has been included in important statistical indicators of Vietnam by GSO.

Third source available for the irrigated areas dataset is General Department of Land Administration (GDLA), which works under Ministry of Natural Resources and Environment. This department is generally responsible for land records, land use and cadastral surveys. As a detailed methodology was not found on internet (language is also a barrier to find information), so it is assumed that information for irrigated area might base on cadastral surveys and aerial/satellite imagery.

Though this data is based on land use information which could be more reliable as GLAD is also directly linked with land use planning, tenure records and other relevant statistics including irrigated areas. But the data available is of year 2000 and only $40 \%$ cadastral mapping was done till then and it was about to be completed by 2005, which could point out some questions on the reliability of this data as well (Dang et al, 2015). Moreover, GLAD started using digital technology from year 1997, so it can be expected that any upcoming irrigated areas dataset would be more reliable as improvement might have been made to develop finer land use statistics. On the contrary, the coordination of MARD with GLAD is not clear which could be a possible cause of any discrepancy in the dataset because agriculture officials might have the first hand information of irrigated areas in comparison with land department who works under a different ministry and procedure for data collections would also be different.

\subsubsection{Reporting Mechanism in Nepal}

Following data sources for irrigated areas were available from Nepal:

1. Ministry of Agriculture and Cooperatives (MoAC)

2. Central Bureau of Statistics (Agricultural Census)

3. Ministry of Water Resources

4. Central Bureau of Statistics (Nepal Living Standards Survey)

Ministry of agriculture and cooperatives gather statistics from their agricultural extension officials, field staff (junior technicians) deputed in 576 service centres country wise and they are responsible to collect data from their assigned rural boundaries (National Planning Commission, 2007). Mostly this data is collected by interviewing farmers but enumeration technique either complete or sample, is not clear. Data disseminated for irrigated areas in statistics report issued by agri-business promotion and statistics division of MoAC has been categorized region wise for two main crops i.e. Wheat and Paddy, while data for other crops which are irrigated in the country, e.g. barely, maize, sugar cane, vegetables etc has not been provided. 
Though a having large presence of local enumerators (more than 2000) could produce relatively reliable data but looking at the priorities of the agriculture ministry's statistics system it was found that getting the data for irrigated areas is not the primary responsibility of enumerators. As primary interest of enumerators is land use statistics including crop area and type while input data including irrigation, fertilizers and agricultural machinery are of secondary importance. This could certainly influence data collectors as they might give less importance to irrigation data and in case if the land use data is collected via complete enumeration, irrigation statistics might be collected by sample survey which would decrease its quality.

Central Bureau of Statistics (CBS) is responsible to collect agricultural data from country after every 10 years by carrying out agricultural census. Previously it was conducted in 2011 and information regarding irrigated areas was also collected along with other important agricultural data. For this purpose sample enumeration technique of data collection was used which covered 124,144 households out of $3,831,903$ which shows a sample representation of $3.4 \%$ country wise (Central Bureau of Statistics, 2011).

Looking at the methodology used for sample enumeration based census, 1600 enumerators and 500 supervisors were hired which were guided by CBS staff. Interviews were conducted from household head ${ }^{18}$, but process of physical or on site verification of agricultural data is not clear. Any type of post enumeration activity has also not been described in the report besides statistical calculation to find out sampling error has been described.

It was realized that $3.4 \%$ coverage is not well enough to collect the agricultural statistics from a country like Nepal where $60 \%$ of the region is covered by mountains; the mighty Himalayas. This has also been expressed in publication in details of problems faced during census, as not sufficient human resources were available in mountainous regions. Secondly, agricultural census team also faced problem due to timings of census as it did not match with cropping season and this issue could induce a high discrepancy in the information of areas actually irrigated. As data collection was done by interviewing and it highly depends upon the record keeping and will of farmer to share exact information about irrigated land with enumerator.

Furthermore, on the dissemination side, the data of irrigated area was published in different categories i.e. source of irrigation, total area of holding and payment terms. In figure 63 the information of irrigated areas based on payment terms has been shown, which also represent the unique type of irrigation sector in Nepal. Which is mostly based on farmer managed irrigation system in which water fee is charged on the basis of area and time. As the argument has been made earlier that enumeration system based on information gathered from farmers could have discrepancy because of under reporting. It can be added with a sub-argument in the context of Nepal where time based water charges are collected and it might bring more transparency in the information shared by those farmers as who are not paying area wise.

\footnotetext{
${ }^{18}$ Minimum standard to include a household in survey was 0.1 ha of land.
} 
Table 4a. Number, area, number of holdings reporting and payment terms (on area or time basis) for irrigation by total area of holding

\begin{tabular}{|c|c|c|c|c|c|c|c|c|c|c|c|c|}
\hline \multirow{4}{*}{ Total area of holding } & \multicolumn{2}{|c|}{ Total } & \multicolumn{10}{|c|}{ Payment terms for Irrigation } \\
\hline & \multirow{3}{*}{$\begin{array}{l}\text { No. of } \\
\text { holdings }\end{array}$} & \multirow{3}{*}{ Area (ha) } & \multirow{3}{*}{$\begin{array}{l}\text { No. of } \\
\text { holdings } \\
\text { reporting }\end{array}$} & \multirow{3}{*}{ Area (ha) } & \multirow{2}{*}{\multicolumn{2}{|c|}{ Did not pay for water }} & \multicolumn{6}{|c|}{ Paid for water } \\
\hline & & & & & & & \multicolumn{2}{|c|}{ On area basis } & \multicolumn{2}{|c|}{ On time basis } & \multicolumn{2}{|c|}{ Other } \\
\hline & & & & & $\begin{array}{c}\text { No. of } \\
\text { holdings }\end{array}$ & Area (ha) & $\begin{array}{c}\begin{array}{c}\text { No. of } \\
\text { holdings }\end{array} \\
\end{array}$ & Area (ha) & $\begin{array}{c}\text { No. of } \\
\text { holdings }\end{array}$ & Area (ha) & $\begin{array}{c}\text { No. of } \\
\text { holdings }\end{array}$ & Area (ha) \\
\hline Holding without land & 115,538 & $3,119.3$ & 8,091 & 167.3 & 5,579 & 110.9 & 36巾 & 21.4 & 2,047 & 33.8 & 105 & \\
\hline Holding with land & $3,715,555$ & $2,522,519.9$ & $2,464,204$ & $1,313,239.1$ & $1,594,378$ & $641,115.4$ & 284,308 & 179,503.5 & 733,076 & $458,078.8$ & 83,029 & 34,541 \\
\hline Under $0.1 \mathrm{ha}$ & 355,549 & $20,076.5$ & 180,940 & 7.417.7 & 107.540 & 4.101 .8 & 14.286 & 655.0 & 52,546 & $2,367.3$ & 8.250 & 29 \\
\hline $0.1 \mathrm{ha}$ and under $0.2 \mathrm{ha}$ & 461,957 & $68,161.8$ & 256,360 & $28,830.1$ & 151,470 & $14,858.2$ & 25,236 & 3.087.3 & 78,832 & 9.865.8 & 8,120 & 1,038 \\
\hline $0.2 \mathrm{ha}$ and under $0.5 \mathrm{ha}$ & $1,169,503$ & $396,720.9$ & 752,818 & $180,713.4$ & 496,876 & $98,582.6$ & 79,752 & $21,716.8$ & 200,426 & 55.590 .3 & 21,104 & 4.823 .5 \\
\hline $0.5 \mathrm{ha}$ and under $1 \mathrm{ha}$ & 984,022 & $695,080.1$ & 698,590 & 333.827.2 & 475,419 & $177,795.8$ & 81,873 & $43,310.3$ & 189,263 & 103,297.3 & 21,875 & 8.823.7 \\
\hline 1 ha and under 2 ha & 548,974 & $749,810.0$ & 417.655 & 398.258 .1 & 270,721 & 193.629.0 & 57.484 & $55,795.2$ & 141,148 & 138,804.6 & 15,046 & 10,028 \\
\hline 2 ha and under 3 ha & 129,364 & $308,568.5$ & 102,888 & $181,574.8$ & 61,058 & 78.450 .0 & 15,852 & 25.309 .3 & 44,080 & $72,745.3$ & 5.018 & 5,070 \\
\hline 3 ha and under 4 ha & 39,507 & 134,353.1 & 32,443 & $83,144.8$ & 18,620 & $33,153.5$ & 5.087 & $11,685.7$ & 15,655 & 35.823 .8 & 1.548 & 2,481 \\
\hline 4 ha and under 5 ha & 14,881 & $65,384.7$ & 12,421 & $42,188.6$ & 6.851 & 15.894.1] & 2,483 & 7.641.3 & 6.235 & $18,023.8$ & 543 & 629.4 \\
\hline $5 \mathrm{ha}$ and under $10 \mathrm{ha}$ & 10,744 & $69,177.1$ & 9.222 & 47.992.3 & 5,571 & $21,136.5$ & 1.962 & $7,815.8$ & 4,568 & $17,939.0$ & 454 & $1,000.8$ \\
\hline 10 ha and over & 1,054 & $15,227.2$ & 845 & $8,182.0$ & 451 & 3.514.1 & 212 & $2,406.7$ & 322 & $2,921.4$ & 60 & 349.8 \\
\hline Total & $3,831,093$ & $2,525,639.2$ & $2,472,296$ & $1,313,406.3$ & $1,599,957$ & $641,226.3$ & 284,668 & 179,524.9 & 735,123 & $458,112.6$ & 83,134 & \\
\hline
\end{tabular}

Figure 63. Irrigated Areas information based on payment terms (Source: Nepal Agricultural Census 2011-12)

Department of Irrigation (DoI) works under Ministry of Water Resources in Nepal, and their main job is the development, operation and maintenance of irrigation infrastructure in country. A regional and district wise data source was available from department of irrigation categorized by type of irrigation scheme i.e. surface irrigation schemes including farmer managed (assisted and non-assisted), irrigation department managed schemes, ground water (shallow and deep wells) and traditional irrigation. (Department of Irrigation, 2007) (Report attached in Appendix F)

Methodology for the data collection about irrigated area was not available on the web, but it is mostly believed that it might depend upon the administrative reports generated by district office of irrigation department. An irrigation official was also interviewed to develop more understanding about the mechanism of reporting for irrigated area. According to him, mostly irrigation department depends upon water user association for the reporting of irrigated area but no survey is conducted to collect information as they are already aware with the command area of schemes. For farmer managed irrigations systems (FMIS); accurate information is only available for those schemes which ask for assistance from irrigation department, as a survey is conduct in first go to start the maintenance or rehabilitation of the irrigation system. Moreover, FMIS with area less than 25 ha in mountainous areas and less than 100 ha in plain lands are not eligible to ask for assistance, which certainly creates some doubts in the data provided by irrigation department as it might miss the small scale irrigation as they are not considered for survey. While the frequency of reporting from district offices to regional and central offices is after every 4 months (3 times in an year) and district officials also conduct regular meetings with water user associations in which irrigated and non-irrigated areas of schemes are also discussed, which might keep them aware with the statistics of actually irrigated area. (Personal Communication, 2015)

Statistics for irrigated agriculture were also collected during Nepal living standard survey (NLSS) carried out by Central Bureau of Statistics in 2010-2011 (Central Bureau of Statistics, 
2011). The information was collected by sample enumeration and 24000 households were interviewed to collect the information which is $0.4 \%$ representation of total households in Nepal (5.4 million). But on other side the primary purpose of this survey was to collect detailed information for living standards in the country, e.g. employment, income, savings, expenses, education, health etc. using 80 pages long questionnaire (NLSS, 2011). As irrigation has its significance importance in income generation so it was also included in the survey. But by having $0.4 \%$ sample size country wise, this data source cannot be considered as very reliable as figures generated in the results are based on statistical extrapolation.

\subsubsection{Reporting Mechanism in Japan}

Following data source for irrigated areas was available from Japan:

\section{Ministry of Agriculture, Forestry and Fisheries (MAFF)}

Information for irrigated areas from Japan was collected from ASEAN's food security information system (AFSIS) which is believed to be provided by MAFF as they are interlinked for the improvement of agricultural statistics in ASEAN region. No information for irrigated areas was available with the database of MAFF, Japan Statistics Bureau and in reports of agricultural census $2010^{19}$

A decentralized system works in Japan to collect information of agricultural statistics. District offices rely on senior enumerators to gather data from sample farms, which are required to maintain a farm log book for all important inputs and financial matters of farms, e.g. fertilizer, seeds, irrigation etc. Enumerators visit the farms after every three months and retrieve the information. While MAFF also collects data from farms via postal services by sending questionnaires to rural communities.

A relatively different kind of reporting mechanism for agricultural statistics can be analysed in Japan, where farmers themselves maintain the records of farms (MAFF, 2015). This advance method could be linked with literacy rate as farming community is well educated and if trained by senior enumerators they can collect data which obviously saves time and also increase the reliability of the first-hand information. As different farms in country could operate in different time frames. Data of irrigated areas has been assumed to have secondary importance in the reporting system as it is not published by MAFF.

On the other hand, this strategy of self-reporting and using postal service for data collection could be seen as innovation in data collection for irrigated areas, as motivation level and prompt response of farmers plays a crucial role in reliable data gathering process.

\footnotetext{
${ }^{19}$ Japan conducts agricultural census after every 5 years.
} 


\subsection{Mechanism of FAO, AQUASTAT and GMIA Statistics}

\subsubsection{FAOSTAT}

FAOSTAT collects information of irrigated area primarily using Land and Irrigation Questionnaire (FAO Code 6690, 6616) which has been shown in Appendix H. While other data sources, e.g. relevant ministries' websites, research reports and international organizations' reports are also referred. The questionnaire is sent to relevant countries to collect statistics for land use and irrigation including agricultural area, temporary crops, permanent crops, area equipped for irrigation, area actually irrigated, forest area, aquaculture, water bodies etc. This questionnaire is sent to national reporting/statistical agency who are responsible to fill it up along with the name and contact details of responsible authority for data collection if it was not collected by the statistical agency.

Though FAO stress more on the quality of data, but they also realize the capability and capacity of statistical agencies to generate quality data. Discussions have been made in FAO statistical data quality framework paper, regarding trade-offs in order to look for the most important data at national levels with regional preferences. Which might necessarily not be agricultural data in every case as it depends upon the size and resources of a country. (FAO, 2004)

Though FAO is involved in developing and improving the capacities for statistical or other relevant agricultural data collection agencies in Asian countries (FAO, 2016). But as having the same data sources, procedures and limitations which have been discussed earlier country wise; some obvious discrepancies might be expected from FAO datasets as well.

\subsubsection{AQUASTAT}

AQUASTAT is considered as a dedicated version of FAOSTAT which is concerned with water and water related statistics. Information available in this portal is more detailed especially for irrigated areas including area equipped for irrigation, means of irrigation, type of irrigation, area actually irrigated, irrigated area under different crops, potential area for irrigated agriculture etc.

AQUASTAT mainly rely on agricultural information which is produced at national and subnational level by agricultural or statistical agency. Irrigation plans, water resources reports, yearbooks, statistical reports and FAO reports are referred to retrieve information which is then published on web portal after analysis and standardization. International and national research organizations' surveys and reports are also considered to collect timely information. Moreover, some information which is unavailable or difficult to gather from country sources, is produced by modelling, estimates and aggregates. 


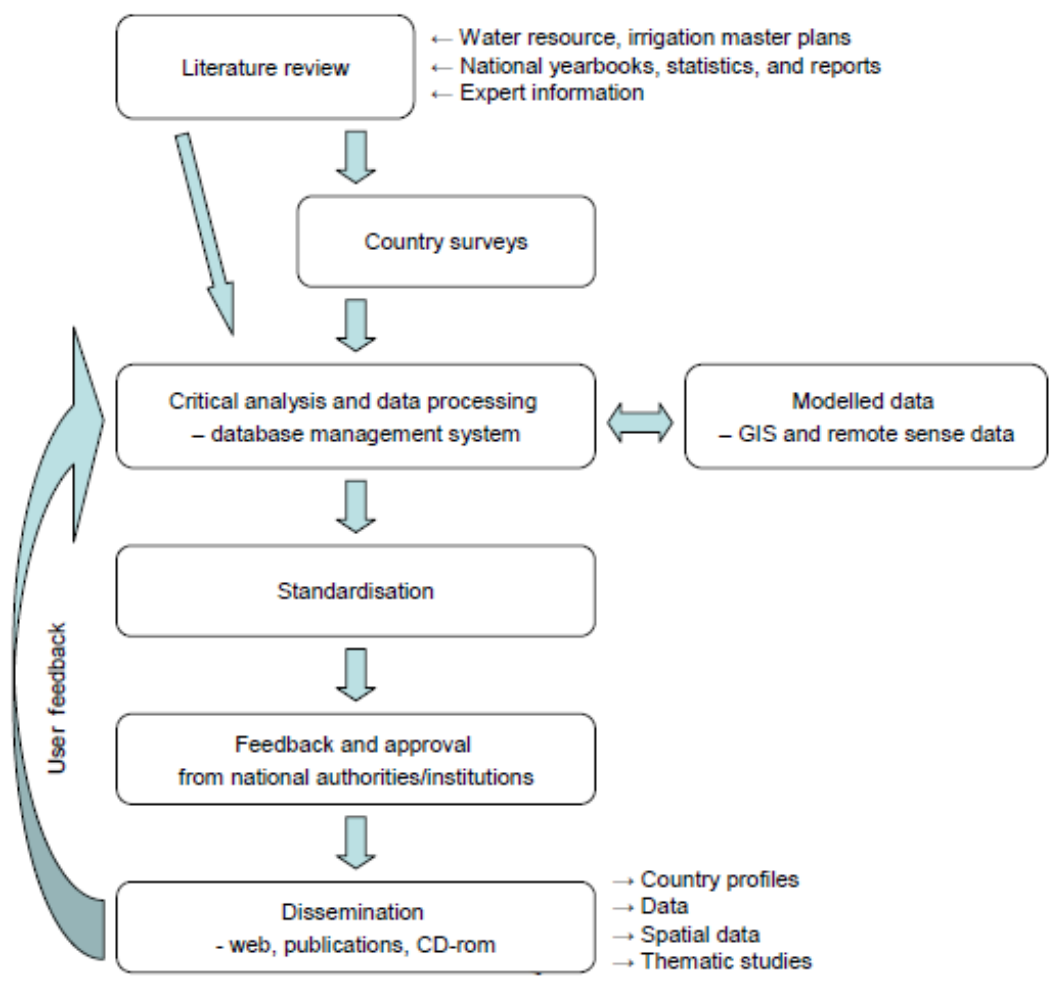

Figure 64. AQUASTAT Data Collection, Analysis and Dissemination Process (Source: AQUASTAT)

It can be realized that AQUASTAT's information is also coming from the same data sources which have been discussed previously and having their limitation and non-uniformity especially in case of irrigated areas information, this source cannot be considered fairly reliable. On other hand, in case of any discrepancy in different sources of same datasets, national statistical figures are considered correct as a part of policy. While it is also worth mentioning here that before getting the information published, it is shared with countries and after their consent it is shared online (FAO, 2003). This can obviously put questions on its reliability as it is feared that countries themselves might induce variation or discrepancy in data in order to save their political concerns.

\subsubsection{Global Map of Irrigated Areas (GMIA)}

GMIA datasets translates the national statistics on a spatial scale with a grid/pixel size of 10 $\mathrm{km} \times 10 \mathrm{~km}$. Two parallel approaches were used while developing these maps. Statistical data including national records and FAO datasets, while available command area maps were digitized according to geographic coordinates. Irrigated areas location were finalized using point and polygon data and land cover maps based on satellite imagery were also used during the process. On other hand, in case the spatial information for the extent of irrigated area was not available; statistical techniques were used to assign the grids with proportional amount of irrigated land (S. Siebert et al, 2005). It is important to mention that during the process, preference was given to national statistics.

Moreover, quality ranking has also been done on the basis of regional statistics within a country and raster maps data, which has been described in table 5. Following flow chart explain the process of data collection and processing schematically: 


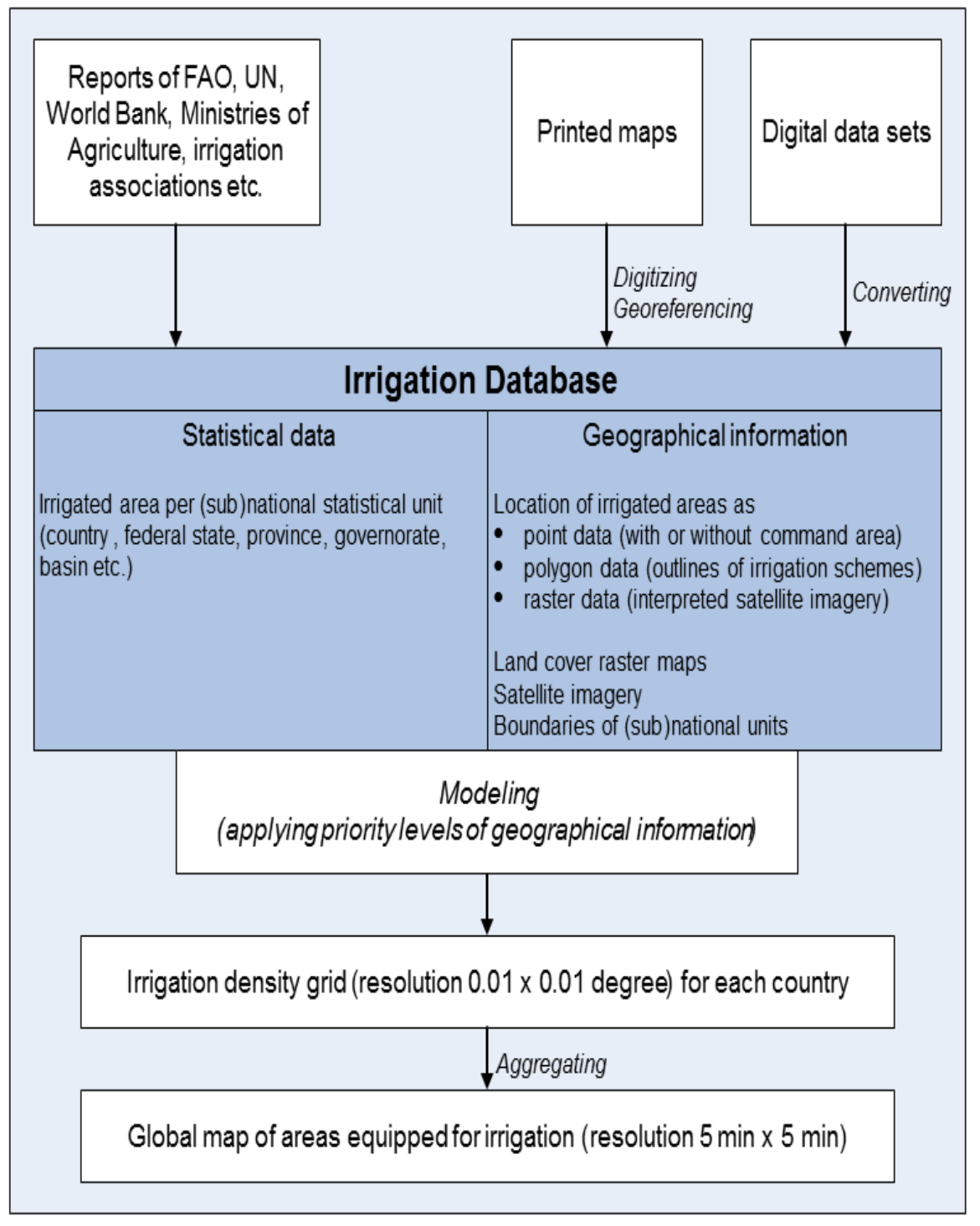

Figure 65. Methodology for Global Irrigated Area Maps (Source: FAO, GMIA) 


\subsection{Scoring System for the Reporting Methods}

A parallel approach has been introduced for quantifying the strength and weaknesses of the reporting methods. A scoring system has been developed to compare the reliability of discussed techniques and procedures of data collection for irrigated areas discussed earlier. After going through the previous section of qualitative analysis it has been realized that while discussing a multi-regional scenario for Asia, these reporting systems have to be compared country wise on a relatively equivalent scale.

After generalizing the parameters and sub-parameters of reporting mechanisms being used in ten Asian countries for the collection of irrigated areas information, following data sources have been sorted out, which were then ranked and quantified accordingly.

- Agricultural Census

- Irrigation Census

- Statistical Agency Surveys (key role /mandate of data collection)

- Agricultural Department Records

- Land Use Statistics

- Irrigation Department Records

- National Land Survey / Other surveys

Translating the qualitative analysis by using a quantitative approach, these data sources were ranked and scaled as per the reporting mechanism working contextually. Rationale for scaling has been described briefly in methodology chapter and step by step approach to produce a scoring system has been discussed here.

In next page, a flow chart diagram (figure 66) has been shown to describe the multifaceted process of irrigated areas data which starts from enumeration approach/strategy for data collection and ends at dissemination. This process can be seen as multi-criteria process, where a same approach can be used in different ways in different countries and in different regional environments within one country as well. This flow chart diagram will help to develop a better understanding for the scaling criteria which has been shown afterwards. 


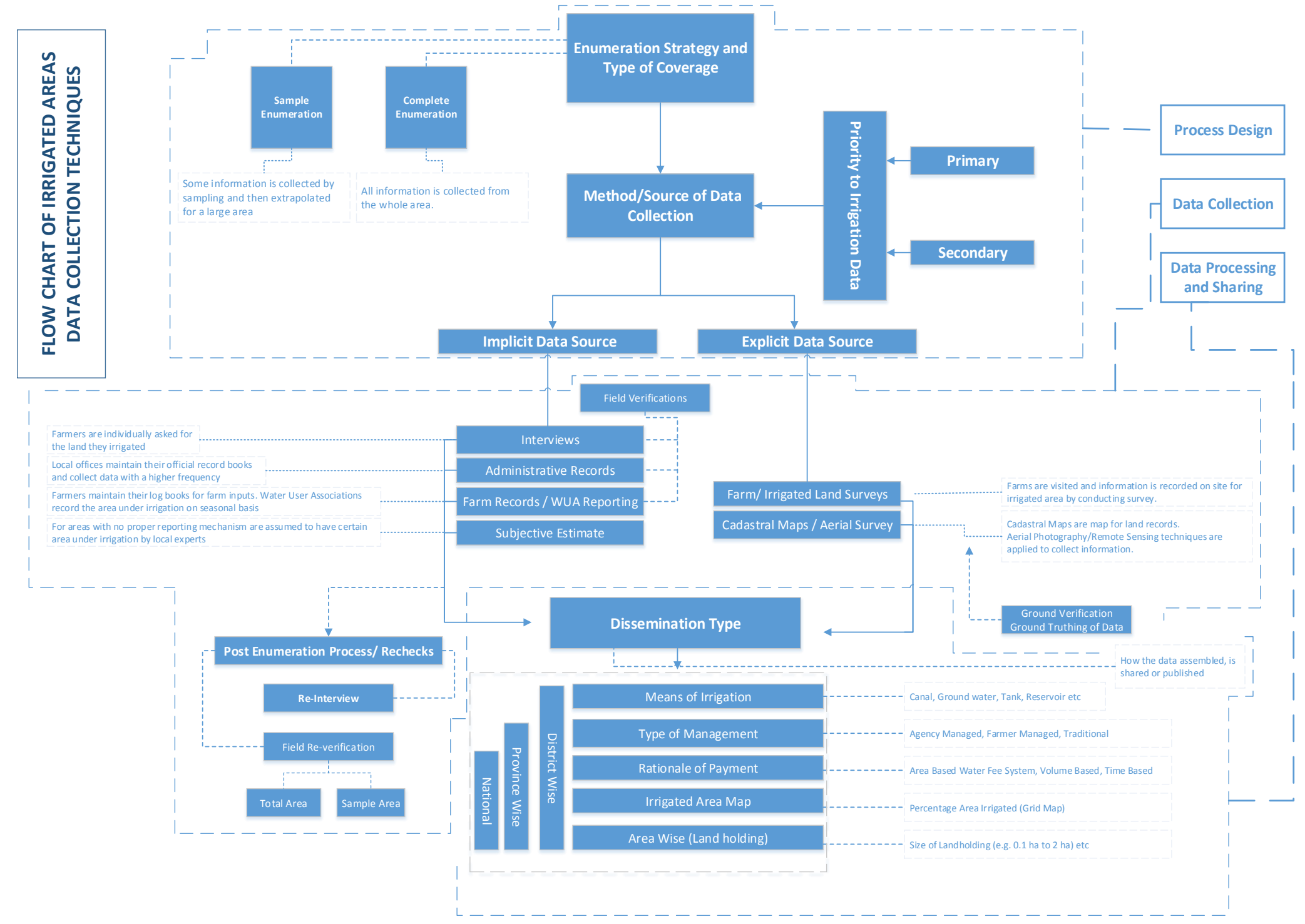

Figure 66. Flow Chart Diagram (General mechanism of irrigated areas reporting systems) Rationale of scoring scale 


\begin{tabular}{|c|c|c|c|c|c|}
\hline Phase & Main Parameter & Sub-Parameter & Code & Reliability & Rank/Impact Range \\
\hline \multirow{4}{*}{ 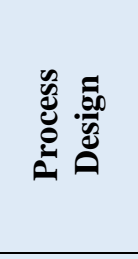 } & \multirow{2}{*}{$\begin{array}{c}\text { Enumeration Strategy and Type of } \\
\text { Coverage }\end{array}$} & Complete Enumeration & $\mathrm{CE}$ & Very Good & $6-7$ \\
\hline & & Sample Enumeration & SE & Fair & $4-5$ \\
\hline & \multirow{2}{*}{ Priority to Irrigation Data } & Secondary & SC & Good & $3-6$ \\
\hline & & Primary & PR & Excellent & $6.1-10$ \\
\hline \multirow{10}{*}{ 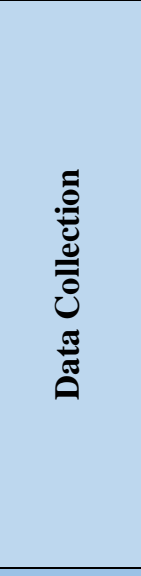 } & \multirow{4}{*}{ Implicit Data Source } & Interviews & IN & Poor & $2.1-3$ \\
\hline & & Administrative Records & AR & Fine & $8.1-9$ \\
\hline & & Farm Records / WUA Reporting & FW & Very Good & $7-8$ \\
\hline & & Subjective Estimate & SM & Very Poor & $1-2$ \\
\hline & \multirow{3}{*}{ Explicit Data Source } & & & & \\
\hline & & Farms/Irrigated Land Survey & FS & Very Good & $5-7$ \\
\hline & & Cadastral Maps/Aerial Survey & MA & Very Good & $5-8$ \\
\hline & \multirow{3}{*}{ Enumeration/Post Enumeration Checks } & Physical Verification (Total Area) & PT & Excellent & $9.1-10$ \\
\hline & & Physical Verification (Sample Area) & PS & Fair & $3-5$ \\
\hline & & Re-Checks (Re-Interview) & $\mathrm{RE}$ & Good & $5.1-6$ \\
\hline \multirow{5}{*}{ 焉 } & \multirow{5}{*}{ Dissemination Type } & Means of Irrigation & MI & Fine & $7.1-9$ \\
\hline & & Type of Management & TM & Very Good & $5-7$ \\
\hline & & Rationale of Payment & PM & Good & $3-6$ \\
\hline & & Irrigated Area Map & MP & Fine & $7.1-9$ \\
\hline & & Area wise (Farm size)land holding & LH & Good & $3-6$ \\
\hline
\end{tabular}

Table 16. Reliability and Impact Range/Ranking Table for Sub-Parameters of Irrigated Areas Reporting Mechanism

Note: Impact range and reliability of the sub-parameters has been decided on the basis of qualitative analysis. It may vary according to different parameters or difference in perception about the process. Moreover, a range of reliability ranking shows the possible variation in the effectiveness of results depending upon the fairness in implementation. 
In Table 16, a breakdown approach has been used to scale different para and sub parameters which are involved in the whole process of data generation starting from the collection to dissemination. Codes have been allotted to every sub-parameter with a score range which is assumed on the basis of qualitative analysis, which shows the range of influence which a subparameter might induce on the reliability of a dataset. An example of total score criteria for irrigation census has been shown below in Table 17.

\begin{tabular}{|c|c|c|c|c|}
\hline Phase & Sub-Parameter & Code & \multicolumn{2}{|c|}{ Score Range } \\
\hline \multirow{2}{*}{ Process Design } & Complete Enumeration & CE & 6 & 7 \\
\hline & Primary & PR & 6.1 & 10 \\
\hline \multirow{5}{*}{ Data Collection } & Interviews & IN & \multirow{2}{*}{$\begin{array}{l}2.1 \\
8.1\end{array}$} & \multirow{2}{*}{$\begin{array}{l}3 \\
9\end{array}$} \\
\hline & Administrative Records & AR & & \\
\hline & \multicolumn{2}{|c|}{$\begin{array}{r}\text { Average Score for (Interviews and } \\
\text { Administrative Records) }\end{array}$} & 5.1 & 6 \\
\hline & $\begin{array}{l}\text { Physical Verifications } \\
\text { (Sample Area) }\end{array}$ & PS & 3 & 5 \\
\hline & Re Checks & RE & 5.1 & 6 \\
\hline Processing / Dissemination & Means of Irrigation & MI & 7.1 & 9 \\
\hline \multicolumn{3}{|c|}{ Total Score $\Sigma$} & 32.4 & 43 \\
\hline
\end{tabular}

Table 17. Example calculation for Scoring System (Irrigation Census)

This example shows use of two sub-parameters which comes under one large parameter "data source", e.g. in India both methods are used to collect data depending upon the availability of land record/revenue system in different states, so an average of their relative score have been added in final sum. This type of scoring could be further improved if instead of simple average formula, a relative average approach is used, linked with the percentage of area which is covered by different methods.

In Table 18, results of qualitative analysis have been shared. A score table has been developed to evaluate country wise reporting mechanisms on the basis Table 16, Table 17. It shows the modified score country wise, which has been standardized according to coefficient of variation in datasets which was produced by comparing different datasets from every country (described in Section 4.2). A detailed table carrying all the scores associated with relevant codes allotted to each method and its sub parameters, has been shown in Appendix G.

\begin{tabular}{|c|c|c|c|}
\hline Country & Average Score Range & $\mathbf{C}_{\boldsymbol{V}}$ \% (Non-RS) & Modified Score Range \\
\hline China & $22.4-30.3$ & 5.7 & $21.2-28.5$ \\
\hline India & $25.0-33.8$ & 5.4 & $23.7-31.9$ \\
\hline Pakistan & $21.5-30.0$ & 17.7 & $17.7-24.7$ \\
\hline Iran & $11.6-17.0$ & 14.1 & $9.9-14.6$ \\
\hline Thailand & $13.9-17.8$ & 17.4 & $11.5-14.7$ \\
\hline Bangladesh & $22.8-32.1$ & 11.9 & $20.1-28.3$ \\
\hline Indonesia & $17.3-23.2$ & 15.0 & $14.7-19.7$ \\
\hline Vietnam & $17.9-24.8$ & 26.9 & $13.1-18.1$ \\
\hline Japan & $19.0-26.0$ & 21.5 & $14.9-20.4$ \\
\hline Nepal & $17.5-25.9$ & 24.4 & $13.2-19.6$ \\
\hline
\end{tabular}

Table 18. Score Table (Standardized Reliability Score for Irrigated Areas Reporting Mechanisms) 
Discussing the modified score range, China, India and Bangladesh have relatively high scores, which positively reflects the impact of primary priority to data collection in their minor irrigation surveys (India and Bangladesh) and aerial imagery based land survey for China. Though in average score range, Bangladesh score is high but due to high coefficient of variation $11.9 \%$, its modified score has been decreased accordingly. But in comparison to India and China, two largest countries on the basis of irrigated areas, Bangladesh has performed well in its data collection method based score.

On other hand, Pakistan also scored between 20 to 30 in average score range but coefficient of variation is higher for Pakistan (17.7\%) which decreases its modified score, though other than irrigation census, in India and Pakistan almost same land record/revenue system is mostly used which was developed during colonial era. Additionally, Nepal's average score is almost in between 17 to 26 , but its modified score is decreased by $24.4 \%$ as a high variation has been noticed in data sets collected during research. It is also worth mentioning here that though Nepal's irrigation department records have been allotted with primary priority of data collection, but the inclusion of subjective estimates (SM) for approximating the extent of farmer managed irrigation systems affected the overall average of this data source.

While Indonesia, Japan, Vietnam scored between ranges of 14 to 20 for the modified scores which reflect some weaknesses in those reporting system in comparison with earlier discussed countries. Moreover, there was no sub-parameter of re-checks (RE) allotted to them and just data source from Indonesia and Vietnam collects the information of irrigated areas on primary basis which also decreased their scores.

Iran and Thailand have scored between the range of 9.9 and 14.7 on the modified scale with coefficient of variation values of 14.4 and 17.4 respectively. Though these $\mathrm{C} v$ values are relatively less than Vietnam and Japan $(26.9,21.5)$ but the average total scores of these countries are relatively low, ranging between 11.6 to 17.8 . This translates the overall low reliability of those datasets which are depending upon interviews with no physical verification or post enumeration checks, while on other hand in Iran there is no method which has been found collecting irrigated areas information on primary basis.

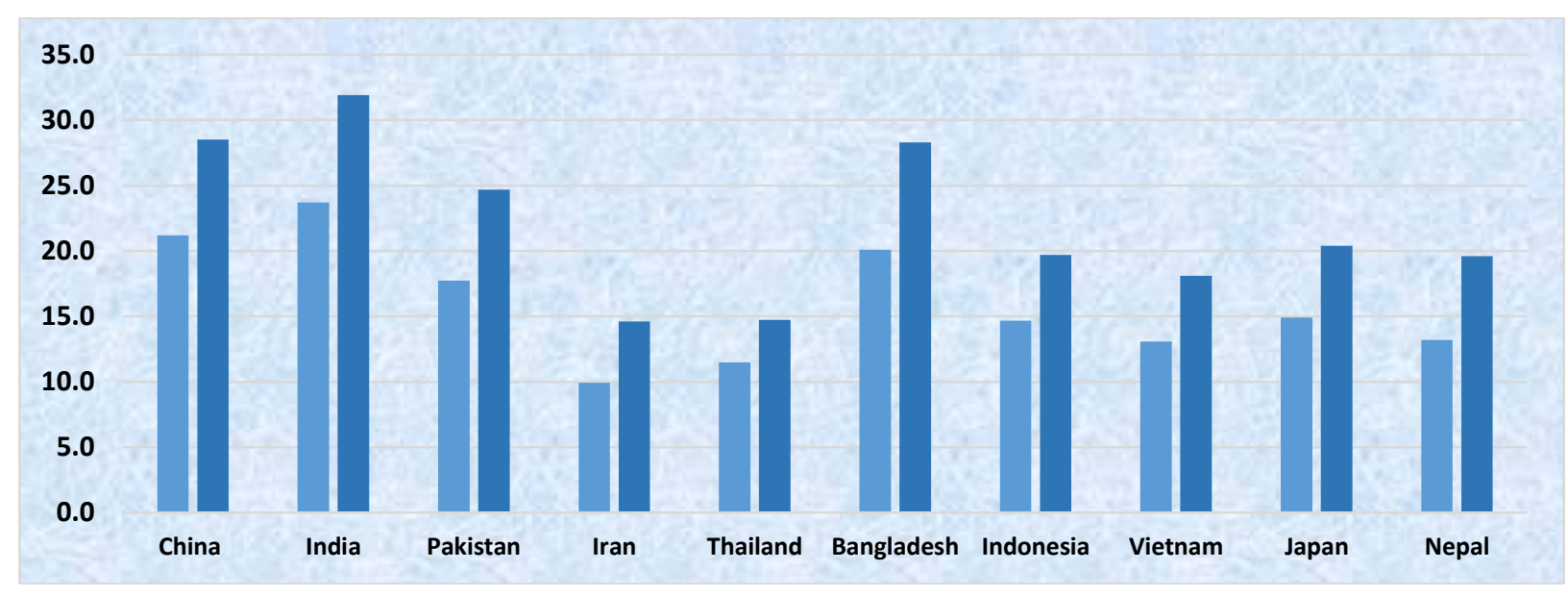

Figure 67. Modified Reliability Score Chart (Results of Qualitative Scoring Method for the methods involved in irrigated Areas reporting) 


\section{CHAPTER 7}

\section{Implication of Uncertainty on Food Production and Water Resources}

Looking at the variation in data sets of irrigated areas and reporting methods working behind them, we can link this uncertainty with food production and water productivity. In this chapter the upper and lower limits of maximum and minimum extent of irrigated areas has been discussed country wise. In order to shed light on the possible implications of this ambiguity in such a vital information on national annual land productivity and actual water use to produce crops.

\subsection{Uncertainty and Link with Food Production}

The relation of food production and irrigated areas can be linked with annual grain production of a country being produced from irrigated agriculture. Following table 19 explains the dependency of Asian countries on irrigation for their grain production.

\begin{tabular}{|c|c|c|}
\hline No & Country & $\begin{array}{c}\text { Share of Grain Production } \\
\text { (Irrigated Agriculture) }\end{array}$ \\
\hline 1 & China & $67 \%$ \\
\hline 2 & India & $56 \%$ \\
\hline 3 & Pakistan & $70 \%$ \\
\hline 4 & Iran & $61 \%$ \\
\hline 5 & Thailand & $40 \%$ \\
\hline 6 & Bangladesh & $47 \%$ \\
\hline 7 & Indonesia & $85 \%$ \\
\hline 8 & Vietnam & $94.5 \%$ \\
\hline 9 & Japan & $98 \%$ \\
\hline 10 & Nepal & $80 \%$ \\
\hline
\end{tabular}

Table 19. Share of Irrigated Agriculture in Grain Production of Asian countries Source: AquaStat, Agricultural Censuses, Annual Crop Reports, Estimates etc

This table shows that on an average, Asian countries depends $70 \%$ on irrigated agriculture for their grain production to fulfil national food requirement and for exports as well, especially rice. Now linking it with uncertainty of data, annual land productivity can be considered as main indicator which is dependent on actual grain production (Factor 1) and irrigated area as (Factor 2).

If it is assumed that annual grain production which is calculated in million tonnes is constant and almost correct amount, while irrigated area could fluctuate in numbers due to short comings of the reporting system. A country could have 2 different annual land Productivity values, one based on national statistics and other based on remote sensing data, i.e. IWMI Global Irrigated Areas Maps. 


\begin{tabular}{|c|c|c|c|c|}
\hline Country & $\begin{array}{c}\text { Gross Irrigated Area } \\
\text { for Grain Production } \\
\text { (M ha) }\end{array}$ & $\begin{array}{c}\text { Irrigation } \\
\text { Intensity (\%) }\end{array}$ & $\begin{array}{c}\text { Net Irrigated Area for } \\
\text { Grain Production (M ha) }\end{array}$ & $\begin{array}{c}\text { Grain produced from } \\
\text { Irrigated Areas } \\
\text { (M tonne) }\end{array}$ \\
\hline China & 65.64 & $176.11 \%$ & 37.27 & 270.7 \\
\hline India & 47.33 & $130 \%$ & 36.41 & 129.8 \\
\hline Pakistan & 11.52 & $111.31 \%$ & 10.35 & 20.7 \\
\hline Iran & 3.53 & $133 \%$ & 2.66 & 11.4 \\
\hline Thailand & 6.26 & $146 \%$ & 4.29 & 13.2 \\
\hline Bangladesh & 4.77 & $110.6 \%$ & 4.31 & 18.5 \\
\hline Indonesia & 12 & $199 \%$ & 6.03 & 33.5 \\
\hline Vietnam & 7.10 & $190.4 \%$ & 3.73 & 11.8 \\
\hline Japan & 1.82 & $113 \%$ & 1.61 & 5.9 \\
\hline Nepal & 1.75 & $163 \%$ & 1.07 & \\
\hline
\end{tabular}

Table 20.Grain Production from Irrigated Agriculture, Source: Calculations based on FAOSTAT Cereals Production Quantity Data

Usually while estimating production of crops, grain produced from irrigated and non-irrigated farms is not classified separately. So, based on the percentage from Table 19, grain produced from irrigated areas has been separated, in order to look for irrigated Annual Land Productivity.

On other hand, Gross irrigated areas for cereal crops has been reduced into net irrigated area, using the values of irrigation intensity, retrieved from AquaStat. Moving towards the impact of the vague role of uncertainty in irrigated areas information, following graph shows 2 different annual land productivity (ALP) values under the constant (Factor 1), which is grain production.

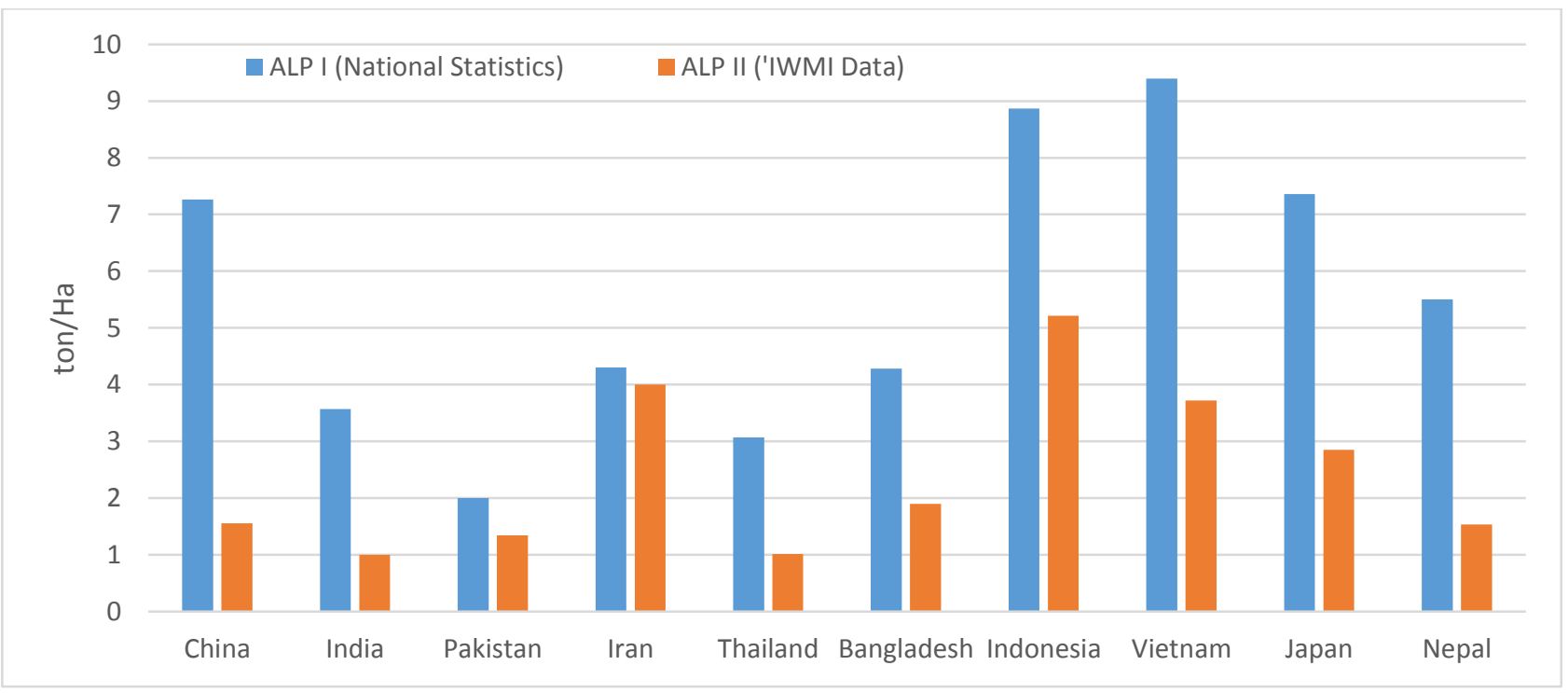

Figure 68. Annual Land Productivity (ALP) Comparison for Irrigated Grain Production (tonne per hectare), Source: Analysis based on FAO grain production data, Irrigated Areas Data from National statistics and IWMI Maps

Comparing the annual land productivity in context of irrigated areas, large difference can be seen for countries under analysis. In case of China, irrigated annual land productivity drops by 5.7 ton/ha in comparison. As the national statistics provide a nice figure of almost 7.26 ton/ha while recalculating it with IWMI data for irrigated areas it goes down to 1.55 ton/ha. For India, 
it goes from 3.56 ton/ha to 1 ton/ha and for Vietnam it drops by 5.67 ton/ha which is quite a significant drop. For Iran, the drop is almost negligible as the irrigated annual land productivity just fluctuate from 4.33 to 3.9 ton/ha.

This analysis could lead the discussion of uncertainty in two directions. Either the overall annual land productivity reported from countries (in terms of yield) is really low but it is exaggerated from statistical agencies or those irrigated areas which are not covered by the reporting system have significantly low yield, which also decrease the cumulative annual productivity for the country when included in total irrigated areas estimates. So, further investigation is required to sort out this riddle.

It is also important to mention here, that most of the times those agencies which collect the data about irrigated areas, also collects the production data from the farms. Which is mostly based on sampling methods and then it is extrapolated using statistical techniques on the basis of average yield. Though, it is quite difficult to weigh every grain produced in the country but by looking at huge unreported irrigated land and making a second assumption of variation or any possible discrepancy in grain production data as well; it could further bring the whole debate of food security towards another dimension.

Afterwards, population has been brought into discussion as (Factor 3), per capita irrigated area would also get significantly changed if the analysis is performed on the basis of IWMI data for irrigated areas. Following graph shows the comparison of irrigated area available per person in Asian countries.

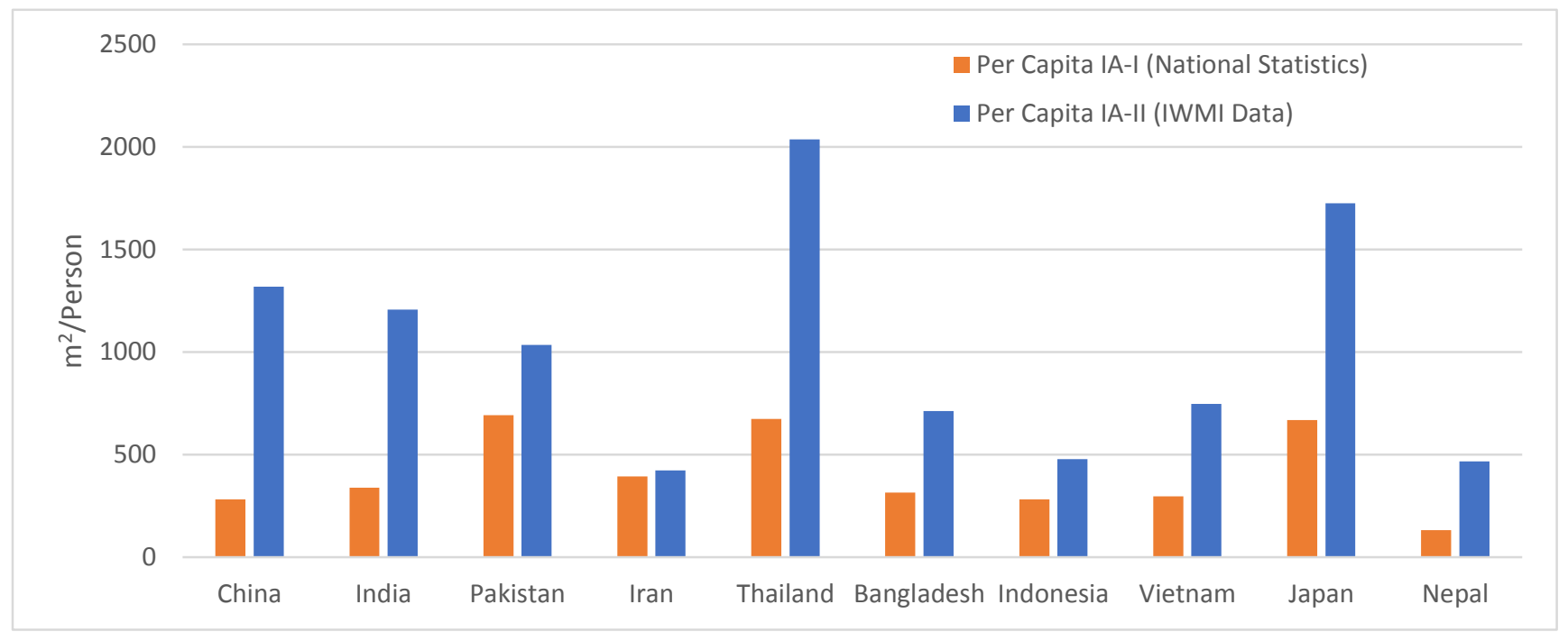

Figure 69. Per Capita availability of Irrigated Areas in Asian Countries Source: Analysis based on FAO Population Estimates (2003-2007) and Irrigated Areas Data from National Statistics and IWMI

Two different possible calculations of per capita irrigated area has been shown in figure 69. A huge difference can be seen for China, India, Thailand, Vietnam, Nepal and Japan, as their availability of irrigated area per person are 129.6\%, 112.4\%, 100\%, 112.753\%, 88.33 and $86.48 \%$ higher than national statistics respectively, in accordance with population estimates of FAO (2003-2007). 
These difference in per capita irrigated areas could induce significant changes in policies linked with food security and irrigated water management. As food production in Asia depends 70\% on irrigation and rest comes from rain-fed agriculture. Moreover, dependency on rain-fed agriculture would decrease in future as rainfall patterns are changing temporally and spatially, and will become more unpredictable due to climate change (Wani et al, 2009).

This make this uncertainty more crucial to tackle timely, as two possible ways could be adopted in order to find a solution. First, if national statistics are considered to be reliable than there would be a need of increasing the annual land productivity along with utilizing the remaining potential for irrigated agriculture. Second, if IWMI datasets are considered to be reliable there is a need to bring all the non-recorded information of irrigated areas in the national statistics books. Only then reliable management policies could be formed for ensuring sustainable grain production to attain food security goals.

\subsection{Uncertainty and Link with Water Resources}

During the phase of data collection, it was found that the most of the countries do not share or maintain the data of total agricultural water use i.e. Canal water withdrawals, Ground water extraction. So, only data available is the estimated values available with AquaStat which are based on modelled data and estimates.

\begin{tabular}{|l|c|c|}
\hline Country & Year & $\begin{array}{c}\text { Agricultural Water Use } \\
\text { (Billion } \mathbf{~}^{\mathbf{3}} \text { ) }\end{array}$ \\
\hline Bangladesh & 2008 & 31.5 \\
\hline China & 2005 & 358 \\
\hline India & 2000 & 558.4 \\
\hline Indonesia & 2000 & 92.76 \\
\hline Iran & 2004 & 86 \\
\hline Japan & 2007 & 54.5 \\
\hline Nepal & 2006 & 9.32 \\
\hline Pakistan & 2000 & 162.7 \\
\hline Thailand & 2007 & 51.79 \\
\hline Viet Nam & 2005 & 77.75 \\
\hline
\end{tabular}

Table 21. Agricultural Water use in Asian Countries (Source: AquaStat)

In the absence of reliable national statistics for surface and ground water use for irrigation, it is difficult to scale the uncertainty. But if it is associated with the argument of small scale farmer managed or non-reported irrigated areas, which in case of China and India are almost 3 and 3.7 times more than official records; the gross water use could rise at least 2 times than estimated numbers. In this case, policies which are based on estimates of water use and planning which is being made to ensure food and water security might stand on ambiguous side. Figure 70 shows the total and utilized irrigation potential of Asian countries in context of national statistics and IWMI-GIAM (Global Irrigated Areas Map 250m). 


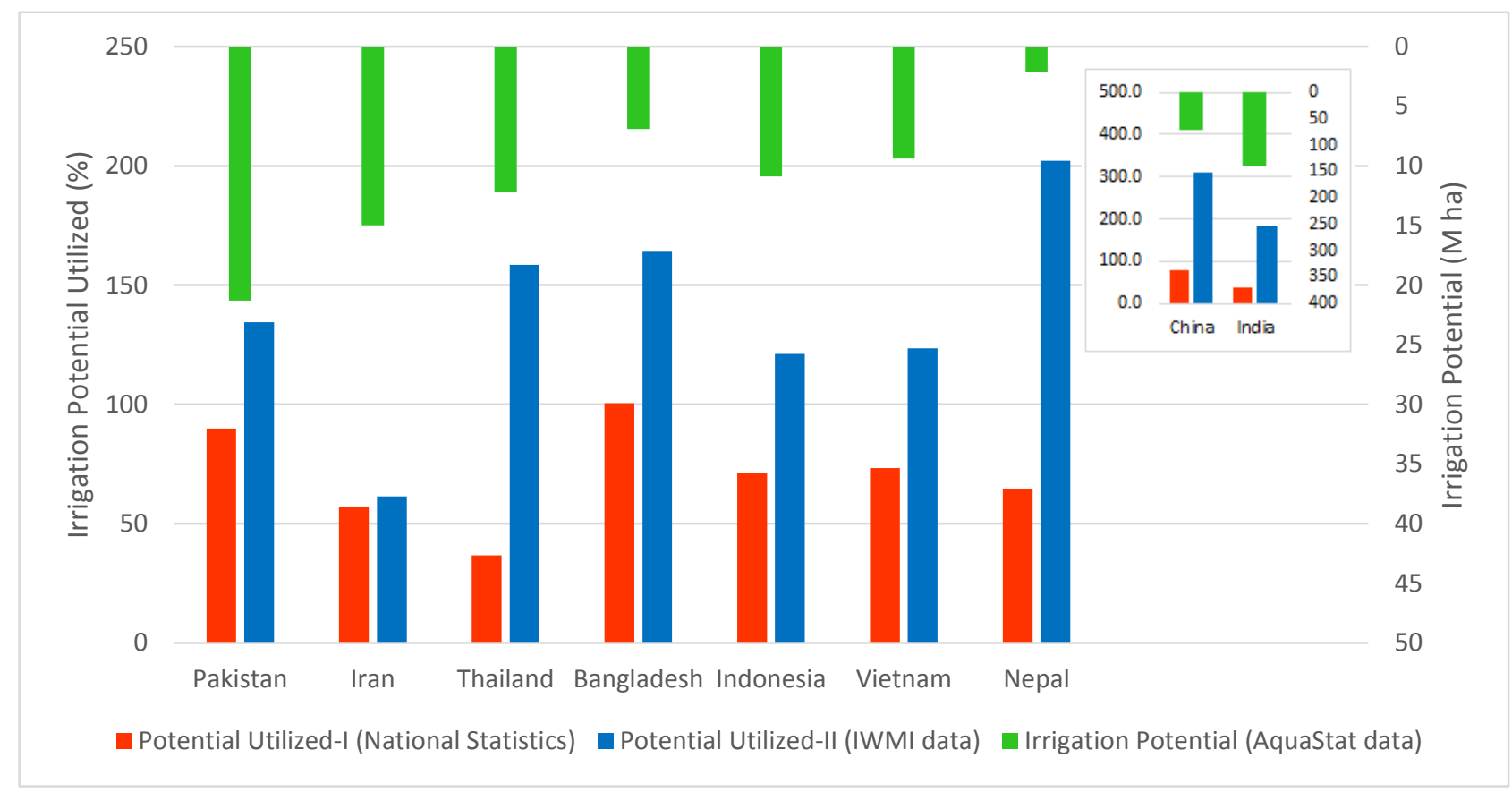

Figure 70. Total Irrigation Potential and so far Utilized, Source: Analysis Based on Data from AquaStat, National Statistics and IWMI-Global Irrigated Areas Map (GIAM)

This analysis shows the official irrigation potential in $M$ ha estimated by Asian countries (available at AquaStat database, excluding Japan) on top right axis. While national statistics for irrigated areas and IWMI data has been compared with this potential to find the percentage utilized so far (shown at left-bottom axis in percentage). Comparing with national statistics for irrigated areas information; Pakistan, China and Bangladesh have almost reached their limits for irrigated areas development. While Indonesia, Vietnam and Nepal has utilized almost 70\% of their irrigation potential and Thailand, India and Iran are at $36.7 \%, 39.4 \%$ and $57.15 \%$ at the utilized potential scale respectively.

On the other hand, calculating the utilized potential for irrigation at national level using IWMI dataset, an average percentage was calculated as almost $160 \%$ and if Iran is excluded from the analysis the vales increases by $10 \%$.While specifically discussing about countries, India and China have the percentage utilized potential of almost $200 \%$ and $300 \%$ respectively. Furthermore, Pakistan, Thailand, Bangladesh, Indonesia, Vietnam and Nepal has the values of $134 \%, 158 \%, 121 \%, 123 \%$ and $202 \%$ correspondingly with a value less than $100 \%$ for Iran $61.5 \%$.

For further discussion on this variation with national estimates of utilized irrigation potential, it is necessary to understand the definition of irrigation development as most of the time countries include public irrigation schemes in development estimates. But in the context of water resources planning, these figures are quite alarming as policy makers might miss the already existing irrigation infrastructure in irrigated agriculture. So, instead of managing the water resources (including ground and surface water) for already present setup and diverting the available water to new development could bring more troubles in future. 


\section{CHAPTER 8}

\section{Conclusions and Recommendation}

\subsection{Conclusions}

Following conclusions can be made on the basis of the study conducted.

\subsubsection{Future of Asia's Irrigated Agriculture}

Growth-track analysis shows that Asia's irrigated agriculture has developed steadily in last 50 years which supported the growing population's food requirements effectively. But in current global scenario; Irrigation in Asia is facing some new challenges. It can be summarized as a new paradigm shift as more emphasis is being given to climate smart agriculture and irrigation technologies are also being evolved and adapted accordingly.

Modern dimension of irrigated areas growth has been integrally linked with poverty reduction and community development. Irrigation is not just a tool to produce food now, but it is being implemented as a key for increasing income for people, which would ultimately promote small scale irrigation in near future. On the other hand, climate change has been seen as a major driver for future development in irrigated agriculture in Asia, resulting in fluctuations of surface water supplies. Consequently, it can be noted that Asia's irrigation trying to rely more on ground water resources, which should be heard as an alarm bell. As high dependency of world's $62 \%$ population on a perishable source could create havoc in future. Need of the time for Asian irrigation sector is to strengthen its policies for water conservation technologies to improve water productivity along with crop yields in order to cope with climate change and poverty. On other hand, integrated water resources management approach is also needed to be adopted to include the element of sustainability into irrigation systems for a safe and long term use of resources.

\subsubsection{Uncertainties in data, Spatial Dispersion and Reporting Methods}

\section{Uncertainty}

Uncertainty analysis brought into light a fact of high variation in datasets of irrigated areas. This variation exist within country's datasets and between FAO data and remote sensing datasets as well. It was found that FAO's information, which was once considered to be quite reliable, and most of the international studies use this data as input, is relying on the same reporting methods which countries use to develop their own data records. While other datasets for example World Bank is relying on FAO, international organizations, e.g. ASEAN is relying on national agricultural ministries. On the other hand, variation has also been noted within remote sending estimates as well. This makes the whole situation, a muddle of figures, as no one is sure that who is correct? 


\section{Spatial Dispersion}

Spatial dispersion analysis helped this study to conclude that uncertainty in irrigated areas information is just not linked with small scale or dispersed irrigation. Though in some countries small scale irrigation has a larger share than medium or large irrigation schemes but countries like China, India, Pakistan, Iran, Nepal, Thailand and Vietnam were found with high discrepancy in large scale irrigation schemes. This uncertainty either could be in public irrigation schemes or in farmer managed irrigation systems. This also raises question on the fairness of reporting methods or the sincerity of countries to share actual data publicly.

\section{Reporting Methods}

Irrigated areas information is not provided primary importance in most of the data collection operations at country level. It is just collected along with other information of agricultural statistics as business as usual. Mostly, these data collection methods are based on sample enumeration by interviewing farmers and even complete enumeration does not have a strong field verification or measurement process. It is quite understandable that countries do not have enough resources to conduct such operations for complete data collection but it ultimately gives us false or non-reliable data inducing fatal implications.

\subsection{Recommendations}

On the basis of this study, following recommendation can be suggested.

- Irrigated areas data should be given primary importance during agricultural surveys and census and should be collected on priority basis with maximum possible precisions, along with physical verification of the area. As most of the countries follow FAO guidelines, APCAS should emphasize more on the importance of irrigated areas in agricultural statistics. GPS tagging of irrigated areas (point data) during enumeration and post enumeration check could help in increasing reliability of process.

- Asian countries should conduct irrigation census once every 5 years in order to get the detailed information about irrigated areas i.e. irrigation intensity, cropping pattern, means of irrigation, type of payment rationale and irrigated yield. India and Bangladesh could share their expertise in this regard. While remote sensing estimate could be used as cross check (post enumeration check) for the actual extent of irrigated areas

- South Asian countries should also develop an information system like AFSIS in ASEAN countries which would be processing the agricultural statistics on annual basis. Moreover, ASEAN countries should try to strengthen the AFSIS on the basis of improved data collection techniques with high sampling ratio. Irrigated area maps could be produced at regional level for an agreed time interval to view the overall situation of the region and to streamline the non-reported irrigated as well but firstly a political census is required in this regard.

- Countries with large variations in their database should investigate the reasons of uncertainty on the basis of spatial dispersion analysis to set the priority and efforts should be made to bring the non-recorded areas in their data archives. Remote sensing would be quite helpful in order to check their datasets for missing areas. 
- Efforts should be made to encourage the registration of farmer managed irrigation systems with irrigation or agricultural department. In case of self-reporting of water user associations, their capacity should be developed to collect accurate data for every crop season and irrigation/agriculture department officials should also make random checks to verify the reporting from farmer bodies.

- Asian countries should emphasize more on water conservation part with more research and development on devising cheap and smart methods for saving water in irrigation. More subsidies can be introduced to encourage farming community to adopt water saving methods. Cropping patterns can also be studied for any possible alternations in order to cope with climate change in long term policies.

\subsection{Prospects for Future Research}

On the basis of this research following prospects could be explored for future research.

- Dispersion analysis showed a big gap of irrigated areas information for large scale and small scale irrigation schemes. These gaps could be investigated country wise, in order to find reasons and loop holes in reporting system which cause this large information slip.

- Scoring table developed in section 6.3 could be further improved as the information regarding data collection and verification process was limited or sometime just briefly shared in literature. Responsible authorities or officials could be interviewed or contacted to share detailed methodology regarding reporting mechanism.

- Data regarding irrigation potential is usually provided by countries and this research shown that some countries are already irrigating beyond their calculated potential. Processes and definitions involved in calculating this potential could be investigated in order to find the actual potential of irrigated areas.

- Uncertainty in irrigated areas could raise questions at irrigated grain production as well, which in this research was obtained from FAO and assumed correct and constant for all numbers of irrigated areas. Including remote sensing techniques and crop classification approach, a detailed country wise study could be conducted to find the actual production coming from irrigated areas. Likewise grain production, water productivity and actual water use of countries can also be calculated on the basis of questions raised in implications part of this study. 


\section{References}

AMAR (2015) Statistical Centre of Iran. Timeline: Irrigated Land Area. Retrieved from http://www.amar.org.ir/english/Databases-Systems/Time-Series

APCAS (2012) FAO. Use of ICT for statistical reporting in Viet Nam's Ministry of Agriculture and Rural Development.

AQUASTAT (2005). Global Map of Irrigation Areas GMIA. Latest version 5.0. Retrieved from http://www.fao.org/nr/water/aquastat/irrigationmap/index10.stm

AQUASTAT (2009) East-Irrigation in Figures. AquaStat Survey 2008. Retrieved from ftp://ftp.fao.org/docrep/fao/012/i0936e/i0936e01.pdf

AQUASTAT (2012) Indonesia Country Profile. Irrigation in Southern and Eastern Asia in figures. Survey, 2011.

ASEAN. (2015) Food security information system: Thailand, Japan. Irrigated Area. Retrieved from http://www.afsisnc.org/statistics/data-selected

Asia and Pacific Commission on Agricultural Statistics APCAS. (2016) Food and Agriculture Organization. Retrieved from http://www.fao.org/economic/ess/ess-events/ess-apcas/en/

Asian Development Bank (2012) Action Plan for Improving Agricultural and Rural Statistics Viet Nam: Statistical System for Agricultural and Rural Statistics

Asian Development Bank (2012) Asian Irrigation Forum. Manila, Philippines. Retrived from http://www.adb.org/news/events/asian-irrigation-forum-2012

ADB (2014) Asia's food security challenges, and how we plan to address them. Retrieved from http://blogs.adb.org/blog/asia-s-food-security-challenges-and-how-we-plan-address-them

Asian Development Bank (2014) Improving Agricultural and Rural Statistics for Food Security. Retrieved from http://www.adb.org/projects/45261-001/main

Asian Development Bank (2015) Projects. Nepal. Project Number 38417-022 (2011). Project Number: 44214-023 (Building Climate Resilience of Watersheds in Mountain Eco-Regions) 2012Retrieved from http://www.adb.org/projects

Asian Development Bank (2015) Projects. Vietnam. Project ID: 41461-042 (2012), 44324-012 (2011) Retrieved from http://www.adb.org/projects

Asian Development Bank (2013). Food Security: What It Means for Asia and the Pacific, Food Security in Asia and the Pacific 
Asian Development Bank (2011). Food Security: Current Status and Factors Climate change and food security in the Pacific. Rethinking the options. Mandaluyong City, Philippines.

BADC (2015) Minor Irrigation Wing, Bangladesh Agricultural Development Corporation. Summary of Irrigation 2014-15. Retrived from http://badc.portal.gov.bd/site/page/ff51fd91-af1b-4606a956-c6ce3ad997a1/Summary-of-Irrigation-2014-15

Bangladesh Bureau of Statistics (2015), Agriculture wing. Agri Activity. Retrieved from http://www.bbs.gov.bd/PageWebMenuContent.aspx?MenuKey=176

Barker, R.; Molle, F. 2004. Evolution of irrigation in South and Southeast Asia. Colombo, Sri Lanka: Comprehensive Assessment Secretariat. (Comprehensive Assessment Research Report 5)

Barker, R.; Molle, F. 2004. Evolution of irrigation in South and Southeast Asia. Colombo, Sri Lanka: Comprehensive Assessment Secretariat. (Comprehensive Assessment Research Report 5)

Bastiaanssen, W. G. M. 1998. Remote sensing in water resources management: The state of the art. Colombo, Sri Lanka: International Water Management Institute.

Benjamin, Paul, Wai Fung Lam, Elinor Ostrom, and Ganesh Shivakoti. (1994). U.S. Agency for International Development. Institutions, incentives and irrigation in Nepal. Decentralization: Finance and Management Project.

Census of Agriculture (2008), Structure of Agricultural Holdings \& Livestock Population, Bangladesh Bureau of Statistics.

Central Bureau of Statistics (2012) Nepal Living Standards Survey 2010-2011, Third Statistical Report (Volume Two). Retrieved from http://cbs.gov.np/nada/index.php/catalog/37

Central Bureau of Statistics (2012). Nepal Living Standards Survey 2010-2011. NLSS Third, Methodology. Retrieved from http://cbs.gov.np/nada/index.php/catalog/37/study-description

Central Bureau of Statistics (2013) National Sample Census of Agriculture Nepal 2011/12. National Report.

Chaudhary, M.J. (1990) The Adoption of Tubewell Technology in Pakistan. The Pakistan Development Review. 29: 3 \& 4 (Autumn - Winter 1990) pp. 291-303

Crop Reporting Service (2012) Punjab. Base Line Survey, Agriculture Information System Building Provincial Capacity for Crop Forecasting and Estimation.

Dang, H.V., Palmkvist, G. (2015) Sweden - Vietnam Cooperation on Land. Administration in Vietnam.

Department of Irrigation (2007) Development of Database for Irrigation Development in Nepal. Planning, Design, and Monitoring \& Evaluation Division. 
Department of Irrigation. (2007) Final Report. Development of Database For Irrigation Development in Nepal.

Droogers, P. 2002. Global irrigated area mapping: Overview and recommendations. Working Paper 36. Colombo, Sri Lanka: International Water Management Institute.

Droogers, P., et al., Estimating actual irrigation application by remotely sensed evapotranspiration observations. Agric. Water Manage. (2010), doi:10.1016/j.agwat.2010.03.017

European Space Agency (2009) Globe Cover. Retrieved from http://due.esrin.esa.int/page_globcover.php

Facon.T. , Mukherji. A. (2010) Small-scale irrigation: Is this the future? Paper presented at the Water Crisis and Choices, ADB and Partners Conference, ADB HQ, Manila, Philippines.

FAO (2003) AQUASTAT- Getting To Grips With Water Information for Agriculture. Land and Water Development Division.

FAO (2004) Statistical Data Quality Framework: A multi-layered approach to monitoring and assessment. Retrieved from http://unstats.un.org/unsd/accsub/2004docs-CDQIO/1-FAO.pdf

FAO (2008) Asia and Pacific Commission on Agricultural Statistics (APCAS) 22nd Session, Country Reports. China.

FAO (2014) Asia and the Pacific must increase food production to meet future demand. Retrived from http://www.fao.org/news/story/en/item/216042/icode/

FAO (2015) Towards a New Green Revolution: Achievements of the Green Revolution.

FAO. IIASA. (2015) Global Agro-ecological Zones: Agro-climatic resources. Growing Period: Reference Length of Growing Period. Retrieved from http://www.gaez.iiasa.ac.at/w

François Molle (2001) Water Pricing in Thailand: Theory and Practice. DORAS-DELTA: Research Report No. 7.

Frolking, S., X. Xiao, Y. Zhuang, W. Salas and C. Li, 1999. Agricultural land-use in China: a comparison of area estimates from ground-based census and satellite-borne remote sensing. Global Ecology and Biogeography 8: 407-416.

Thenkabail. T, Schull. M, Turral. H. (2005) Ganges and Indus river basin land use/land cover (LULC) and irrigated area mapping using continuous streams of MODIS data International Water Management Institute (IWMI)

General Statistics Office (2006) Report on Rural, Agricultural \& Fishery Census in Vietnam, Retrieved from http://agro.gov.vn/map3/content/default_E.htm, http://www.gso.gov.vn/default_en.aspx?tabid=477\&idmid=4\&ItemID=13399 
General Statistics office (2015) National Statistics Indicator System. Group Targets. Agricultural Forestry and Fisheries Department. Retrieved from https://gso.gov.vn/default.aspx?tabid=732

Global irrigation water demand: Variability and uncertainties arising from agricultural and climate data sets Dominik Wisser, Steve Frolking, Ellen M. Douglas, Balazs M. Fekete, Charles J. Vo"ro"smarty, and Andreas H. Schumann

Gu Yuping (2001) Water Saving Irrigation Practice in China Demands, Technical System, Current Situation, Development Objective, and Countermeasures. China Irrigation \& Drainage Development Center, Ministry of Water Resources. Retrieved from http://www.icid.org/ws1_2001.pdf

Haghighi. A.T, Keshtkaran. P. (2008) Methods of Facing with Drought in Fars Province - Iran. Islamic Azad University, Estahban branch

Hugh Turral, David Molden, Prasad Thenkabail, Chandrashekkar Biradar, and Venkateswarlu Dheeravath, Notes on a meeting attended by November (4) 2005

ICID (2012). The Economics of Irrigated Rice in Thailand: what options for financing irrigation? ICID TF-FIN Workshop on Country Case Studies of Water Use Charging Systems and Available Finance of Irrigation (June 26, 2012) Retrieved from http://ppts.icidonline.org/adelaide/adel_fin_1.pdf

IFAD (2011) Smallholder Farming in Asia and the Pacific: Challenges and Opportunities. Retrieved from http://www.ifad.org/events/agriculture/doc/papers/ganesh.pdf

IIMI (1998) Asrar-ul-Haq. Managing Irrigation for Environmentally Sustainable Agriculture in Pakistan. Case Study of Punjab Irrigation Department, Consultancy Report.

International Commission on Irrigation and Drainage (2015) Country Profile. Indonesia. Retrieved from http://www.icid.org/cp_indonesia.html

International Water Management Institute (2016) Irrigated Area Maps. Retrieved from http://waterdata.iwmi.org/applications/irri_area/

Investing in Food and Agriculture in Asia and the Pacific. (2014, July 24). Retrieved from http://www.adb.org/news/infographics/investing-food-and-agriculture-asia-and-pacific

Irrigation and Public Health Department (2015) India. Himachal Pradesh. Job Profile Duties and Responsibilities of Various Posts in Irrigation and Public Health Department.

IWMI (2001) Tahir, Z. \& Habib, Z. Land and Water Productivity: Trends across Punjab Canal Commands, IWMI working Paper 14.

Japan International Cooperation Agency. JICA (2007), The Agricultural Statistics and Economic Analysis Development Project, Summary of Evaluation Results. Thailand. 
Joint Research Centre (2000) Global Land Cover (South Asia) Retrieved from http://forobs.jrc.ec.europa.eu/products/glc2000/products.php

MARD (2010) Heat, drought kill, damage 100,000ha of rice. Retrieved from http://www.mard.gov.vn/en/Pages/news_detail.aspx?NewsId=385\&Page=4

Merrey, D. J. (1996). Institutional design principles for accountability in large irrigation systems. Research Report 8. Colombo, Sri Lanka: International Irrigation Management Institute (IIMI).

Messdaghinia A, Alavi N (2010) Water situation in Iran: Challenges and achievements (Cross reference: Fundamentals of Irrigation Development and Planning, M.H. Ali, Fundamentals of Irrigation and On-farm Water Management: Volume 1)

Ministry of Agriculture (2014) Mehrdad, N.A, The Agricultural Survey Improvement Program in Islamic Republic of Iran. Center for Information \& Communication Technology.

Ministry of Agriculture (2014) Statistical analysis harvested area and yield of crops in 36 years (19822013): Total Harvested Area in Country. Retrived from http://amar.maj.ir/Portal/File/ShowFile.aspx?ID=ae2df9ab-7ad5-4c8d-82a3-ebb54dffd5bb

Ministry of Agriculture and Farmer Welfare (2012) Agricultural Statistics at a Glance 2012.

Department of Economic and Statistics. Retrieved from http://eands.dacnet.nic.in/latest_2012.htm

Ministry of Agriculture and Rural Development, MARD. (2000) Agriculture and Rural Development 5-Year Plan (2001-2005)

Ministry of Agriculture, 2015 Centre for Agriculture Data and Information Systems, Agricultural Statistics System in Indonesia, Ministry of Agriculture Indonesia.

Ministry of Agriculture, Forestry and Fisheries MAFF (2015). Statistics Department, Agricultural Statistical System in Japan. Retrieved from http://www.maff.go.jp/e/

Ministry of Energy (2015) Iran. Overview of Water Resources in Iran: Development Operations in Agricultural Lands.

Ministry of Land, Infrastructure, Transport and Tourism (2008) Water Balance in Japan: State of Water Use. Retrieved from

http://www.mlit.go.jp/tochimizushigen/mizsei/water_resources/contents/current_state.html

Ministry of Statistics and Program Implementation (2015) Agricultural Statistics. Crop and Land Use Statistics. Retrieved from http://mospi.nic.in/nscr/as.htm

Minor Irrigation Wing (2007) Ministry of Water Resources. Inida. 4th Census of Minor Irrigation Schemes (2006-2007). Table I- Minor Irrigation Schemes at a Glance. 
Molden, D, T. Oweis, P.Steduto, J.W. Kijne, M.A. Hanjra, P.S. Bindraban. 2007b. Pathways for increasing agricultural water productivity. In: Molden, D. (ed). Water for Food, Water for Life: A Comprehensive Assessment of Water Management in Agriculture. London: Earthscan and Colombo: International Water Management Institute

Mukherji, A.; Facon, T.; Burke, J.; de Fraiture, C.; Faurès, J.-M.; Füleki, B.; Giordano, M.; Molden, D.; Shah, T. 2009. Revitalizing Asia's irrigation: to sustainably meet tomorrow's food needs. Colombo, Sri Lanka: International Water Management Institute; Rome, Italy: Food and Agriculture Organization of the United Nations.

National Bureau of Statistics of China (2001) Communiqué on the results of the survey main data of land use (in Chinese language). Retrieved from http://www.stats.gov.cn/tjsj/tjgb/nypcgb/qgnypcgb/200203/t20020331_30456.html

National Bureau of Statistics of China (2008) Communiqué on Major Data of the Second National Agricultural Census of China. Retrieved from http://www.stats.gov.cn/english/NewsEvents/200802/t20080226_25993.html

Nickum, J.E (1995) Dam Lies and other Statistics, Taking the measure of irrigation in China, 1931-91. East-West Center Occasional Papers. Environmental Series.

Nickum, J.E. (2003) Irrigated Area Figures as Bureaucratic Construction of Knowledge: The Case of China, International Journal of Water Resources Development, 19:2, 249-262.

Oldenborgh G.J., Anne,U., Allen.M. (2012). The absence of a role of climate change in the 2011 Thailand floods. Retrieved from http://www1.ncdc.noaa.gov/pub/data/cmb/bamssotc/extreme-events/van-Oldenborgh-et-al.pdf

Pakistan Bureau of Statistics (2010) Agricultural Census 2010 Pakistan Report. All Pakistan Tables. Retrieved from http://www.pbs.gov.pk/content/agricultural-census-2010-pakistan-report

Pakistan Bureau of Statistics (2012) Methodology of Crop Estimates. Retrieved from http://www.pbs.gov.pk/content/methodology-crop-estimate

Rahman, M.W., \& Parvin, L. (2009). Impact of Irrigation on Food security in Bangladesh for the Past Three Decade. Journal of Water Resource and Protection, p.p. 216-225.

Ministry of Statistics and Programme Implementation, India (2001) National Report of the National Statistical Commission: Agricultural Statistics. Retrieved from http://mospi.nic.in/nscr/as.htm

Reuters India, (2015). India to spend $\$ 8$ billion to boost irrigation, reduce dependence on monsoon. Retrieved from http://in.reuters.com/article/india-irrigation-idINKCNOPCOPT20150702

Rosegrant, M., \& Svendsen, M. (1993). Asian food production in the 1990s: Irrigation investment and management policy. Food Policy, 18(1), 13-32. 
Postel. S (1999). Pillar of Sand: Can the Irrigation Miracle Last? New York: W.W. Norton \& Company. (Retrieved from Original Book)

Shiati, K. (1999) World Water Vision for Food: Country Case Study, Iran. Paper presented at the Middle East and North Africa (MENA) Consultation Meeting, Italy. (Cross reference from IWMI working paper 118)

Siebert.S , Doll.P, Hoogeveen.J , Faures. J.-M., Frenken. K , and Feick. S (2005) Development and validation of the global map of irrigation areas. Hydrology and Earth System Sciences, 9, $535-547$.

Statistics Centre of Iran (2003) Agriculture Census 2003. Explanatory Notes. Retrieved From http://www.fao.org/fileadmin/templates/ess/documents/world_census_of_agriculture/main_res ults_by_country/Iran_2003F.pdf

Thenkabail, P.S.; Lyon, G.J.; Turral, H.; Biradar, C.M. Remote Sensing of Global Croplands for Food Security; CRC Press-Taylor and Francis Group: Boca Raton, London, UK, 2009; p. 556.

Thenkabail. P.S. , Dheeravath. V , Biradar.C.M , Reddy P.O Gangalakunta , Noojipady. P, Gurappa.C , Velpuri. M , Gumma. M and Li.Y , (2009) Irrigated Area Maps and Statistics of, Irrigated Area Maps and Statistics of India Using Remote Sensing and National Statistics

Thenkabail, P.S., Biradar.C.M., Noojipady. P, Dheeravath, Venkateswarlu, Li, Yuanjie, Velpuri, Manohar, Gumma, Muralikrishna. G, Obi Reddy P., Hugh. T, Cai. X, Vithanage. J. S, Mitchell A. and Dutta. R (2009) Global irrigated area map (GIAM), derived from remote sensing, for the end of the last millennium', International Journal of Remote Sensing,30:14,3679-3733

United Nations (2006) Goals, targets and indicators Millennium ProjectGoals, targets \& indicators. (n.d.). Retrieved from http://www.unmillenniumproject.org/goals/gti.htm

USDA (2015). THAILAND: Irrigation Shortage Reduces 2015/16 Rice Production. Foreign Agricultural Services, Commodity Intelligence Report. Retrieved from http://www.pecad.fas.usda.gov/highlights/2015/10/th/index.htm

USDA. (2008). IRAN: 2008/09 Wheat Production Declines Due to Drought. Foreign Agricultural Services, Commodity Intelligence Report. Retrieved from http://www.pecad.fas.usda.gov/highlights/2008/05/iran_may2008.htm

USGS (2015) Global Land Cover Characterization. LULC 1992. Retrieved from https://lta.cr.usgs.gov/GLCC

Vaidyanathan, A., and K. Sivasubramaniyan, 2004. Efficiency of water use in agriculture, Economic and Political Weekly, pp. 2989-2996.

Wani, S.P., Rockstrom, J. Oweis, T. (2009) Rainfed Agriculture: Unlocking the Potential. CA CABI Series. 
Wim G.M. Bastiaanssen, David J. Molden1, Ian W. Makin. (2000). Remote sensing for irrigated agriculture: examples from research and possible applications. Agricultural Water Management 46 (137-155)

World Bank (1991) Project Completion Report. Bangladesh Second Deep Tubewells Project. Repot No. 9983.

World Bank (2015) Projects and Operations. Indonesia. Irrigation and Drainage Sector. Project ID: P003735, P003718. P003712, P003706, P003702, P115052 Retrieved from http://www.worldbank.org/projects

World Bank (2015) Projects and Operations. Nepal. Irrigation and Drainage Sector. Project ID: Nepal 2007 World Bank, Project ID P105860 (Poverty Alleviation Fund II ), ID P099296 (Irrigation and Water Resources Management Project) 2007, ID P118179 (Modernization of R-J-K Irrigation Scheme-I) 2011. Retrieved from http://www.adb.org/projects

World Bank (2015) Projects and Operations. Vietnam. Irrigation and Drainage Sector. Project ID P004834 P152309, P127201, P131775, P130014. Retrieved from http://www.worldbank.org/projects

Xiangming Xiao a, Stephen Boles, Steve Frolking, Changsheng Li, Jagadeesh Y. Babu, William Salas, Berrien Moore III . Mapping paddy rice agriculture in South and Southeast Asia using multitemporal MODIS images, 2005

Y.J.Li. (2009)History of Irrigated Areas of World, Remote Sensing Of Global Croplands for Food Security, Edited by Prasad S. Thenkabail 


\section{Appendices}

Appendix A (Questionnaire Sample - Response from Nepal)

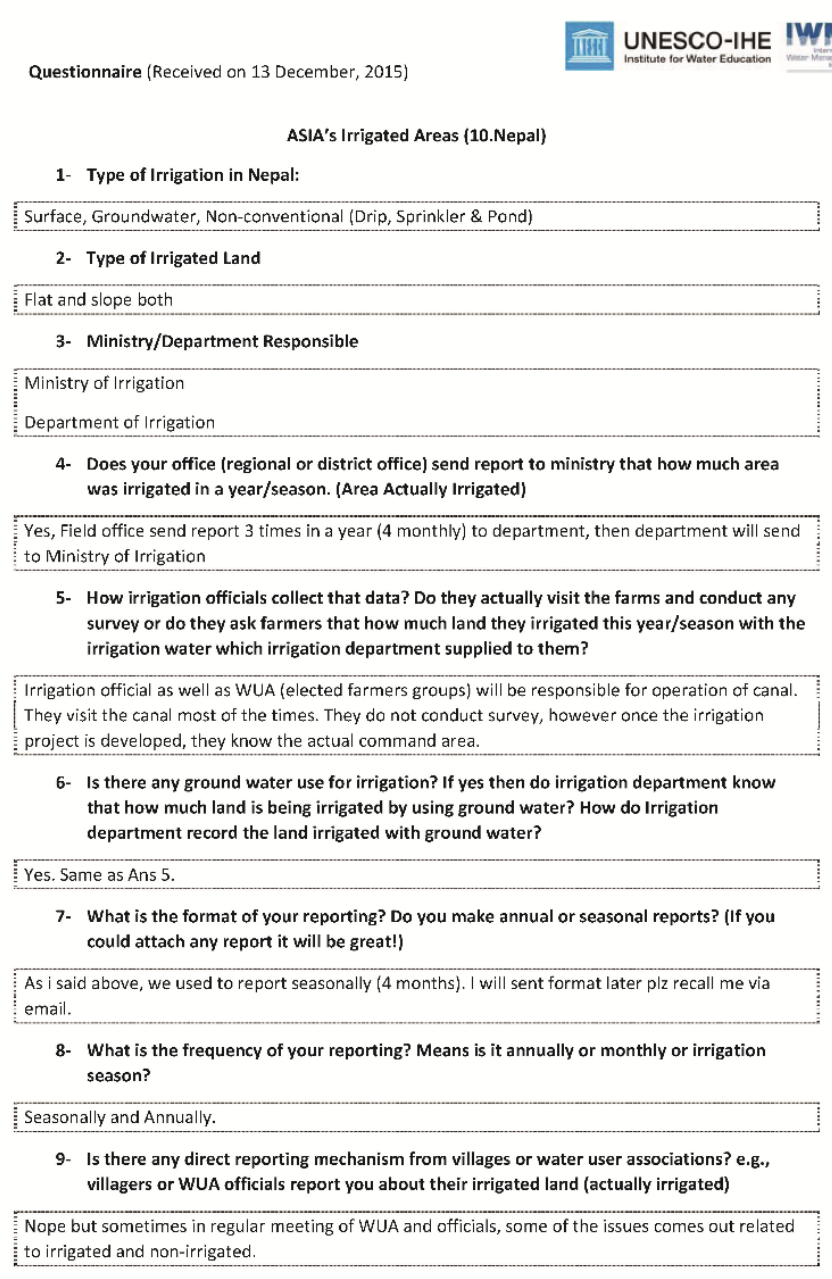
IIIIII UNESCO-IHE IWM
10- Is there any tax or fees linked with irrigation water which irrigation department supply them? Is water fee structure is linked with irrigated land or volume of water?
Yes there is Irrigation service fees (ISF). The amount to be collected depends on WUA. The water fees is collected according to irrigated land on yearly basis. ISF ranges from 3-10 USS/ha/year - in some irrigation project, ISF is collected seasonally.
11- What is the reporting mechanism of Farmer Managed Irrigation Systems? How Irrigation record the Irrigated Area under FMIS?
Most of the FMIS system needs rehabilitation/maintenance cost yearly. Govt. allocates the budget for FMIS through field office. Once the officials goes to FMIS system, they record the irrigated area
12- Does irrigation department maintain any records of informal irrigation systems in the area? Do irrigation department conducts any surveys to record informal irrigation registered with department How that survey is conducted?
No, there are so many informal irrigation system. Department of lrrigation do not develop and
maintenance the project which has command area less than 25 ha in hill and 100 ha in Plain area.
13- Any other information which you think would be useful for study and to develop
understanding about Nepal's irrigation sector.




\section{Appendix B (Irrigation Census India, Questionnaire for Minor Irrigation Schemes)}

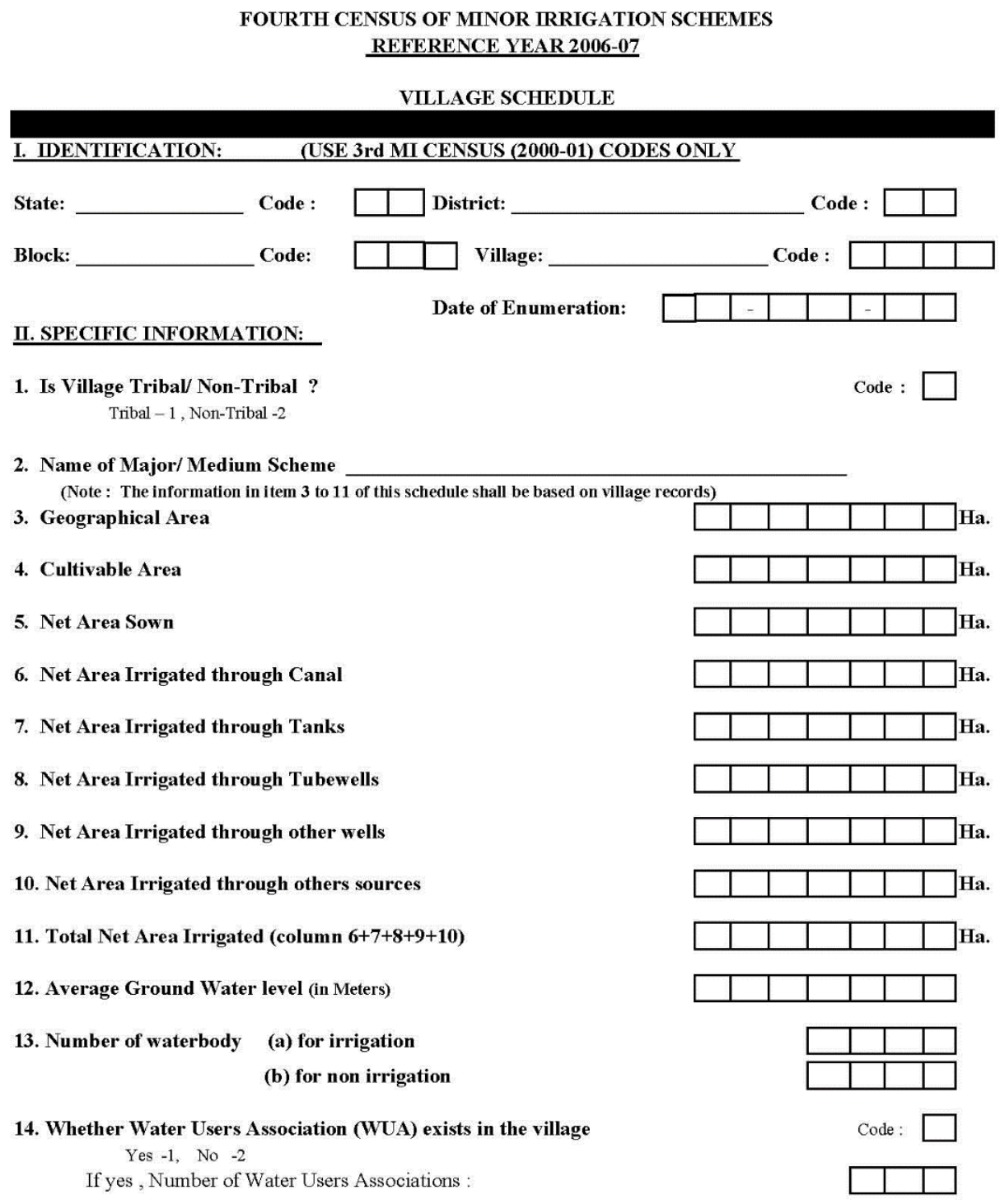

Schedule wise Summary of M I schemes in the village

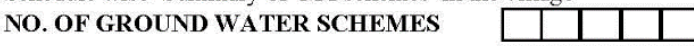

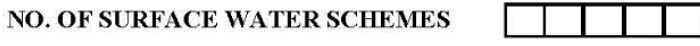

NO. OF TOTAL SCHEMES

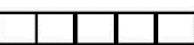

Checked by:

Name

Signature of Enumerator:

Designation of Supervisory officer:

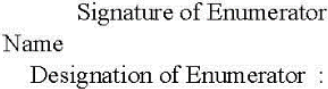




\title{
(Questionnaire for Ground Water Resources)
}

\author{
FOURTH CENSUS OF MINOR IRRIGATION SCHEMES \\ REFERENCE YEAR 2006-07
}

SCHEDULE 1 : GROUND WATER SCHEMES

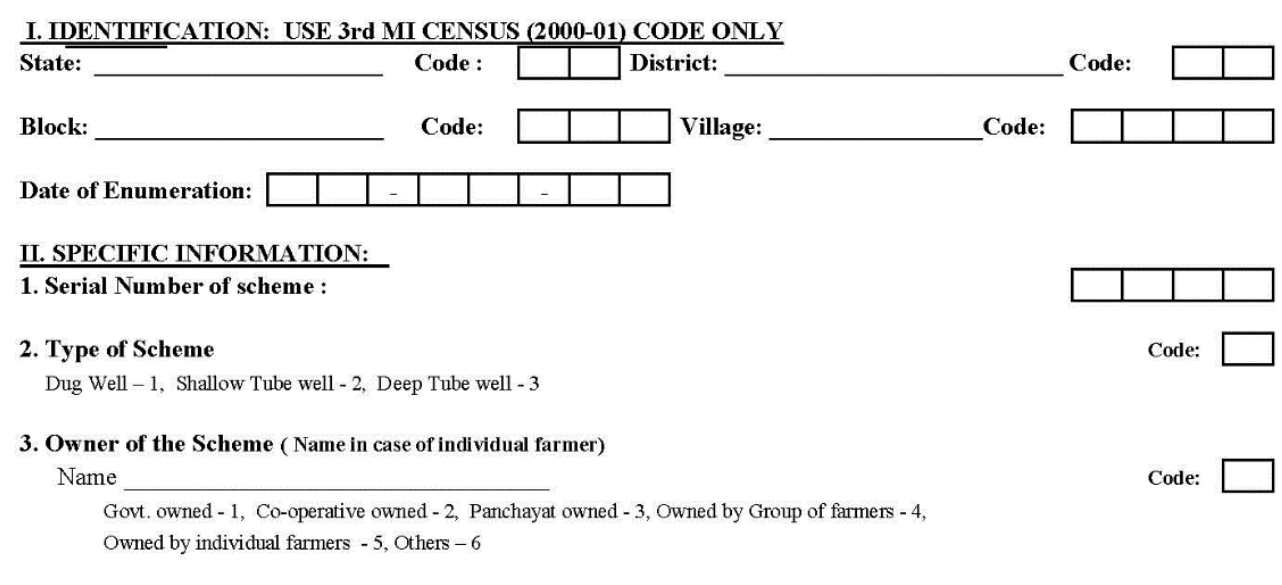

4. Khasra number /Plot No./Survey No. in which the scheme is located

5(a). Total Holding of owner (in case of individual owner only)

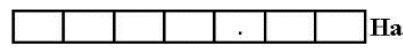

(b) Social Status of Owner (in case of individual owner only) Scheduled caste -1 , Scheduled tribe -2, OBC- 3 , Others 4

6. Year of Commissioning of the Scheme

On or before 2000-2001-1, during 2001-02 - 2, during 2002-03 - 3, during 2003-04 - 4

during 2004-05 -5, during 2005-06 -6, during 2006-07 - 7

7. Nature of scheme

Dugwell : Pucca-1, Kuchha-2, Dug-cum-bore well-3, Others-4

Shallow Tubewell : Shallow Tube well -1, Filter point-2, Others - 3

Deep Tubewell : Deep Tube Well - 1, Others - 2

8. Details of the scheme

(a) Depth of the well (in metres)

(b ) Diameter (unit in meters for dug well and $\mathrm{mm}$ for tube well )

(c) Depth of Bore (in meters) (in case of Dug-cum-bor ewell)

(d) Distance of nearest well (in metres)

9. (a) Cost of construction of the scheme

(b) Cost of machinery

(c) Cost of maintenance during (2006-07)

(Rs.)

(Rs.)

(Rs.)

10. Major source of finance

Bank loan - 1, Government fund -2 , Own savings -3 , Money lender -4 , Others -5

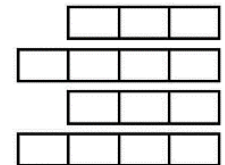

Code:

Code :

Code : 
In use -1 , Temporarily Not in Use -2 , Permanently Not in use - 3

12. Reason code for Temporarily "not in use" Scheme (code - 2 in item 11)

Code:

Non availability of adequate power -1 , Mechanical break down -2 ,

Less discharge in the well - 3, Any other reason - 4

13. Reason code for Permanently "not in use" Scheme (code -3 in item 11)

Code

Due to salinity - 1, Dried up - 2, Destroyed beyond repair - 3

Due to sea water intrusion - 4, Due to industrial effluents - 5,

Due to other reasons - 6

14. Water distribution / application method used

Code :

Open Water Channel (lined / pucca) - 1, Open Water Channel(unlined / kucha) - 2

Under ground pipe -3 , Surface pipe - 4, Drip - 5, Sprinkler - 6 , Other - 7

15. Lifting device

Code :

Submersible pump - 1, Centrifugal Pump - 2, Turbine - 3, Manual/animal - 4, Other - 5

16. Source of energy

Code :

Electric - 1, Diesel - 2, Wind Mills - 3, Solar - 4, Manual/animal - 5, Others - 6

17. Horse Power of Lifting device

(ignore if lifting device is manual/animal driven )

18. Number of days operating pump (ignore, if lifting device is manualanimal driven )

During Kharif season

During Rabi season

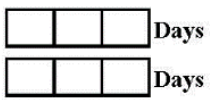

19. Average hours of pumping per day (ignore, if lifting device is manualanimal driven )

During Kharif season

During Rabi season

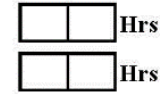

20. Culturable Command Area

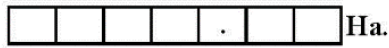

21. Whether the scheme is located in the command of

Major \& Medium Schemes like Canals etc.

Code :

\begin{tabular}{|c|c|c|}
\hline No & --1 & ( Keep item 34 to item 38 blank) \\
\hline & & ep item 27 to item 31 blank) \\
\hline ( for augumentation only) & --3 & (Keep item 22 to item 38 blank) \\
\hline
\end{tabular}



22. Kharif
23. Rabi
24. Perennial

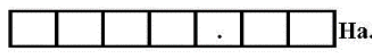
25. Other
26 Total

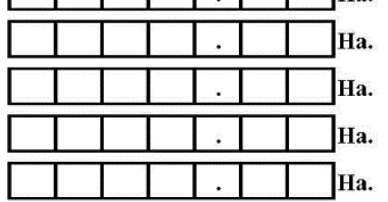

SEASON WISE ACTUAL AREA IRRIGATED DURING 2006-07 (IPU)
27. Kharif
28. Rabi
29. Perennial
30. Other
31. Total

\begin{tabular}{|l|l|l|l|l|l|l}
\hline & & & &. & & \\
\hline \hline & & & &. & & \\
\hline на. \\
\hline \hline & & & &. & & \\
\hline & & & &. & & на. \\
\hline & & & &. & & \\
\hline & & & &. & & \\
\hline & & & & На. \\
\hline
\end{tabular}

32. Whether the scheme is functioning well since its commissioning ? ( $\mathrm{Y} / \mathrm{N})$

Code :

33. If No, Maximum Potential utilised from the Scheme in any year

SEASON WISE AREA IRRIGATED BY THE MINOR IRRIGATION SCHEMES (DURING 2006-07) AS SUPPLEMENTARY SOURCE IN THE COMMAND OF MAJOR \& MEDIUM

\section{SCHEMES}
34. Kharif
35. Rabi
36. Perennial
37. Other
38. Total

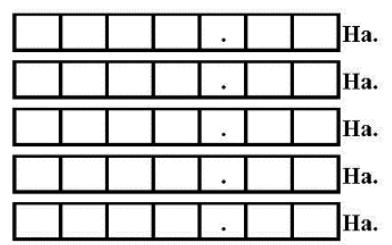

39. Reasons for under utilisation of schemes

Non availability of adequate power -1 , Mechanical break down -2 ,

Code : $\square$

Less discharge in the well -3 , Any other reason - 4 , Not applicable - 5

Checked by:

Name

Designation
Signature of Enumerator:

Name

Designation : 


\section{(Questionnaire for Surface Water Schemes)}

FOURTH CENSUS OF MINOR IRRIGATION SCHEMES

\section{REFERENCE YEAR 2006-07}

SCHEDULE 2 : SURFACE WATER SCHEMES

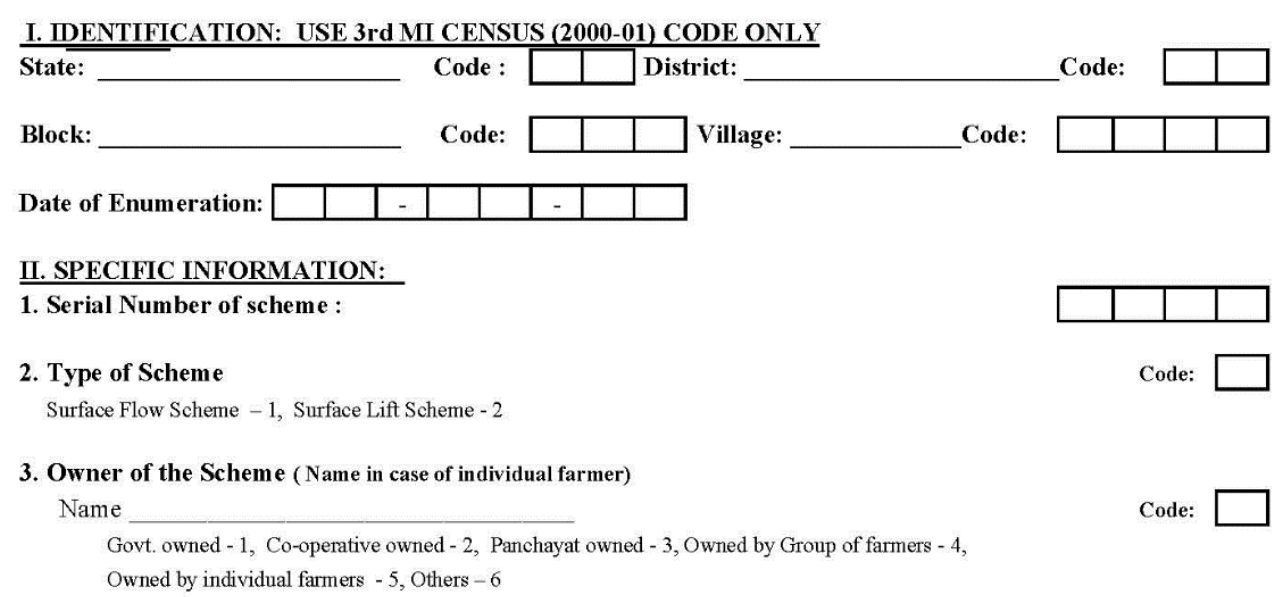

4. Khasra number/Plot No./Survey No. in which the scheme is located

5(a). Total Holding of owner (in case of individual owner only)

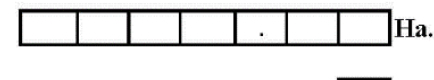

(b) Social Status of Owner (in case of individual owner only)

Code: Scheduled caste -1 , Scheduled tribe $-2, \mathrm{OBC}-3$, Others 4

6. Year of Commissioning of the Scheme

Code :

On or before 2000-2001 - 1, during 2001-02 - 2, during 2002-03 - 3, during 2003-04 - 4

during 2004-05 -5, during 2005-06 -6, during 2006-07 - 7

7. Nature of scheme

Code :

Surface Flow Scheme : Reservoirs - 1, Tanks -2, Other Storages -3, Permanent diversion - 4, Temporary diversion - 5

Water conservation-cum-ground water recharge schemes /percolation tanks/check dams etc - 6

Spring Channel - 7, Other - 8

Surface lift Scheme : On River - 1, On Stream - 2, On drain/canal - 3, On Tanks/Ponds/Reservoirs - 4, Others - 5

8. (a) Cost of construction of the scheme

(b) Cost of machinery

(c) Cost of maintenance during (2006-07)

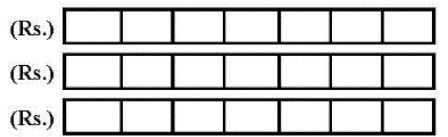

9. Major source of finance

Bank loan -1 , Government fund -2 , Own savings -3 , Money lender -4 , Others -5

Code : 
10. Current Status of the Scheme

Code:

In use -1 , Temporarily Not in Use - 2, Permanently Not in use - 3

11. Reason code for Tem porarily "not in use" Scheme (code - 2 in item 10)

Code:

Non availability of adequate power -1 , Mechanical break down -2 ,

Less discharge of water -3 , Storage not filled up fully - 4

Siltation of canal/storage - 5 , Breakdown of channels - 6 , Any other reason - 7

12. Reason code for Permanently "not in use" Scheme (code - 3 in item 10)

Code:

Due to salinity - 1, Dried up - 2 , Destroyed beyond repair - 3 ,

Due to sinking - 4, Due to other reasons - 5

13. Water distribution / application method

Code :

Open Water Channel (lined / pucca) - 1, Open Water Channel(unlined / kucha) - 2

Under ground pipe -3 , Surface pipe -4 , Drip -5 , Sprinkler -6 , Others -7

14. Lifting device (in case of Surface lift scheme)

Code :

Submersible pump - 1, Centrifugal Pump - 2, Turbine - 3, Manual/animal - 4, Other - 5

15. Source of energy

Code :

Electric - 1, Diesel - 2, Wind Mills - 3, Solar - 4, Manual/animal - 5, Others - 6

16. Horse Power of Lifting device (ignore, if lifting device is manualanimal driven )

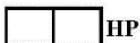

17. Number of days operating pump (ignore, if lifting device is manual/animal driven )

During Kharif season

During Rabi season

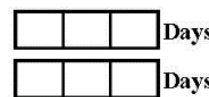

18. Average hours of pumping per day (ignore, if lifting device is manual/animal driven )

During Kharif season

During Rabi season

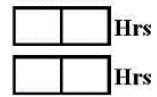

19. Culturable Command Area

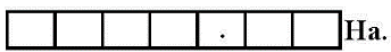

20. Whether the scheme is located in the command of

Major \& Medium Schemes like Canals etc.

Code :
No
--- 1 (Keep item 33 to item 37 blank)
Yes
-- 2 (Keep item 26 to item 30 blank)
Yes(for augumentation only) $\quad---3$ (Keep item 21 to item 37 blank) 
10. Current Status of the Scheme

Code:

In use -1 , Temporarily Not in Use - 2, Permanently Not in use - 3

11. Reason code for Tem porarily "not in use" Scheme (code - 2 in item 10)

Code:

Non availability of adequate power -1 , Mechanical break down -2 ,

Less discharge of water -3 , Storage not filled up fully - 4

Siltation of canal/storage - 5 , Breakdown of channels - 6 , Any other reason - 7

12. Reason code for Permanently "not in use" Scheme (code - 3 in item 10)

Code:

Due to salinity - 1, Dried up - 2 , Destroyed beyond repair - 3 ,

Due to sinking - 4, Due to other reasons - 5

13. Water distribution / application method

Code :

Open Water Channel (lined / pucca) - 1, Open Water Channel(unlined / kucha) - 2

Under ground pipe -3 , Surface pipe -4 , Drip -5 , Sprinkler -6 , Others -7

14. Lifting device (in case of Surface lift scheme)

Code :

Submersible pump - 1, Centrifugal Pump - 2, Turbine - 3, Manual/animal - 4, Other - 5

15. Source of energy

Code :

Electric - 1, Diesel - 2, Wind Mills - 3, Solar - 4, Manual/animal - 5, Others - 6

16. Horse Power of Lifting device (ignore, if lifting device is manualanimal driven )

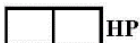

17. Number of days operating pump (ignore, if lifting device is manual/animal driven )

During Kharif season

During Rabi season

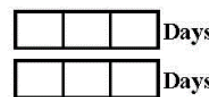

18. Average hours of pumping per day (ignore, if lifting device is manual/animal driven )

During Kharif season

During Rabi season

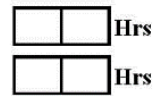

19. Culturable Command Area

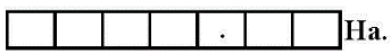

20. Whether the scheme is located in the command of

Major \& Medium Schemes like Canals etc.

Code :
No
--- 1 (Keep item 33 to item 37 blank)
Yes
-- 2 (Keep item 26 to item 30 blank)
Yes(for augumentation only) $\quad---3$ (Keep item 21 to item 37 blank) 


\section{Appendix C (Questionnaire, Agriculture Census -2008)}

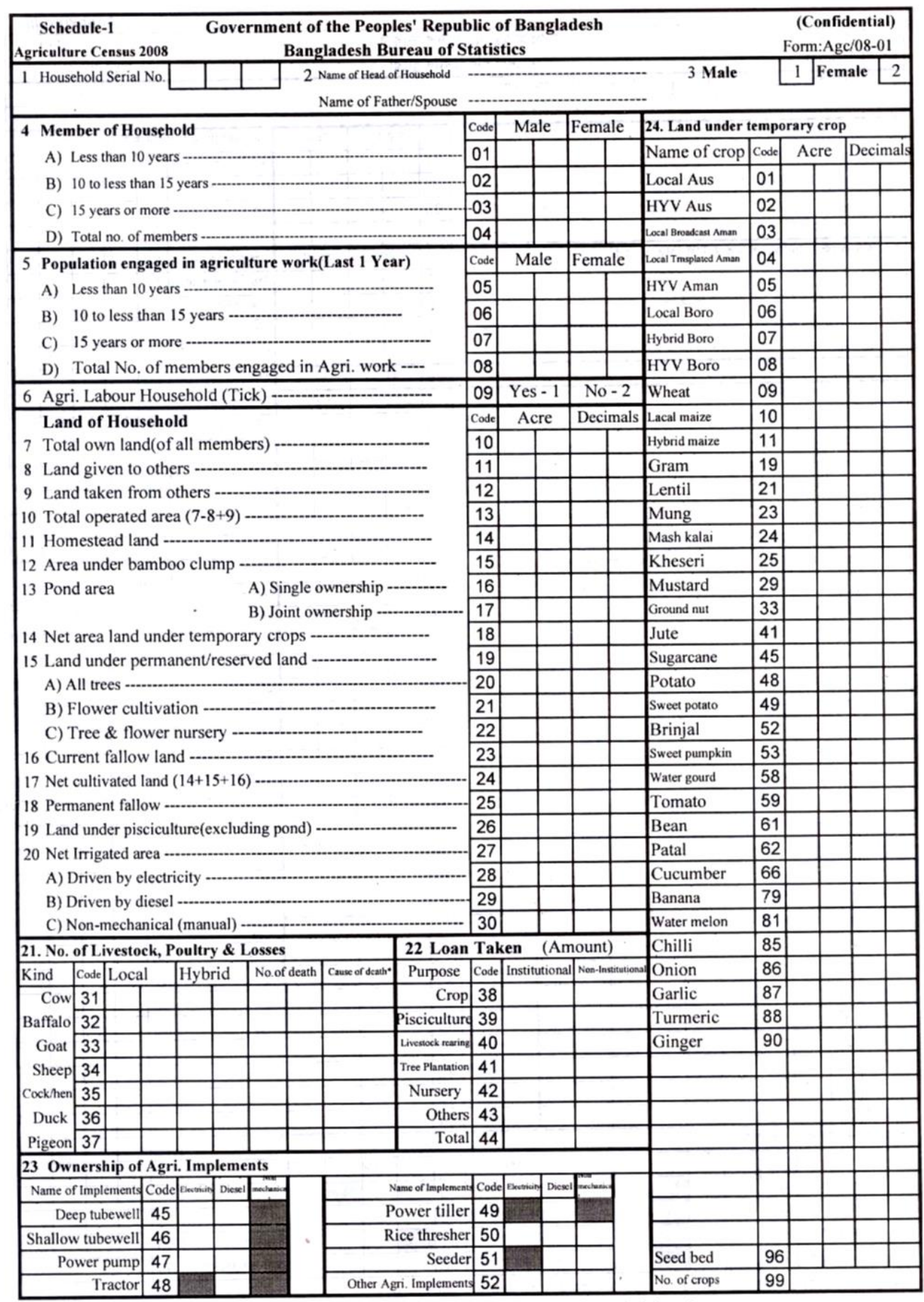

${ }^{*}$ Cause of Death Code: Flood -1, Cyclone-2, Epidemic-3, Disease-4, Snake Bite-5 \& Other-6 


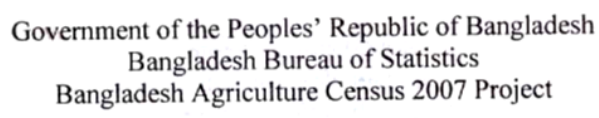

\section{Agriculture Census-2008}

\section{TALLY SHEET}

Part-1: Identification of Enumeration Area

\begin{tabular}{|l|l|l|l|}
\hline \multicolumn{1}{|c|}{ Identification } & \multicolumn{1}{c|}{ Name Code } \\
\hline District/Zila & & & \\
\hline Upazila/Thana & & & \\
\hline Union/Ward & & & \\
\hline Mauza/Mahalla & & & \\
\hline Enumeration Area No. & & \\
\hline R.M.O Code & & \\
\hline
\end{tabular}

Part-2: Situated within this Enumeration Area

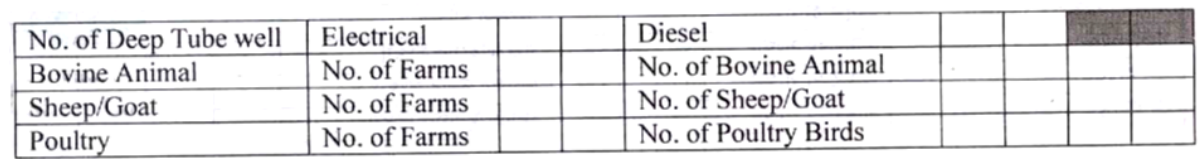

\section{Part-3: Included in this Enumeration Area}

\begin{tabular}{|c|l|c|c|c|}
\hline S1. No. & \multicolumn{1}{|c|}{ Kind of Household } & \multicolumn{2}{|c|}{ Number } \\
\hline 1. & Total Household (Ques. 1) & & & \\
\hline 2. & Agriculture Labour Household(Ques. 6) & & & \\
\hline 3. & Household with no own land (Ques.7) & & & \\
\hline 4. & Household took land from others (Ques.9) & & \\
\hline 5. & Household with Cultivated Area 5 decimals or more (Ques.17) & & \\
\hline 6. & Household cultivated Hybrid Boro (Ques. 24, Code 07) & \\
\hline
\end{tabular}

\section{Part-4: Identification of Enumerator \& Data Entry Operator}

\begin{tabular}{|l|l|l|l|}
\hline \multicolumn{1}{|c|}{ Designation } & Name & Signature & Date \\
\hline Enumerator & & & \\
\hline Supervisor & & & \\
\hline Zonal Officer & & & \\
\hline Data Editor & & & \\
\hline Data Entry Operator & & & \\
\hline
\end{tabular}




\section{Appendix D (Official Reporting Document - National Statistical Agency, Indonesia)}

BADAN PUSAT STATISTIK

DAN

SP-LAHAN

\section{LAPORAN PENGGUNAAN LAHAN}

(Isian dalam hektar bilangan bulat)

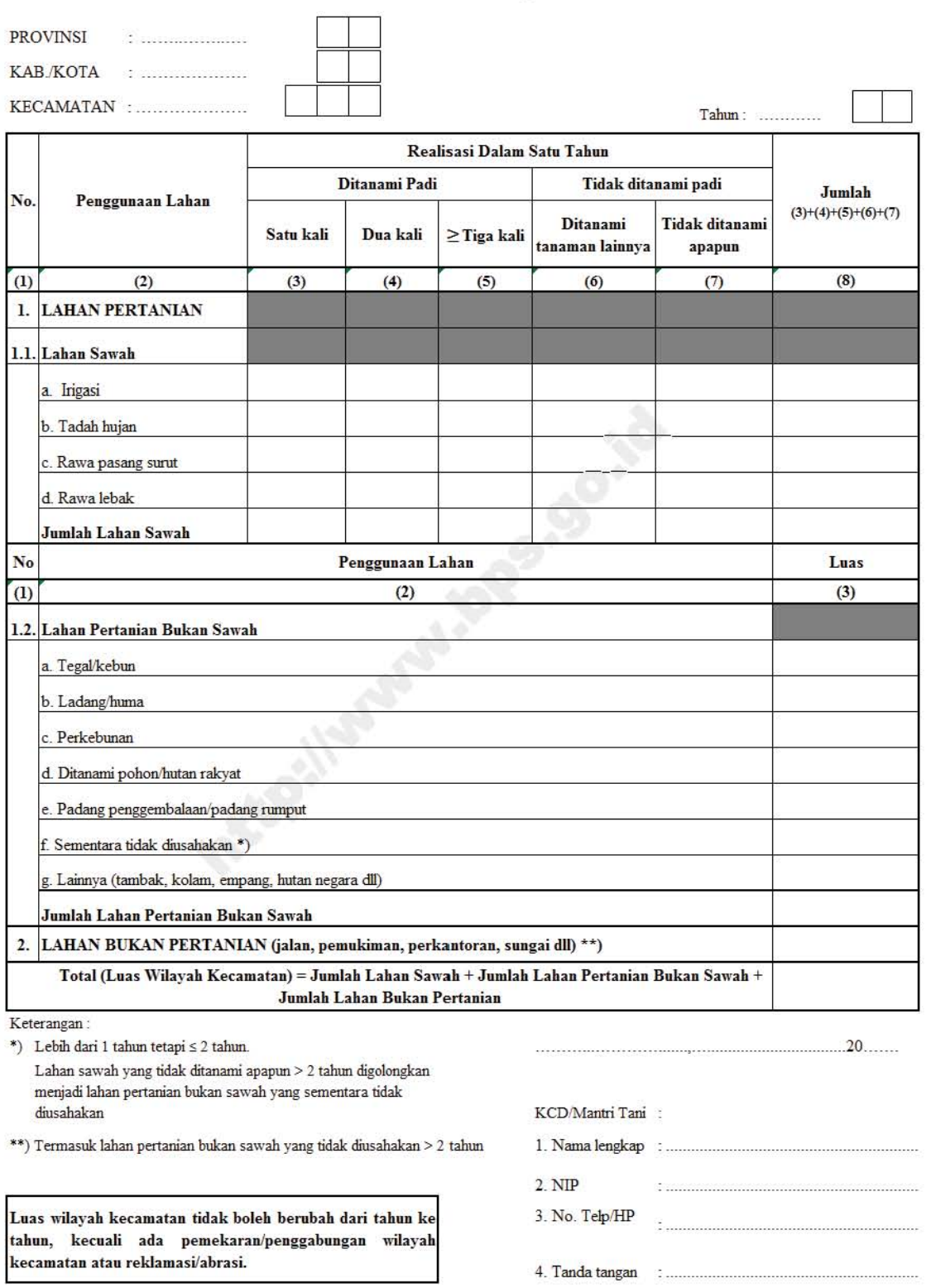


Appendix E (Official Reporting Form, District Irrigation Officer, Indonesia)

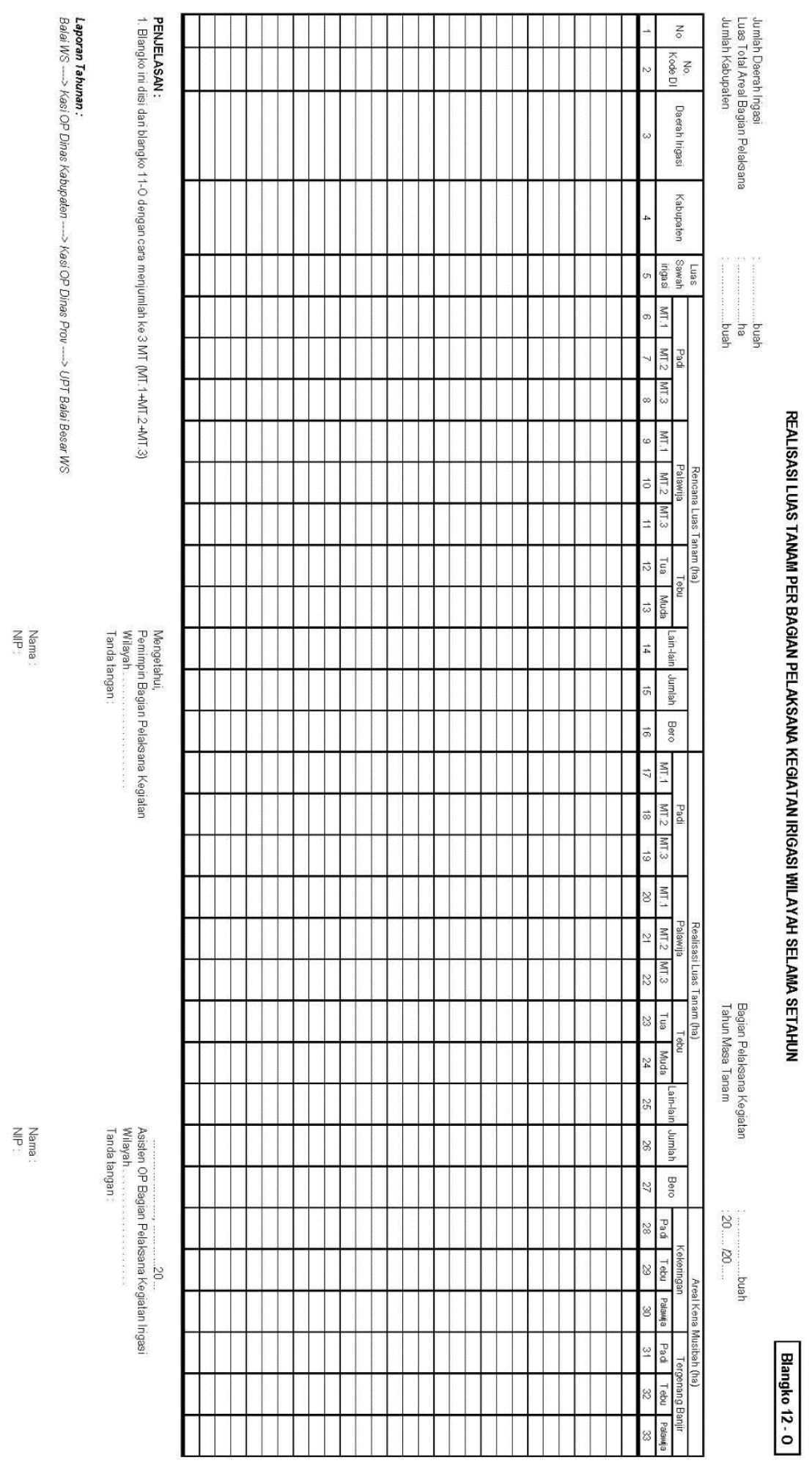




\section{Appendix F Irrigated Areas information in Nepal (District wise)}

TABLE 7

Present Level of Irrigation Development

\begin{tabular}{|c|c|c|c|c|c|c|c|c|c|c|c|c|c|}
\hline \multirow{3}{*}{ DISTRICT } & \multirow{3}{*}{$\underset{\text { OVERALI }}{\text { TOTAL }}$} & \multirow{3}{*}{$\begin{array}{c}\text { TOTAL } \\
\text { IRRIGABLE }\end{array}$} & \multicolumn{4}{|c|}{ SURFACE FMIS } & & & & & & & \\
\hline & & & AGENCIES & ISSTTED & & & DOI & TOTAI & & ONDWA] & TER & NON- & $\begin{array}{c}\text { TOTAL } \\
\text { IRRIGATED }\end{array}$ \\
\hline & & & NEW & REH & & & & & STW & DTW & TOTAL & & $\mathrm{EA}(\mathbf{H} \mathbf{H})$ \\
\hline Eastern Development Region & & & & & & & & & & & & & \\
\hline Eastem Region Terai Ecologieal Belt & & & & & & & & & & & & & \\
\hline Thapa & 109529 & 109530 & 4482 & 8553 & 46951 & 59986 & 8000 & 67986 & 20794.5 & 240 & 21034.5 & 1153 & 90174 \\
\hline Morang & 102938 & 99959 & 996 & 15322 & 17068 & 33386 & 33500 & 66886 & 22155.5 & 270 & 22425.5 & 440 & 89752 \\
\hline Saptari & 76949 & 76950 & 210 & 5665 & 1863 & 7738 & 36425 & 44163 & 11387 & 80 & 11467 & 168 & 55798 \\
\hline Siraha & 77726 & 77726 & 1083 & 6150 & 3186 & 10419 & 14815 & 25234 & 13163.5 & 620 & 13783.5 & 89 & 39107 \\
\hline Sunsari & 71757 & 70629 & $\begin{array}{r}110 \\
\end{array}$ & 8171 & $\begin{array}{r}557 \\
557\end{array}$ & $\begin{array}{r}8838 \\
\end{array}$ & 34500 & 43338 & 21612 & 40 & $\begin{array}{r}21652 \\
\end{array}$ & 167 & 65157 \\
\hline Eastern Terai & 438899 & 434794 & 6881 & 43861 & 69625 & 120367 & 127240 & 247607 & 89112.5 & 1250 & 90362.5 & 2017 & 339987 \\
\hline Eastern Region Hill Ecological Belt & & & & & & & & & & & & 0 & \\
\hline Bhojpur & 34676 & 6820 & 810 & 1126 & 361 & 2297 & 0 & 2297 & 0 & 0 & 0 & 210 & 2507 \\
\hline Dhankuta & 26797 & 7495 & 825 & 1986 & 2228 & 5039 & 0 & 5039 & 0 & 0 & 0 ] & 205 & 5244 \\
\hline Iam & 36405 & 12742 & 1381 & 3158 & 975 & 5514 & 0 & 5514 & 0 & 0 & 0 & 1338 & 6852 \\
\hline Khotang & 37950 & 8859 & 1133 & 1764 & 1750 & 4647 & 200 & 4847 & 0 & 0 & 0 & 33 & 4880 \\
\hline Okhaldhunga & 24151 & 4478 & $\begin{array}{r}852 \\
\end{array}$ & 1187 & 1311 & 3350 & 240 & 3590 & 0 & 0 & 0 & 9 & 3599 \\
\hline Panchthar & 32252 & 7241 & 956 & 1753 & 5337 & 8046 & 0 & 8046 & 0 & 0 & 0 & 647 & 8693 \\
\hline Terathum & 21662 & 6282 & 972 & 1492 & 2253 & 4717 & 0 & 4717 & 0 & 0 & 0 & 215 & 4932 \\
\hline Udaypur & 30773 & 18408 & 1136 & 1713 & 7969 & 10818 & 390 & 11208 & 674 & 0 & 674 & 91 & 11973 \\
\hline \begin{tabular}{|l|l|} 
Eastern Hill \\
\end{tabular} & 244666 & 72325 & 8065 & 14179 & 22184 & 44428 : & 830 & 45258 & 674 & 0 & 674 & 2748 & 48680 \\
\hline Eastern Region Mountain Ecological & 1 Belt & & & & & & & & & & & 0 & \\
\hline Sankhuwasabha & 25972 & 5170 & 466 & 1877 & 3818 & 6161 & 0 & 6161 & 0 & 0 & 0 & 176 & 6337 \\
\hline $\begin{array}{l}\text { Solukhumbu } \\
\text { Sula }\end{array}$ & 17734 & 2038 & 164 & 977 & 2712 & 3853 & 0 & 3853 & 0 & 0 & 0 & 29 & 3882 \\
\hline $\begin{array}{l}\text { Taplejung } \\
\text { Toung }\end{array}$ & 22102 & 7443 & 1227 & 1454 & 4586 & $\begin{array}{l}7033 \\
7267\end{array}$ & 0 & 7267 & 0 & 0 & 0 & 491 & 7758 \\
\hline Eastern Mountain & 65808 & 14651 & 1857 & 4308 & 11116 & 17281 & 0 & 17281 & 0 & 0 & 0 & 696 & 17977 \\
\hline Eastern Region & 749373 & 521770 & 16803 & 62348 & 102925 & 182076 & 128070 & 310146 & 897865 & 1250 & 910365 & 5461 & 4066435 \\
\hline Central Developmen & & & & & & & & & & & & 0 & \\
\hline Central Region Terai Ecological Belt & & & & & & & & & & & & 0 & \\
\hline Bara & 61766 & 60390 & 0 & 9820 & 8802 & 18622 & 13720 & 32342 & 21309 & 620 & 21929 & 54 & 54325 \\
\hline Chitwan & 44537 & 41963 & 1009 & 14365 & 0 & 15374 & 10900 & 26274 & 3013 & 280 & 3293 & 56 & 29623 \\
\hline Dhanusha & 72925 & 72925 & 1475 & 5700 & 8457 & 15632 & 14500 & 30132 & 11442 & 2790 & 14232 & 707 & 45071 \\
\hline Mahottari & 60649 & 60633 & 888 & 3803 & 22253 & 26944 & 0 & 26944 & 7639 & 1288 & 8927 & 781 & 36652 \\
\hline Parsa & 48374 & 48374 & 282 & 4992 & 2356 & 7630 & 16180 & 23810 & 5068 & 48 & 5116 & 128 & 29054 \\
\hline Rautahat & 56390 & 56141 & 8 & 6318 & 1249 & 7575 & 33200 & 40775 & 13338 & 40 & 13378 & 55 & 54208 \\
\hline Sarlahi & 73710 & 73521 & 2500 & 5582 & 15478 & 23560 & 28400 & 51960 & $\begin{array}{r}1330 \\
16114.5 \\
\end{array}$ & 590 & $\begin{array}{r}16704.5 \\
\end{array}$ & 73 & 68738 \\
\hline Central Terai & 418351 & 413947 & 6162 & 50580 & 58595 & 115337 & 116900 & 232237 & 77923.5 & 5656 & 835795 & 1854 & 317671 \\
\hline Central Region Hill Ecological Belt & & & & & & & & & & & & 0 & \\
\hline $\begin{array}{ll}\text { Bhaktapur } \\
\end{array}$ & 7223 & 6274 & 181. & 2900 & 0 & 3081 & 1205 & 4286 & 0 & 0 & 0 & 33 & 4319 \\
\hline $\begin{array}{l}\text { Dhanading } \\
\text { Dhat }\end{array}$ & $\begin{array}{r}36190 \\
6\end{array}$ & $\begin{array}{r}10839 \\
1083\end{array}$ & $\begin{array}{r}1836 \\
1836\end{array}$ & 2182 & 3006 & . 7024 & 360 & 7384 & 0 & 0 & 0 & 291 & 7675 \\
\hline Kathmandu & 17104 & 14069 & 736 & 1826 & 0 & 2562 & 2130 & 4692 & 0 & 0 & 0 & 437 & 5129 \\
\hline Kavre & 29921 & 7958 & 936 & 2833 & 402 & 4171 & 0 & 4171 & 0 & 0 & 0 & 207 & 4378 \\
\hline Lalitpur & 11068 & 7425 & 0 & 3467 & 0 & 3467 . & 1410 & 4877 & 0 & 0 & 0 & 47 & 4924 \\
\hline Makawanpur & 35776 & 23502 & 931 & 2093 & 222 & 3246 & 0 & 3246 & 53 & 0 & 53 & 34 & 3333 \\
\hline Nuwakot & 31783 & 15047 & 1851 & 2971 & 380 & $\begin{array}{l}5202 \\
5202\end{array}$ & 1172 & $\begin{array}{l}5374 \\
6374\end{array}$ & $\begin{array}{r}0 \\
0\end{array}$ & 0 & 0 & 33 & 6407 \\
\hline Ramechap & 32276 & 4248 & 1264 & 1688 & 2434 & 5386 & 0 & 5386 & 0 & 0 & 0 & 1 & 5387 \\
\hline Sindhuli & 34333 & 20652 & 1364 & 2181 & 7119 & 10664 & 60 & 10724 & 4 & 0 & 4 & 0 & 10728 \\
\hline \begin{tabular}{|l|l} 
Central Hill \\
\end{tabular} & 235674 & 110014 & 9099 & 22141 & 13563 & 44803 & 6337 & 51140 & 57 & 0 & 57 & 1083 & 52280 \\
\hline Central Region Mountain Ecological & Belt & & & & & & & & & & & 0 & \\
\hline Dolakha & 24042 & 4911 & 1127 & 1464 & 2311 & 4902 & 175 & 5077 & 0 & 0 & o) & 124 & 5201 \\
\hline Rasuwa & 5201 & 836 & $\begin{array}{r}539 \\
539\end{array}$ & 411 & 675 & 1625 & 0 & 1625 & 0 & 0 & 0 & 8 & 1633 \\
\hline Sindhupalchowk & 33820 & 12276 & 1834 & 3017 & 3069 & 7920 & 0 & 7920 & 0 & 0 & 0 & 84 & 8004 \\
\hline Central Moumtain & 63063 & 18023 & 3500 & 4892 & 6055 & 14447 & 175 & 14622 & 0 & 0 & 0 & 216 . & 14838 \\
\hline Central Region & 717088 & 541984 & 18761 & 77613 & 78213 & 174587 & 123412 & 297999 & 779805 & 5656 & 836365 & 3153 & 3847885 \\
\hline Westem Development Region & & & & & & & & & & & & 0 & \\
\hline Western Region Ter: & & & & & & & & & & & & 0 & \\
\hline Kapilvastu & 84785 & 84453 & 337 & 7992 & 12412 & 20741 & 6900 & 27641 & 2796 & 1600 & 4396 & 71 & 32108 \\
\hline alparasi & 55238 & 50690 & 191 & 6770 & 12220 & 19181 & 13830 & 33011 & 6083 & 1160 & 7243 & 79 & 40333 \\
\hline $\begin{array}{l}\text { Nowapaparasi } \\
\text { Rupandehi }\end{array}$ & 88416 & $\begin{array}{l}8705079 \\
87970\end{array}$ & $\begin{array}{r}191 \\
15\end{array}$ & 17142 & 18437 & 35594 & r 1300 & 42894 & 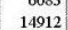 & 20909 & 35821 & 173 & 78888 \\
\hline Western Terai & 228439 & 223122 & 543 & 31904 & 43069 & 75516 & 28030 & 103546 & 23791 & 23669 & 47460 & 322.88 & 151329 \\
\hline Westem Region Hill Ecological Belt & & & & & & & & & & & & 0 & \\
\hline \begin{tabular}{|l|} 
Arghakhanchi \\
\end{tabular} & 20020 & 4799 & 50 & 1732 & 654 & 2436 & 0 & 2436 & 0 & 0 & 0 & 415 & 2851 \\
\hline & 2652 & 7780 & 293 & 1278 & 190 & 1761 & 0 & 1761 & 0 & 0 & 0 & 149 & 1910 \\
\hline $\begin{array}{l}\text { Gorkha } \\
\text { Gort }\end{array}$ & 33914 & 11027 & 147 & $\begin{array}{l}2535 \\
253\end{array}$ & 711 & 3393 & 489 & 3882 & 0 & 0 & 0 & 118 & 4000 \\
\hline & 25606 & 4240 & 111 & 1913 & 0 & 2024 & 160 & & 0 & 0 & 0 & 370 & 2554 \\
\hline Kask & 3140 & 15960 & $\begin{array}{r}311 \\
36\end{array}$ & 2879 & 4044 & 6959: & $\begin{array}{r}100 \\
3740\end{array}$ & 10699 & 0 & 0 & 0 & $\begin{array}{r}89 \\
89\end{array}$ & 10788 \\
\hline Lamjung & 23848 & 11937 & 107. & 3988 & 0 & 4095 & 714 & 4809 & 0 & 0 & 0 & 128 & 4937 \\
\hline Myagdi & 15740 & 3685 & 185 & 1354 & 98 & 1637 & 0 & 1637 & 0 & 0 & 0 & 90 & 1727 \\
\hline & 3035 & 885 & $\begin{array}{r}10 \\
14\end{array}$ & 213 & 1231 & 3381 & 282 & 3663 & 0 & 0 & 0 & 333 & 3996 \\
\hline Parbat & 15231 & 6455 & 200 & 2743 & 118 & 3061 & 425 & 3486 & 0 & 0 & 0 & 49 & 3535 \\
\hline Syangja & 31018 & 9848 & 22 & 3989 & 0 & 4011 & 0 & 4011 & 0 & 0 & 0 & 45 & 4056 \\
\hline Tanahu & 33972 & 14496 & 20 & 2658 & 0 & 2678 & 790 & 3468 & 1 & & 1 & 174 & 3643 \\
\hline Western Hill & 287630 & 99084 & 1185 & 27205 & 7046 & 35436 & 6600 & $\frac{34036}{42036}$ & $\frac{1}{1}$ & 0 & 1 & 1960.35 & 43997 \\
\hline Western Region Mountain & cal Belt & & & & & & & & & & & 0 & \\
\hline $\begin{array}{l}\text { Manang } \\
\end{array}$ & 718 & 121 & 0 & 348 & 0 & 348 & 0 & 348 & 0 & 0 & 0 & 0 & 348 \\
\hline Mustang & 4221 & 159 & 55 & 1015 & 263 & 1333 & 51 & 1384 & 0 & 0 & 0 & 2 & 1386 \\
\hline
\end{tabular}


TABLE 7

Present Level of Irrigation Development

\begin{tabular}{|c|c|c|c|c|c|c|c|c|c|c|c|c|c|}
\hline \multirow{3}{*}{ DISTRICT } & \multirow{3}{*}{$\begin{array}{c}\text { OVERALL } \\
\text { TOTAL }\end{array}$} & \multirow{3}{*}{$\begin{array}{c}\text { TOTAL } \\
\text { IRRIG ABLE }\end{array}$} & \multicolumn{4}{|c|}{ SURFACE FMIS } & \multirow{3}{*}{$\begin{array}{c}\text { DOI } \\
\text { SURFACE }\end{array}$} & \multirow{3}{*}{\begin{tabular}{|} 
TOTAL \\
SURFACE
\end{tabular}} & \multirow{2}{*}{\multicolumn{3}{|c|}{ GRONDWATER }} & \multirow{3}{*}{\begin{tabular}{|c|} 
NON- \\
CONVENT \\
IONAL
\end{tabular}} & \multirow{3}{*}{$\begin{array}{c}\text { TOTAL } \\
\text { IRRIGATED } \\
\text { AREA (HA) }\end{array}$} \\
\hline & & & \multicolumn{2}{|c|}{ AGENCIES ASSITED } & \multirow{2}{*}{\begin{tabular}{|c|} 
NON- \\
ASSITED
\end{tabular}} & \multirow{2}{*}{$\begin{array}{l}\text { TOTAL } \\
\text { FMIS }\end{array}$} & & & & & & & \\
\hline & & & NEW & REH & & & & & STW & DTw & TOTAL & & \\
\hline Western Mountain & 4939 & 280 & 55 & 1363 & 263 & 1681 & 51 & 1732 & 0 & 0 & 0 & 2 & 1734 \\
\hline \begin{tabular}{|l|} 
Western Region \\
\end{tabular} & 521008 & 322486 & 1783 & 60472 & 50378 & 112633 & 34681 & 147314 & 23792 & 23669 & 47461 & 2285.23 & 197060.23 \\
\hline Mid-Westerm Development Region & & & & & & & & & & & & 0 & \\
\hline Mid-Western Region Terai Ecologi & ical Belt & & & & & & & & & & & 0 & \\
\hline Banke & 49525 & 48550 & 0 & 4460 & 1669 & 6129 & 1250 & 7379 & 8173 & 2380 & 10553 & 320 & 18252 \\
\hline Bardiya & 52836 & 52660 & 0 & 31918 & 0 & 31918 & 960 & 32878 . & 7835 & 600 & 8435 & 152 & 41465 \\
\hline Dang & 64522 & 59505 & 192. & 17960 & 13756 & 31908 . & 2585 & 34493 & 2848 & 1675 & 4523. & 288 & 39304 \\
\hline Mid-Western Terai & 166883 & $\mid 160715$ & 192 & 54338 & 15425 & 69955 & 4795 & 74750 & $\begin{array}{l}18856 \\
\end{array}$ & 4655 & 23511 & 760 & 99021 \\
\hline Mid-Western Region Hill Ecologice & alt Belt & & & & & & & & & & & 0 & \\
\hline Dailekh & 28373 & 7075 & 61 & 840 & 1957 & 2858 & 0 & 2858 & 0 & 0 & 0 & 27 & 2885 \\
\hline Jajarkot & 21114 & 4143 & 150 & 949 & 350 & 1449 & 0 & 1449 & 0 & 0 & 0 & 10 & 1459 \\
\hline Pyuthan & 23197 & 7037 & 0 & 1257 & 2476 & 3733 & 340 & 4073 & 0 & 0 & 0 & 9 & 4082 \\
\hline Rolpa & 29651 & 3980 & 0 & 1011 & 0 & 1011 & 0 & 1011 & 0 & 0 & 0 & 36 & 1047 \\
\hline Rukum & 23592 & 4170 & 15 & 1344 & 41 & 1400 & 600 & 2000 & 0 & 0 & 0 & 37 & 2037 \\
\hline Salyan & 28033 & 5282 & 0 & 1356 & 1440 & 2796 & 0 & 2796 & 0 & 0 & 0 & 40 & 2836 \\
\hline Surkhet & 31231 & 19275 & 513. & 4620 & 5242 & 10375 & 387 & 10762 & 0 & 0 & 0 & 125 & 10887 \\
\hline Mid-Western Hill & 185191 & 50962 & 739 & 111377 & 11506 & 23622 & 1327 & 24949 & 0 & 0 & 0 & 283.95 & 25233 \\
\hline Mid-Western Region Mountain Eco & ological Belt & & & & & & & & & & & 0 & \\
\hline Dolpa & & 544 & 77. & 534 & 546 & 1157 & 0 & 1157 & 0 & 0 & 0 & 21 & 1178 \\
\hline & & 969 & 0 & 575 & 0 & 575 & 0 & 575 & 0 & 0 & 0 & 7 & 582 \\
\hline Jumla & 12642 & 4765 & 0 & 588 & 1006 & 1594 & 0 & 1594 & 0 & 0 & 0 & 13 & 1607 \\
\hline Kalikot & 131 & 3084 & 0 & 1483 & 240 & 1723 & 0 & 1723 & 0 & 0 & 0 & 4 & 1727 \\
\hline Mugu & & 2030 & 0 & 235 & 735 & 970 & 0 & 970 & 0 & 0 & 0 & 0 & 970 \\
\hline Mid-Western Mountain & 45363 & 11392 & 77 & 3415 & 2527 & 6019 & 0 & 6019 & 0 & 0 & 0 & 45 & 6064 \\
\hline Mid-Western Region & 397437 & 223069 & 1008 & 69130 & 29458 & 99596 & 6122 & 105718 & 18856 & 4655 & 23511 & 1088.95 & 130318 \\
\hline Far-Western Development Region & & & & & & & & & & & & 0 & \\
\hline Far-Western Region Terai Ecologic & & & & & & & & & & & & 0 & \\
\hline Kailali & 66723 & 64112 & 0 & 13334 & 15688 & 29022 & 7133 & 36155 & 18724 & 1840 & 20564 & 263 & 56982 \\
\hline Kanchanpur & & 40891 & 103. & 3614 & 2270 & 5987 & 11600 & 17587. & 10919 & 1030 & 11949 & 472 & 30008 \\
\hline Far-Western Terai & 107693 & 105003 & 103 & 16948 & 17958 & 35009 & 18733 & 53742 & 29643 & 2870 & 32513 & 735 & 86990 \\
\hline Far-Western Region Hill Ecological & Belt & & & & & & & & & & & 0 & \\
\hline Achham & 31982 & 10972 & 133 & 1267 & 1099 & 2499 & 871 & 3370 & 0 & 0 & 0 & 1 & 3371 \\
\hline Baitadi & 255 & 7450 & 30 & 2206 & 0 & 2236 & 395 & 2631 & 0 & 0 & o] & 223 & 2854 \\
\hline Dadeldhura & & 7266 & 7 & 2730 & 0 & 2737 . & 0 & 273 & 0 & 0 & 0 & 27 & 2764 \\
\hline Doti & & 10468 & 0 & 1969 & 554 & 2523 & 603. & 3126 & 0 & 0 & 0 & 9. & 3135 \\
\hline Far-Western Hill & 101119 & 36156 & 170 & 8172 & 1653 & 9995: & 1869 & 11864 & 0 & 0 & 0 & 259.84 & 12124 \\
\hline Far-Western Region Mountain Ecol & ogical Belt & & & & & & & & & & & 0 & \\
\hline Bajhang & 22642 & 7549 & 0 & 1049 & 643 & 1692 & 1354 & 3046 & 0 & 0 & 0 & 4 & 3050 \\
\hline & 121 & & 0 & 655 & 3120 & & 280 & 405 & 0 & 0 & 0 & 0 & 4055 \\
\hline Darchula & 13201 & 4239 & 22 & 2278 & 0 & 2300 & 0 & 2300 & 0 & 0 & 0 & 24 & 2324 \\
\hline Far-Western Mountain & 48024 & 15372 & 22 & 3982 & 3763 & 7767 & 1634 & 9401 & 0 & 0 & 0 & 28 & 9429 \\
\hline Far-Western Region & 256836 & 156531 & 295 & 29102 & 23374 & 52771 & 22236 & 75007 & 29643 & 2870 & 32513 & 1022.84 & 108542.84 \\
\hline Total & 2641742 & 1765840 & 38650 & 298665 & 284348 & 621663 & 314521 & 936184 & 240058 & 38100 & 278158 & 13011.02 & 1227353.02 \\
\hline
\end{tabular}




\section{Appendix G (Scoring Table with Country wise relevant Codes)}

\begin{tabular}{|c|c|c|c|c|c|c|c|}
\hline Countries & Agricultural Census & Irrigation Census & Statistical Agency & $\begin{array}{l}\text { Agricultural Department } \\
\text { Records }\end{array}$ & $\begin{array}{l}\text { Land Use } \\
\text { data }\end{array}$ & $\begin{array}{l}\text { Irrigation Department } \\
\text { Records }\end{array}$ & $\begin{array}{l}\text { National Land } \\
\text { Survey / Others* }\end{array}$ \\
\hline China & $|\mathrm{CE}| \mathrm{RE}|\mathrm{IN}| \mathrm{SC} \mid$ & & $|\mathrm{CE}| \mathrm{FW}|\mathrm{PR}| \mathrm{TM} \mid$ & & & $|\mathrm{CE}| \mathrm{AR}|\mathrm{PR}| \mathrm{SE} \mid$ & $\begin{array}{c}|\mathrm{CE}| \mathrm{RE} \mid \\
|\mathrm{MA}| \mathrm{PS}|\mathrm{PR}|\end{array}$ \\
\hline India & $\begin{array}{l}\text { ICE }|S E| R E|S C| M I \mid \\
\text { LH }|A R| I N \mid\end{array}$ & $\begin{array}{c}|\mathrm{CE}| \mathrm{RE}|\mathrm{PS}| \mathrm{IN} \mid \mathrm{PR} \\
|\mathrm{AR}|\end{array}$ & & $|\mathrm{CE}| \mathrm{SE}|\mathrm{RE}| \mathrm{PR} \mid$ & & $|A R| C E|R E| P S|I N| P R \mid$ & \\
\hline Pakistan & $|\mathrm{SE}| \mathrm{IN}|\mathrm{MI}| \mathrm{SC}|\mathrm{LH}|$ & & & $|\mathrm{FS}| \mathrm{AR}|\mathrm{SE}| \mathrm{SC} \mid$ & & $|\mathrm{AR}| \mathrm{CE}|\mathrm{RE}| \mathrm{PS}|\mathrm{IN}| \mathrm{PR} \mid$ & \\
\hline Iran & $|\mathrm{CE}| \mathrm{IN}|\mathrm{SC}|$ & & & $\mathrm{FS}|\mathrm{SE}| \mathrm{SC} \mid$ & & & \\
\hline Thailand & & & $|S E| I N|S C|$ & SE $|I N| F S|S C|$ & & $|A R| F W|P R|$ & \\
\hline Bangladesh & $\begin{array}{l}|\mathrm{CE}| \mathrm{RE}|\mathrm{IN}| \mathrm{MI}|\mathrm{SC}| \\
\mathrm{LH} \mid\end{array}$ & $\begin{array}{c}\text { |SE | PS| PR | } \\
\text { MI|IN| }\end{array}$ & $\mathrm{SE}|\mathrm{PS}| \mathrm{FS}|\mathrm{SE}| \mathrm{MI}$ & & & $|\mathrm{CE}| \mathrm{AR}|\mathrm{FW}| \mathrm{PR} \mid$ & \\
\hline Indonesia & & & & $|\mathrm{SE}| \mathrm{IN}|\mathrm{AR}| \mathrm{SC} \mid$ & & $|\mathrm{AR}| \mathrm{PR}|\mathrm{FW}| \mathrm{SE}|\mathrm{TM}|$ & $|\mathrm{CE}| \mathrm{PR}|\mathrm{IN}|$ \\
\hline Vietnam & $|\mathrm{SE}| \mathrm{IN}|\mathrm{RE}| \mathrm{SC}|\mathrm{MP}|$ & & $|S E| P R|A R|$ & $\mathrm{AR}|\mathrm{FS}| \mathrm{SE}|\mathrm{SC}|$ & & & $|\mathrm{SC}| \mathrm{SE}|\mathrm{MA}|$ \\
\hline Japan & & & & $|\mathrm{FS}| \mathrm{SE}|\mathrm{FW}| \mathrm{SC} \mid$ & & & \\
\hline Nepal & $\begin{array}{l}|\mathrm{SE}| \mathrm{IN}|\mathrm{SC}| \mathrm{MI}|\mathrm{PM}| \\
\mathrm{LH} \mid\end{array}$ & & & $|\mathrm{SE}| \mathrm{IN}|\mathrm{PR}|$ & & $|\mathrm{PR}| \mathrm{SE}|\mathrm{CE}| \mathrm{SM}|\mathrm{TM}| \mathrm{FW}|\mathrm{FS}|$ & |SE |IN |SC|RE| \\
\hline
\end{tabular}


(Final cumulative scores) Lower Range \& Upper Range

\begin{tabular}{|c|c|c|c|c|c|c|c|c|c|c|}
\hline Countries & China & India & Pakistan & Iran & Thailand & Bangladesh & Indonesia & Vietnam & Japan & Nepal \\
\hline Agricultural Census & 16.2 & 23.2 & 19.2 & 11.1 & & 26.3 & & 21.3 & & 22.2 \\
\hline Irrigation Census & & 22.3 & & & & 20.2 & & & & \\
\hline $\begin{array}{c}\text { Statistical Agency Surveys (Key Role in } \\
\text { data Collection) }\end{array}$ & 24.1 & & & & 9.1 & 23.1 & & 18.2 & & \\
\hline Agricultural Department Records & & 21.2 & 20.1 & 12 & 14.1 & & 12.1 & 20.1 & 19 & 12.2 \\
\hline Land Use data & & & & & & & 14.2 & & & \\
\hline Irrigation Department Records & 24.2 & 25.3 & 25.3 & & 18.5 & & 25.5 & & & 21.4 \\
\hline National Land Survey / Others* & 25.2 & & & & & & & 12 & & 14.2 \\
\hline Average Score & 22.4 & 25.0 & 21.5 & 11.6 & 13.9 & 23.9 & 17.3 & 17.9 & 19.0 & 17.6 \\
\hline Coefficient of Variation \% (Non-RS) & 5.7 & 5.4 & 17.7 & 14.1 & 17.4 & 11.9 & 15.0 & 26.9 & 21.5 & 24.4 \\
\hline Final Score (Lower Range) & 21.2 & 23.7 & 17.7 & 9.9 & 11.5 & 21.1 & 14.7 & 13.1 & 14.9 & 13.2 \\
\hline
\end{tabular}

\begin{tabular}{|c|c|c|c|c|c|c|c|c|c|c|}
\hline Countries & China & India & Pakistan & Iran & Thailand & Bangladesh & Indonesia & Vietnam & Japan & Nepal \\
\hline Agricultural Census & 22 & 33 & 29 & 16 & & 37 & & 29 & & 35 \\
\hline Irrigation Census & & 31 & & & & 29 & & & & \\
\hline Statistical Agency Surveys & 32 & & & & 14 & 31 & & 24 & & \\
\hline Agricultural Department Records & & 28 & 27 & 18 & 21 & & 17 & 27 & 26 & 18 \\
\hline Land Use data & & & & & & & 20 & & & \\
\hline National Land Survey / Others* & 36 & & & & & & & 19 & & 20 \\
\hline Average Score & 30.3 & 33.8 & 30.0 & 17.0 & 17.8 & 34.0 & 23.2 & 24.8 & 26.0 & 25.9 \\
\hline Coefficient of Variation \% (Non-RS) & 5.7 & 5.4 & 17.7 & 14.1 & 17.4 & 11.9 & 15.0 & 26.9 & 21.5 & 24.4 \\
\hline Final Score (Upper Range) & 28.5 & 31.9 & 24.7 & 14.6 & 14.7 & 30.0 & 19.7 & 18.1 & 20.4 & 19.6 \\
\hline
\end{tabular}




\section{Appendix H (FAO Questionnaire mentioning Irrigated Areas)}

FOOD AND AGRICULTURE ORGANIZATION OF THE UNITED NATIONS

STATISTICS DIVISION

Reference Years: 2008-2013

Questionnaire on Agricultural Resources

Land use and Irrigation

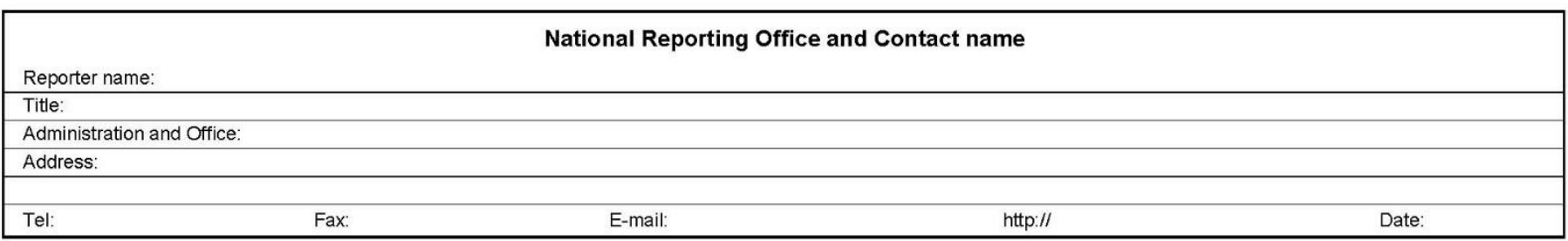

- The Land and Irrigation Questionnaire has three major sections

Land use and Irrigation, Land use - plantations and Metadata.

- We have included detailed concepts and definitions of the land use categories

in the Explanatory Notes sheet.

- Please include notes on any deviation from the concepts and definitions regarding the specific data requested.

- If your organization is not responsible for the data collection of one or more variables, we kindly ask you to indicate the contact detail of the organization responsible in the section "Land use - contact details"

- If you have any query regarding the questionnaire please contact:

Mr Josef Schmidhuber

tel: (+39) 0657056264

e-mail: Josef.Schmidhuber@fao.org

http://uww.fao.org/corp/statistics/en/

We kindly ask you to provide a reply by $02 / \mathrm{Feb} / 2015$

FAO takes this opportunity to thank your Government for its assistance in completing this questionnaire and looks forward to receiving a reply. Please return one copy to: resource-statistics@fao.org

FAO, Statistics Division, Viale delle Terme di Caracalla, 00153 Rome, Italy, or forward via the FAO Representative Office in your country Contact person: Mr Josef Schmidhuber, tel: (+39) 065705 6264, e-mail: Josef.Schmidhuber@fao.org 
- Please report Land use data according to the classification listed in the questionnaire. However, if a different classification and land definitions have been used, please explain the differences in the NOTES column a supplementary information sheet).

For Land use categories description and other important instructions, please refer to the "Explanatory notes" and "Instructions" sheets

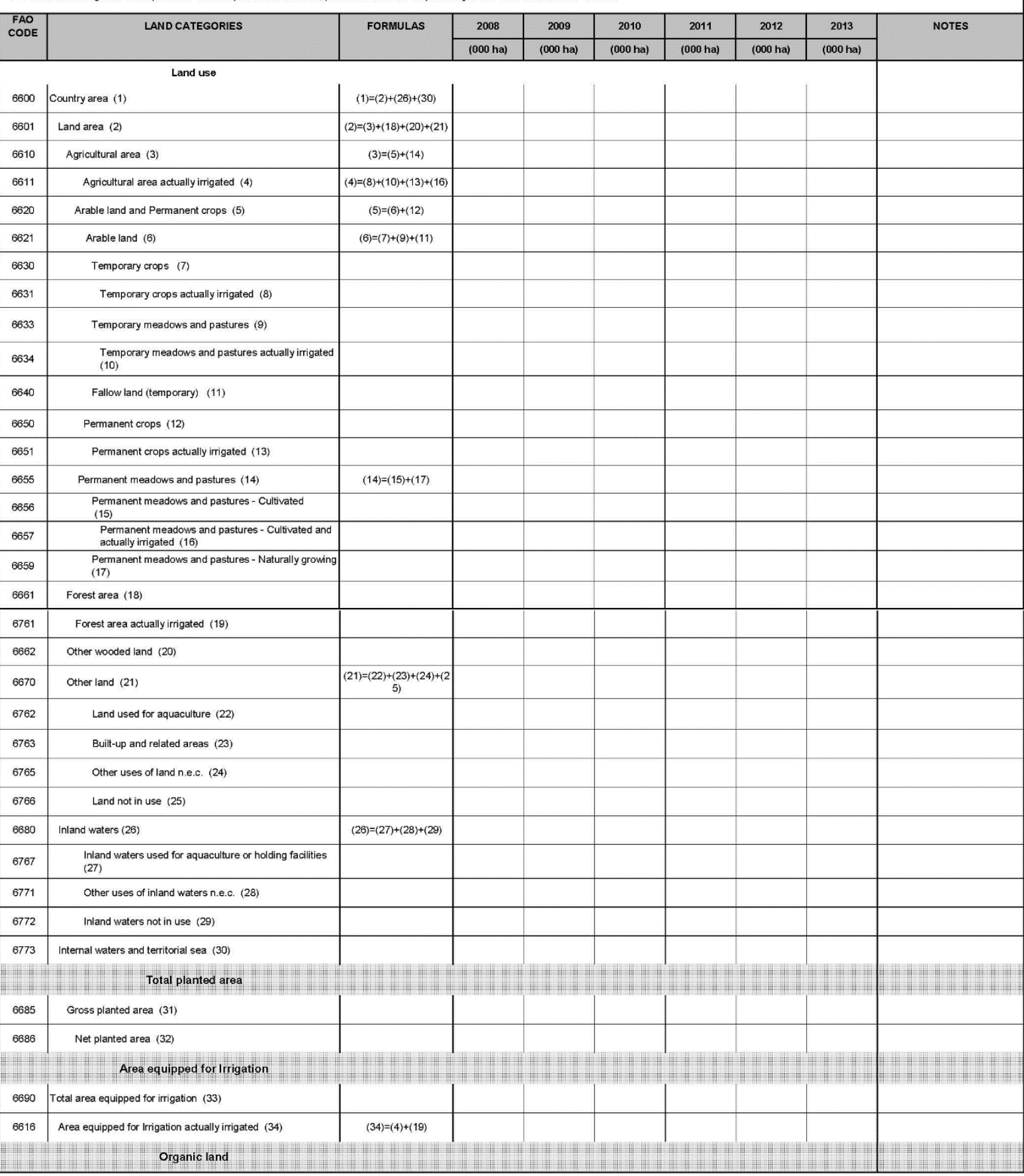




\begin{tabular}{|c|c|c|c|c|c|c|c|c|c|}
\hline \multicolumn{10}{|c|}{ FOOD AND AGRICULTURE ORGANIZATION OF THE UNITED NATIONS - STATISTICS DIVISION } \\
\hline \multicolumn{10}{|c|}{ AGRICULTURAL RESOURCES - LAND USE AND IRRIGATION (000 ha) } \\
\hline \multicolumn{10}{|c|}{$\begin{array}{l}\text { - Please report Land use data according to the classification listed in the questionnaire. However, if a different classification and land definitions have been used, please explain the differences in the NOTES column } \\
\text { - (or by adding a supplementary information sheet). } \\
\text { - For Land use categories description and other important instructions, please refer to the "Explanatory notes" and "Instructions" sheets. }\end{array}$} \\
\hline \multirow{2}{*}{$\begin{array}{l}\text { FAO } \\
\text { CODE }\end{array}$} & \multirow[t]{2}{*}{ LAND CATEGORIES } & \multirow[t]{2}{*}{ FORMULAS } & 2008 & 2009 & 2010 & 2011 & 2012 & 2013 & \multirow[t]{2}{*}{ NOTES } \\
\hline & & & (000 ha) & (000 ha) & (000 ha) & (000 ha) & (000 ha) & (000 ha) & \\
\hline 6671 & Agricultural area organic, total (35) & $\begin{array}{c}(35)=(38)+(41)+(44) \\
(35)=(36)+(37)\end{array}$ & & & & & & & \\
\hline 6672 & Area certified organic (36) & & & & & & & & \\
\hline 6673 & Area in conversion to organic (37) & & & & & & & & \\
\hline 6674 & Arable land organic, total (38) & $(38)=(39)+(40)$ & & & & & & & \\
\hline 6675 & Area certified organic (39) & & & & & & & & \\
\hline 6676 & Area in conversion to organic (40) & & & & & & & & \\
\hline 6677 & Permanent crops organic, total (41) & $(41)=(42)+(43)$ & & & & & & & \\
\hline 6678 & Area certified organic (42) & & & & & & & & \\
\hline 6679 & Area in conversion to organic (43) & & & & & & & & \\
\hline 6681 & Permanent meadows and pastures organic, total (44) & $(44)=(45)+(46)$ & & & & & & & \\
\hline 6682 & Area certified organic (45) & & & & & & & & \\
\hline 6683 & Area in conversion to organic (46) & & & & & & & & \\
\hline \multirow[b]{2}{*}{6774} & Land under protective cover & 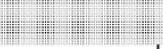 & 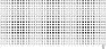 & 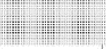 & $=$ & $=-3=$ & $=-1$ & 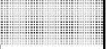 & 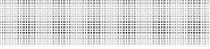 \\
\hline & $\begin{array}{l}\text { Area of arable land and permanent crops under protective } \\
\text { cover }(47)\end{array}$ & & & & & & & & \\
\hline 6775 & $\begin{array}{l}\text { Area of buildings on farms (excl. arable land and permanent } \\
\text { crops under protective cover, buildings for agro-food } \\
\text { manufacture, and buildings in rural areas for exclusive } \\
\text { residential purpose) ( } 48 \text { ) }\end{array}$ & & & & & & & & \\
\hline \multicolumn{2}{|r|}{ Coastal water and Exclusive Economic Zone (EEZ) } & $=$ & in & 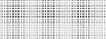 & $=$ & $=$ & :-ie: & $=$ & (1:- \\
\hline 6776 & Coastal water and EEZ area (49) & $(49)=(50)+(51)+(52)$ & 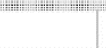 & a & 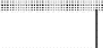 & 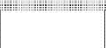 & $=$ & $y=$ & 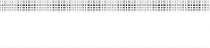 \\
\hline 6777 & $\begin{array}{l}\text { Coastal water and EEZ area used for aquaculture or holding } \\
\text { facilities }(50)\end{array}$ & & & & & & & & \\
\hline 6781 & Other uses of coastal water and EEZ area n.e.c. (51) & & & & & & & & \\
\hline 6782 & Coastal water and EEZ area not in use (52) & & & & & & & & \\
\hline 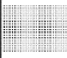 & $\begin{array}{l}\text { Areas used for maintenance and restoration of } \\
\text { evironmental functions }\end{array}$ & 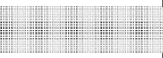 & 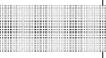 & $=:-1=$ & $=5$ & 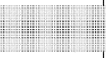 & 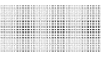 & $=$ & 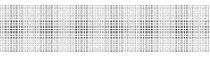 \\
\hline 6764 & $\begin{array}{l}\text { Land used for maintenance and restoration of environmental } \\
\text { functions (53) }\end{array}$ & & & & & & & & \\
\hline 6768 & $\begin{array}{l}\text { Inland waters used for maintenance and restoration of } \\
\text { environmental functions including enhanced areas (54) }\end{array}$ & $(54)=(55)+(56)$ & & & & & & & \\
\hline 6769 & $\begin{array}{l}\text { Inland waters used for maintenance and restoration of } \\
\text { environmental functions (55) }\end{array}$ & & & & & & & & \\
\hline 6770 & Enhanced inland waters (56) & & & & & & & & \\
\hline 6778 & $\begin{array}{l}\text { Coastal water and EEZ area used for maintenance and } \\
\text { restoration of environmental functions including enhanced } \\
\text { areas (57) }\end{array}$ & $(57)=(58)+(59)$ & & & & & & & \\
\hline 6779 & $\begin{array}{l}\text { Coastal water and EEZ area used for maintenance and } \\
\text { restoration of environmental functions (58) }\end{array}$ & & & & & & & & \\
\hline \multirow[t]{2}{*}{6780} & Enhanced coastal water and EEZ area (59) & & & & & & & & \\
\hline & Permanent water & & & & & & & & \\
\hline 6787 & Minimum inland water surface area (64) & & & & & & & & \\
\hline 6788 & Rice-fields with water (65) & & & & & & & & \\
\hline & & Genera & mentsin & on this sect & & & & & \\
\hline
\end{tabular}




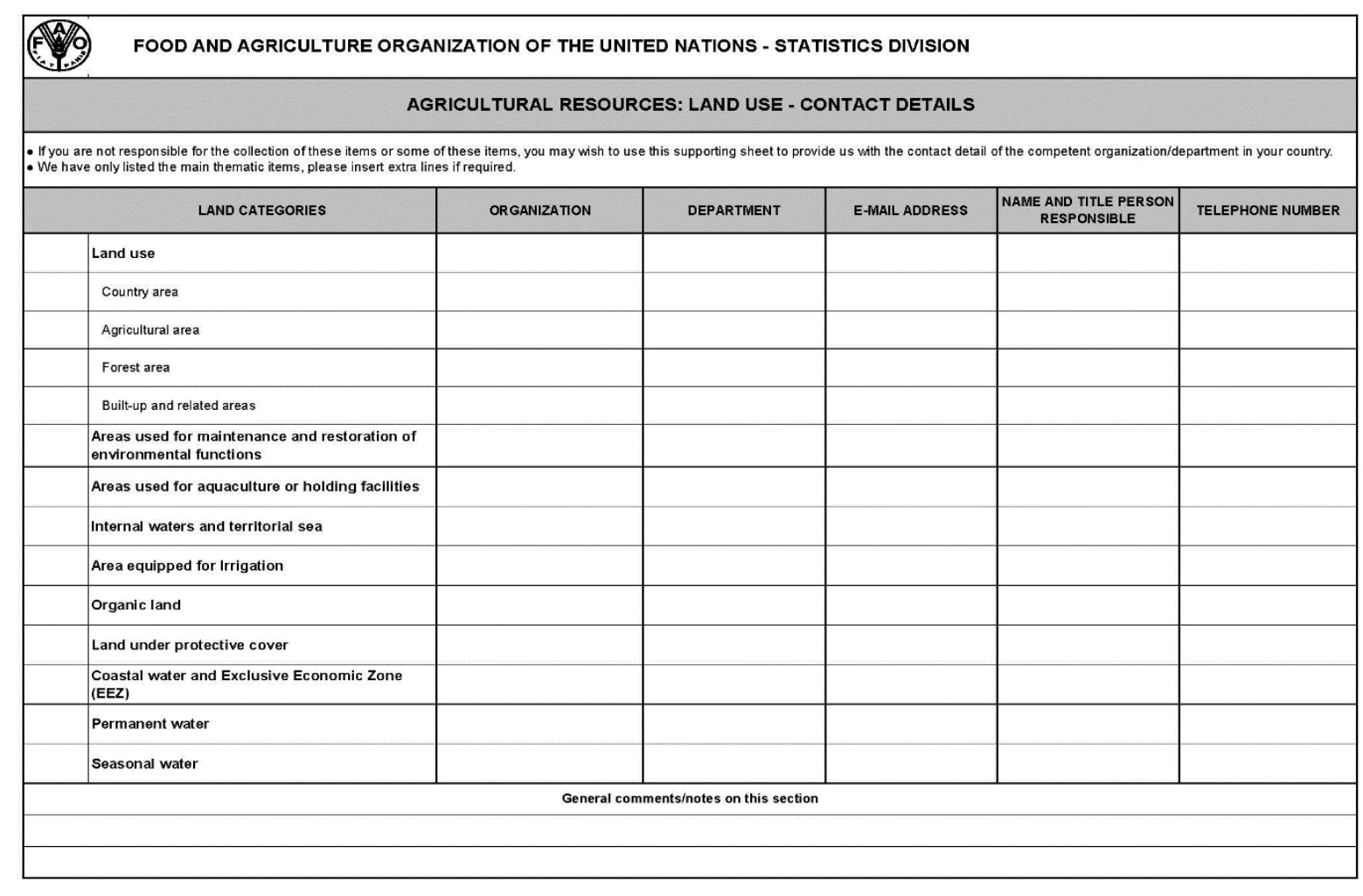

Land use - contact details $1 / 1$ 